\title{
Fatty acid metabolism, impaired glucose tolerance and the effects of lifestyle
}

Citation for published version (APA):

Corpeleijn, E. (2006). Fatty acid metabolism, impaired glucose tolerance and the effects of lifestyle. [Doctoral Thesis, Maastricht University]. Universitaire Pers Maastricht. https://doi.org/10.26481/dis.20061110ec

Document status and date:

Published: 01/01/2006

DOI:

10.26481/dis.20061110ec

Document Version:

Publisher's PDF, also known as Version of record

\section{Please check the document version of this publication:}

- A submitted manuscript is the version of the article upon submission and before peer-review. There can be important differences between the submitted version and the official published version of record.

People interested in the research are advised to contact the author for the final version of the publication, or visit the DOI to the publisher's website.

- The final author version and the galley proof are versions of the publication after peer review.

- The final published version features the final layout of the paper including the volume, issue and page numbers.

Link to publication

\footnotetext{
General rights rights.

- You may freely distribute the URL identifying the publication in the public portal. please follow below link for the End User Agreement:

www.umlib.nl/taverne-license

Take down policy

If you believe that this document breaches copyright please contact us at:

repository@maastrichtuniversity.nl

providing details and we will investigate your claim.
}

Copyright and moral rights for the publications made accessible in the public portal are retained by the authors and/or other copyright owners and it is a condition of accessing publications that users recognise and abide by the legal requirements associated with these

- Users may download and print one copy of any publication from the public portal for the purpose of private study or research.

- You may not further distribute the material or use it for any profit-making activity or commercial gain

If the publication is distributed under the terms of Article $25 \mathrm{fa}$ of the Dutch Copyright Act, indicated by the "Taverne" license above, 
Fatty acid metabolism, impaired glucose tolerance and the effects of lifestyle 


\section{nutútim}

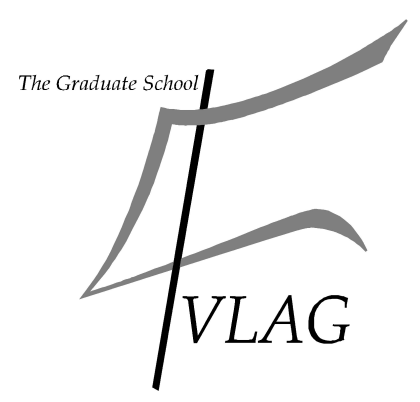

The study presented in this thesis was performed at the Nutrition and Toxicology Research Institute Maastricht (NUTRIM) which participates in the Graduate School VLAG (Food Technology, Agrobiotechnology, Nutrition and Health Sciences), accredited by the Royal Netherlands Academy of Arts and Sciences

Cover picture: M.C. Escher's "Klimmen en Dalen"

(C) 2006 The M.C. Escher Company B.V. - Baarn - Holland. Alle rechten voorbehouden. All rights reserved.

Cover Design: Eva Corpeleijn

Layout: Eva Corpeleijn

Printed by: Datawyse

(C) Eva Corpeleijn, 2006

ISBN-10 90-5278-567-8

ISBN-13 978-90-5278-567-7 


\section{Fatty acid metabolism,}

\section{impaired glucose tolerance and the effects of lifestyle}

\section{PROEFSCHRIFT}

ter verkrijging van de graad van doctor aan de Universiteit Maastricht, op gezag van de Rector Magnificus, Prof. mr. G.P.M.F. Mols

volgens het besluit van het College van Decanen, in het openbaar te verdedigen

op vrijdag 10 november 2006 om 14:00 uur

door

Eva Corpeleijn 


\section{Promotores:}

Prof. dr. ir. Wim H. M. Saris

Prof. dr. Tjerk W. A. de Bruin

\section{Copromotor:}

Dr. ir. Ellen E. Blaak

\section{Beoordelingscommissie:}

Prof. dr. R.P. Mensink (voorzitter)

Prof. dr. K. Frayn (The Oxford Centre for Diabetes, Endocrinology and Metabolism, UK)

Dr. H.A. Keizer

Prof. dr. ir. J.C. Seidell (Vrije Universiteit Amsterdam)

Prof. dr. C.D.A. Stehouwer

The research described in this thesis was supported by grants of the Dutch Diabetes Research Foundation (DFN 98.901 and DFN 2000.00.020) and the Netherlands Organization for Scientific Research (ZonMW 940-35-034 and 2200.0139)

Financial support by the Dutch Diabetes Research Foundation and the Netherlands Association for the Study of Obesity (NASO) for the publication of this thesis is gratefully acknowledged.

Printing of this thesis was financially supported by Boehringer Ingelheim BV, Eli Lilly Nederland BV, Novo Nordisk Farma BV and Pfizer BV. 


\section{CONTENTS}

\section{Chapter 1}

General Introduction

\section{Chapter 2}

Study on lifestyle-intervention and impaired glucose tolerance

Maastricht (SLIM): design and screening results

\section{Chapter 3}

Impaired skeletal muscle substrate oxidation in glucose-intolerant men improves after weight loss

\section{Chapter 4}

Insulin acutely upregulates protein expression of the fatty acid transporter CD36 in human skeletal muscle in vivo - Disturbed regulation in insulin resistance

\section{Chapter 5}

Direct association of a promoter polymorphism in the CD36/FAT fatty acid transporter gene with diabetes mellitus type 2 and insulin resistance

\section{Chapter 6}

Postprandial Interleukin-6 Release from Skeletal Muscle in Men with Impaired Glucose Tolerance can be Reduced by Weight Loss

\section{Chapter 7}

Improvements in glucose tolerance and insulin sensitivity after lifestyle intervention are related to changes in serum fatty acid profile and desaturase activities: the SLIM study

\section{Chapter 8}

General Discussion

Samenvatting / Summary

Dankwoord

Curriculum Vitae

List of Publications 



\section{CHAPTER 1}

\section{GENERAL INTRODUCTION}

Diabetes mellitus type 2: a 'prosperity' disease

\&

Fatty acid metabolism 


\section{CONTENTS}

DIABETES MELLITUS TYPE 2: A ‘PROSPERITY’ DISEASE

Diabetes mellitus type 2: prevalence, pathogenesis, and predisposition 10

$\begin{array}{ll}\text { Prevalence } & 10\end{array}$

Diagnosis and treatment $\quad 10$

$\begin{array}{ll}\text { Pathogenesis } & 11\end{array}$

Predisposition: Lifestyle factors $\quad 13$

Predisposition: Genes and gene-environment interactions 14

Impaired glucose tolerance $\quad 15$

$\begin{array}{ll}\text { Characterization } & 15\end{array}$

Prevalence and progression of IGT 15

Risk factors for progression of impaired glucose tolerance to diabetes mellitus type 216

Prevention of diabetes mellitus type 2 17

$\begin{array}{ll}\text { Concluding remarks } & 19\end{array}$

FATTY ACID METABOLISM $\quad 20$

Fatty acid handling in healthy muscle $\quad 20$

$\begin{array}{ll}\text { Fatty acid availability } & 22\end{array}$

Fat oxidation $\quad 23$

Fat storage in skeletal muscle $\quad 25$

Fatty acid handling in insulin resistance and diabetes mellitus type 2

$\begin{array}{ll}\text { General paradigms } & 26\end{array}$

Defects in fatty acid utilization $\quad 27$

Inflammation, insulin resistance and diabetes mellitus type $2 \quad 31$

The endocrine paradigm $\quad 31$

Effect of lifestyle factors on defects in fat metabolism 32

Energy restriction and exercise $\quad 32$

Dietary fat quality 34

Concluding remarks $\quad 35$

OUTLINE OF THIS THESIS 


\section{DIABETES MELLITUS TYPE 2: A 'PROSPERITY' DISEASE}

There are several forms of diabetes of which type $1(\sim 15 \%)$ and type 2 diabetes mellitus $(\sim 85 \%)$ are the major forms. Type 1 diabetes mellitus is characterized by onset at young age and destruction of pancreatic beta-cells, resulting in insulin deficiency. Diabetes mellitus type 2 is a multi-factorial disease characterized by hyperglycaemia, impaired insulin action and impaired insulin secretion. Historically it is associated with older age, but nowadays the term 'diabetes of the obese' applies more than 'diabetes of the elderly' as it occurs more and more at younger age.

Diabetes is associated with severe complications. Long-term hyperglycaemia and hyperlipidaemia lead to multilevel organ damage, ranging from damage to blood vessels, nerves, eyes and kidneys. This may lead to loss of sight, foot ulcers and amputations and kidney damage. A major problem of diabetes is the two- to three-fold increased risk for cardiovascular disease, which is the leading cause of death in diabetic patients (1-4).

The phenotype of diabetes mellitus type 2 (DM2) is determined by the interaction between genes and the environment. The Western society nowadays has brought about a lifestyle with a deficiency in physical activity and an abundance of palatable, energy-dense foods rich in saturated fatty acids. A lifestyle that is rapidly being adopted by developing countries (5-7). This has resulted in an increase in the prevalence of obesity as well as of DM2, since obesity, in particular abdominal obesity, is a strong determinant for the development of insulin resistance and DM2 (8).

The first part of this chapter will describe the prevalence development, pathogenesis and epidemiological risk factors for the development of DM2. Then it will go into further detail by describing the impaired glucose tolerant state and risk factors for the progression of impaired glucose tolerance to DM2, concluding with studies that have been conducted in an attempt to prevent or postpone the onset of DM2. The second part will go into detail about the role of fatty acid metabolism in the development of insulin resistance and DM2 with special attention to the role of an impaired skeletal muscle metabolism. 


\section{Diabetes mellitus type 2: prevalence, pathogenesis and predisposition}

\section{Prevalence}

In the year 2000, the prevalence of diabetes worldwide was around 151 million people, with estimates for the year 2010 of 221 million, and for 2025 of about 324 million people $(9,10)$. In 2004, about 480,000 people in the Netherlands had diabetes, of which $85 \%$ had DM2 (11). A major concern is the increase in DM2 prevalence in children $(12,13)$. In Japan, DM2 is already more prevalent among children than diabetes mellitus type 1 (14).

\section{Diagnosis and treatment}

In daily practice, the diagnosis will be made based upon the clinical picture of (severe) symptoms and gross hyperglycaemia. However, the symptoms of DM2, like thirst, glucosuria, extreme tiredness, itching, blurred vision and weight loss will indicate that the patient has already developed (severe) complications. For the early detection of DM2 or the prediabetic state, the World Health Organization recommends to perform a standardized oral glucose tolerance test (15). In this test, blood glucose is measured during fasting and 2 hours after the intake of a 75 g-glucose load, dissolved in $250 \mathrm{ml}$ water. This test is preferably performed twice. According to the WHO criteria, subjects can be classified as having normal glucose tolerance (NGT), impaired fasting glucose (IFG), impaired glucose tolerance (IGT) or DM2 (Table 1.1.). IFG and IGT can be seen as 'prediabetic' states (Figure 1.1.).

Treatment and prevention of diabetes has changed a lot over the past decades. A Dutch cooking book from the 1920's states that 'With new times comes new knowledge' which is certainly true for the treatment of diabetes. The Dutch dietary guideline from that period states that all sugar and carbohydrates should be completely banned and replaced by large amounts of protein and easily digestible fats (16). This was rather a strategy to survive than to treat. Life for diabetes patients changed with the actual treatment of diabetes, which started in 1922 after the discovery of insulin in 1921 by F. Banting (17).

Nowadays, the first advice for newly diagnosed DM2 is to improve diet, physical activity pattern and reduce overweight. Next, patients can be treated 
with one or more of the following medications: sulfonylureas to stimulate insulin secretion, biguanides (metformin) to reduce hepatic glucose output, alphaglucosidase inhibitors (acarbose) to delay glucose uptake from the gut, thiazolidinediones (glitazones) to increase peripheral insulin sensitivity and/or insulin therapy.

Table 1.1. WHO criteria for the diagnosis of impairmed glucose metabolism (1999).

\begin{tabular}{lcccc}
\hline & $\begin{array}{c}\text { Venous blood } \\
(\mathrm{mmol} / \mathrm{l})\end{array}$ & $\begin{array}{c}\text { Venous plasma } \\
(\mathbf{m m o l} / \mathbf{l})\end{array}$ & $\begin{array}{c}\text { Capillar blood } \\
(\mathrm{mmol} / \mathrm{l})\end{array}$ & $\begin{array}{c}\text { Capillar } \\
\text { plasma } \\
(\mathbf{m m o l} / \mathbf{l})\end{array}$ \\
\hline $\begin{array}{l}\text { Normoglycaemia } \\
\text { fasting }\end{array}$ & $<5.6$ & $<\mathbf{6 . 1}$ & $<5.6$ & $<\mathbf{6 . 1}$ \\
$\begin{array}{l}\text { 2-hr glucose } \\
\text { Impaired Fasting Glucose }\end{array}$ & $<6.7$ & $<\mathbf{7 . 8}$ & $<7.8$ & $<\mathbf{8 . 9}$ \\
$\quad$ fasting & $5.6 \leq \mathrm{x}<6.1$ & $\mathbf{6 . 1} \leq \mathbf{x}<\mathbf{7 . 0}$ & $5.6 \leq \mathrm{x}<6.1$ & $\mathbf{6 . 1}-\mathbf{7 . 0}$ \\
2-hr glucose & $<6.7$ & $<\mathbf{7 . 8}$ & $<7.8$ & $<\mathbf{8 . 9}$ \\
$\begin{array}{l}\text { Impaired Glucose } \\
\text { Tolerance } \\
\text { fasting }\end{array}$ & $<6.1$ & $<\mathbf{7 . 0}$ & $<6.1$ & $<\mathbf{7 . 0}$ \\
2-hr glucose & $6.7 \leq \mathrm{x}<10.0$ & $\mathbf{7 . 8} \leq \mathbf{x}<\mathbf{1 1 . 1}$ & $7.8 \leq \mathrm{x}<11.1$ & $\mathbf{8 . 9} \leq \mathbf{x}<\mathbf{1 2 . 2}$ \\
$\begin{array}{l}\text { Diabetes Mellitus Type 2 } \\
\text { fasting }\end{array}$ & & & & $\geq 7.1$ \\
2-hr glucose & $\geq 6.1$ & $\geq \mathbf{7 . 0}$ & $\geq 6.1$ & $\geq \mathbf{1 2 . 2}$ \\
\hline
\end{tabular}

\section{Pathogenesis}

DM2 is characterized by insulin resistance and beta-cell failure. Insulin resistance is the reduced ability of insulin to stimulate glucose uptake in peripheral tissues, mainly skeletal muscle (18). Beta-cell failure is characterised by the inability of the pancreatic beta-cell to secrete insulin in adequate amounts. This can be due to a reduced glucose sensitivity, to a reduced beta-cell mass, to a reduced pulsatility of insulin secretion and to a reduced first-phase insulin response to a meal (19). The impairments in insulin sensitivity and insulin secretion initially result in mild hyperinsulinaemia and hyperglycaemia. The development of DM2 may take many years, progressing from the normal glucose tolerant state to impaired glucose tolerance (Figure 1.1.), a condition characterized 
by relatively normal fasting glucose concentrations combined with postprandial hyperglycaemia (20). Subsequent deterioration of insulin resistance and beta-cell failure will lead to overt DM2 (Figure 1.1.) $(20,21)$. Both insulin resistance and beta-cell failure occur very early in the course of DM2, and both factors contribute to the progression of NGT to IGT and of IGT to DM2. The relative contribution of each of these factors strongly depends on the environmental and genetic heterogeneity of the patient population $(22,23)$.

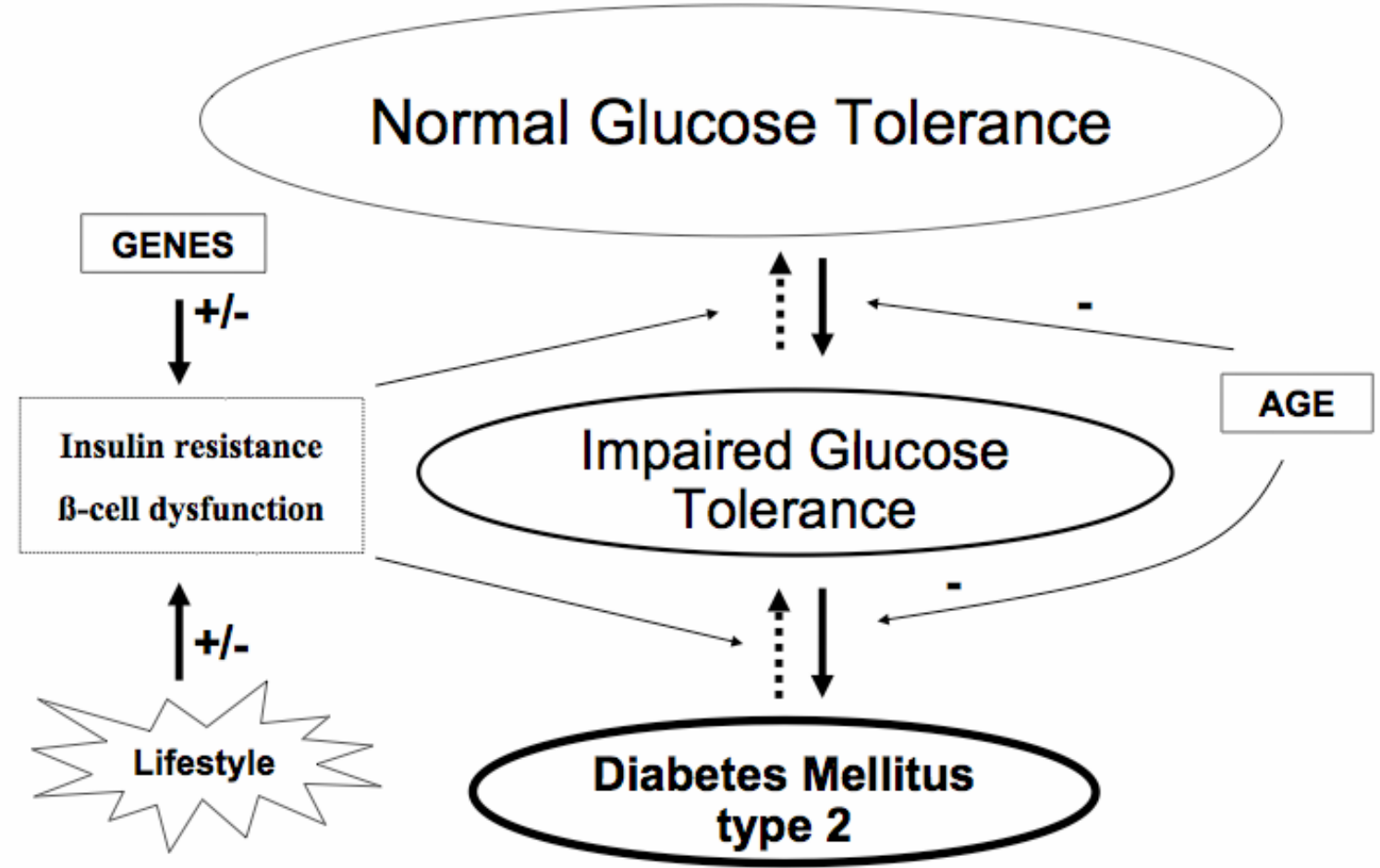

Figure 1.1. Transition from normal glucose tolerance to diabetes mellitus type 2: three step model (adapted from Saad et al.). The development of normal glucose tolerance to impaired glucose tolerance and diabetes mellitus type 2 can be affected by older age, genes and lifestyle. It is (partly) reversible by healthy changes in lifestyle.

Some evidence is emerging that mechanisms that lead to muscle insulin resistance may simultaneously lead to a reduced glucose sensitivity of the pancreatic beta cell (24). Lifestyle factors play an important role in the deterioration of insulin sensitivity and beta cell function. 


\section{Predisposition: Lifestyle factors}

Several lifestyle and lifestyle-associated factors are related to the incidence of DM2. The strongest modifiable risk factor for progression to DM2 is obesity. Data from the Nurses' Health Study, a large prospective study, showed that risk of DM2 was strongly associated with BMI at age 18 and with body weight gain. Weight gain of 11-20 kg in 14 years of follow-up increased ageadjusted relative risk 5.4-fold among female nurses who had normal weight at age 18 (BMI 22-25) relative to nurses with normal weight at age 18 who had no weight gain or loss of more than $5 \mathrm{~kg}$ (25). In addition to over-all obesity, body fat distribution and especially increased (intra)abdominal fat is a predictor of DM2 $(26,27)$. Other important lifestyle factors for the development of DM2 are smoking, physical inactivity and dietary factors, like total fat intake, dietary fat quality, dietary fibre, alcohol consumption, coffee consumption and glycemic index/glycemic load (28). Cross-sectional epidemiological studies showed that the consumption of saturated fat was inversely related to insulin sensitivity and glucose tolerance, whereas a positive association was found for unsaturated fat (29-31). In addition, prospective studies in healthy subjects have shown that a serum fatty acid profile of high saturated fatty acids or low unsaturated fatty acids can predict the development of diabetes mellitus type $2(29,32,33)$. Also the total fat intake is an important risk factor for the development of DM2, although it is less clear whether this is independent of obesity. In the San Louis Valley Diabetes Study, a 40g higher fat intake corresponded with a 6-fold increase in diabetes risk in IGT subjects after adjustment for obesity and markers of glucose metabolism (i.e. fasting glucose and insulin) (34). In the Nurses' Health Study, investigators reported an inverse association between the development of DM2 and the intake of vegetable and polyunsaturated fat, a positive association for trans-fatty acids, but no association for total fat in the diet (35). Furthermore, a low glycemic diet with a high amount of fiber and whole grain products lowers the risk of DM2. Dietary fibres can reduce the rate of glucose absorption in the intestine, thereby lowering postprandial glycemic and insulinemic responses (36). Prospective studies have shown an inverse relation between fibre intake and the development of DM2, which was stronger for cereal fibre than for fibre from other sources (e.g. fruits and vegetables)(37-39). The adjusted risk reduction was $22 \%$ for the highest quintile of fibre intake relative to the lowest quintile of fibre intake (37). Also moderate consumption of filtered coffee (40) and alcohol may be protective 
against the development of DM2 $(28,41)$. Furthermore, cigarette smoking has been associated with increased diabetes risk (28) ranging from $42 \%$ increased risk (> 25 cigarettes/day) in the Nurses Health study (42) to $70 \%$ increased risk $(>20$ cigarettes/day) in the Physicians'Health Study cohort (43) after adjustment for obesity and other risk factors. Finally, physical activity has been shown to be protective against DM2 and may even improve or reverse the diabetic state. In a study following 5,990 men for 14 years, those who exercised regularly, at moderate of vigorous intensity, had a 35\% lower risk of developing DM2 than men who were sedentary (44). In the Nurses' Health Study it was shown that even among women who did not perform vigorous physical activity, diabetes risk was reduced with $26 \%$ after 8 years of follow-up for those who had walked most relative to those who walked least (45). Several prospective studies show a significant graded inverse association between levels of self-reported physical activity and incident DM2 over long follow-up periods. These associations remained significant after extensive adjustment for confounding, including BMI (46). The effect of lifestyle factors on the incidence of diabetes as described above strongly supports the emerging concept that DM2 is a preventable disease.

\section{Predisposition: Genes and gene-environment interactions}

Genes modulate the individual susceptibility for multi-factorial diseases like DM2 and cardiovascular disease. Genes involved in lipid metabolism, insulin signalling and many other metabolic processes, may predispose to DM2 (47). The genetic variations that predispose for a disease are usually common variants of the gene (polymorphisms) that are functionally different with a modest effect on the individual level. This implicates that many genes make a small contribution to diabetes risk. The 'thrifty 'genotype hypothesis reasons that at some time in evolution, genes allowing for efficient storage of energy during periods of food abundance did aid to survive in times of food scarcity. However, these previously beneficial genes have become deleterious now that times of food scarcity have become very rare and physical activity is deficient in our daily living pattern (48, 49). The development of a pathological phenotype in a population with the deleterious genotype strongly depends on the interaction with the environment. This was typically demonstrated by migration studies. The prevalence of DM2 in the Japanese rapidly increased after migration to the US, where they adapted a 
Western lifestyle and, specifically, a Western diet (50). Thus, "genes load the gun, lifestyle pulls the trigger".

\section{Impaired glucose tolerance}

\section{Characterization}

DM2 is a disease that progresses slowly over years, and is preceded by the impaired glucose tolerant state (20). Subjects with impaired glucose tolerance have hyperglycaemia after a glucose load, but are still able to reduce glucose levels back to normal in the fasting state, although it may take more time relative to normal glucose tolerant subjects. Metabolic abnormalities that are associated with the impaired glucose tolerant state are part of a clustering of risk factors for DM2 called the metabolic syndrome or syndrome $X$, including (abdominal) obesity, increased blood pressure, high LDL or low HDL cholesterol and hypertriglyceridaemia (8). This is related to impairments in a variety of tissues, e.g. abnormalities in lipid metabolism (51), abnormalities in liver glucose output (52-54), endothelial dysfunction and low-grade inflammation $(55,56)$.

The clustering of risk factors for DM2 is also a risk factor for cardiovascular disease. The long period of IGT before the onset of overt DM2 contributes to the initiation and progression of cardiovascular disease (57-60). A recent meta-analysis concluded that in non-diabetic individuals the relative risk of cardiovascular disease events was 1.26 for subjects in the highest category of blood glucose compared with subjects in the lowest blood glucose category (61).

Many risk factors for DM2, the metabolic syndrome and cardiovascular disease are related to lifestyle. Therefore, lifestyle changes may offer a good means to prevent these metabolic disorders.

\section{Prevalence and progression of IGT}

The prevalence of IGT is strongly dependent on the characteristics of the population, including age, BMI and ethnicity, and ranges from $2 \%$ in rural areas to more than $20 \%$ in high-risk populations (62). In the Dutch Hoorn study (19891992), a population-based screening in 2484 randomly selected adults aged 50-74 
years, the reported prevalence was 10.3\% for IGT and 8.3\% for DM2 (known and newly diagnosed) (63).

Impaired glucose tolerance is a very strong risk factor for the development of diabetes mellitus type 2. In the Dutch Hoorn study, the cumulative incidence of DM2 for normal glucose tolerant adults was $4.5 \%$ over 6 years, whereas it was $64.5 \%$ for IGT. The Odds Ratio for the development of DM2 in IGT subjects after correction for age and gender was 39.5 (95\% confidence interval 17.0 - 92.1). The Odds Ratio for subjects with impaired fasting glucose concentrations was 10.0 (95 \% CI 6.1 - 16.5) (64).

Risk factors for progression of impaired glucose tolerance to diabetes mellitus type 2

The most important modifiable risk factor for progression to DM2 is obesity. BMI was strongly associated with the incidence of DM2 independent of fasting or 2-hour glucose concentrations (65). The combined adjusted relative hazard ratio was 1.13 per $4 \mathrm{~kg} / \mathrm{m}^{2}$ increase in BMI. In addition to over-all obesity, central obesity was found to be a risk factor for developing DM2 (34, 64, 65). Beside obesity, dietary fat intake was shown to predict DM2 risk in IGT subjects in the San Louis Valley Diabetes Study (34). After adjustment for obesity and markers of glucose metabolism (i.e. fasting glucose and insulin), a $40 \mathrm{~g}$ higher fat intake was related to a 6-fold increase in diabetes risk. Age, sex and family history of diabetes may be risk factors for the development of diabetes per se, but were generally not independently related to the progression of IGT to DM2 (64-66).

The effects of lifestyle factors on diabetes risk differs between individuals, which is due to the interaction with the genetic background of the individual. However, up till now, little information is available about the effect of changes in lifestyle on the development of diabetes and the interaction with diabetes-related genes. The problem of studies investigating gene-environment interactions is that they need sufficient power as well as thoroughly phenotyped subjects. Subjects with impaired glucose tolerance may be a very useful population to study the effects of lifestyle changes and gene-environment interactions on the progression towards diabetes, since they can be identified with a reliable test (OGTT), are at high risk of DM2 and the changes in lifestyle are likely to have a large impact in this specific population. 


\section{Prevention of diabetes mellitus type 2}

As described in the previous paragraphs, the progression of NGT to IGT and of IGT to DM2 is importantly influenced by modifiable lifestyle factors, such as obesity, diet and physical activity. This led to the idea that the development of DM2 is reversible and that changes in lifestyle could provide an important means to prevent or postpone the onset of DM2. Also drugs that reverse the metabolic impairments that are associated with the development of DM2 have the potential to reduce the progression to DM2.

Drugs

The first studies that aimed to postpone or prevent the progression of IGT to DM2 were conducted in the 1980 's. Some studies used hypoglycemic drugs (67, 68 ) and others a restriction of carbohydrate intake with or without phenformin (69), but these results were not very promising. Later on, studies with medication like sulfonylureas $(70,71)$, acarbose $(72,73)$ and thiazolidinediones $(74,75)$ were able to show positive effects in reversing the progression of impaired glucose tolerance and insulin resistance. The STOP-NIDDM trial showed a $25 \%$ reduction in progression to DM2 in the acarbose treated group after 3.3 years (73).

Beside the aforementioned diabetes drugs, interest has risen in the antidiabetic effect of anti-hypertensive drugs that inhibit the renin-angiotensin system (RAS), i.e. angiotensin-converting enzyme (ACE) inhibitors and angiotensin II receptor blockers (ARBs). A meta-analysis was performed with randomized clinical trials that compared RAS blockade (ACE-inhibitors or ARBs) versus nonRAS blockade in very diverse groups of hypertensive subjects at risk for cardiovascular disease, who have a high prevalence of insulin resistance. ACEinhibitors reduced the incidence of diabetes by $14 \%$ to $34 \%$, and ARBs reduced the incidence of diabetes by $19 \%$ to $25 \%$. The overall risk reduction was $22 \%(95 \% \mathrm{CI}=$ $17 \%-26 \%)(76)$.

\section{Dietary intervention}

An early study on the prevention of DM2 using lifestyle intervention aimed at carbohydrate restriction with or without phenformin in subjects with 'borderline diabetes', which had no effect on the development of DM2 (69). A few years later it was shown that dietary advice, including a reduction in fat intake and an increase in fibre-rich foods, had beneficial effects on glucose metabolism 
$(77,78)$, mainly by reducing fasting hyperglycemia (78). The Chinese Da Qing IGT and Diabetes study assessed the effect of diet alone, exercise alone, or a combined diet and exercise intervention. The diet intervention consisted of recommendations to consume 55-65 energy \% (E\%) of carbohydrates, $10-15 \mathrm{E} \%$ of protein and 25-30 E\% of fat in combination with weight loss. The progression of IGT to DM2 was reduced with $31 \%$ after 6 years of intervention (79). However, the risk reduction was even larger in the other treatment groups (exercise only or combined diet and exercise intervention).

\section{Lifestyle programs}

Several important large lifestyle intervention studies to prevent DM2 combining dietary advice, exercise and/or hypoglycemic drugs have been conducted in the past years.

The Malmö-study consisted of a diet-exercise program in IGT men for 6 years. The progression of IGT to DM2 was $10.6 \%$ in the intervention group versus $28.6 \%$ in the control group, reducing diabetes risk by more than $50 \%(80,81)$. The Chinese Da Qing IGT and Diabetes study, which was mentioned earlier, included 577 men and women with IGT who were randomised per centre to a group with diet alone, exercise alone, diet + exercise or controls. The progression of IGT to DM2 was reduced with $31 \%$ in the diet group, with $46 \%$ in the exercise group and $42 \%$ in the diet + exercise group (79). However, these results should be taken with care, as progression to DM2 in the control group after 6 years was rather high $(67.7 \%)$ and centres instead of individuals were randomised to different interventions. The Finnish Diabetes Prevention Study included 522 volunteers with IGT (80). The intervention group received dietary advice, an individually guided exercise program and was stimulated to lose weight (-5\% of initial body weight). After 3.2 years, progression to DM2 was $11 \%$ in the intervention group and $23 \%$ in the control group, which indicates that lifestyle can reduce diabetes risk by $58 \%$. A comparable reduction in diabetes risk achieved with lifestyle intervention was found in the Diabetes Prevention Program in the USA (75). IGT subjects were randomised to a diet + exercise lifestyle program $(n=1079)$, to treatment with metformin $(n=1073)$ or to a control group $(n=1082)$. Metformin, which suppresses hepatic glucose production, was less effective to reduce DM2 risk $(-31 \%)$ than lifestyle $(-58 \%)$ after 2.8 years of intervention. In the Netherlands, the Study on Lifestyle intervention in Impaired glucose tolerance Maastricht (SLIM) was conducted with 147 IGT subjects from a population cohort, who were 
randomised to a control and diet + exercise lifestyle intervention group. After 2 years, the postprandial glucose concentration in the lifestyle group was $1.5 \mathrm{mmol} / \mathrm{l}$ lower than in the control group, which represents a substantial reduction in diabetes risk (83). The setup of this study is characterised by an extensive metabolic profiling of the participants. This will allow a more mechanistic approach to explain the effects of lifestyle changes on the progression of DM2.

The studies mentioned above clearly indicate that improvements in lifestyle can have a large impact on diabetes risk. In addition, healthy changes in lifestyle may not only be beneficial for the prevention of DM2, but may also reverse features of the metabolic syndrome (84) and improve cardiovascular risk profile (85). The exact effect of the different components of the lifestyle program (e.g. a reduction in total fat intake, a change in type of dietary fat, increasing physical activity, or a reduction in body weight) is not elucidated yet. The Oslo Diet and Exercise study concluded that the combination of diet and exercise was most effective to decrease insulin resistance (86). In the Chinese Da Qing IGT and Diabetes Study diet and exercise were equally effective as exercise alone to prevent the progression of IGT to DM2. Post-hoc analysis of the SLIM study indicated that the combination of diet and exercise was more effective than diet or exercise alone (83).

\section{Concluding remarks}

Lifestyle changes in subjects with IGT improve glucose metabolism and reduce or delay the development of DM2. However, the effectiveness of different aspects of the lifestyle intervention may differ between individuals, depending on their genetic background and the interaction of genes with lifestyle. Therefore it is important to elucidate the metabolic mechanisms that underlie the effects of lifestyle, since knowledge about these mechanisms may contribute to a more efficient and targeted intervention to prevent and/or treat DM2 in the future. 


\section{FATTY ACID METABOLISM}

Skeletal muscle, and in particular an impaired lipid metabolism in skeletal muscle, may play an important role in the development of insulin resistance and DM2. Due to its large total mass, skeletal muscle plays a major role in carbohydrate and lipid metabolism in general, even at rest. To further elucidate the role of impairments in skeletal muscle fatty acid metabolism in the development of DM2, it is important to investigate this in subjects at high risk for DM2, i.e. subjects with impaired glucose tolerance, rather than in diabetic subjects, since muscle metabolism can be profoundly altered by the consequences of diabetes itself. Disturbances that are found in IGT subjects may represent primary factors in the aetiology of DM2. Below, fatty acid handling in healthy muscle will be described first, followed by the impairments in fatty acid handling that are characteristic of skeletal muscle in insulin resistant and/or diabetic subjects. An overview will be presented on the link between obesity, impairments in lipid metabolism, impairments in skeletal muscle metabolism and the development of insulin resistance. At last, the potential effects of lifestyle factors on skeletal muscle metabolism, insulin resistance and DM2 are pointed out.

\section{Fatty acid handling in healthy muscle}

Fatty acids and carbohydrates are the major substrates available in the body to provide energy. Whereas the amount of fat that can be stored is almost unlimited, glucose can only be stored as glycogen in relatively small amounts in liver and muscle. The consequence of this is that during fasting conditions, glucose will be saved for organs that are glucose-dependent, whereas other organs, like skeletal muscle, will rely on fatty acid oxidation. Skeletal muscle is the most important organ concerning the uptake and oxidation of fatty acids. At rest, about $60-80 \%$ of muscle energy production is provided by fat oxidation (Figure 1.2A). Furthermore, in absolute terms, skeletal muscle is a major consumer of $\mathrm{O}_{2}$ due to its large total mass, although the oxygen consumption of skeletal muscle per unit of mass is rather low $(4 \mathrm{ml} \mathrm{O} / \mathrm{kg}$ wet weight). During exercise, the oxygen consumption may increase enormously, up to $\sim 350 \mathrm{ml} \mathrm{O}_{2} / \mathrm{kg}$ wet weight (87). In the postprandial phase, glucose will be present in abundance (Figure 1.2A and 1.2B). High glucose concentrations have potential toxic effects, and skeletal muscle will prevent toxic glucose concentrations by increasing glucose uptake and 


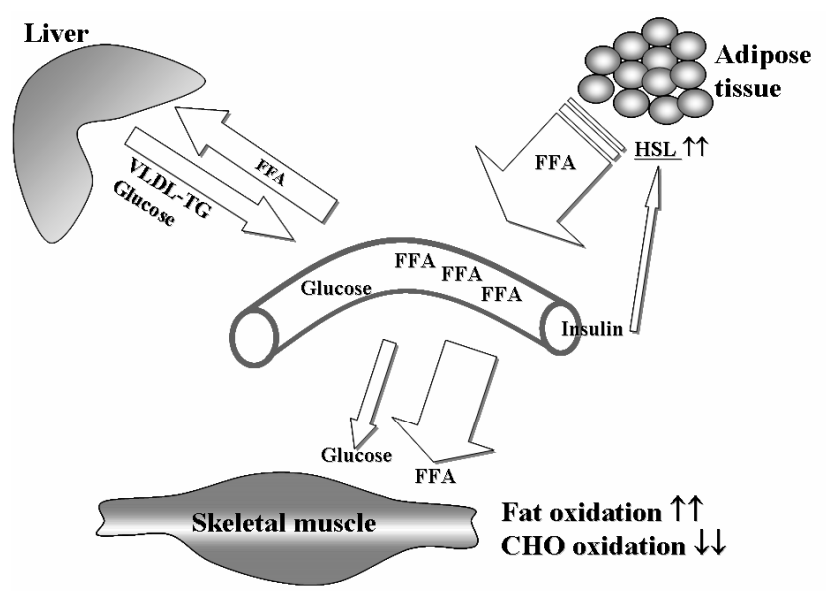

1.2A Healthy; Fasting

The fatty acid supply from adipose tissue is high, skeletal muscle oxidizes predominantly fatty acids.

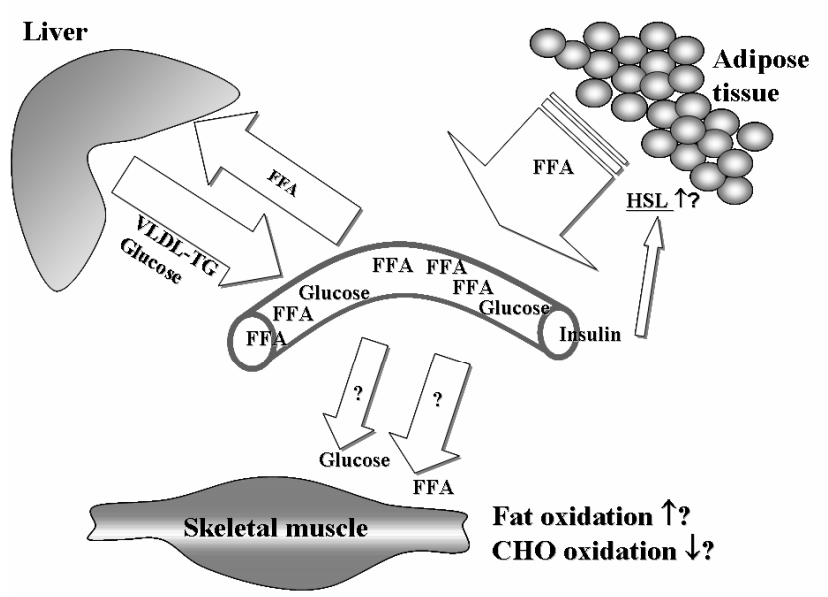

1.2C Insulin Resistant; Fasting

The fatty acid supply from the expanded adipose tissue is high, skeletal muscle fat oxidation is blunted.

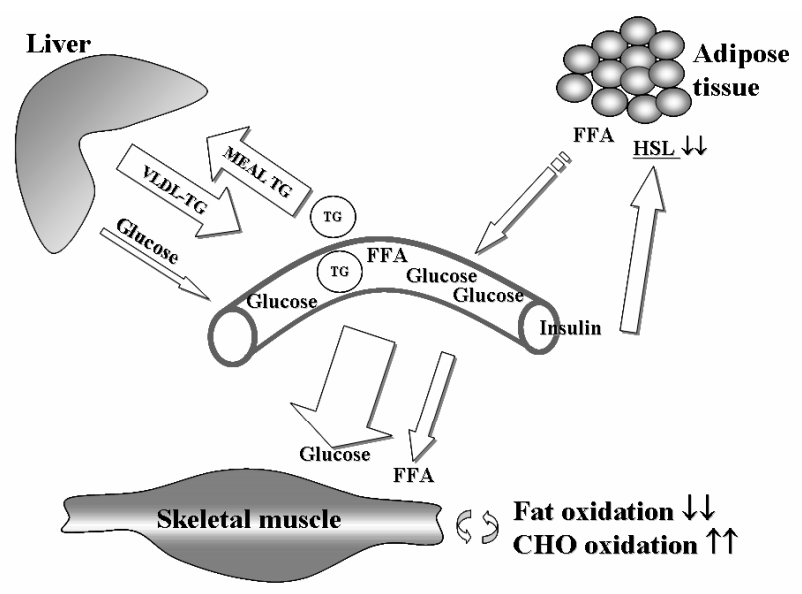

1.2B Healthy; Postprandial

The fatty acid supply from the expanded adipose tissue is suppressed by insulin, skeletal muscle switches from fat oxidation to carbohydrate oxidation.

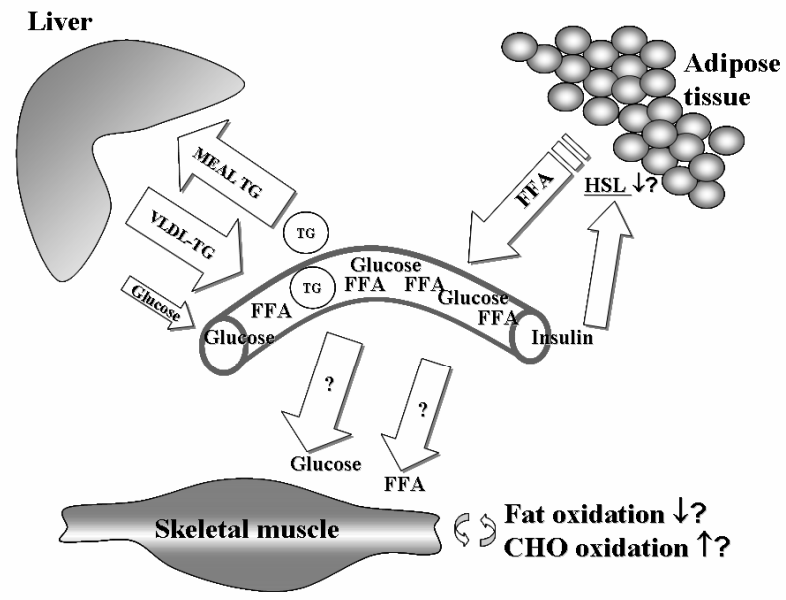

1.2D Insulin Resistant; Postprandial

The fatty acid supply from the expanded adipose tissue is less suppressed, the ability of skeletal muscle to switch from fat oxidation to carbohydrate oxidation is blunted.

Figure 1.2. Metabolic fluxes of fatty acids and glucose between organs in healthy subjects during fasting $(A)$ and in the postprandial phase $(B)$ and in the same conditions characterized by insulin resistance $(C, D)$. CHO, carbohydrate; FFA, free fatty acids; $H S L$, Hormone Sensitive Lipase; VLDL-TG, very low density lipoproteins; meal-TG, chylomicrons.

oxidation at the cost of fatty acid uptake and oxidation. In insulin-stimulated conditions $\sim 80 \%$ of the glucose utilization is accounted for by skeletal muscle (88). 


\section{Fatty acid availability}

In general, fatty acids are released into the circulation by adipose tissue and taken up in the peripheral tissues such as skeletal muscle by facilitated diffusion. These fatty acids can be stored or transported into the mitochondria for oxidation.

\section{Fatty acid mobilisation, transport and supply}

Fatty acids are present in the circulation as free fatty acids bound to plasma proteins, as VLDL-triglycerides produced by the liver or as triglycerides in chylomicrons after a meal. Plasma free fatty acid concentrations largely reflect lipolytic activity in adipose tissue. In adipose tissue, hormone-sensitive lipase (HSL) hydrolyzes triglycerides to glycerol and free fatty acids via diacylglycerol (DAG) and monoacylglycerol. Recently a second enzyme, adipose triglyceride lipase (ATGL), has been discovered. This enzyme is also capable to hydrolyse triglycerides to diacylglycerol (89). The free fatty acids are released into the circulation and bind to plasma proteins, in particular to albumin. HSL activity is stimulated by adrenaline and noradrenalin, whereas insulin can almost completely suppress HSL activity, which results in a dramatic fall in plasma free fatty acids after a meal (87). Beside this fatty acid supply from circulating albuminbound FFA, fatty acids can also be derived from lipolysis of circulating triglycerides. Triglycerides can be hydrolysed by lipoprotein lipase (LPL) in the capillary endothelium (90). In addition, blood flow is a major determinant of plasma-derived fatty acid supply.

\section{Fatty acid uptake into skeletal muscle}

Fatty acid uptake is dependent on diffusion and thus on the concentration gradient over muscle membrane, which is determined by the plasma free fatty acid (FFA) concentration and the rate of cellular metabolism (intracellular FFA concentration). Evidence from the past years has shown that fatty acid uptake in muscle is not just a passive diffusion process, but that it is facilitated by specific transport proteins (Figure 1.3)(91). Among these proteins are the membrane bound fatty acid transporters, in particular fatty acid translocase (FAT/CD36), which is identical to glycoprotein IV or CD36 on human blood platelets and leukocytes, fatty acid binding protein (FABPm) and fatty acid transport protein (FATP) and two cytosolic proteins: cytosolic fatty acid binding protein (FABPc) and acyl-CoA binding protein (ACBP)(91). 
The fatty acid transporter CD36 appears to play a major role in the regulation of fatty acid uptake. Research with rodents has shown that CD36 may be present in a membrane as well as in a cytosolic compartment, and that both insulin and muscle contraction can induce the translocation of CD36 to the plasma membrane $(91,93,94)$. In human skeletal muscle, CD36 expression is sensitive to regulation by (agonists of) PPAR- $\gamma(95,96)$. Furthermore, the relative contribution of CD36 to fatty acid uptake is likely to be larger when the fatty acid:albumin ratio is low (97).

\section{Fatty acid uptake into mitochondria}

The uptake of fatty acids into mitochondria is assumed to be regulated by the activity of carnitine palmitoyl transferase-1 (CPT-1) system. CPT-1 catalyzes the trans-esterification of fatty acyl-CoA into acylcarnitine using carnitine as a cofactor. Acylcarnitine can then be translocated to the inner mitochondrial membrane by carnitine:acylcarnitine translocase and finally acylcarnitine is regenerated to acyl-CoA by CPT-2 in the mitochondrial matrix. The activity of CPT-1 is suppressed by cytosolic malonyl-CoA, which in its turn is formed by acetyl-CoA carboxylase (ACC) or degraded by malonyl-CoA decarboxylase (MCD) as illustrated in Figure 1.3. (98-101). Recently it was suggested that the fatty acid transporter CD36 may also play a role in the mitochondrial uptake of long chain fatty acids. It was shown in mitochondria from rat tibialis anterior muscle that a specific inhibitor of CD36 (sulfo-N-succimidyl oleate) suppressed specific mitochondrial palmitate binding and oxidation and reduced CPT-1 activity. It was hypothesized that CD36 may act as a long-chain fatty acid acceptor in the CPT-1 system (102).

\section{Fat oxidation}

Inside the mitochondrial matrix, fatty acyl-CoA is stepwise degraded to acetyl-CoAs in a process called beta-oxidation. Hydroxyacyl-CoA dehydrogenase (HAD), the enzyme catalyzing the final step of the beta-oxidation, is assumed to be the rate-limiting step. The acetyl-CoAs from both beta-oxidation and glycolysis then enter the TCA-cycle. The first step is the formation of citrate by citrate synthase (CS). Next, acetyl-CoA is completely oxidized by a series of enzymatic reactions. The biochemical energy released during $\beta$-oxidation and in the TCAcycle is transferred to hydrogen atoms bound to nicotinamide- and flavin adenine 


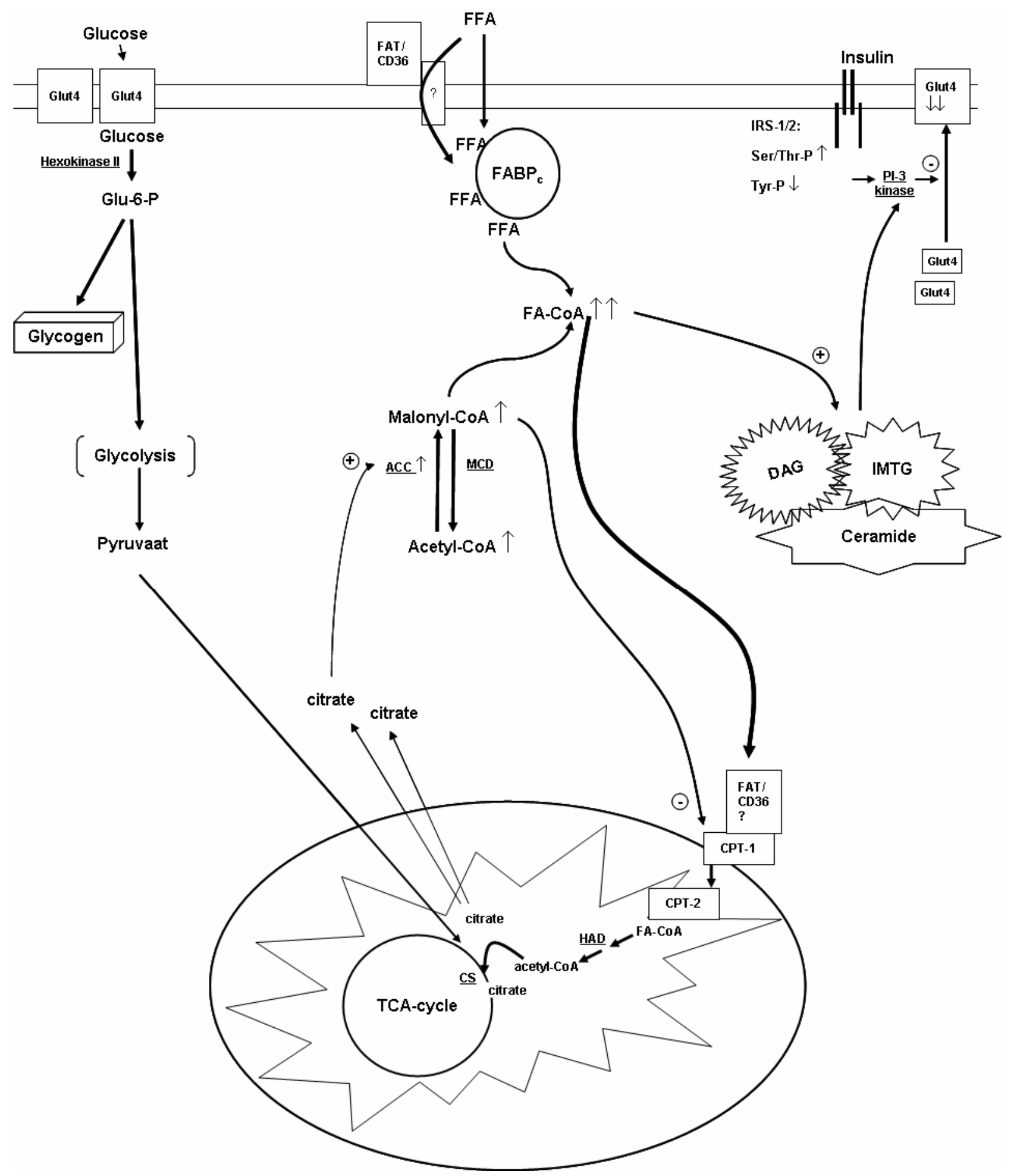

Figure 1.3. Cell metabolism in the myocyte: key actors in the pathogenesis of fat-induced muscular insulin resistance (adapted from Perseghin et al.(128)).

The intra-muscular fuel-sensing pathway may be represented by the malonyl-CoA (FACoA) metabolic pathway. Intra-muscular malonyl-CoA is a potent allosteric inhibitor of carnitine-palmitoyl transferase-1 (CPT-1). Malonyl-CoA concentration is synthesized by 
dinucleotide (NAD+/FAD), which are transferred to the respiratory chain. There they are used in the formation of adenosine triphosphate (ATP) (103).

\section{Fat storage in skeletal muscle}

Muscle as an organ contains two triglyceride depots. One is extramyocellular and is probably located in adipocytes interlaced in muscle and the other is intramyocellular triglyceride (IMTG). This IMTG depot is estimated to contain about the same amount of energy as the muscle glycogen stores (104). IMTG is located nearby the mitochondria and the amount of lipid, the dispersion of droplets in the muscle fibre as well as the size of the droplets may vary greatly between muscle types and individuals (105-108). IMTG is more abundant in (oxidative) type 1 fibres than in (more glycolytic) type 2 fibres (106, 109, 110). IMTG can be hydrolyzed by HSL (111), and it was found that the IMTG-derived FFAs can be oxidized during exercise $(112,113)$. It is not clear yet whether and how much IMTG may contribute to skeletal muscle fat oxidation in other conditions.

the acetyl-CoA carboxylase-2 (ACC2) and broken down by malonyl-CoA decarboxylase (MCD). When nutrients are plentiful, glucose and fatty acid fluxes increases intramitochondrial citrate -through the tricarboxylic acid (TCA) cycle-and of cytosolic citrate, which is able to stimulate ACC2 and which in turn increases the production of malonyl-CoA. Malonyl-CoA, inhibiting CPT-1, will then block mitochondrial FACoA uptake and therefore limit Beta-oxidation. The consequent accumulation of FACoA and malonyl-CoA will drive fatty acid synthesis, resulting in increased levels of diacylglycerol (DAG), triacylglycerol (IMTG) and ceramide. Nutrient excess will therefore limit its own oxidation and will stimulate storage. In contrast, when nutrients are not in excess and during exercise, the energy demand will be mediated by a drop in citrate levels and a subsequent drop in malonyl-CoA levels, resulting in facilitation of FA-CoA uptake by CPT-1, which will stimulate fatty acid oxidative disposal. $C S=$ citrate synthase; $F A B P c=$ cytosolic fatty acid binding protein; FAT/CD36 = fatty acid transporter/CD36; FFA = free fatty acid; Glut4 = glucose transporter 4; HAD = hydroxyacyl-CoA dehydrogenase; IRS = insulin receptor substrates; Ser = Serine; Thr = Threonine. 


\section{Fatty acid handling in insulin resistance and diabetes mellitus type 2}

\section{General paradigms}

Impairments in lipid metabolism play an important role in the development of insulin resistance and DM2, and the term ' diabetes lipidus' instead of ' diabetes mellitus' has even been suggested $(24,114)$. But what are the underlying mechanisms explaining the relation between an impaired glucose and fatty acid utilization in skeletal muscle and insulin resistance? Several paradigms have been developed to explain this.

\section{The glucose-fatty acid cycle}

The first concept to explain fatty acid-induced insulin resistance was the glucose-fatty acid cycle proposed by Sir Randle in 1963, which was based on substrate competition between fatty acids and glucose (115). The Randle glucosefatty acid cycle coupled an increase in FFA availability to an increased FFA oxidation. This would in turn reduce the glucose that is available for oxidation by inhibition of the pyruvate dehydrogenase complex, phosphofructokinase and hexokinase. A subsequent rise in intracellular glucose concentrations would then result in a negative feedback to glucose uptake. This concept of a high availability of FFA that stimulates fat oxidation and reduces glucose oxidation seems to fit cardiac muscle (116) better than skeletal muscle. Studies that argue against the post-receptor mechanisms of the Randle cycle as originally proposed point to an inhibition of the insulin signalling cascade by FFA or lipid intermediates (117-119). Studies with FFA infusions show a delay in the effect of fatty acids on muscle insulin resistance. This delayed inhibition of insulin-stimulated glucose uptake may be caused by an accumulation of IMTG and lipid intermediates interfering with insulin signaling (118), rather than by acute post-receptor mechanisms. In addition, there is increasing evidence that in skeletal muscle of obese and/or diabetic subjects, fatty acid uptake and oxidation are reduced rather than increased (120-122).

\section{The accumulation of intramyocellular lipids}

More recent insights have led to the hypothesis that an accumulation of triglycerides in muscle impairs insulin signalling, since the accumulation of triglycerides in skeletal muscle strongly correlates to insulin resistance and DM2 
(123-126), and infusion of insulin combined with elevated levels of plasma FFA time-dependently (over $6 \mathrm{hrs}$ ) increased the amount of IMTG and decreased insulin sensitivity (127). Even in lean, sedentary subjects, a positive relation between insulin resistance and IMTG content was found $(128,129)$. Ravikumar and coworkers found an increase in postprandial IMTG during the day in diabetic patients, but not in age- and body fat mass-matched controls (130). However, the relation between high IMTG content and insulin resistance becomes a paradox when the observations in trained athletes are included. Trained athletes are markedly insulin sensitive, despite high IMTG content. In endurance-trained athletes, an elevated IMTG content can even be predictive of high insulin sensitivity (131). An important difference between obese subjects and endurancetrained athletes with high IMTG content is muscle oxidative capacity $(109,131$, 132). It seems likely that the capacity to mobilize and/or oxidize IMTG stores is one of the main factors that modulates the association between IMTG storage and the development of skeletal muscle insulin resistance (104). In insulin resistance, the fine tuning between fatty acid uptake and oxidation may be impaired, increasing the accumulation of intermediates of lipid metabolism such as fatty acyl CoA, ceramides and diacylglycerol, that appear to have the potential to increase insulin resistance (Figure 1.3) $(124,125,133,134)$.

Ectopic fat storage, i.e. in other organs than adipose tissue, not only occurs in skeletal muscle, but also in the liver and pancreas $(87,135)$. Ectopic fat storage in the liver is related to fat mass, in particular to abdominal fat mass, which may be due to the inability of insulin to decrease lipolysis and thus fatty acid release from adipose tissue (136-138). An increased supply of fatty acids to the liver results in an increased VLDL production (139), an increased glucose output in the fasting state, an impaired insulin-mediated suppression of glucose output (140, 141) and diminished hepatic insulin clearance (140) (Figure 1.2). Furthermore, evidence starts to emerge that lipid accumulation may also play a role in the 'glucose-insensitivity' of the beta-cell, leading to inadequate insulin secretion (19).

\section{Defects in fatty acid utilization}

The accumulation of IMTG is dependent on the balance between fatty acid uptake and fatty acid oxidation. A dysbalance between fatty acid uptake and oxidation in skeletal muscle may in turn be explained by an increased supply of 
FFA from the circulation or a reduced regulation and/or capacity to oxidize fatty acids in skeletal muscle.

\section{Impaired fatty acid utilization in obesity and diabetes mellitus type 2}

An increased supply of fatty acids to other organs than adipose tissue (ectopic fat storage) may be related to an increased adipose tissue mass, a reduced clearance of plasma lipids and altered activities of lipase enzymes. In obese, insulin resistant subjects, the mass effect of expanded adipose tissue may contribute to an increased fasting FFA concentration. In addition, there is evidence that the insulin-mediated suppression of lipolysis in adipose tissue is decreased, thereby impairing the postprandial suppression of plasma free fatty acids (138, $142,143)$. Furthermore, insulin resistance is associated with an impaired clearance of dietary triglycerides by adipose tissue and an impaired insulin mediated suppression of VLDL production in the liver. The subsequent increased availability of fatty acids may enhance ectopic fat storage in skeletal muscle. In addition, HSL and possibly ATGL may play a role in the hydrolysis of IMTG to DAG and mono-acylglycerol in skeletal muscle (144), but the exact role of these lipases in muscle insulin resistance is still unclear.

In addition to an impaired supply of fatty acids to skeletal muscle, there is a growing body of evidence that a reduced ability to regulate the uptake and oxidation of fatty acids may play a role in the development of insulin resistance. Blaak and coworkers were the first to report an impaired ability to utilize fatty acids in skeletal muscle of obese (insulin resistant) subjects in the postabsorptive state and during beta-adrenergic stimulation (121). Later on, similar observations were made during exercise as well, in diabetic patients (145) and in men with impaired glucose tolerance $(122,146)$. Also in viscerally obese women, leg muscle fat oxidation was reduced during fasting when compared to lean controls (147). In diabetic subjects it was shown that the uptake as well as the oxidation of fatty acids in leg and forearm muscle were reduced when compared to lean controls $(120,148)$. In addition, it was found that after meal intake, the suppression of fatty acid uptake was blunted in the diabetic subjects, indicating an impaired regulation of fatty acid uptake (120). Furthermore, Kelley and coworkers showed a reduced fat oxidation during fasting and an impaired suppression of fat oxidation during insulin stimulation (149). This resulted in the concept of 'metabolic flexibility' of substrate oxidation (Figure 1.4.), stating that in the insulin resistant condition, the ability to stimulate fat oxidation in the fasting state and to suppress fat oxidation 
after insulin stimulation was impaired.

As mentioned before, DM2 has also been associated with impairments in fatty acid uptake in skeletal muscle. Fatty acid uptake is determined by fatty acid supply (plasma FFA concentrations), intracellular lipid metabolism (intracellular FFA concentrations) and the facilitation of diffusion by fatty acid transporters. Evidence is accumulating that alterations in the fatty acid transporter CD36 are related to insulin resistance and/or DM2 (95, 150, 151). Wilmsen and coworkers treated skeletal muscle fibres obtained from diabetic patients with thiazolidinediones, which are insulin-sensitising drugs. They showed that this treatment restored insulin sensitivity in parallel with the protein-mediated palmitate uptake, which was strongly associated with an upregulation of CD36

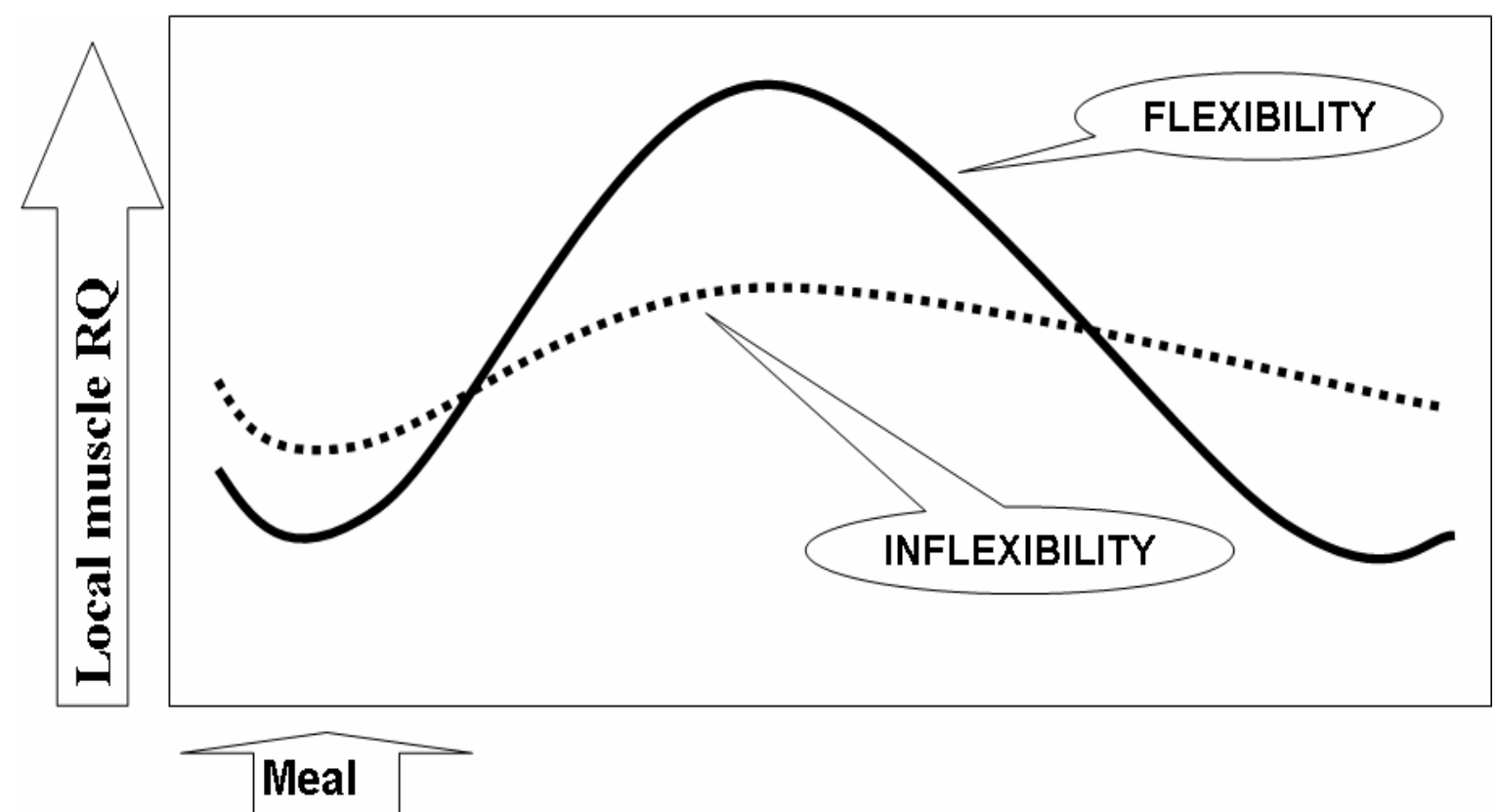

Figure 1.4. Metabolic flexibility $\mathcal{E}$ metabolic inflexibility: model for postabsorptive and postprandial adaptations in skeletal muscle substrate oxidation. A low respiratory quotient $(R Q)$ indicates a relatively high fat oxidation, a high $R Q$ indicates a relatively low fat oxidation.

expression. They suggested that CD36 may mediate part of the insulin sensitising effects of thiazolidinediones (95). In addition, Blaak and coworkers found a lowered cytosolic fatty acid binding protein $(\mathrm{FABPc})$ content in skeletal muscle in parallel with a lowered muscle plasma FFA uptake in diabetic subjects relative to lean controls (148). Kempen and coworkers found that the FABPc content of 
skeletal muscle increased after a period of energy restriction in obese premenopausal women (152). Furthermore, Bonen and coworkers suggested that fatty acid uptake may be increased in type 2 diabetic muscle, which may enhance IMTG storage. Abdominal muscle strips were obtained from diabetic and obese subjects, and basal fatty acid uptake was measured with the giant vesicle model. With this model, membrane-bound processes such as uptake can be studied without the influence of intracellular metabolism. Fatty acid uptake was increased 4-fold compared to overweight and lean controls (153). This was explained by the finding that obesity and DM2 were associated with an increased translocation of the fatty acid transporter CD36 to the plasma membrane. This study shows that the fatty acid uptake capacity may be increased in the obese and diabetic condition. At first sight, the increased fatty acid uptake capacity may seem in contrast with the previously reported in vivo findings that muscle fatty acid uptake was reduced in diabetic subjects. However, in vivo, fatty acid uptake is determined by the plasma FFA concentration, intracellular FFA concentration as well as the fatty acid uptake capacity. Up till now, very little is known about the precise function or regulation of CD36 under different physiological conditions in human skeletal muscle in vivo.

The reduced ability to regulate fat oxidation in skeletal muscle may be a primary factor in the aetiology of DM2. Studies in the 90's have found that a high whole body respiratory quotient, indicative of a relatively low fat oxidation, could predict the development of obesity and insulin resistance, even after adjustment for differences in energy balance, adiposity and gender $(154,155)$. Studies with muscle strips obtained from diabetic subjects showed that the reduced fat oxidation was still present after isolation and cultivation in vitro (156), suggesting that the reduced capacity to oxidize fatty acids may be of genetic origin. This was further supported by the observation that the ability of myotubes from healthy donors to regulate fat oxidation in vitro reflected the metabolic flexibility of substrate oxidation in vivo $(157,18)$. Furthermore, a reduced oxidative capacity was observed in subjects with impaired glucose tolerance, which suggests that it is an early factor in the progression towards DM2 $(122,146)$.

A reduced fat oxidative capacity has been associated with several mitochondrial impairments, such as a reduced mitochondrial fatty acid uptake, a reduced mitochondrial density, a reduced enzyme activity and/ or dysfunctional electron transport capacity. Insulin resistance has been related to a reduced CPT-1 activity, which is the rate-limiting step in the uptake of fatty acids into the 
mitochondria and thus of the rate of beta-oxidation. A reduced CPT- 1 activity may be caused by increased malonyl-CoA concentration (159, 160) (Figure 1.3.). Interestingly, it was shown in human skeletal muscle that malonyl-CoA concentrations could be increased by a combination of hyperglycaemia and hyperinsulinaemia, thereby lowering fat oxidation, implicating a 'reverse Randle cycle' in which glucose availability regulates FFA availability to the mitochondria $(99,101)$. Furthermore, a reduced mitochondrial density and/ or dysfunction have been found in diabetic subjects, explaining a reduced muscle oxidative capacity (161-1635). In addition, the enzyme activities for beta-oxidation may be reduced, as well as electron transport capacity. Interestingly, Ritov found that the electron transport capacity was reduced in particular in mitochondria of the subsarcolemmal pool in skeletal muscle of obese subjects, and even more in obese DM2 subjects $(164,165)$. Whether a reduced energetic support of membranebound processes may play a role the impaired ability to regulate fatty acid uptake and oxidation in skeletal muscle is still unclear.

In general, the balance between uptake and oxidation in the insulin resistant muscle appears to be directed more towards fat storage that to fat oxidation.

\section{Inflammation, insulin resistance and diabetes mellitus type 2}

\section{The Endocrine paradigm}

Obesity and DM2 have been associated with increased levels of proinflammatory markers like adipokines, the cytokine interleukin-6 (IL-6) and the acute-phase protein C-Reactive Protein (166-168). The discovery of leptin in 1994 (169) has shown that adipose tissue is not just an organ to store fat. It appears to be a very active endocrine organ, secreting adipokines, like leptin, adiponectin, TNF $\alpha$ and resistin, cytokines like interleukin-6 (IL-6) and hormones like angiotensin II (135). Plasma IL-6 has been shown to be predictive of the development of DM2 in several prospective studies $(170,171)$. These observations have led to the endocrine hypothesis, stating that adipokines produced by adipose tissue may impair metabolism and insulin sensitivity in distant tissues. In this context, it was suggested that IL-6 may play a role in the abnormalities in muscle fatty acid handling that are observed in the insulin resistant state. IL-6 blunted the insulininduced suppression of fat oxidation in isolated rat soleus muscle (172) and 
enhanced the inhibiting effect of palmitate on glucose uptake in C2C12 muscle cells (173). Interestingly, recent investigations have shown that skeletal muscle as well can secrete inflammatory markers like IL-6 during exercise (174, 175). Whether muscle can release inflammatory markers like IL-6 under other physiological conditions than exercise is not known.

\section{Effect of lifestyle factors on defects in fat metabolism}

\section{Energy restriction and exercise}

As insulin resistance and DM2 are associated with obesity, it seems reasonable to suggest that weight loss would improve insulin sensitivity and reduce concomitant impairments in metabolism. This is partly true. Weight loss improves insulin sensitivity and reduces fasting glucose, insulin and FFA plasma concentrations in obese, insulin resistant and diabetic subjects. Weight loss has also been shown to improve the insulin-mediated suppression of fat oxidation (149). On the other hand it has been shown that weight loss failed to improve fasting fat oxidation in skeletal muscle $(121,149,176)$ or skeletal muscle markers of fat oxidation (177). A similar lack of improvement in skeletal muscle fat oxidation after weight loss was found during beta-adrenergic stimulation and exercise (121, 176). The effect of weight loss on impairments in fatty acid uptake and oxidation in the postprandial phase is not clear yet. A lack of improvement after weight loss would support the hypothesis that impairments in muscle lipid metabolism are primary rather than adaptive in the development of obesity and insulin resistance.

Another lifestyle factor that is associated with the incidence of DM2 is physical activity. It has been shown that exercise training is able to improve insulin sensitivity in different populations (178). In trained athletes, it is known that exercise may increase skeletal muscle capillarization (179), CPT-1 activity (180) and the oxidative capacity of skeletal muscle. Theoretically, an improved (skeletal muscle) fat oxidation may restore the balance between fatty acid uptake and oxidation, thereby reducing the level of lipid intermediates (fatty acyl-CoA, DAG, ceramide) that have the potential to induce insulin resistance. In elderly subjects $(\sim 74 \mathrm{yr})$, of whom it is known that they have a reduced rate of fat oxidation, endurance training for 16 weeks increased the rate of fat oxidation during exercise (181). In healthy trained subjects (182) and in obese men (183), low-intensity training $\left(40 \% \mathrm{VO}_{2} \max \right)$ tended to increase total fat oxidation during 
exercise, but not during fasting. This increase in fat oxidation could not be accounted for by plasma-derived FFA oxidation, but more likely by an increased oxidation of IMTG-derived or plasma TG-derived fatty acids. Furthermore, in the study with the healthy men, a decrease (-36\%) in ACC mRNA was observed after training, which could be in favour of fat oxidation.

In most studies the exercise intervention was combined with dietary advice or energy restriction, which generally improved insulin sensitivity. Goodpaster and coworkers performed a combined training and weight loss study in obese subjects. This program did improve fat oxidation during fasting as well as the insulin-mediated switch from fat oxidation to carbohydrate oxidation. The improvements in fasting fat oxidation were strongly related to improvements in insulin sensitivity (184). They also showed that both exercise and diet alone improved insulin sensitivity, but the combination of diet and exercise was most effective. Mensink and coworkers showed that a combined diet-exercise lifestyle intervention in overweight IGT subjects improved insulin sensitivity after one year of intervention, which was accompanied by a reduction in the muscle mRNA expression of ACC2 (see also Figure 1.3.) (185). Furthermore, the IGT subjects that followed the lifestyle intervention were able to maintain or even slightly improve the capacity to oxidize fatty acids, whereas in IGT subjects of the control group the fatty acid oxidation was reduced (186).

The effects of lifestyle on IMTG storage are diverse and seem to depend on the type of intervention. Weight loss induced by energy restriction has been shown to improve insulin sensitivity and to reduce IMTG in obese subjects (110, 187), whereas exercise had a positive effect on insulin sensitivity and increased basal fat oxidation, but without reducing IMTG in overweight to obese men (188). Malenfant and coworkers did not find a significant decrease in IMTG (-35\%) after energy restriction or exercise in obese subjects (189). A study by He and coworkers in obese subjects did not show a reduction in IMTG after a combined exercise and energy restriction program neither, but found that the lipids were dispersed into smaller droplets (16). This might enhance the availability of lipids in the IMTG pool for oxidation, increasing IMTG turnover and reducing the level of lipid intermediates that may downregulate insulin signalling.

In summary, some of these studies have shown no effect of weight loss on skeletal muscle fat oxidation, whereas others suggest that weight loss induced by energy restriction and low-intensity exercise training may have beneficial effects on skeletal muscle fat oxidation and insulin sensitivity. Whether and how the 
effects of weight loss on insulin sensitivity are indeed mediated by changes in muscle fatty acid handling, IMTG and/or intracellular lipid intermediates needs further elucidation.

\section{Dietary fat quality}

Insulin sensitivity is also affected by the quality of dietary fat, and it is generally recommended in lifestyle programs that the intake of total fat is reduced and that saturated fat is replaced by unsaturated fat. In particular an excess of saturated fat may have detrimental effects on skeletal muscle insulin sensitivity $(29,32,190)$. Recently, two well-controlled human studies were able to show an improved insulin sensitivity when saturated fatty acids in the diet were replaced either by mono-unsaturated fat (191) or poly-unsaturated fat (192). Insulin sensitivity improved in particular in subjects with a low total fat intake (191). The relation between insulin sensitivity and n-3 poly-unsaturated fatty acids (PUFAs) is less clear. Most studies using a euglycemic hyperinsulinemic clamp have found no effect of n-3 PUFAs on insulin sensitivity in healthy or diabetic subjects (191195). Furthermore, n-3 PUFAs reduce plasma triglyceride levels, but increase low density lipoprotein cholesterol, which is a risk factor for cardiovascular disease (31).

The potential effect of dietary fatty acids on insulin sensitivity in skeletal muscle is hypothesized to be mediated by changes in membrane fluidity. This may result in changes in insulin receptor binding or affinity, membrane ion permeability and cell signalling (31). Furthermore, highly unsaturated fatty acids can be ligands for transcription factors like PPARs, HNF4, NFkB, and SREBP which interact with genes that are involved in lipogenesis and fatty acid oxidation (196). The degree of unsaturation of lipids throughout the body is regulated by the activity of desaturase enzymes. Recently, it was found that the $\Delta 9$-desaturase (stearyl-CoA desaturase-1) mRNA expression was upregulated in rectus abdominus muscle of obese subjects (197). This $\Delta 9$-desaturase catalyzes the conversion of palmitic and stearic acid into palmitoleic and oleic acid respectively, and its activity in myocytes was associated with low rates of fatty acid oxidation and increased triacylglycerol synthesis (197). Whether these desaturase enzymes play a role in the development of insulin resistance and/or impaired glucose tolerance, and whether changes in lifestyle may have an effect on desaturase activities has not yet been investigated. 


\section{Concluding remarks}

Lipids play a key role in the development of insulin resistance and DM2. In particular impairments in fatty acid metabolism of skeletal muscle prove to be of importance for the development of insulin resistance. Impairments in muscle fatty acid metabolism include a dysregulation of fatty acid uptake and oxidation, a reduced oxidative capacity, and an increased IMTG storage. Very little is known about these impairments in IGT subjects, such as whether the impairments in fat metabolism are already present in the prediabetic state and whether healthy changes in lifestyle may provide a means to improve skeletal muscle metabolism and thereby whole-body metabolism.

\section{OUTLINE OF THIS THESIS}

Lifestyle intervention in subjects with impaired glucose tolerance improves insulin resistance, reduces postprandial glucose concentrations and reduces the incidence of DM2. In Chapter 2 the rationale and design of the SLIMstudy (Study on Lifestyle intervention and Impaired glucose tolerance Maastricht) are described. The screening results illustrate the high prevalence of a disturbed glucose metabolism in a population at risk. Further results from the SLIM Study show that improvements in dietary fat quality, physical activity pattern and body weight contribute to a reduction in diabetes risk. The physiological mechanisms that mediate the beneficial effects of lifestyle may be strongly related to improvements in skeletal muscle fatty acid handling. However, it is difficult to investigate skeletal muscle abnormalities when the diabetic state has already developed, since it is impossible to differentiate between primary factors and adaptations that have developed later on. However, disturbances that are found in IGT subjects, a prediabetic state, may represent early or primary factors in the development towards DM2 rather than metabolic adaptations due to the diabetic state. As people in the Western societies are in the postprandial state most of the day, we have paid special attention to the handling of fatty acids by skeletal muscle after a meal.

To investigate the role of a disturbed fat metabolism in the development of insulin resistance and DM2 as well as its role in the effects of lifestyle intervention on insulin resistance, we investigated skeletal muscle fatty acid 
handling (uptake, oxidation and storage of fatty acids) in subjects with impaired glucose tolerance before and after weight loss. Disturbances that are found in the capacity to regulate fatty acid uptake and oxidation in skeletal muscle of IGT men are reported in Chapter 3. Part of the impairments in fatty acid uptake in skeletal muscle may be the result of impairments in fatty acid transporters. The role of the fatty acid transporter CD36 in insulin resistance and DM2 is investigated in Chapter 4 and 5. Chapter 4 describes the CD36 protein content in skeletal muscle in relation to insulin resistance before and after insulin stimulation in vivo, and Chapter 5 describes the association of a single nucleotide polymorphism in the promoter region of the CD36 gene with the prevalence of DM2 in 675 in a population-based cohort. Obesity and insulin resistance have also been associated with increased release of pro-inflammatory markers from adipose tissue, with a potential effect on insulin resistance and fatty acid metabolism. Recently, it was shown that skeletal muscle could also release the pro-inflammatory cytokine interleukin-6, during exercise. In Chapter 6 we investigated whether skeletal muscle of obese, insulin resistant subjects releases pro-inflammatory markers during fasting, whether this would be enhanced after a meal with high fat content, and whether there would be differences between the prediabetic men and the control men. In Chapter 7, we investigated whether lifestyle-induced changes in serum fatty acid profile were related to changes in glucose tolerance and insulin resistance. Finally, the results and conclusions of the previous chapters are integrated in Chapter 8. In this last chapter, the implications of the work presented in this thesis are discussed with respect to the understanding of the role of fatty acid handling in the aetiology of insulin resistance and DM2 and the underlying physiological mechanisms with respect to fatty acid handling that mediate the effects of lifestyle on insulin resistance and the development of DM2. 


\section{REFERENCES}

1 Grundy SM, Benjamin IJ, Burke GL, et al. (1999) Diabetes and cardiovascular disease: a statement for healthcare professionals from the American Heart Association. Circulation 100:1134-1146

2 Bertoni AG, Tsai A, Kasper EK and Brancati FL (2003) Diabetes and idiopathic cardiomyopathy: a nationwide case-control study. Diabetes Care 26:2791-2795

3 Fox CS, Coady S, Sorlie PD, et al. (2004) Trends in cardiovascular complications of diabetes. Jama 292:2495-2499

4 Mensah GA, Mokdad AH, Ford E, et al. (2004) Obesity, metabolic syndrome, and type 2 diabetes: emerging epidemics and their cardiovascular implications. Cardiol Clin 22:485-504

Pan XR, Yang WY, Li GW and Liu J (1997) Prevalence of diabetes and its risk factors in China, 1994. National Diabetes Prevention and Control Cooperative Group. Diabetes Care 20:1664-1669

Ramachandran A, Snehalatha C, Baskar AD, et al. (2004) Temporal changes in prevalence of diabetes and impaired glucose tolerance associated with lifestyle transition occurring in the rural population in India. Diabetologia 47:860-865

7 Soderberg S, Zimmet P, Tuomilehto J, et al. (2005) Increasing prevalence of Type 2 diabetes mellitus in all ethnic groups in Mauritius. Diabet Med 22:61-68

8 Cheng D (2005) Prevalence, predisposition and prevention of Type II Diabetes. Nutr Metab (Lond) 2:29

9 King H, Aubert RE and Herman WH (1998) Global burden of diabetes, 1995-2025: prevalence, numerical estimates, and projections. Diabetes Care 21:1414-1431

10 Zimmet P, Alberti KG and Shaw J (2001) Global and societal implications of the diabetes epidemic. Nature 414:782-787

11 Rijks Instituut voor Volksgezondheid en Milieu (2005) Diabetes mellitus. Omvang van het probleem. Available from http://www.nationaalkompas.nl, accessed 13 November 2005

12 ADA (2000) Type 2 diabetes in children and adolescents. American Diabetes Association. Pediatrics 105:671-680

13 Molnar D (2004) The prevalence of the metabolic syndrome and type 2 diabetes mellitus in children and adolescents. Int J Obes Relat Metab Disord 28 Suppl 3:S70-74

14 Alberti G, Zimmet P, Shaw J, Bloomgarden Z, Kaufman F and Silink M (2004) Type 2 diabetes in the young: the evolving epidemic: the international diabetes federation consensus workshop. Diabetes Care 27:1798-1811

15 World Health Organization (1999) Definition, diagnosis and classification of diabetes mellitus and its complications. Report of a WHO consultation part 1: diagnosis and classification of diabetes mellitus. WHO technical report series ( $\mathrm{p}$ 1-59)

16 Wittopkoning M (1922) Eenvoudige recepten. 40th Ed, Nijgh \& van Ditmar's uitgevers mij, Rotterdam

17 Gorden P (1997) Non-insulin dependent diabetes--the past, present and future. Ann Acad Med Singapore 26:326-330

18 Caro JF, Dohm LG, Pories WJ and Sinha MK (1989) Cellular alterations in liver, skeletal muscle, and adipose tissue responsible for insulin resistance in obesity and type II diabetes. Diabetes Metab Rev 5:665-689

Leahy JL (2005) Pathogenesis of type 2 diabetes mellitus. Arch Med Res 36:197-209 
Saad MF, Knowler WC, Pettitt DJ, Nelson RG, Charles MA and Bennett PH (1991) A two-step model for development of non-insulin-dependent diabetes. Am J Med 90:229-235

Nijpels G (1998) Determinants for the progression from impaired glucose tolerance to noninsulin-dependent diabetes mellitus. Eur J Clin Invest 28 Suppl 2:8-13

Groop L (2000) Pathogenesis of type 2 diabetes: the relative contribution of insulin resistance and impaired insulin secretion. Int J Clin Pract Suppl3-13

Kitabchi AE, Temprosa M, Knowler WC, et al. (2005) Role of insulin secretion and sensitivity in the evolution of type 2 diabetes in the diabetes prevention program: effects of lifestyle intervention and metformin. Diabetes 54:2404-2414

Shafrir E and Raz I (2003) Diabetes: mellitus or lipidus? Diabetologia 46:433-440

Colditz GA, Willett WC, Rotnitzky A and Manson JE (1995) Weight gain as a risk factor for clinical diabetes mellitus in women. Ann Intern Med 122:481-486

Chan JM, Rimm EB, Colditz GA, Stampfer MJ and Willett WC (1994) Obesity, fat distribution, and weight gain as risk factors for clinical diabetes in men. Diabetes Care 17:961-969

Han TS, Feskens EJ, Lean ME and Seidell JC (1998) Associations of body composition with type 2 diabetes mellitus. Diabet Med 15:129-135

Bazzano LA, Serdula M and Liu S (2005) Prevention of type 2 diabetes by diet and lifestyle modification. J Am Coll Nutr 24:310-319

Feskens EJ and van Dam RM (1999) Dietary fat and the etiology of type 2 diabetes: an epidemiological perspective. Nutr Metab Cardiovasc Dis 9:87-95

Hu FB, van Dam RM and Liu S (2001) Diet and risk of Type II diabetes: the role of types of fat and carbohydrate. Diabetologia 44:805-817

Riccardi G, Giacco R and Rivellese AA (2004) Dietary fat, insulin sensitivity and the metabolic syndrome. Clin Nutr 23:447-456

Vessby B, Aro A, Skarfors E, Berglund L, Salminen I and Lithell H (1994) The risk to develop NIDDM is related to the fatty acid composition of the serum cholesterol esters. Diabetes 43:1353-1357

Wang L, Folsom AR, Zheng ZJ, Pankow JS and Eckfeldt JH (2003) Plasma fatty acid composition and incidence of diabetes in middle-aged adults: the Atherosclerosis Risk in Communities (ARIC) Study. Am J Clin Nutr 78:91-98

Marshall JA, Hoag S, Shetterly S and Hamman RF (1994) Dietary fat predicts conversion from impaired glucose tolerance to NIDDM. The San Luis Valley Diabetes Study. Diabetes Care 17:50-56

Salmeron J, Hu FB, Manson JE, et al. (2001) Dietary fat intake and risk of type 2 diabetes in women. Am J Clin Nutr 73:1019-1026

Jenkins DJ, Axelsen M, Kendall CW, Augustin LS, Vuksan V and Smith U (2000) Dietary fibre, lente carbohydrates and the insulin-resistant diseases. Br J Nutr 83 Suppl 1:S157-163

Meyer KA, Kushi LH, Jacobs DR, Jr., Slavin J, Sellers TA and Folsom AR (2000) Carbohydrates, dietary fiber, and incident type 2 diabetes in older women. Am J Clin Nutr 71:921-930

Stevens J, Ahn K, Juhaeri, Houston D, Steffan L and Couper D (2002) Dietary fiber intake and glycemic index and incidence of diabetes in African-American and white adults: the ARIC study. Diabetes Care 25:1715-1721 
van Dam RM and Feskens EJ (2002) Coffee consumption and risk of type 2 diabetes mellitus. Lancet 360:1477-1478

Schulze MB and Hu FB (2005) Primary prevention of diabetes: what can be done and how much can be prevented? Annu Rev Public Health 26:445-467

Rimm EB, Manson JE, Stampfer MJ, et al. (1993) Cigarette smoking and the risk of diabetes in women. Am J Public Health 83:211-214

Manson JE, Ajani UA, Liu S, Nathan DM and Hennekens CH (2000) A prospective study of cigarette smoking and the incidence of diabetes mellitus among US male physicians. Am J Med 109:538-542

Helmrich SP, Ragland DR, Leung RW and Paffenbarger RS, Jr. (1991) Physical activity and reduced occurrence of non-insulin-dependent diabetes mellitus. N Engl J Med 325:147-152

Hu FB, Sigal RJ, Rich-Edwards JW, et al. (1999) Walking compared with vigorous physical activity and risk of type 2 diabetes in women: a prospective study. Jama 282:1433-1439

LaMonte MJ, Blair SN and Church TS (2005) Physical activity and diabetes prevention. J Appl Physiol 99:1205-1213

Patti ME (2004) Gene expression in humans with diabetes and prediabetes: what have we learned about diabetes pathophysiology? Curr Opin Clin Nutr Metab Care 7:383-390

Stannard SR and Johnson NA (2004) Insulin resistance and elevated triglyceride in muscle: more important for survival than "thrifty" genes? J Physiol 554:595-607

Neel JV (1962) Diabetes mellitus: a "thrifty" genotype rendered detrimental by "progress"? Am J Hum Genet 14:353-362

Kawate R, Yamakido M, Nishimoto Y, Bennett PH, Hamman RF and Knowler WC (1979) Diabetes mellitus and its vascular complications in Japanese migrants on the Island of Hawaii. Diabetes Care 2:161-170

Blaak EE (2004) Basic disturbances in skeletal muscle fatty acid metabolism in obesity and type 2 diabetes mellitus. Proc Nutr Soc 63:323-330

Weyer C, Bogardus C and Pratley RE (1999) Metabolic characteristics of individuals with impaired fasting glucose and/or impaired glucose tolerance. Diabetes 48:2197-2203

Pimenta W, Mitrakou A, Jensen T, Yki-Jarvinen H, Daily G and Gerich J (1996) Insulin secretion and insulin sensitivity in people with impaired glucose tolerance. Diabet Med 13:S33-36

Davies MJ, Rayman G, Grenfell A, Gray IP, Day JL and Hales CN (1994) Loss of the first phase insulin response to intravenous glucose in subjects with persistent impaired glucose tolerance. Diabet Med 11:432-436

Esposito K, Nappo F, Marfella R, et al. (2002) Inflammatory cytokine concentrations are acutely increased by hyperglycemia in humans: role of oxidative stress. Circulation 106:2067-2072

Gavella M, Lipovac V, Car A, Vucic M, Sokolic L and Rakos R (2003) Serum sialic acid in subjects with impaired glucose tolerance and in newly diagnosed type 2 diabetic patients. Acta Diabetol 40:95-100

Shaw JE, Hodge AM, de Courten M, Chitson P and Zimmet PZ (1999) Isolated post-challenge hyperglycaemia confirmed as a risk factor for mortality. Diabetologia 42:1050-1054

Tominaga M, Eguchi H, Manaka H, Igarashi K, Kato T and Sekikawa A (1999) Impaired glucose tolerance is a risk factor for cardiovascular disease, but not impaired fasting glucose. The Funagata Diabetes Study. Diabetes Care 22:920-924

DECODE (2003) Is the current definition for diabetes relevant to mortality risk from all causes and cardiovascular and noncardiovascular diseases? Diabetes Care 26:688-696 
Deedwania PC and Fonseca VA (2005) Diabetes, prediabetes, and cardiovascular risk: shifting the paradigm. Am J Med 118:939-947

61 Levitan EB, Song Y, Ford ES and Liu S (2004) Is nondiabetic hyperglycemia a risk factor for cardiovascular disease? A meta-analysis of prospective studies. Arch Intern Med 164:2147-2155

Unwin N, Shaw J, Zimmet P and Alberti KG (2002) Impaired glucose tolerance and impaired fasting glycaemia: the current status on definition and intervention. Diabet Med 19:708-723

Mooy JM, Grootenhuis PA, de Vries H, et al. (1995) Prevalence and determinants of glucose intolerance in a Dutch caucasian population. The Hoorn Study. Diabetes Care 18:1270-1273

de Vegt F, Dekker JM, Jager A, et al. (2001) Relation of impaired fasting and postload glucose with incident type 2 diabetes in a Dutch population: The Hoorn Study. Jama 285:2109-2113

Edelstein SL, Knowler WC, Bain RP, et al. (1997) Predictors of progression from impaired glucose tolerance to NIDDM: an analysis of six prospective studies. Diabetes 46:701-710

Hu FB, Manson JE, Stampfer MJ, et al. (2001) Diet, lifestyle, and the risk of type 2 diabetes mellitus in women. N Engl J Med 345:790-797

Papoz L, Job D, Eschwege E, et al. (1978) Effect of oral hypoglycaemic drugs on glucose tolerance and insulin secretion in borderline diabetic patients. Diabetologia 15:373-380

Tan MH, Graham CA, Bradley RF, Gleason RE and Soeldner JS (1977) The effects of long-term therapy with oral hypoglycemic agents on the oral glucose tolerance test dynamics in male chemical diabetics. Diabetes 26:561-570

Jarrett RJ, Keen H, Fuller JH and McCartney M (1977) Treatment of borderline diabetes: controlled trial using carbohydrate restriction and phenformin. Br Med J 2:861-865

Ratzmann KP, Witt S and Schulz B (1983) The effect of long-term glibenclamide treatment on glucose tolerance, insulin secretion and serum lipids in subjects with impaired glucose tolerance. Diabete Metab 9:87-93

Pontiroli AE, Perfetti MG and Pozza G (1991) Acute effect of glipizide on glucose tolerance in obesity and diabetes mellitus (NIDDM). Eur J Clin Pharmacol 40:23-26

Chiasson JL, Josse RG, Leiter LA, et al. (1996) The effect of acarbose on insulin sensitivity in subjects with impaired glucose tolerance. Diabetes Care 19:1190-1193

Chiasson JL, Josse RG, Gomis R, Hanefeld M, Karasik A and Laakso M (2002) Acarbose for prevention of type 2 diabetes mellitus: the STOP-NIDDM randomised trial. Lancet 359:20722077

Buchanan TA, Xiang AH, Peters RK, et al. (2002) Preservation of pancreatic beta-cell function and prevention of type 2 diabetes by pharmacological treatment of insulin resistance in highrisk hispanic women. Diabetes 51:2796-2803

Knowler WC, Barrett-Connor E, Fowler SE, et al. (2002) Reduction in the incidence of type 2 diabetes with lifestyle intervention or metformin. N Engl J Med 346:393-403

Jandeleit-Dahm KA, Tikellis C, Reid CM, Johnston CI and Cooper ME (2005) Why blockade of the renin-angiotensin system reduces the incidence of new-onset diabetes. J Hypertens 23:463473

Sartor G, Schersten B, Carlstrom S, Melander A, Norden A and Persson G (1980) Ten-year follow-up of subjects with impaired glucose tolerance: prevention of diabetes by tolbutamide and diet regulation. Diabetes 29:41-49

Bitzen PO, Melander A, Schersten B and Svensson M (1988) Efficacy of dietary regulation in primary health care patients with hyperglycaemia detected by screening. Diabet Med 5:640-647 
Pan XR, Li GW, Hu YH, et al. (1997) Effects of diet and exercise in preventing NIDDM in people with impaired glucose tolerance. The Da Qing IGT and Diabetes Study. Diabetes Care 20:537544

Eriksson KF and Lindgarde F (1991) Prevention of type 2 (non-insulin-dependent) diabetes mellitus by diet and physical exercise. The 6-year Malmo feasibility study. Diabetologia 34:891898.

Eriksson KF and Lindgarde F (1998) No excess 12-year mortality in men with impaired glucose tolerance who participated in the Malmo Preventive Trial with diet and exercise. Diabetologia 41:1010-1016

Tuomilehto J, Lindstrom J, Eriksson JG, et al. (2001) Prevention of type 2 diabetes mellitus by changes in lifestyle among subjects with impaired glucose tolerance. N Engl J Med 344:13431350 .

Mensink M, Blaak EE, Corpeleijn E, Saris WH, de Bruin TW and Feskens EJ (2003) Lifestyle intervention according to general recommendations improves glucose tolerance. Obes Res 11:1588-1596

Stone NJ and Saxon D (2005) Approach to treatment of the patient with metabolic syndrome: lifestyle therapy. Am J Cardiol 96:15E-21E

Bassuk SS and Manson JE (2005) Epidemiological evidence for the role of physical activity in reducing risk of type 2 diabetes and cardiovascular disease. J Appl Physiol 99:1193-1204

Torjesen PA, Birkeland KI, Anderssen SA, Hjermann I, Holme I and Urdal P (1997) Lifestyle changes may reverse development of the insulin resistance syndrome. The Oslo Diet and Exercise Study: a randomized trial. Diabetes Care 20:26-31

Frayn KN, Blaak EE (2005) Metabolic fuels and obesity: carbohydrate and lipid metabolism in skeletal muscle and adipose tissue, In: Kopelman PG, Caterson ID, Diets WH (eds) Clinical Obesity in Adults and Children. Blackwell Publishing Ltd, p 102-122

DeFronzo RA, Jacot E, Jequier E, Maeder E, Wahren J and Felber JP (1981) The effect of insulin on the disposal of intravenous glucose. Results from indirect calorimetry and hepatic and femoral venous catheterization. Diabetes 30:1000-1007

89 Zimmermann R, Strauss JG, Haemmerle G, et al. (2004) Fat mobilization in adipose tissue is promoted by adipose triglyceride lipase. Science 306:1383-1386

Mead JR, Irvine SA and Ramji DP (2002) Lipoprotein lipase: structure, function, regulation, and role in disease. J Mol Med 80:753-769

Glatz JF, Bonen A and Luiken JJ (2002) Exercise and insulin increase muscle fatty acid uptake by recruiting putative fatty acid transporters to the sarcolemma. Curr Opin Clin Nutr Metab Care 5:365-370

92 Abumrad N, Coburn C and Ibrahimi A (1999) Membrane proteins implicated in long-chain fatty acid uptake by mammalian cells: CD36, FATP and FABPm. Biochim Biophys Acta 1441:4-13

93 Luiken JJ, Koonen DP, Willems J, et al. (2002) Insulin stimulates long-chain fatty acid utilization by rat cardiac myocytes through cellular redistribution of FAT/CD36. Diabetes 51:3113-3119

94 Luiken JJ, Coort SL, Willems J, et al. (2003) Contraction-induced fatty acid translocase/CD36 translocation in rat cardiac myocytes is mediated through AMP-activated protein kinase signaling. Diabetes 52:1627-1634

Wilmsen HM, Ciaraldi TP, Carter L, Reehman N, Mudaliar SR and Henry RR (2003) Thiazolidinediones upregulate impaired fatty acid uptake in skeletal muscle of type 2 diabetic subjects. Am J Physiol Endocrinol Metab 285:E354-362 
Cha BS, Ciaraldi TP, Carter L, et al. (2001) Peroxisome proliferator-activated receptor (PPAR) gamma and retinoid $X$ receptor (RXR) agonists have complementary effects on glucose and lipid metabolism in human skeletal muscle. Diabetologia 44:444-452

97 Febbraio M, Abumrad NA, Hajjar DP, et al. (1999) A null mutation in murine CD36 reveals an important role in fatty acid and lipoprotein metabolism. J Biol Chem 274:19055-19062.

99 Sidossis LS and Wolfe RR (1996) Glucose and insulin-induced inhibition of fatty acid oxidation: the glucose-fatty acid cycle reversed. Am J Physiol 270:E733-738

100 McGarry JD and Brown NF (1997) The mitochondrial carnitine palmitoyltransferase system. From concept to molecular analysis. Eur J Biochem 244:1-14

101 Rasmussen BB, Holmback UC, Volpi E, Morio-Liondore B, Paddon-Jones D and Wolfe RR (2002) Malonyl coenzyme A and the regulation of functional carnitine palmitoyltransferase-1 activity and fat oxidation in human skeletal muscle. J Clin Invest 110:1687-1693

102 Campbell SE, Tandon NN, Woldegiorgis G, Luiken JJ, Glatz JF and Bonen A (2004) A novel function for fatty acid translocase (FAT)/CD36: involvement in long chain fatty acid transfer into the mitochondria. J Biol Chem 279:36235-36241

103 Moffett DF, Moffett SB, Schauf CL (1993) Human Physiology. Foundations \& Frontiers. Mosby, Missouri USA.

104 van Loon LJ (2004) Use of intramuscular triacylglycerol as a substrate source during exercise in humans. J Appl Physiol 97:1170-1187

105 Levin K, Daa Schroeder H, Alford FP and Beck-Nielsen H (2001) Morphometric documentation of abnormal intramyocellular fat storage and reduced glycogen in obese patients with Type II diabetes. Diabetologia 44:824-833.

106 Malenfant P, Joanisse DR, Theriault R, Goodpaster BH, Kelley DE and Simoneau JA (2001) Fat content in individual muscle fibers of lean and obese subjects. Int J Obes Relat Metab Disord 25:1316-1321

107 He J, Goodpaster BH and Kelley DE (2004) Effects of weight loss and physical activity on muscle lipid content and droplet size. Obes Res 12:761-769

108 Howald H, Boesch C, Kreis R, et al. (2002) Content of intramyocellular lipids derived by electron microscopy, biochemical assays, and (1)H-MR spectroscopy. J Appl Physiol 92:22642272

109 He J, Watkins S and Kelley DE (2001) Skeletal muscle lipid content and oxidative enzyme activity in relation to muscle fiber type in type 2 diabetes and obesity. Diabetes 50:817-823

110 Gray RE, Tanner CJ, Pories WJ, MacDonald KG and Houmard JA (2003) Effect of weight loss on muscle lipid content in morbidly obese subjects. Am J Physiol Endocrinol Metab 284:E726-732

111 Holm C, Osterlund T, Laurell H and Contreras JA (2000) Molecular mechanisms regulating hormone-sensitive lipase and lipolysis. Annu Rev Nutr 20:365-393

112 Romijn JA, Coyle EF, Sidossis LS, et al. (1993) Regulation of endogenous fat and carbohydrate metabolism in relation to exercise intensity and duration. Am J Physiol 265:E380-391

113 van Loon LJ, Koopman R, Stegen JH, Wagenmakers AJ, Keizer HA and Saris WH (2003) Intramyocellular lipids form an important substrate source during moderate intensity exercise in endurance-trained males in a fasted state. J Physiol 553:611-625

114 Bjorntorp P (2003) -to: Shafrir E, Raz I (2003) For debate. Diabetes: mellitus or lipidus? Diabetologia 46: 433-440. Diabetologia 46:1586-1587; author reply 1587 
115 Randle PJ, Garland PB, Hales CN and Newsholme EA (1963) The glucose fatty-acid cycle. Its role in insulin sensitivity and the metabolic disturbances of diabetes mellitus. Lancet 1:785-789

116 Lopaschuk GD (2002) Metabolic abnormalities in the diabetic heart. Heart Fail Rev 7:149-159

117 Roden M, Krssak M, Stingl H, et al. (1999) Rapid impairment of skeletal muscle glucose transport/phosphorylation by free fatty acids in humans. Diabetes 48:358-364

118 Boden G, Lebed B, Schatz M, Homko C and Lemieux S (2001) Effects of acute changes of plasma free fatty acids on intramyocellular fat content and insulin resistance in healthy subjects. Diabhetes 50:1612-1617.

119 Dresner A, Laurent D, Marcucci M, et al. (1999) Effects of free fatty acids on glucose transport and IRS-1-associated phosphatidylinositol 3-kinase activity. J Clin Invest 103:253-259.

120 Kelley DE and Simoneau JA (1994) Impaired free fatty acid utilization by skeletal muscle in non-insulin-dependent diabetes mellitus. J Clin Invest 94:2349-2356

121 Blaak EE, Van Baak MA, Kemerink GJ, Pakbiers MT, Heidendal GA and Saris WH (1994) Betaadrenergic stimulation of energy expenditure and forearm skeletal muscle metabolism in lean and obese men. Am J Physiol 267:E306-315

122 Turpeinen AK, Takala TO, Nuutila P, et al. (1999) Impaired free fatty acid uptake in skeletal muscle but not in myocardium in patients with impaired glucose tolerance: studies with PET and 14(R,S)-[18F]fluoro-6-thia-heptadecanoic acid. Diabetes 48:1245-1250

123 Krssak M, Falk Petersen K, Dresner A, et al. (1999) Intramyocellular lipid concentrations are correlated with insulin sensitivity in humans: a $1 \mathrm{H}$ NMR spectroscopy study. Diabetologia 42:113-116.

124 Schmitz-Peiffer C (2000) Signalling aspects of insulin resistance in skeletal muscle: mechanisms induced by lipid oversupply. Cell Signal 12:583-594

125 Itani SI, Ruderman NB, Schmieder F and Boden G (2002) Lipid-induced insulin resistance in human muscle is associated with changes in diacylglycerol, protein kinase C, and IkappaBalpha. Diabetes 51:2005-2011

126 Boden G and Laakso M (2004) Lipids and glucose in type 2 diabetes: what is the cause and effect? Diabetes Care 27:2253-2259

127 Bachmann OP, Dahl DB, Brechtel K, et al. (2001) Effects of intravenous and dietary lipid challenge on intramyocellular lipid content and the relation with insulin sensitivity in humans. Diabetes 50:2579-2584

128 Perseghin G, Scifo P, De Cobelli F, et al. (1999) Intramyocellular triglyceride content is a determinant of in vivo insulin resistance in humans: a $1 \mathrm{H}-13 \mathrm{C}$ nuclear magnetic resonance spectroscopy assessment in offspring of type 2 diabetic parents. Diabetes 48:1600-1606.

129 Jacob S, Machann J, Rett K, et al. (1999) Association of increased intramyocellular lipid content with insulin resistance in lean nondiabetic offspring of type 2 diabetic subjects. Diabetes 48:1113-1119.

130 Ravikumar B, Carey PE, Snaar JE, et al. (2005) Real-time assessment of postprandial fat storage in liver and skeletal muscle in health and type 2 diabetes. Am J Physiol Endocrinol Metab 288:E789-797

131 Thamer C, Machann J, Bachmann O, et al. (2003) Intramyocellular lipids: anthropometric determinants and relationships with maximal aerobic capacity and insulin sensitivity. J Clin Endocrinol Metab 88:1785-1791 
132 Goodpaster BH, He J, Watkins S and Kelley DE (2001) Skeletal muscle lipid content and insulin resistance: evidence for a paradox in endurance-trained athletes. J Clin Endocrinol Metab 86:5755-5761

133 Adams JM, 2nd, Pratipanawatr T, Berria R, et al. (2004) Ceramide content is increased in skeletal muscle from obese insulin-resistant humans. Diabetes 53:25-31

134 Ellis BA, Poynten A, Lowy AJ, et al. (2000) Long-chain acyl-CoA esters as indicators of lipid metabolism and insulin sensitivity in rat and human muscle. Am J Physiol Endocrinol Metab 279:E554-560

135 Heilbronn L, Smith SR and Ravussin E (2004) Failure of fat cell proliferation, mitochondrial function and fat oxidation results in ectopic fat storage, insulin resistance and type II diabetes mellitus. Int J Obes Relat Metab Disord 28 Suppl 4:S12-21

136 Kissebah AH and Krakower GR (1994) Regional adiposity and morbidity. Physiol Rev 74:761811

137 Bjorntorp P (1990) "Portal" adipose tissue as a generator of risk factors for cardiovascular disease and diabetes. Arteriosclerosis 10:493-496

138 Arner P (2005) Human fat cell lipolysis: biochemistry, regulation and clinical role. Best Pract Res Clin Endocrinol Metab 19:471-482

139 Frayn KN, Williams CM and Arner P (1996) Are increased plasma non-esterified fatty acid concentrations a risk marker for coronary heart disease and other chronic diseases? Clin Sci (Lond) 90:243-253

140 Lewis GF, Vranic M, Harley P and Giacca A (1997) Fatty acids mediate the acute extrahepatic effects of insulin on hepatic glucose production in humans. Diabetes 46:1111-1119

141 Seppala-Lindroos A, Vehkavaara S, Hakkinen AM, et al. (2002) Fat accumulation in the liver is associated with defects in insulin suppression of glucose production and serum free fatty acids independent of obesity in normal men. J Clin Endocrinol Metab 87:3023-3028

142 Saloranta C and Groop L (1996) Interactions between glucose and FFA metabolism in man. Diabetes Metab Rev 12:15-36

143 Yeaman SJ (2004) Hormone-sensitive lipase--new roles for an old enzyme. Biochem J 379:11-22

144 Watt MJ and Spriet LL (2004) Regulation and role of hormone-sensitive lipase activity in human skeletal muscle. Proc Nutr Soc 63:315-322

145 Blaak EE, van Aggel-Leijssen DP, Wagenmakers AJ, Saris WH and van Baak MA (2000) Impaired oxidation of plasma-derived fatty acids in type 2 diabetic subjects during moderateintensity exercise. Diabetes 49:2102-2107.

146 Mensink M, Blaak EE, van Baak MA, Wagenmakers AJ and Saris WH (2001) Plasma free Fatty Acid uptake and oxidation are already diminished in subjects at high risk for developing type 2 diabetes. Diabetes 50:2548-2554

147 Colberg SR, Simoneau JA, Thaete FL and Kelley DE (1995) Skeletal muscle utilization of free fatty acids in women with visceral obesity. J Clin Invest 95:1846-1853

148 Blaak EE, Wagenmakers AJ, Glatz JF, et al. (2000) Plasma FFA utilization and fatty acid-binding protein content are diminished in type 2 diabetic muscle. Am J Physiol Endocrinol Metab 279:E146-154.

149 Kelley DE, Goodpaster B, Wing RR and Simoneau JA (1999) Skeletal muscle fatty acid metabolism in association with insulin resistance, obesity, and weight loss. Am J Physiol 277:E1130-1141 
150 Pravenec M, Landa V, Zidek V, et al. (2001) Transgenic rescue of defective Cd36 ameliorates insulin resistance in spontaneously hypertensive rats. Nat Genet 27:156-158

151 Pravenec M, Landa V, Zidek V, et al. (2003) Transgenic expression of CD36 in the spontaneously hypertensive rat is associated with amelioration of metabolic disturbances but has no effect on hypertension. Physiol Res 52:681-688

Kempen KP, Saris WH, Kuipers H, Glatz JF and Van Der Vusse GJ (1998) Skeletal muscle metabolic characteristics before and after energy restriction in human obesity: fibre type, enzymatic beta-oxidative capacity and fatty acid-binding protein content. Eur J Clin Invest 28:1030-1037

153 Bonen A, Parolin ML, Steinberg GR, et al. (2004) Triacylglycerol accumulation in human obesity and type 2 diabetes is associated with increased rates of skeletal muscle fatty acid transport and increased sarcolemmal FAT/CD36. Faseb J 18:1144-1146

154 Zurlo F, Lillioja S, Esposito-Del Puente A, et al. (1990) Low ratio of fat to carbohydrate oxidation as predictor of weight gain: study of 24-h RQ. Am J Physiol 259:E650-657

Seidell JC, Muller DC, Sorkin JD and Andres R (1992) Fasting respiratory exchange ratio and resting metabolic rate as predictors of weight gain: the Baltimore Longitudinal Study on Aging. Int J Obes Relat Metab Disord 16:667-674

156 Gaster M, Rustan AC, Aas V and Beck-Nielsen H (2004) Reduced lipid oxidation in skeletal muscle from type 2 diabetic subjects may be of genetic origin: evidence from cultured myotubes. Diabetes 53:542-548

157 Ukropcova B, McNeil M, Sereda O, et al. (2005) Dynamic changes in fat oxidation in human primary myocytes mirror metabolic characteristics of the donor. J Clin Invest 115:1934-1941

Kelley DE (2005) Skeletal muscle fat oxidation: timing and flexibility are everything. J Clin Invest 115:1699-1702

159 McGarry JD (2002) Banting lecture 2001: dysregulation of fatty acid metabolism in the etiology of type 2 diabetes. Diabetes 51:7-18

160 Ruderman NB, Saha AK, Vavvas D and Witters LA (1999) Malonyl-CoA, fuel sensing, and insulin resistance. Am J Physiol 276:E1-E18

161 Lowell BB and Shulman GI (2005) Mitochondrial dysfunction and type 2 diabetes. Science 307:384-387

162 Mootha VK, Lindgren CM, Eriksson KF, et al. (2003) PGC-1alpha-responsive genes involved in oxidative phosphorylation are coordinately downregulated in human diabetes. Nat Genet 34:267-273

163 Patti ME, Butte AJ, Crunkhorn S, et al. (2003) Coordinated reduction of genes of oxidative metabolism in humans with insulin resistance and diabetes: Potential role of PGC1 and NRF1. Proc Natl Acad Sci U S A 100:8466-8471

164 Ritov VB, Menshikova EV, He J, Ferrell RE, Goodpaster BH and Kelley DE (2005) Deficiency of subsarcolemmal mitochondria in obesity and type 2 diabetes. Diabetes 54:8-14

165 Hood DA (2001) Invited Review: contractile activity-induced mitochondrial biogenesis in skeletal muscle. J Appl Physiol 90:1137-1157

166 Hanley AJ, Festa A, D'Agostino RB, Jr., et al. (2004) Metabolic and inflammation variable clusters and prediction of type 2 diabetes: factor analysis using directly measured insulin sensitivity. Diabetes 53:1773-1781

167 Laaksonen DE, Niskanen L, Nyyssonen K, et al. (2004) C-reactive protein and the development of the metabolic syndrome and diabetes in middle-aged men. Diabetologia 47:1403-1410 
168 Muller S, Martin S, Koenig W, et al. (2002) Impaired glucose tolerance is associated with increased serum concentrations of interleukin 6 and co-regulated acute-phase proteins but not TNF-alpha or its receptors. Diabetologia 45:805-812

169 Zhang Y, Proenca R, Maffei M, Barone M, Leopold L and Friedman JM (1994) Positional cloning of the mouse obese gene and its human homologue. Nature 372:425-432

170 Pradhan AD, Manson JE, Rifai N, Buring JE and Ridker PM (2001) C-reactive protein, interleukin 6, and risk of developing type 2 diabetes mellitus. Jama 286:327-334

171 Spranger J, Kroke A, Mohlig M, et al. (2003) Inflammatory cytokines and the risk to develop type 2 diabetes: results of the prospective population-based European Prospective Investigation into Cancer and Nutrition (EPIC)-Potsdam Study. Diabetes 52:812-817

172 Bruce CR and Dyck DJ (2004) Cytokine regulation of skeletal muscle fatty acid metabolism: effect of interleukin-6 and tumor necrosis factor-alpha. Am J Physiol Endocrinol Metab 287:E616-621

173 Jove M, Planavila A, Laguna JC and Vazquez-Carrera M (2005) Palmitate-induced interleukin 6 production is mediated by protein kinase $\mathrm{C}$ and nuclear-factor kappaB activation and leads to glucose transporter 4 down-regulation in skeletal muscle cells. Endocrinology 146:3087-3095

174 Keller P, Keller C, Carey AL, et al. (2003) Interleukin-6 production by contracting human skeletal muscle: autocrine regulation by IL-6. Biochem Biophys Res Commun 310:550-554

175 Fischer CP, Hiscock NJ, Penkowa M, et al. (2004) Supplementation with vitamins C and E inhibits the release of interleukin-6 from contracting human skeletal muscle. J Physiol 558:633645

176 Blaak EE, Wolffenbuttel BH, Saris WH, Pelsers MM and Wagenmakers AJ (2001) Weight reduction and the impaired plasma-derived free fatty acid oxidation in type 2 diabetic subjects. J Clin Endocrinol Metab 86:1638-1644

177 Simoneau JA, Veerkamp JH, Turcotte LP and Kelley DE (1999) Markers of capacity to utilize fatty acids in human skeletal muscle: relation to insulin resistance and obesity and effects of weight loss. Faseb J 13:2051-2060.

178 Borghouts LB and Keizer HA (2000) Exercise and insulin sensitivity: a review. Int J Sports Med 21:1-12

179 Andersen P and Henriksson J (1977) Capillary supply of the quadriceps femoris muscle of man: adaptive response to exercise. J Physiol 270:677-690

180 Mole PA, Oscai LB and Holloszy JO (1971) Adaptation of muscle to exercise. Increase in levels of palmityl Coa synthetase, carnitine palmityltransferase, and palmityl Coa dehydrogenase, and in the capacity to oxidize fatty acids. J Clin Invest 50:2323-2330

181 Sial S, Coggan AR, Hickner RC and Klein S (1998) Training-induced alterations in fat and carbohydrate metabolism during exercise in elderly subjects. Am J Physiol 274:E785-790

182 Schrauwen P, van Aggel-Leijssen DP, Hul G, et al. (2002) The effect of a 3-month low-intensity endurance training program on fat oxidation and acetyl-CoA carboxylase-2 expression. Diabetes 51:2220-2226

183 van Aggel-Leijssen DP, Saris WH, Wagenmakers AJ, Senden JM and van Baak MA (2002) Effect of exercise training at different intensities on fat metabolism of obese men. J Appl Physiol 92:1300-1309

184 Goodpaster BH, Katsiaras A and Kelley DE (2003) Enhanced fat oxidation through physical activity is associated with improvements in insulin sensitivity in obesity. Diabetes 52:2191-2197 
185 Mensink M, Blaak EE, Vidal H, De Bruin TW, Glatz JF and Saris WH (2003) Lifestyle changes and lipid metabolism gene expression and protein content in skeletal muscle of subjects with impaired glucose tolerance. Diabetologia 46:1082-1089

186 Mensink M, Blaak EE, Wagenmakers AJ and Saris WH (2005) Lifestyle intervention and fatty acid metabolism in glucose-intolerant subjects. Obes Res 13:1354-1362

187 Goodpaster BH, Theriault R, Watkins SC and Kelley DE (2000) Intramuscular lipid content is increased in obesity and decreased by weight loss. Metabolism 49:467-472

188 Gan SK, Kriketos AD, Ellis BA, Thompson CH, Kraegen EW and Chisholm DJ (2003) Changes in aerobic capacity and visceral fat but not myocyte lipid levels predict increased insulin action after exercise in overweight and obese men. Diabetes Care 26:1706-1713

189 Malenfant P, Tremblay A, Doucet E, Imbeault P, Simoneau JA and Joanisse DR (2001) Elevated intramyocellular lipid concentration in obese subjects is not reduced after diet and exercise training. Am J Physiol Endocrinol Metab 280:E632-639.

190 Borkman M, Storlien LH, Pan DA, Jenkins AB, Chisholm DJ and Campbell LV (1993) The relation between insulin sensitivity and the fatty-acid composition of skeletal-muscle phospholipids. N Engl J Med 328:238-244

191 Vessby B, Unsitupa M, Hermansen K, et al. (2001) Substituting dietary saturated for monounsaturated fat impairs insulin sensitivity in healthy men and women: The KANWU Study. Diabetologia 44:312-319

192 Summers LK, Fielding BA, Bradshaw HA, et al. (2002) Substituting dietary saturated fat with polyunsaturated fat changes abdominal fat distribution and improves insulin sensitivity. Diabetologia 45:369-377

193 Borkman M, Chisholm DJ, Furler SM, et al. (1989) Effects of fish oil supplementation on glucose and lipid metabolism in NIDDM. Diabetes 38:1314-1319

194 McManus RM, Jumpson J, Finegood DT, Clandinin MT and Ryan EA (1996) A comparison of the effects of n-3 fatty acids from linseed oil and fish oil in well-controlled type II diabetes. Diabetes Care 19:463-467

195 Rivellese AA, Maffettone A, Iovine C, et al. (1996) Long-term effects of fish oil on insulin resistance and plasma lipoproteins in NIDDM patients with hypertriglyceridemia. Diabetes Care 19:1207-1213

196 Jump DB and Clarke SD (1999) Regulation of gene expression by dietary fat. Annu Rev Nutr 19:63-90

197 Hulver MW, Berggren JR, Carper MJ, et al. (2005) Elevated stearoyl-CoA desaturase-1 expression in skeletal muscle contributes to abnormal fatty acid partitioning in obese humans. Cell Metab 2:251-261 



\section{CHAPTER 2}

\section{Study on Lifestyle-Intervention and Impaired Glucose Tolerance Maastricht (SLIM): Design and Screening Results}

Marco Mensink (1), Eefje Corpeleijn (1), Edith J.M. Feskens (2), Margriet Kruijshoop (1), Wim H.M. Saris (1), Tjerk W.A. de Bruin (3) and Ellen E. Blaak (1)

(1) Dept of Human Biology, Nutrition and Toxicology Research Institute NUTRIM, Maastricht University, Maastricht, The Netherlands.

(2) Dept of Health and Nutrition, National Institute for Public Health and the Environment, Bilthoven, The Netherlands

(3) Dept of Medicine and Endocrinology, Cardiovascular Research Institute CARIM, University Hospital Maastricht, Maastricht, The Netherlands

Diab Res Clin Pract 2003; 61: 49-58 


\begin{abstract}
The Study on Lifestyle-intervention and Impaired Glucose Tolerance Maastricht (SLIM) is a 3 year randomised clinical trial designed to evaluate the effect of a combined diet and physical activity intervention program on glucose tolerance in a Dutch population at increased risk for developing type 2 diabetes. Here the design of the lifestyle-intervention study is described and results are presented from the preliminary population screening, conducted between March 1999 and June 2000. In total, 2820 subjects with an increased risk of having disturbances in glucose homeostasis (i.e. age $>40$ years and BMI $>25 \mathrm{~kg} / \mathrm{m}^{2}$ or a family history of diabetes) underwent a first oral glucose tolerance test (OGTT). Abnormal glucose homeostasis was detected in 826 subjects (30.4\%): 226 type 2 Diabetes (type 2DM, $8.3 \%$ ), 215 Impaired Fasting Glucose (IFG, 7.9\%) and 385 Impaired Glucose Tolerance (IGT, 14.2\%). Both increasing age and BMI were strongly related to the prevalence of IGT and diabetes. After a second OGTT, 114 subjects with glucose intolerance and in otherwise good health were eligible for participation in the intervention study (SLIM). The high prevalence of disturbances in glucose homeostasis observed in the preliminary screening underscore the importance of early (lifestyle) interventions in those at risk for developing diabetes. The Study on Lifestyle-intervention and IGT Maastricht (SLIM) will address this topic in the Dutch population.
\end{abstract}




\section{INTRODUCTION}

Type 2 diabetes mellitus is rapidly becoming one of the main health issues in the 21 st century. Prevalence has explosively increased the last two decades, and global estimates indicate a further rise from a current 150 million people with diabetes, to 300 million in 2025 [1,2]. Impaired glucose tolerance (IGT) is the obligatory transition state preceding type 2 diabetes. Prevalence of IGT varies widely between populations, from as low as $2.0 \%$ in rural populations to more than $20 \%$ in high-risk populations [3]. Cumulative incidence of type 2 diabetes in subjects with IGT ranged from $3.6 \%$ to $8.7 \%$ per year in six prospective studies [4], and is strongly related to the fasting and the 2-hour plasma glucose concentrations at the time of IGT recognition [4,5]. Most important modifiable risk factor for progression from IGT to diabetes is obesity. Body Mass Index (BMI) at the time of IGT recognition is a strong predictor of progression, independently of fasting and 2-hour blood glucose concentrations [4]. Dietary factors, especially a high fat intake are also related to the risk of conversion from IGT to diabetes [6].

Several recent studies have reported the feasibility and efficacy of interventions to prevent or delay the progression to type 2 diabetes in subjects with IGT [7-13]. Acarbose, [13], as well as metformin [12], have been shown to reduce the incidence of diabetes in a population with IGT. Other studies have focused on the potential of lifestyle changes to reduce the progression rate from IGT to type 2 diabetes. The Finnish Diabetes Prevention Study [11] and the US Diabetes Prevention Program [12] reported that weight-loss, changes in dietary intake, and increased physical activity resulted in a 58\% reduction in the incidence of diabetes after a mean follow-up of only 3 years. Moreover, lifestyle-intervention was much more effective in reducing the incidence of diabetes than pharmacological intervention (i.e. metformin) [12]. It is important to confirm these observations in different populations, with a different dietary and physical activity background, and a different attitude towards changing lifestyle-habits.

The Study on Lifestyle-intervention and Impaired Glucose Tolerance Maastricht (SLIM) is a 3 year randomised clinical trial designed to evaluate the effect of a combined diet and physical activity intervention program on glucose tolerance in a Dutch population at increased risk for developing type 2 diabetes. Furthermore, we will consider changes in anthropometric measurements, aerobic capacity and cardiovascular risk factors. Additional measurements will be performed in subgroups of the study population in search for underlying mechanisms.

The objective of this report is to describe the design of the lifestyleintervention study and to evaluate the results of the preliminary population screening, form which the subjects were recruited for the intervention study. Data 
are presented about the prevalence of disturbances in glucose homeostasis in a middle-aged Dutch population.

The Study on Lifestyle-intervention and IGT, Maastricht (SLIM), is designed to study whether a diet/physical activity intervention program can improve glucose tolerance in subjects with a high risk for developing type 2 diabetes mellitus. Total duration of the study is three years. The Medical Ethical Review Committee of Maastricht University approved the study protocol, and all subjects gave their written informed consent before the start of the study.

\section{MATERIAL \& METHODS}

\section{Recruitment of subjects.}

The recruitment period started March 1999 and was completed at the end of May 2000. Subjects with an increased risk for glucose intolerance, i.e. those of age $>40$ years and a family history of diabetes or a BMI $>25 \mathrm{~kg} / \mathrm{m}^{2}$, were selected from a large existing cohort, monitoring health and disease in the general population [14], and invited to undergo a standard OGTT (glucose load 75 g)[15]. Blood glucose was measured in capillary blood using the Glucometer Elite (Bayer, Zurich, Schweiz). Furthermore, body weight was measured, without wearing shoes and jackets. Subjects with known diabetes, or those with fasting glucose values $>8.5 \mathrm{mmol} / 1 \mathrm{did}$ not participate in the OGTT. Those subjects with a 2-hour blood glucose concentration $>7.8 \mathrm{mmol} / \mathrm{l}$ at the preliminary screening and which were otherwise in good health ( i.e. no history of cardiovascular disease, or any (chronic) disease or medication use that makes participation in a lifestyle intervention program impossible) were invited for a second OGTT. During this second OGTT, glucose tolerance was measured in venous plasma. Furthermore a medical history was taken, a physical examination was performed and several additional measurements were performed (see under measurements, below).

For definitive inclusion in the lifestyle-intervention study, mean 2-hour glucose concentration of both OGTTs had to be between 7.8 and $12.5 \mathrm{mmol} / \mathrm{l}$, together with a fasting glucose concentration of less than $7.8 \mathrm{mmol} / \mathrm{l}$. Other inclusion and exclusion criteria for participation in the intervention study are indicated in Table 2.1. To follow changes in glucose tolerance over time, data obtained by the second (venous) OGTT were used as baseline values. After final recruitment, subjects were randomised to two study groups, the lifestyle intervention group or the control group. Randomisation was carried out with stratification for sex and mean 2hr-plasma glucose concentration. It was calculated, according the preliminary results after 1 year of the Finnish DPS [16], that 50-60 subjects per group would be sufficient to detect a $1.0 \mathrm{mmol} / \mathrm{l}$ difference in 2-hour glucose concentration between groups. 


\section{Table 2.1. Inclusion and exclusion criteria Lifestyle-intervention study}

\begin{tabular}{|c|c|}
\hline Inclusion criteria: & $\begin{array}{l}\text { Mean 2-hour blood glucose }>7.8 \text { and }<12.5 \mathrm{mmol} / 1 \\
\text { Mean fasting blood glucose }<7.8 \mathrm{mmol} / 1 \\
\text { Caucasian } \\
\text { Age } 40-70 \text { years }\end{array}$ \\
\hline Exclusion criteria: & $\begin{array}{l}\text { Known diabetes mellitus } \\
\text { Mean 2-hour blood glucose }>12.5 \mathrm{mmol} / 1 \\
\text { Mean fasting blood glucose }>7.8 \mathrm{mmol} / 1 \\
\text { Any chronic illness that makes } 5 \text {-year survival improbable, } \\
\text { or that interferes with glucose tolerance, } \\
\text { or makes participation in a lifestyle-intervention impossible } \\
\text { Medication known to interfere with glucose tolerance } \\
\text { Participation in a vigourous exercise and/or diet program }\end{array}$ \\
\hline
\end{tabular}

\section{Lifestyle-intervention program}

The intervention program consists of a dietary and physical activity part. Dietary recommendations are based on the Dutch guidelines for a healthy diet (Dutch Nutrition Council, 1992, Table 2.2). Participants are encouraged to stop smoking and, if necessary, to reduce alcohol intake. Dietary advice is given at regular intervals by a skilled dietician on an individual basis after consideration of a 3-day food record (Table 2.2.). A body weight loss of $5-7 \%$ is the objective. If subjects do not loose weight on this regimen during the first year, a mild energy restriction is prescribed during the second year. No very-low calorie diet or dietary products are used to loose weight.

Subjects are stimulated to increase their level of physical activity to at least 30 minutes of moderate physical activity a day for at least 5 days a week [17]. Individual advice is given on how to increase daily physical activity (walking, cycling, swimming), and goals are set. Furthermore, subjects are encouraged to participate in an exercise program, especially designed for this study, including components of aerobic exercise training and components of resistance training [18]. Subjects have free access to these training sessions, and are stimulated to participate at least one hour a week. Participation to the exercise sessions is recorded.

Subjects in the control group are informed, orally and written, about the beneficial effects of a healthy diet, weight loss and increased physical activity, whereas no individual advices or programs are provided. No additional appointments are scheduled, apart from the annual visits for follow-up measurements. 


\section{Measurements}

At the start of the study, and every year thereafter several measurements are performed, in both the intervention and control group. A standard OGTT is performed every year, according to the guidelines described by the WHO [15]. Venous blood samples are immediately centrifuged and plasma is frozen at $-80^{\circ} \mathrm{C}$ until analysis. Plasma glucose and FFA concentrations are measured with a standard enzymatic techniques (Glucose HK 125, ABX diagnostics, Montpellier, France; FFA-C test kit, Wako chemicals, Neuss, Germany, respectively). Plasma insulin concentration is measured with an ELISA assay (Mercodia, Uppsala, Sweden), which shows no cross-reactivity with pro-insulin. Glycated haemoglobin (HbA1c) is determined with the HPLC technique (reference value for our laboratory $4.4-6.2 \%$ ). Insulin sensitivity is estimated with the HOMA-index and insulin secretion with the insulinogenic index 30' (Insulin30-Insulin0)/(glucose 30glucose0) [19]. Blood lipids are measured with standard enzymatic techniques in

Table 2.2. Details of the dietary intervention

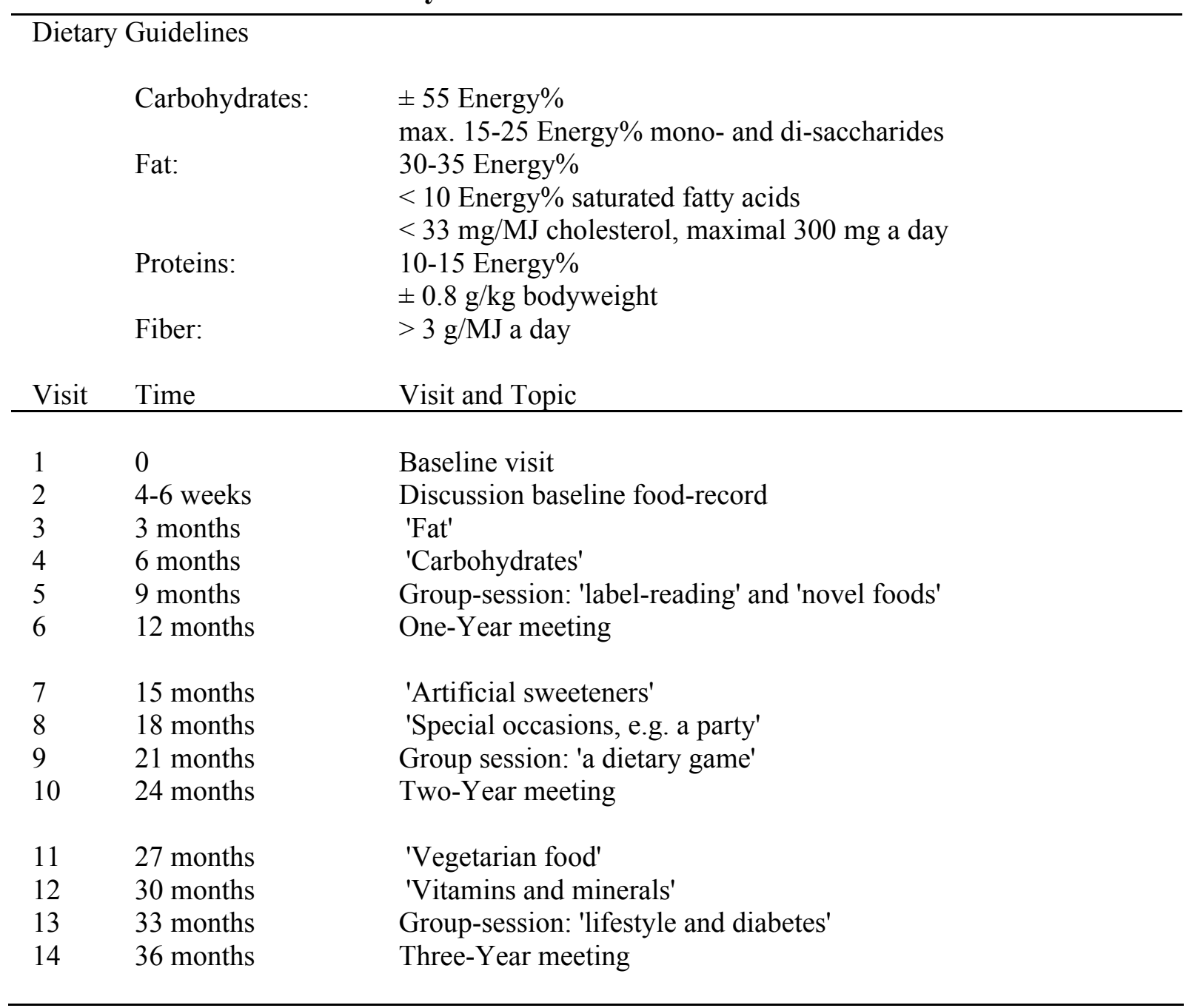


fasting serum samples (triglycerides: Sigma, St Louis, USA; cholesterol: cholesterol 100, ABX diagnostics, Montpellier, France; HDL: HDL-C Roche, Indianapolis, USA). LDL cholesterol is calculated according to the formula of Friedewald [20].

Body weight is measured on an electronical scale. BMI is calculated as the ratio of weight and height squared $\left(\mathrm{kg} / \mathrm{m}^{2}\right)$. Skinfold measurements are performed to calculate fat mass, fat free mass and body fat percentage [21]. Waist circumference (waist) is measured at the level midway between the lowest rib and the iliacal crest. Hip circumference is measured as the maximum circumference over the buttocks. Sagittal and transverse abdominal diameter are measured with the subject in a recumbent position, at the level of the crista iliaca using a sliding beam calliper.

To evaluate changes in aerobical fitness, an incremental exhaustive exercise test is performed on an electronically braked bicycle ergometer (Lode Excalibur, Groningen, the Netherlands). The test starts at a workload of 0.75 $\mathrm{W} / \mathrm{kgFFM}$ for 3 minutes, followed by 3 minutes at $1.5 \mathrm{~W} / \mathrm{kgFFM}$. Subsequently, workload is increased every 3 minutes by $0.5 \mathrm{~W} / \mathrm{kgFFM}$ until exhaustion. $\mathrm{O}_{2-}$ consumption and $\mathrm{CO}_{2}$-production are measured with an Oxycon-Beta (Mijnhardt, Breda, the Netherlands) to define maximal $\mathrm{VO}_{2}$.

At every (annual) visit a physical examination is performed, including recording a 12-lead resting ECG. Blood pressure is measured twice on the right arm with a standard sphygmomanometer, after at least $10 \mathrm{~min}$ of rest. Subjects taking any blood pressure-lowering medication are asked not to take these at the morning of the measurements. A 3-day food record (two weekdays and 1 weekend day) is kept at the start of the study and every year thereafter. Food records are checked by a dietician and intake of nutrients is calculated with a computer program according to the Dutch food table.

\section{Outcome}

Primary outcome measure is the change in glucose tolerance (i.e. 2-hour blood glucose), one of the most important risk factors for progression to diabetes [4]. Secondary outcome measures are changes in fasting plasma glucose concentration, plasma insulin concentration, insulin resistance, $\mathrm{HbA} 1 \mathrm{c}$, and changes in body weight, body composition and $\mathrm{VO}_{2}$ max. Furthermore changes in cardiovascular risk factors are assessed (blood pressure and blood lipid profile).

\section{Statistical analysis}

Data from the intervention study are analysed according to the intentionto-treat principle. Differences between groups (over time) are analysed by 
unpaired t-tests or ANOVA (repeated measures). Level of significance is set at 0.05. Results of the preliminary screening were analysed with ANOVA (differences between categories) and Chi-square-testing (Frequency distribution of disturbances in glucose homeostasis).

\section{RESULTS}

\section{Subjects}

In total 6108 subjects were invited to participate in the preliminary screening. Of those, 2820 subjects were willing to participate in this -first- oral glucose tolerance test (OGTT). Non-response was observed in 3288 cases $(53.8 \%)$. Mean age of the non-responders was $55.7 \pm 0.1$ year, which was significant lower compared to the responders $(n=2820$; age $56.8 \pm 0.1$; $p$-value $<0.001)$. No difference was seen in sex between responders and non-responders (50.6\% male vs. $50.9 \%$ male respectively $\mathrm{P}=\mathrm{ns}$ ). After considering the initial selection criteria (a 2-hour blood glucose concentration $>7.8 \mathrm{mmol} / \mathrm{l}$ at the preliminary screening and with no history of cardiovascular disease, or any (chronic) disease or medication use that makes participation in a lifestyle intervention program impossible), 379 men and women were invited for the second OGTT, of whom 177 were willing to do so. Finally, 114 subjects, 64 men and 50 women, were included in the lifestyle intervention study (SLIM).

Table 2.3 Results of the preliminary screening $(n=2715)$

\begin{tabular}{llccccc}
\hline & \multicolumn{1}{c}{ NGT } & \multicolumn{1}{c}{ IFG } & \multicolumn{1}{c}{ IGT } & type 2 DM & P-value \\
\hline number & $(\%(\mathrm{n}))$ & $69.9(1889)$ & $7.9(215)$ & $14.2(385)$ & $8.3(226)$ & \\
sex & $(\%$ male $)$ & 47.5 & 61.2 & 49.1 & 67.8 & $<0.0001$ \\
age & $($ year $)$ & $55.9 \pm 0.2$ & $58.8 \pm 0.4$ & $57.1 \pm 0.5$ & $59.8 \pm 0.4$ & $<0.0001$ \\
BMI & $\left(\mathrm{kg} / \mathrm{m}^{2}\right)$ & $28.0 \pm 0.1$ & $29.7 \pm 0.3$ & $29.5 \pm 0.2$ & $30.6 \pm 0.3$ & $<0.0001$ \\
FBG & $(\mathrm{mmol} / \mathrm{l})$ & $5.2 \pm 0.1$ & $6.3 \pm 0.1$ & $5.8 \pm 0.1$ & $7.4 \pm 0.1$ & $<0.0001$ \\
2hr BG & $(\mathrm{mmol} / \mathrm{l})$ & $6.5 \pm 0.1$ & $6.8 \pm 0.1$ & $10.1 \pm 0.1$ & $13.0 \pm 0.2^{*}$ & $<0.0001$ \\
\hline
\end{tabular}

Data are mean \pm sem; FBG $=$ Fasting Blood Glucose, $r$ BG = 2-hour Blood Glucose; comparison of frequencies was done by a Chi-square test; * subjects with fasting glucose $>8.5 \mathrm{mmol} / \mathrm{L}$ did not undergo an OGTT $(\mathrm{n}=28)$

\section{Preliminary screening}

From the 2820 subjects participating in the screening OGTT, 105 were excluded from the analysis: 48 because of recently diagnosed diabetes; 57 because of non-caucasian ethnicity, non-fasting state, or incomplete data. Results from the remaining 2715 subjects are depicted in Table 2.3. WHO criteria of 1999 for capillary plasma were applied, as the glucometer Elite measures glucose levels 
equivalent to capillary plasma [15]. Abnormal glucose homeostasis was detected in 826 subjects (30.4\%): 226 subjects with type 2 Diabetes (type 2DM, $8.3 \%$ ), 215 with Impaired Fasting Glucose (IFG, 7.9\%) and 385 with Impaired Glucose Tolerance (IGT, 14.2\%). Of the latter group, almost two-third $(\mathrm{n}=244)$ had normal

Table 2.4 Prevalence of disturbances in glucose homeostasis according to age and BMI groups, for men and women separately $(n=2715)$

\begin{tabular}{|c|c|c|c|c|c|c|c|c|c|c|}
\hline & \multicolumn{5}{|c|}{ MEN } & \multicolumn{5}{|c|}{ WOMEN } \\
\hline & $\mathrm{n}$ & $\begin{array}{l}\mathrm{DM} \\
(\%)\end{array}$ & IGT (\%) & $\begin{array}{l}\text { IFG } \\
(\%)\end{array}$ & $\begin{array}{c}\text { NGT } \\
(\%)\end{array}$ & $\mathrm{n}$ & $\begin{array}{l}\mathrm{DM} \\
(\%)\end{array}$ & IGT (\%) & $\begin{array}{l}\text { IFG } \\
(\%)\end{array}$ & $\begin{array}{c}\text { NGT } \\
(\%)\end{array}$ \\
\hline \multicolumn{11}{|l|}{ Age } \\
\hline$<50$ & 289 & 6.6 & 8.0 & 6.2 & 79.2 & 254 & 0.8 & 9.1 & 2.4 & 87.8 \\
\hline $50-54$ & 256 & 7.8 & 10.2 & 13.7 & 68.4 & 252 & 2.4 & 13.9 & 6.7 & 77.0 \\
\hline $55-59$ & 289 & 11.1 & 14.5 & 12.5 & 61.9 & 281 & 6.8 & 14.6 & 7.8 & 70.8 \\
\hline $60-64$ & 301 & 14.0 & 16.3 & 9.0 & 60.8 & 322 & 8.6 & 15.8 & 6.8 & 70.5 \\
\hline$>65$ & 238 & 16.8 & 20.6 & 7.1 & 55.5 & 233 & 10.3 & 19.7 & 6.4 & 63.5 \\
\hline BMI & & & & & & & & & & \\
\hline$<27$ & 477 & 6.7 & 10.5 & 6.1 & 76.7 & 515 & 3.1 & 10.1 & 4.1 & 82.7 \\
\hline $27-30$ & 484 & 8.9 & 10.5 & 9.7 & 70.9 & 415 & 4.1 & 15.7 & 5.5 & 74.7 \\
\hline$>30$ & 412 & 18.9 & 21.4 & 13.8 & 45.9 & 412 & 9.7 & 19.2 & 9.2 & 61.9 \\
\hline Total & 1373 & 11.1 & 13.8 & 9.7 & 65.4 & 1342 & $5.4^{* *}$ & 14.6 & $6.1 * *$ & $73.8^{* *}$ \\
\hline
\end{tabular}

fasting glucose (NFG/IGT) and one-third $(n=141)$ impaired fasting glucose (IFG/IGT). Prevalence of type $2 \mathrm{DM}$ and IFG was higher among men than women. A strong upward trend for age and BMI was seen from NGT to type 2 DM, with IGT and IFG in between (Table 2.3). In Table 2.4 the prevalence of NGT, IFG, IGT and type $2 \mathrm{DM}$ is given for age and BMI groups, for men and women separately. In both men and women, prevalence of disturbed glucose homeostasis increased with age, except for IFG which reached the highest prevalence in the age group of $55-59$ years. In the population of 65 years and older only $55.5 \%$ of the men and $63.5 \%$ of the women had normal glucose homeostasis. In men and women with a BMI above $30 \mathrm{~kg} / \mathrm{m}^{2}$, diabetes was three times more prevalent and IFG and IGT were two times more prevalent, compared to those with a BMI below $27 \mathrm{~kg} / \mathrm{m}^{2}$. Prevalence of newly diagnosed diabetes was almost two times higher in men than in women in each BMI and age group. Likewise, IFG was 1.5 times more frequent in men than in women, which was most pronounced in the age groups below 55 years. Additionally, more women were normoglycemic compared to men $(\mathrm{P}<0.001)$. 


\section{DISCUSSION}

\section{Lifestyle-intervention}

Justification of lifestyle-intervention studies is that they may prevent or postpone the onset of type 2 diabetes and related complications. Both, the Finnish Diabetes Prevention Study (DPS) and the U.S. Diabetes Prevention Program (DPP) reported that changing dietary and physical activity habits reduce the incidence of diabetes by about 58\% [11,12]. Confirmation of these results in different populations is important. SLIM will consider this in a middle-aged Dutch population at increased risk for diabetes. The Dutch population has a low prevalence of obesity [22], and Dutch subjects are known for their relatively high level of physical activity. In 1997 slightly more than one-half of the population was, on average, moderately active for more than half an hour per day [23], compared to about one-third of the US adults [24]. As obesity and physical activity are important factors associated with diabetes, it is important to know whether lifestyle-changes result in a comparable risk reduction in the Dutch population as in the Finnish and American population.

Dietary and physical activity intervention strategies are combined, as earlier reports indicated that the combination is most effective [25,26]. The intervention strategy in this randomised study is based on general public health recommendations for nutritional intake and physical activity. A regimen, based on general recommendations, is much more suitable to prevent diabetes, as it is less time consuming and much better tolerated than very intensive intervention programmes. Furthermore, we will perform additional measurements in small subgroups of the intervention and control population ( $\mathrm{n}=10$ per group) using stable isotopes, indirect calorimetry and muscle biopsies. Since type 2 diabetes and IGT are characterized by disturbances in (skeletal muscle) fatty acid uptake and oxidation [27-29], the question will be addressed whether changes in glucose tolerance are accompanied by changes in (skeletal muscle) fatty acid metabolism. These additional measurements could identify some of the mechanisms underlying the development of insulin resistance and type 2 diabetes mellitus.

\section{Methodological considerations}

Participation rate was relatively low in the present study, approximately $50 \%$. As subjects were selected from an ongoing monitoring project for health and disease, some 'research-fatigue' could not be excluded, and this could have led to some selection-bias. Classification of the subjects was based on a single OGTT (with the glucometer Elite), and was not confirmed by repeated testing as 
recommended. Some misclassification might have occurred because of the known high intra-individual variability in glucose levels. However, a previous Dutch study showed that the prevalence of IGT and diabetes was not different between the first and the second test [30]. Only when the diagnosis was based on meeting classification criteria at both OGTT's, prevalence decreased. Finally, we tested the consistency in classification between measurements made with the glucometer Elite and measurements made with a standard enzymatic technique in venous plasma. Consistency in classification according to the WHO criteria was good (69\%, kappa 0.55, P-value <0.001; $\mathrm{n}=245$; ref. [31]).

\section{Preliminary screening}

The results of the preliminary screening confirm the high-risk profile of the population under study. Three out of every ten subjects had a disturbed glucose homeostasis, which is quite comparable with the results reported in the STOP-NIDDM trial, also a screening in a high-risk population [32]. Prevalence of IGT and newly diagnosed diabetes in the screening population was higher than reported in the Dutch Hoorn Study over the period 1989-1992 (10.3\% for IGT and $4.8 \%$ for newly diagnosed diabetes [33]). This may reflect the (world-wide) increasing prevalence of disturbances in glucose homeostasis [1], and parallels the increasing prevalence of obesity reported in the Dutch population [22]. However, in the Hoorn Study the old WHO criteria (1985) were used. Since the fasting glucose level for the diagnosis of diabetes is reduced, this could partly explain the higher prevalence of diabetes in our study, but not the higher prevalence of IGT. In line with other populations, the present study confirmed that IGT is considerably more prevalent than IFG, and that overlap between the two categories is limited [3]. This limited overlap points towards the difference in metabolic background: IGT is primarily associated with insulin resistance while IFG is associated with a more pronounced defect in insulin secretion and endogenous glucose output [34].

A strong positive relation was observed between increasing age and prevalence of IGT and diabetes. For IFG, the highest prevalence was seen in middle-aged subjects (55-59 year). This is a consistent finding in European populations, particularly among men [3]. The prevalence of disturbances in glucose homeostasis was almost twofold higher in the group with a BMI $>30$ $\mathrm{kg} / \mathrm{m}^{2}$ compared to those with a BMI $<30 \mathrm{~kg} / \mathrm{m}^{2}$. This underscores earlier reports, showing dramatic increases in relative risk of diabetes in the highest BMI groups, compared to the lowest BMI group [35].

Type 2 diabetes is generally more prevalent in women compared to men [1]. In contrast, we observed a prevalence of diabetes being (two times) higher in males than in females, in all BMI and age groups. In the Finnmark study [36], BMI 
was reported to be a dominant risk factor for both sexes. In women, however, the relation was confounded by other factors as blood pressure, height, HDL, glucose, smoking and physical activity. Furthermore, in addition to over-all adiposity, body fat distribution is an important risk factor for diabetes [35]. Thus, differences in other risk factors, beside age and BMI, can underlie the observed higher prevalence of diabetes in men in the present study.

\section{Conclusion}

The high prevalence of disturbances in glucose homeostasis observed in the preliminary screening underscores the importance of early interventions in those at risk for developing diabetes. Changes in dietary habits and physical activity have shown to reduce the incidence of diabetes. Additional studies are required to confirm these results in different populations with a different dietary and physical activity background. The Study on Lifestyle-intervention and IGT Maastricht (SLIM) will address this question in the Dutch population.

\section{ACKNOWLEDGEMENTS}

We are grateful to Rob van Dam, Tanja Hermans-Limpens, and Ilse Nijs for their work during the preliminary screening. This study is supported by grants from the Netherlands Organisation for Scientific Research (ZonMW: 940-35-034) and the Dutch Diabetes Research Foundation (DFN: 98.901).

\section{REFERENCES}

1 King H, Aubert RE, Herman WH. Global burden of diabetes, 1995-2025: prevalence, numerical estimates, and projections. Diabetes Care 1998; 21: 1414-31.

2 Zimmet P, Alberti KG, Shaw J. Global and societal implications of the diabetes epidemic. Nature 2001; 414: 782-7.

3 Unwin N, Shaw J, Zimmet $\mathrm{P}$, Alberti KG. Impaired glucose tolerance and impaired fasting glycaemia: the current status on definition and intervention. Diabet Med 2002; 19: 708-23.

4 Edelstein SL, Knowler WC, Bain RP et al. Predictors of progression from impaired glucose tolerance to NIDDM: an analysis of six prospective studies. Diabetes 1997; 46: 701-10.

5 de Vegt F, Dekker JM, Jager A et al. Relation of impaired fasting and postload glucose with incident type 2 diabetes in a Dutch population: The Hoorn Study. Jama 2001; 285: 2109-13. 
6 Marshall JA, Hoag S, Shetterly S, Hamman RF. Dietary fat predicts conversion from impaired glucose tolerance to NIDDM. The San Luis Valley Diabetes Study. Diabetes Care 1994; 17: 50-6.

7 Eriksson KF, Lindgarde F. Prevention of type 2 (non-insulin-dependent) diabetes mellitus by diet and physical exercise. The 6-year Malmo feasibility study. Diabetologia 1991; 34: 891-8.

8 Page RC, Harnden KE, Cook JT, Turner RC. Can life-styles of subjects with impaired glucose tolerance be changed? A feasibility study. Diabetic Medicine 1992; 9: 562-6.

9 Bourn DM, Mann JI, McSkimming BJ, Waldron MA, Wishart JD. Impaired glucose tolerance and NIDDM: does a lifestyle intervention program have an effect? Diabetes Care 1994; 17: 1311-9.

10 Pan XR, Li GW, Hu YH et al. Effects of diet and exercise in preventing NIDDM in people with impaired glucose tolerance. The Da Qing IGT and Diabetes Study. Diabetes Care 1997; 20: 537-44.

11 Tuomilehto J, Lindstrom J, Eriksson JG et al. Prevention of type 2 diabetes mellitus by changes in lifestyle among subjects with impaired glucose tolerance. N Engl J Med 2001; 344: 1343-50.

12 Knowler WC, Barrett-Connor E, Fowler SE et al. Reduction in the incidence of type 2 diabetes with lifestyle intervention or metformin. N Engl J Med 2002; 346: 393403.

13 Chiasson JL, Josse RG, Gomis R et al. Acarbose for prevention of type 2 diabetes mellitus: the STOP-NIDDM randomised trial. Lancet 2002; 359: 2072-7.

14 van Dam RM, Boer JM, Feskens EJ, Seidell JC. Parental history of diabetes modifies the association between abdominal adiposity and hyperglycemia. Diabetes Care 2001; 24: 1454-9.

15 World Health Organization. Definition, diagnosis and classification of diabetes mellitus. Report of a WHO Consultation. Part 1: Diagnosis and Classification of Diabetes Mellitus. Geneva, Switzerland,1999. Publication WHO/NCD/NCS/99.2.

16 Eriksson J, Lindstrom J, Valle T et al. Prevention of Type II diabetes in subjects with impaired glucose tolerance: the Diabetes Prevention Study (DPS) in Finland. Study design and 1-year interim report on the feasibility of the lifestyle intervention programme. Diabetologia 1999; 42: 793-801.

17 American College of Sports Medicine Position Stand. The recommended quantity and quality of exercise for developing and maintaining cardiorespiratory and muscular fitness, and flexibility in healthy adults. Medicine And Science In Sports And Exercise 1998; 30: 975-91.

18 Eriksson J, Tuominen J, Valle $\mathrm{T}$ et al. Aerobic endurance exercise or circuit-type resistance training for individuals with impaired glucose tolerance? Horm Metab Res 1998; 30: 37-41. 
19 Albareda M, Rodriguez-Espinosa J, Murugo M, de Leiva A, Corcoy R. Assessment of insulin sensitivity and beta-cell function from measurements in the fasting state and during an oral glucose tolerance test. Diabetologia 2000; 43: 1507-11.

20 Friedewald WT, Levy RI, Fredrickson DS. Estimation of the concentration of lowdensity lipoprotein cholesterol in plasma, without use of the preparative ultracentrifuge. Clin Chem 1972; 18: 499-502.

21 Durnin JV, Womersley J. Body fat assessed from total body density and its estimation from skinfold thickness: measurements on 481 men and women aged from 16 to 72 years. Br J Nutr 1974; 32: 77-97.

22 Visscher TL, Kromhout D, Seidell JC. Long-term and recent time trends in the prevalence of obesity among Dutch men and women. Int J Obes Relat Metab Disord 2002; 26: 1218-24.

23 Schuit AJ, Feskens EJ, Seidell JC. [Physical activity in relation to sociodemographic variables and health status of adult men and women in Amsterdam, Doetinchem and Maastricht]. Ned Tijdschr Geneeskd 1999; 143: 1559-64.

24 Jones DA, Ainsworth BE, Croft JB et al. Moderate leisure-time physical activity: who is meeting the public health recommendations? A national cross-sectional study. Arch Fam Med 1998; 7: 285-9.

25 Torjesen PA, Birkeland KI, Anderssen SA et al. Lifestyle changes may reverse development of the insulin resistance syndrome. The Oslo Diet and Exercise Study: a randomized trial. Diabetes Care 1997; 20: 26-31.

$26 \mathrm{Li} \mathrm{G}, \mathrm{Hu}$ Y, Yang W et al. Effects of insulin resistance and insulin secretion on the efficacy of interventions to retard development of type 2 diabetes mellitus: the DA Qing IGT and Diabetes Study. Diabetes Res Clin Pract 2002; 58: 193-200.

27 Kelley DE, Simoneau JA. Impaired free fatty acid utilization by skeletal muscle in non-insulin-dependent diabetes mellitus. Journal Of Clinical Investigation 1994; 94 : 2349-56.

28 Blaak EE, Wagenmakers AJ, Glatz JF et al. Plasma FFA utilization and fatty acidbinding protein content are diminished in type 2 diabetic muscle. Am J Physiol Endocrinol Metab 2000; 279: E146-54.

29 Mensink M, Blaak EE, van Baak MA, Wagenmakers AJ, Saris WH. Plasma free Fatty Acid uptake and oxidation are already diminished in subjects at high risk for developing type 2 diabetes. Diabetes 2001; 50: 2548-54.

30 Mooy JM, Grootenhuis PA, de Vries $\mathrm{H}$ et al. Intra-individual variation of glucose, specific insulin and proinsulin concentrations measured by two oral glucose tolerance tests in a general Caucasian population: the Hoorn Study. Diabetologia 1996; 39: 298-305.

31 Kruijshoop M, Feskens EJM, Blaak EE, Heine RJ, de Bruin TWA. Validation of capillary glucose measurements to detect type 2 diabetes mellitus in the general population: The CoDAM-study. Diabetologia 2002; 42: A98 (abstract). 
32 Chiasson JL, Gomis R, Hanefeld M et al. The STOP-NIDDM Trial: an international study on the efficacy of an alpha-glucosidase inhibitor to prevent type 2 diabetes in a population with impaired glucose tolerance: rationale, design, and preliminary screening data. Study to Prevent Non-Insulin-Dependent Diabetes Mellitus. Diabetes Care 1998; 21: 1720-5.

33 Mooy JM, Grootenhuis PA, de Vries $\mathrm{H}$ et al. Prevalence and determinants of glucose intolerance in a Dutch caucasian population. The Hoorn Study. Diabetes Care 1995; 18: 1270-3.

34 Weyer C, Bogardus C, Pratley RE. Metabolic characteristics of individuals with impaired fasting glucose and/or impaired glucose tolerance. Diabetes 1999; 48: 2197-203.

35 Chan JM, Rimm EB, Colditz GA, Stampfer MJ, Willett WC. Obesity, fat distribution, and weight gain as risk factors for clinical diabetes in men. Diabetes Care 1994; 17: 961-9.

36 Njolstad I, Arnesen E, Lund-Larsen PG. Sex differences in risk factors for clinical diabetes mellitus in a general population: a 12-year follow-up of the Finnmark Study. Am J Epidemiol 1998; 147: 49-58. 



\section{CHAPTER 3}

\section{Impaired skeletal muscle substrate oxidation in glucose-intolerant men improves after weight loss}

Eva Corpeleijn (1), Marco Mensink (1), Marianne E. Kooi (2), Paul M.H.J.

Roekaerts (3), Wim H.M. Saris(1), Ellen E. Blaak (1)

From the (1) Department of Human Biology, the Nutrition and Toxicology Research Institute NUTRIM, Maastricht University, Maastricht, The Netherlands; (2) the Department of Radiology, Maastricht University Hospital Maastricht, The Netherlands; and (3) the Department of Anesthesiology, University Hospital Maastricht, Maastricht, The Netherlands 


\begin{abstract}
Objective: An impaired fatty acid handling in skeletal muscle may be involved in the development of insulin resistance and diabetes mellitus type 2 (DM2). We investigated muscle fatty acid metabolism in glucose-intolerant men (IGT), a prediabetic state, relative to BMI-matched control men (NGT) during fasting and after a high fat meal, since most people in the Western society are in the fed state most of the day.

Research Methods and Procedures: Skeletal muscle free fatty acid uptake and oxidation were studied using the stable isotope tracer $[2,2-2 \mathrm{H}]$-palmitate and muscle indirect calorimetry in the forearm model during fasting and after a mixed meal (30 energy\% carbohydrates, 60 energy\% fat). Intramyocellular triglycerides were monitored with ${ }^{1} \mathrm{H}$-Magnetic Resonance Spectroscopy. IGT men were reexamined after weight loss (-15\% of body weight).

Results: The postprandial increase in forearm muscle respiratory quotient (RQ) was blunted in IGT compared to NGT, but improved after weight loss. Weight loss also improved fasting fat oxidation and tended to decrease intramyocellular triglycerides $(p=0.08)$. No differences were found in fasting and postprandial forearm muscle fatty acid uptake between NGT and IGT, or in IGT before and after weight loss.

Discussion: The ability to switch from fat oxidation to carbohydrate oxidation after a meal is already impaired in the prediabetic state, suggesting this may be an early factor in the development towards diabetes mellitus type 2. This impaired ability to regulate fat oxidation during fasting and after a meal (impaired metabolic flexibility) can be (partly) reversed by weight loss.
\end{abstract}




\section{INTRODUCTION}

There is increasing evidence that insulin resistance and diabetes mellitus type 2 (DM2) are strongly related to disturbances in skeletal muscle lipid metabolism (15). Both muscle fatty acid uptake and oxidation were found to be impaired (5-9). An imbalance between fatty acid uptake and oxidation may enhance the accumulation of triglycerides in skeletal muscle. These intramyocellular triglycerides (IMTG) and, more likely, lipid intermediates, may interfere with the insulin signaling cascade, inducing insulin resistance (10-12).

Impairments in fatty acid uptake and oxidation have been found during fasting, during exercise (6), after beta-adrenergic stimulation (7) and after a meal (8). A reduced fasting fat oxidation was also found to predispose to obesity and insulin resistance $(13,14)$. However, it is important to realize that the majority of people in Western countries are in the fed state most of the day, and that fatty acid uptake and oxidation in skeletal muscle are very dynamic processes depending on substrate availability and energy demand. Normally, healthy muscle switches rapidly from a predominant fat oxidation during fasting to carbohydrate oxidation in the postprandial state. In obese, insulin resistant subjects, it was shown that the fat oxidation in skeletal muscle was reduced during fasting and that after insulin stimulation the fat oxidation was less suppressed (9). In addition, it was found that the uptake of plasma free fatty acids into skeletal muscle was reduced during fasting in subjects with impaired glucose tolerance (15) and in diabetic patients $(6,8)$ and that in diabetic patients the regulation of fatty acid uptake after a meal was impaired as well (8). To what extent the impaired fatty acid handling in skeletal muscle may be cause or consequence of diabetes mellitus type 2 is not clear yet. Because of the multiple aberrations that are observed in type 2 diabetes, including hormonal and metabolic abnormalities, it is impossible to differentiate whether impairments are primary or acquired. Studying subjects who are prone to develop diabetes, i.e. subjects with impaired glucose tolerance, will provide important clues towards the mechanisms behind the pathogenesis of diabetes. Nevertheless, studies on the postprandial dynamics of skeletal muscle fat oxidation and uptake in vivo are sparse and have never been performed before in impaired glucose tolerance. Therefore, we investigated the regulation of skeletal muscle fatty acid uptake and oxidation in obese subjects with impaired glucose tolerance relative to obese controls, both during fasting and after ingestion of a mixed meal with high fat content and related this to baseline intramyocellular triglyceride storage. Our second aim was to investigate whether impairments in skeletal muscle fatty acid handling in impaired glucose tolerance could be reversed with weight loss. 


\section{RESEARCH METHODS AND PROCEDURES}

\section{Subjects}

Thirteen obese men with impaired glucose tolerance (IGT) and nine obese men with normal glucose tolerance (NGT), matched for age and BMI, participated in the study. Glucose tolerance was determined with a standard oral glucose tolerance test according to the WHO guidelines with capillary plasma sampling at baseline and after $2 \mathrm{hrs}$ (capillary plasma IGT: fasting $<7.0 \mathrm{mmol} / \mathrm{l} ; 2 \mathrm{hr}$ postload between 8.9 and $12.2 \mathrm{mmol} / \mathrm{l}$ ) (16). Additional inclusion criteria were obesity (BMI $>30 \mathrm{~kg} / \mathrm{m}^{2}$ ), diastolic blood pressure $<100 \mathrm{mmHg}$, no major organ dysfunction, and no use of medication that could influence the results. The NGT men had no family history of diabetes. Subjects were not involved in any regular physical activity for more than 3 hours a week. The experimental protocol was approved by the local Medical Ethical Committee of the Maastricht University. All subjects gave written informed consent.

\section{Experimental design}

The NGT men and IGT men underwent measurements for insulin sensitivity, skeletal muscle metabolism, muscle lipid content, body composition and aerobic capacity as described below. Eight IGT men were re-examined after weight loss.

\section{Weight loss period}

Eight men from the IGT group were willing to follow a 12-week weight loss program. During the first four weeks the subjects were provided with a very low calory diet (2 MJ/day) based on shakes (Modifast Nutrition et Santé, Breda, the Netherlands) containing all the essential macro- and micronutrients. From week five to week eight, the shakes were gradually replaced by normal meals, increasing the energy content of the diet up to $4.2 \mathrm{MJ} /$ day. In the last four weeks the subjects were kept in energy balance by prescribing detailed weekly menus. After at least 2 weeks of energy balance the measurements as described below were repeated (week 10-12).

\section{Body composition and aerobic capacity, insulin sensitivity and muscle biopsies}

Body weight (BW), fat mass (FM) and fat free mass (FFM) were determined by hydrostatic weighing with simultaneous correction for lung volume according to Siri (17). Maximal aerobic power (Wmax) and peak oxygen uptake ( $\left.\mathrm{VO}_{2} \max \right)$ were 
determined during an incremental exhaustive bicycle ergometer test (18). Waist and hip circumference were measured to the nearest $1 \mathrm{~cm}$. Insulin sensitivity was determined with a hyperinsulinemic euglycemic clamp. Subjects arrived at the laboratory by car or public transport after an overnight fast (10-12 hrs). Percutaneous needle biopsies were taken during fasting from the $\mathrm{m}$. vastus lateralis under local anesthesia of the skin using the Bergström method with suction (19). Biopsies were immediately frozen in liquid nitrogen. Insulin was infused at a constant rate $\left(1 \mathrm{mU}^{*} \mathrm{~kg} \mathrm{BW}{ }^{-1 *} \mathrm{~min}^{-1}\right)$ with glucose clamped at $4.5 \pm 0.9$ $\mathrm{mmol} / \mathrm{l}$ with an intravenous infusion of $20 \% \mathrm{w} / \mathrm{v}$ glucose solution. Insulin sensitivity (M-value) was calculated as the glucose infusion rate per $\mathrm{kg}$ FFM $\left(\mathrm{mmol}^{*} \mathrm{kgFFM}^{-1 *} \mathrm{~min}^{-1}\right)$ during a steady state of 30 minutes after at least 120 minutes of insulin infusion.

\section{Intramyocellular triglycerides}

Intramyocellular triglyceride content (IMTG) was measured in the m. vastus lateralis with ${ }^{1} \mathrm{H}-\mathrm{MRS}$ on a $1.5 \mathrm{~T}$ whole body scanner (Intera, Philips Medical Systems, Best, The Netherlands) as described before (20). The average of at least two different voxels $(12 \times 11 \times 18 \mathrm{~mm})$ per subject was taken. For one IGT subject, only one voxel could be measured before and after weight loss. To reproduce the same three voxel positions $(12 \times 11 \times 18 \mathrm{~mm})$ for measurements after weight loss, the longitudinal distance of the voxel from the intercondylar eminence of the knee joint and patterns of fat distribution were used. IMTG content is expressed as $\%$ of the area of the $\mathrm{CH}_{2}$ resonance of IMTG compared to the area of water resonance, corrected for T1 and T2 relaxation. Complete data sets of 6 NGT and 7 IGT men before and after weight loss were obtained.

\section{Fasting and postprandial fatty acid metabolism}

\section{Forearm model}

Skeletal muscle metabolism was studied in the forearm model, using arteriovenous concentration differences corrected for blood flow. One catheter was inserted under local anesthesia of the skin in the radial artery of the forearm. In the same arm, a second catheter was inserted in an antecubital vein for the infusion of the stable isotope tracer $\left[2,2-{ }^{2} \mathrm{H}\right]$-palmitate. The use of stable isotopes permits the measurement of the uptake of plasma FFA across the forearm despite the negative net balance of plasma FFA. In the contralateral arm, a third catheter was inserted in retrograde direction in an antecubital vein for the sampling of deep venous blood, draining forearm muscle $\left(\mathrm{O}_{2}\right.$-saturation $\left.<60 \%\right)$. To exclude 
metabolism of the hand, a hand cuff was inflated for 1 minute above $200 \mathrm{~mm} \mathrm{Hg}$ before sampling. During this minute forearm blood flow was measured in triplicate by venous occlusion plethysmography with a mercury strain gauge (EC5R plethysmograph, Hokanson, Bellevue, USA).

\section{Postprandial test}

Subjects were instructed to consume a prescribed carbohydrate-rich dinner the day before the test. Subjects came to the laboratory by car or public transport after an overnight fast (10-12 hrs). Blood samples were drawn before (at $-120,-60,-30$ and 0 minutes) and after a mixed meal with high fat content (at 30,60, 90, 120, 180, and $240 \mathrm{~min})$. The meal provided 2.6 MJ consisting of 33 energy \% (E\%) carbohydrates, $61 \mathrm{E} \%$ from fat $(35.5 \mathrm{E} \%$ saturated, $18.8 \mathrm{E} \%$ mono-unsaturated and $1.7 \mathrm{E} \%$ polyunsaturated fat) and $6 \mathrm{E} \%$ protein.

\section{Whole Body Respiratory Quotient}

Whole body $\mathrm{O}_{2}$ consumption and $\mathrm{CO}_{2}$ production were measured with an opencircuit ventilated hood system (Oxycon Beta, Mijnhardt, Breda, The Netherlands) at baseline and at 30,60, 90, 120, 180 and 240 minutes after the meal.

\section{Forearm Muscle Substrate Oxidation}

At every blood sampling time point, $\mathrm{pH}$, hemoglobin, oxygen saturation of hemoglobin and $\mathrm{pCO}_{2}$ were analyzed immediately in triplicate samples (ABL 510 blood gas analyser, Radiometer, Copenhagen, Denmark) to calculate $\mathrm{O}_{2}$ and $\mathrm{CO}_{2}$ concentration (21) assuming a fixed protein oxidation. For these calculations, data sets of 8 NGT men, and 8 IGT men before and after weight loss were available.

\section{Isotope infusion}

After taking background blood samples $(t=-120)$, a continuous infusion of [2,2$\left.{ }^{2} \mathrm{H}\right]$-palmitate (98\% enrichment, Cambridge Isotope Laboratories Inc, USA) was started $\left(0.035 \mathrm{mmol}^{*} \mathrm{~kg} \mathrm{BW}{ }^{-1 *} \mathrm{~min}^{-1}\right)$ using a calibrated infusion pump (IVAC 560 pump, San Diego, CA). Sampling started after 1 hour of isotopic equilibration. The exact concentration of $\left[2,2-{ }^{2} \mathrm{H}\right]$-palmitate in the infusate was analyzed for each experiment $(2.335 \pm 0.036 \mathrm{mM})$.

\section{Calculations}

Metabolite fluxes over the forearm muscle were calculated as forearm arteriovenous differences multiplied by forearm plasmaflow (bloodflow * 1 hematocrit/100) or total blood flow (for $\mathrm{O}_{2}$ and $\mathrm{CO}_{2}$ exchange). A positive flux indicates uptake by muscle and a negative flux indicates release from muscle. The palmitate rate of appearance $(\mathrm{Ra})$ and rate of disappearance $(\mathrm{Rd})$ were calculated with Steele's equation for steady state during fasting and with Steele's single-pool 
non-steady state equations in the postprandial phase (22). The fractional extraction was calculated as the arteriovenous difference of $\left[2,2-{ }^{2} \mathrm{H}\right]$-palmitate by the arterial $[2,2-2 \mathrm{H}]$-palmitate concentration. Total forearm muscle free fatty acid (FFA) uptake was calculated by multiplying the fractional extraction with arterial FFA concentration and plasma blood flow, as described before $(7,23)$.

\section{Biochemical analysis}

Plasma FFA, total glycerol, free glycerol, and glucose were analyzed in EDTA plasma using standard enzymatic techniques automated on the COBAS Fara centrifugal analyzer at $550 \mathrm{~nm}$ (for FFA: FFA-C test kit, Wako chemicals, Neuss, Germany; for glycerol: EnzyPlus, Diffchamb AB, Västra Frölunda, Sweden; for glucose: Roche Unikit III, Hoffman-la-Roche, Basel, Switzerland). Insulin was analyzed using a fluoroimmunometric assay (autoDELFIA Insulin, PerkinElmer, Turku, Finland) with no cross-reactivity with pro-insulin or split forms of proinsulin. For the analysis of plasma palmitate, FFAs were extracted from plasma, isolated by thin-layer chromatography, and derivatized to their methyl esthers. Isotope enrichment of palmitate was analyzed by GC-isotope ratio mass spectrometry (Finnigan Incos-XL GC-MS). Plasma palmitate concentrations were analyzed on an analytical GC with ion flame detection using heptadecanoic acid as internal standard. The palmitate fraction of total plasma FFA $(26.8 \pm 0.7 \%)$ was comparable in NGT men, IGT men and IGT men before and after weight loss. In muscle biopsies, enzyme activities of citrate synthase (CS) and 3-hydroxyacyl-CoA dehydrogenase (HAD) activity were determined as described before $(7,24,25)$.

\section{Statistical analysis}

IGT $(n=13)$ and NGT men $(n=9)$ were compared with a two-tailed Student's ttest for independent samples. As the means for $n=13$ showed no significant or relevant differences to the means for $\mathrm{n}=9$, the lines in the figures for IGT men before weight loss represent $n=13$. The IGT men that did not follow the weight loss period were included in the baseline comparison with NGT to increase power. IGT men before $(n=8)$ and after weight loss $(n=8)$ were compared with a two-tailed Student's t-test for paired samples. For fasting values the average of time points $-60,-30$ and 0 was taken. The postprandial response was calculated as the incremental area under the curve (iAUC = total $\mathrm{AUC} / \mathrm{min}-$ fasting value). Correlations were tested using Pearson's correlation coefficient (r). Results are given as mean \pm sem. A p-value $<0.05$ was considered as statistically significant. Statistical analysis was performed using SPSS 10.0 for Macintosh. 


\section{RESULTS}

\section{Subject characteristics and whole body metabolism}

The IGT and NGT men were comparable with respect to age, body fat percentage and aerobic capacity, but insulin sensitivity tended to be lower in IGT compared to NGT ( $p=0.09$, Table 3.1.). The postprandial increase in both glucose and insulin tended to be higher in the IGT men than in the NGT men (iAUC, $p=0.09, p=0.08$ respectively, Figure 3.1.), whereas postprandial FFAs were equally suppressed. Weight loss in the IGT men $(-14.0 \pm 1.6 \mathrm{~kg})$ improved insulin sensitivity (Table 3.1.) and reduced the total postprandial area under the curve for glucose $(-8 \%)$ and insulin $(-40 \%)$, but did not change the postprandial suppression of FFA (Figure 3.1.). The rate of appearance ( $\mathrm{Ra}$ ) of FFA, expressed per $\mathrm{kg}$ fat free mass, was comparable in NGT and IGT during fasting and decreased to a similar extent after the meal (Fig. 1). The same pattern was observed for the rate of disappearance of FFA (data not shown). After weight loss, the Ra of FFA was comparable to before weight loss during fasting and was equally suppressed in the postprandial phase (iAUC, Figure 3.1.). Whole body respiratory quotient (RQ) during fasting and in the postprandial phase was not different between IGT and NGT and did not change after weight loss (data not shown).

Table 3.1. General and metabolic characteristics

\begin{tabular}{|c|c|c|c|c|}
\hline & \multirow[t]{2}{*}{ NGT } & \multirow[t]{2}{*}{ IGT } & \multicolumn{2}{|c|}{ IGT } \\
\hline & & & before WL & after WL \\
\hline & $\mathrm{n}=9$ & $\mathrm{n}=13$ & $\mathrm{n}=8$ & $\mathrm{n}=8$ \\
\hline Age (yrs) & $57.1 \pm 2.6$ & $55.7 \pm 2.1$ & $56.1 \pm 3.2$ & - \\
\hline Body weight (kg) & $107.0 \pm 6.4$ & $96.4 \pm 2.8$ & $93.7 \pm 2.8$ & $79.7 \pm 2.4 * *$ \\
\hline Fat free mass (kg) & $69.5 \pm 3.6$ & $65.2 \pm 1.6$ & $62.8 \pm 1.2$ & $58.8 \pm 1.3 * *$ \\
\hline Body fat $(\%)$ & $34.7 \pm 1.9$ & $32.3 \pm 0.9$ & $31.0 \pm 1.8$ & $20.8 \pm 1.4 * *$ \\
\hline BMI $\left(\mathrm{kg} / \mathrm{m}^{2}\right)$ & $34.2 \pm 1.5$ & $32.1 \pm 0.7$ & $32.3 \pm 0.6$ & $27.5 \pm 0.5 * *$ \\
\hline Waist-hip ratio & $1.02 \pm 0.02$ & $1.02 \pm 0.01$ & $1.04 \pm 0.01$ & $0.99 \pm 0.01 * *$ \\
\hline $\mathrm{VO}_{2}$ peak $\left(\mathrm{ml} \mathrm{O}_{2} * \mathrm{~kg} \mathrm{FFM}^{-1} * \min ^{-1}\right)$ & $40.5 \pm 2.0$ & $40.6 \pm 1.4$ & $39.2 \pm 1.6$ & $41.1 \pm 2.5$ \\
\hline $\mathrm{Wmax}(\mathrm{W})$ & $178 \pm 12$ & $173 \pm 13$ & $152 \pm 10$ & $157 \pm 28$ \\
\hline Glucose, fasting (capillary, mmol/l) & $5.7 \pm 0.2$ & $6.6 \pm 0.3 \dagger$ & $6.7 \pm 0.4$ & - \\
\hline $\begin{array}{l}\text { Glucose, } 2 \text { hrs after } 75 \mathrm{~g} \text { glucose load } \\
\text { (capillary, } \mathrm{mmol} / \mathrm{l} \text { ) }\end{array}$ & $6.7 \pm 0.4$ & $11.7 \pm 0.6 \dagger$ & $12.7 \pm 0.8$ & - \\
\hline $\begin{array}{l}\text { Insulin sensitivity } \\
\left(\mathrm{M} \text {-value, } \mu \mathrm{mol}^{*} \mathrm{~kg} \mathrm{FFM}^{-1} * \mathrm{~min}^{-1}\right)\end{array}$ & $32.2 \pm 4.5$ & $22.8 \pm 3.1 \%$ & $21.7 \pm 3.3$ & $37.9 \pm 3.9 * *$ \\
\hline
\end{tabular}

\section{Skeletal muscle metabolism}

In Figure 3.2, the forearm muscle respiratory quotient and estimated rates of fat and carbohydrate oxidation during fasting and after a high fat, mixed meal are 
shown time-dependently. During fasting, no differences were found in forearm muscle respiratory quotient (RQ) or the rate of fat oxidation in forearm muscle. After the meal, the relative switch from fat oxidation to carbohydrate oxidation, expressed as an increase in RQ (iAUC), was blunted in IGT men compared to NGT men $(p=0.03$, Figure 3.2A). Weight loss in IGT men decreased fasting forearm muscle $R Q$, reflecting an improved stimulation of fatty acid oxidation during fasting $(\mathrm{p}=0.02$, Figure $3.2 \mathrm{D}$ and $3.2 \mathrm{~F})$. The fatty acid and glucose oxidation is also presented in relation to fatty acid and glucose uptake in Table 3.2. In addition, the postprandial response in muscle RQ (iAUC) was larger after weight loss $(p=0.03)$, reflecting trends for an improved suppression of fat oxidation and an improved stimulation of carbohydrate oxidation (Figures 3.2E and 3.2F; Table 3.2.). No differences in forearm blood flow, forearm glucose uptake or plasma-derived FFA uptake were found between NGT and IGT, or before and after weight loss during fasting or after the meal (Table 3.2.). Net glycerol flux and net triglyceride flux were not different neither between groups or after weight loss (data not shown).

Table 3.2. Skeletal muscle substrate metabolism during fasting and after a mixed meal with high fat content in NGT, IGT men and in IGT men after weight loss.

\begin{tabular}{|c|c|c|c|}
\hline & \multirow[t]{2}{*}{ NGT } & \multicolumn{2}{|c|}{ IGT } \\
\hline & & before WL & after WL \\
\hline FASTING & $\mathrm{n}=8$ & $\mathrm{n}=8$ & $\mathrm{n}=8$ \\
\hline Blood flow $\left(\mathrm{ml} * 100 \mathrm{ml}\right.$ tissue $\left.{ }^{-1 *} \min ^{-1}\right)$ & $1.51 \pm 0.17$ & $1.68 \pm 0.21$ & $1.44 \pm 0.10$ \\
\hline Glucose uptake $^{\mathrm{a}}$ & $180 \pm 49$ & $102 \pm 57$ & $222 \pm 37$ \\
\hline Glucose oxidation $^{\mathrm{a}}$ & $202 \pm 107$ & $379 \pm 116$ & $209 \pm 82 \#$ \\
\hline Total FFA uptake ${ }^{\mathrm{a}}$ & $199 \pm 46$ & $285 \pm 57$ & $252 \pm 28$ \\
\hline Total fatty acid oxidation ${ }^{\mathrm{a}}$ & $181 \pm 36$ & $160 \pm 35$ & $211 \pm 23 *$ \\
\hline \multicolumn{4}{|l|}{ POSTPRANDIAL } \\
\hline Blood flow $\left(\mathrm{ml} * 100 \mathrm{ml}\right.$ tissue $\left.{ }^{-1} * \min ^{-1}\right)$ & $1.82 \pm 0.22$ & $1.54 \pm 0.14$ & $1.33 \pm 0.05$ \\
\hline Total glucose uptake ${ }^{\mathrm{a}}$ & $558 \pm 96$ & $333 \pm 99+$ & $423 \pm 38$ \\
\hline Change in glucose uptake ${ }^{a}$ & $+379 \pm 107$ & $+231 \pm 50$ & $+201 \pm 101$ \\
\hline Total glucose oxidation $^{\mathrm{a}}$ & $446 \pm 123$ & $316 \pm 92$ & $375 \pm 98$ \\
\hline Change in glucose oxidation ${ }^{a}$ & $+245 \pm 92$ & $-63 \pm 90 \dagger$ & $+166 \pm 130 \#$ \\
\hline Total FFA uptake ${ }^{a}$ & $163 \pm 46$ & $185 \pm 32$ & $123 \pm 14$ \\
\hline Change in FFA uptake ${ }^{a}$ & $-33 \pm 23$ & $-69 \pm 46$ & $-112 \pm 24$ \\
\hline Total fatty acid oxidation ${ }^{\mathrm{a}}$ & $145 \pm 27$ & $163 \pm 20$ & $163 \pm 11$ \\
\hline Change in fatty acid oxidation ${ }^{\mathrm{a}}$ & $-36 \pm 22$ & $+3 \pm 24$ & $-48 \pm 43 \#$ \\
\hline
\end{tabular}

Means \pm sem. NGT $=$ normal glucose tolerance; IGT $=$ impaired glucose tolerance; $\mathrm{WL}=$ weight loss. ${ }^{\mathrm{a}}$ Glucose and FFA uptake and glucose and fatty acid oxidation are expressed as nmol*100 $\mathrm{ml}$ tissue $\mathrm{e}^{-1} \mathrm{~min}^{-1}$. 'Total' indicates the total AUC/min; 'Change' indicates the postprandial change from baseline (iAUC); * $p<0.05$ for IGT before weight loss vs after weight loss; $\$ \mathrm{p}<0.10$ for NGT vs IGT; $\uparrow \mathrm{p}<0.05$ for IGT vs NGT; $\# \mathrm{p}<0.10$ for IGT before weight loss vs after weight loss. 


\section{Skeletal muscle characteristics}

IMTG content was comparable in NGT and IGT men, but after weight loss the IMTG content of muscle was reduced in 6 out of 7 IGT subjects ( $p=0.08$, Figure 3.3.). The reduction in IMTG strongly correlated with the loss of fat mass $(r=0.79$, $p=0.03)$, and a reduced postprandial insulin response $(r=0.89, p=0.02)$. The HAD activity did not change, but CS activity increased after weight loss in IGT men (Table 3.3.).

Table 3.3. Intramyocellular storage of triglycerides and enzyme activities of $\mathbf{m}$. vastus lateralis in obese men with normal glucose tolerance (NGT) and impaired glucose tolerance (IGT) before and after weight loss

\begin{tabular}{lcccc}
\hline & NGT & IGT & \multicolumn{2}{c}{ IGT } \\
& & & before WL & after WL \\
\hline IMTG (\% of $\mathrm{H}_{2} \mathrm{O}$ resonance) & $\mathrm{n}=6$ & $\mathrm{n}=7$ & $\mathrm{n}=7$ & $\mathrm{n}=7$ \\
& $0.69 \pm 0.10$ & $0.60 \pm 0.06$ & $0.60 \pm 0.06$ & $0.43 \pm 0.07 \#$ \\
& & & & \\
HAD (U/g wet weight) & $\mathrm{n}=9$ & $\mathrm{n}=8$ & $\mathrm{n}=7$ & $\mathrm{n}=7$ \\
CS (U/g wet weight) & $4.99 \pm 0.72$ & $4.75 \pm 0.50$ & $4.69 \pm 0.58$ & $3.85 \pm 0.79$ \\
\hline
\end{tabular}

Mean \pm sem. IMTG $=$ intramyocellular triglycerides; HAD = 3-hydroxyacyl-CoA dehydrogenase; $\mathrm{CS}=$ citrate synthase activity. $\# \mathrm{p}<0.10$ for IGT before weight loss vs after weight loss. ${ }^{* *} \mathrm{p}<0.01$ for IGT before weight loss vs after weight loss.

\section{DISCUSSION}

The main finding of the present study is that in obese IGT men, a prediabetic state, forearm muscle showed a reduced capacity to switch from a predominant fat oxidation in the fasting state to a predominant carbohydrate oxidation after a mixed meal with high fat content. This inability to suppress fat oxidation after a meal was described earlier in diabetic subjects compared to overweight controls (8). The results of the present study provide strong evidence that this impaired ability to regulate fat oxidation is an early impairment in the development of diabetes mellitus type 2 , since impaired glucose tolerance is considered to be the transitional state between normal glucose tolerance and diabetes mellitus type 2 . This impaired ability to switch between fuels after insulin stimulation, i.e. after a meal, was defined as a reduced 'metabolic flexibility' of substrate oxidation $(9,26)$. We also found that this impaired 'metabolic flexibility' of substrate oxidation could be reversed by weight loss, in parallel with an improvement in insulin sensitivity, suggesting that the degree of impairment is partly dependent on obesity and/or insulin resistance. 

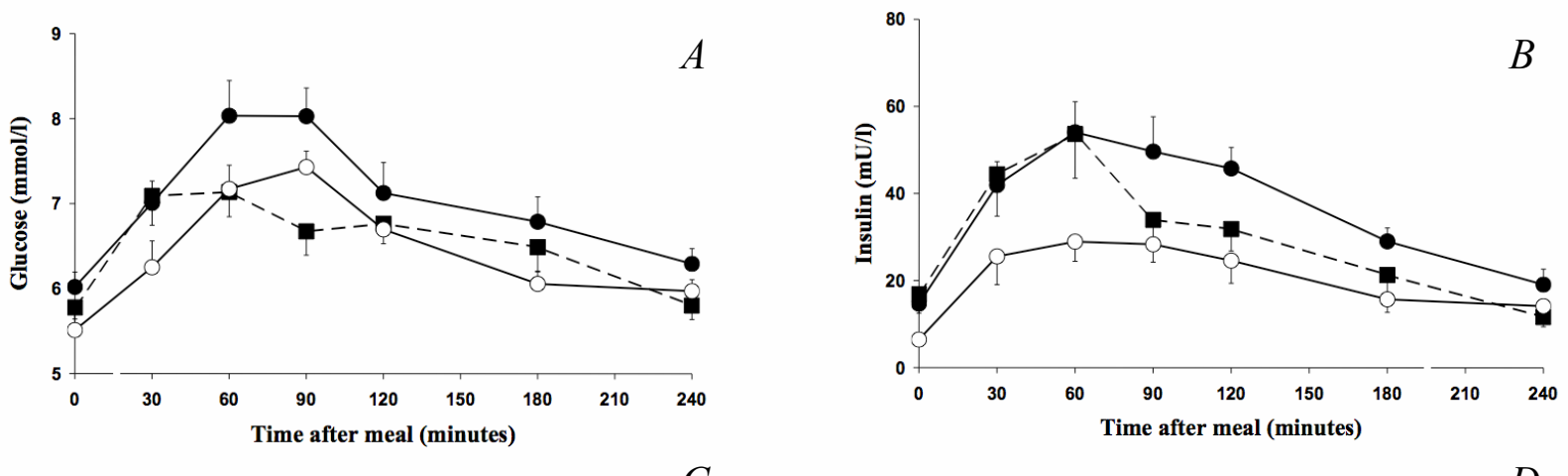

$C$

$D$
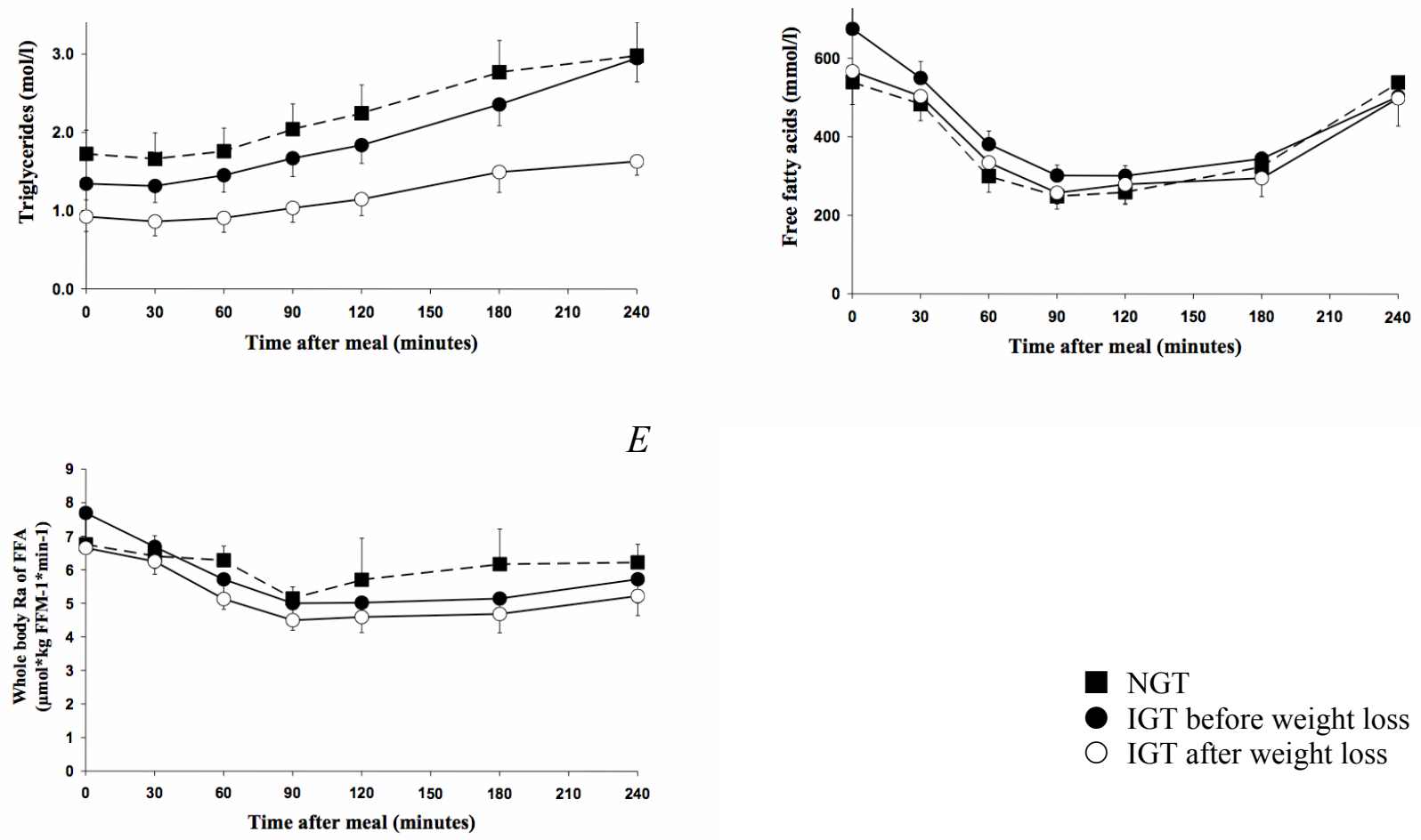

NGT

- IGT before weight loss $\bigcirc$ IGT after weight loss

Figure 3.1. Arterial plasma metabolites during fasting and after mixed meal with high fat content in obese men with normal glucose tolerance (NGT, solid squares and dotted line) and obese men with impaired glucose tolerance (IGT) before (solid circles) and after (open circles) weight loss.

A. Arterial glucose (mmol/l). Postprandial total AUC: IGT before vs after weight loss (WL): $p=$ 0.02 .

B. Arterial insulin (mU/l). Fasting: IGT before vs after $W L p<0.01$. Postprandial iAUC: NGT vs IGT $p=0.08$; IGT before vs after WL $p=0.01$.

C. Arterial triglycerides (mol/l) Fasting: IGT before vs after WL $p<0.05$; Postprandial iAUC: IGT before vs after WL $p<0.01$.

D. Arterial free fatty acids (mmol/l). Fasting: IGT before vs after $W L p<0.05$.

$E$. Whole body rate of appearance of free fatty acids per $\mathrm{kg}$ fat free mass ( $\left.\mu \mathrm{mol}^{*} \mathrm{~kg} F F M^{-1 *} \mathrm{~min}^{-1}\right)$. Postprandial total AUC: $p<0.01$ for IGT before vs after weight loss. 
The finding that the ability of skeletal muscle to switch between fuels in the postprandial phase was reduced in IGT subjects relative to NGT subjects well matched for environmental factors, e.g. body fat mass and physical activity, suggests that this reduced 'metabolic flexibility' may be an intrinsic characteristic of skeletal muscle involved in the development of DM2. Also the reduced ability to stimulate fat oxidation during exercise, as previously found in diabetic subjects, was already present in the IGT state (23). In myotubes from diabetic patients it was shown that the reduced fat oxidation was still present after isolation and cultivation in vitro (28), suggesting that the reduced capacity to oxidize fatty acids may be of genetic origin. Furthermore, even in cultured myotubes from healthy young men, the ability to regulate fat oxidation in vitro was positively related to the in vivo 'metabolic flexibility' of muscle substrate oxidation of the donor (29). These studies support the idea that the impaired ability to regulate fat oxidation may be a primary characteristic of skeletal muscle in IGT men.

In the present study, weight loss in IGT men $(-14 \mathrm{~kg})$ improved the postprandial switch from fat oxidation to carbohydrate oxidation as well as skeletal muscle fat oxidation in the fasting state. The improvement in postprandial metabolism is well in line with previous studies. These show improvements in the suppression of fat oxidation by insulin in weight loss studies with energy restriction $(-15 \mathrm{~kg})(9)$ and a combined energy restriction (- $7 \mathrm{~kg}$ body weight loss) and exercise $\left(+20 \%\right.$ increase in $\left.\mathrm{VO}_{2} \max \right)$ program (27) in obese subjects.

Our study provides evidence that also fasting fat oxidation can be improved by weight reduction. However, previous studies report various findings. In obese subjects, weight loss with energy restriction did not change fasting fat oxidation (9) and a combined energy restriction and exercise program improved fasting fat oxidation (27), whereas weight loss in diabetic patients (-15 $\mathrm{kg}$ ) had no effect on plasma-derived fatty acid oxidation and whole body fat oxidation during fasting or during exercise (30). Altogether, there are clear indications that weight loss is able to reverse impairments in metabolic flexibility of substrate oxidation, although with respect to fasting fat oxidation, this could not be confirmed in all studies.

In addition to impairments in fat oxidation, impairments in fatty acid uptake have been implicated in the etiology of diabetes. In most in vivo studies, a decreased FFA uptake into skeletal muscle was found in obese subjects with impaired glucose tolerance and diabetes mellitus type $2(6,15)$. On the other hand, an increased muscle FFA uptake was shown in the giant vesicle model, using muscle biopsies from obese Zucker rats (31), obese subjects (32) and diabetic patients (32). The main difference between these studies is the applied model. The giant vesicles contain plasma and cytosolic membranes, but lack intracellular metabolism, and may thus reflect the fatty acid transport capacity of the muscle 

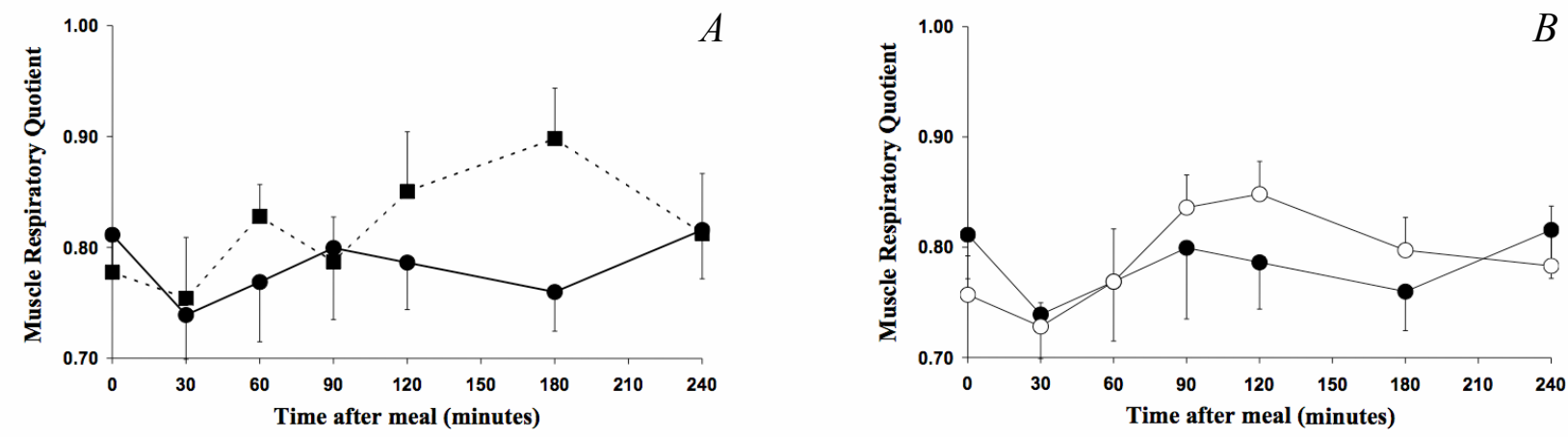

$C$
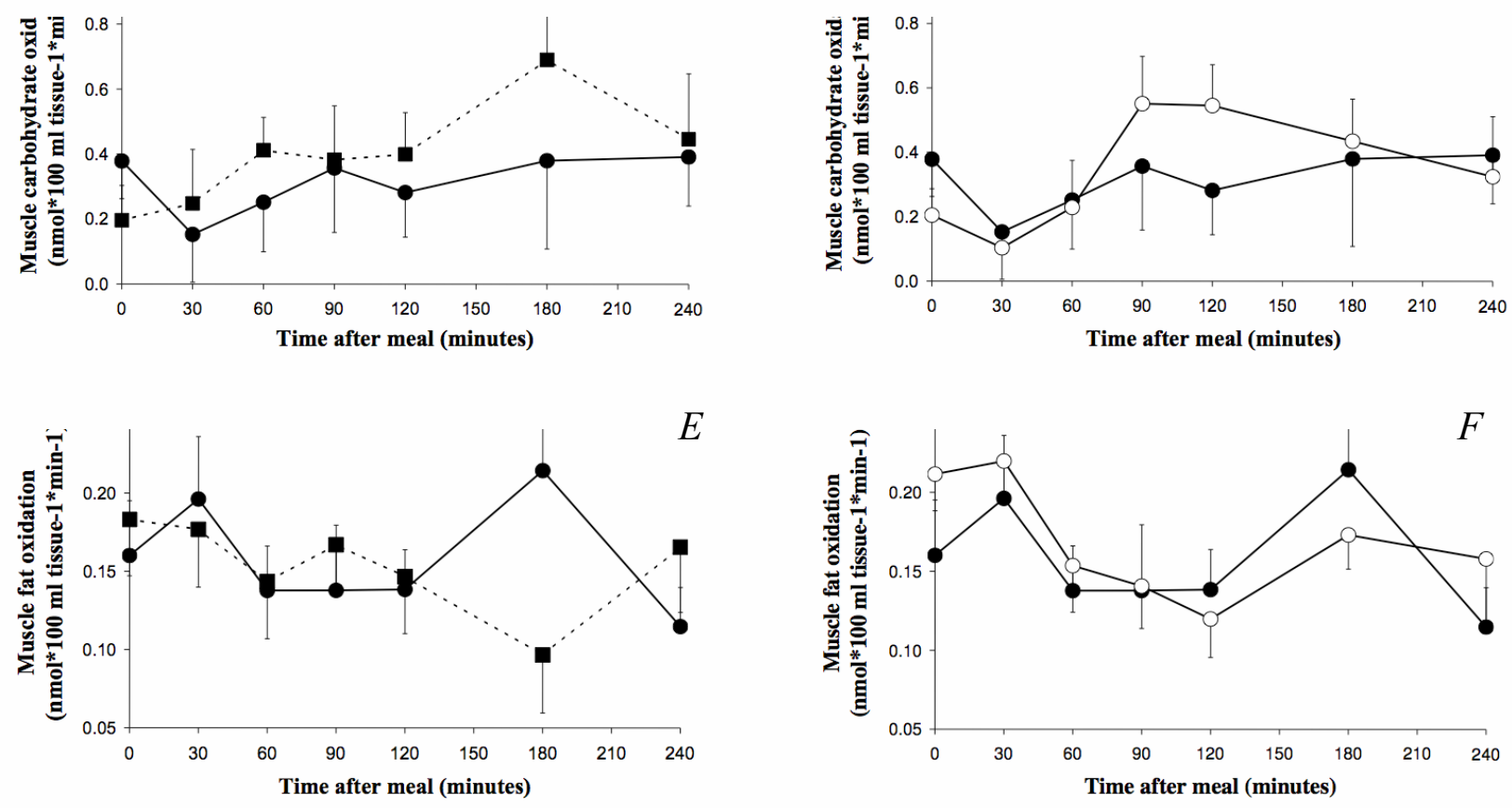

NGT

IGT before weight loss

IGT before weight loss

IGT after weight loss

Figure 3.2. Forearm muscle respiratory quotient, carbohydrate oxidation and fat oxidation in obese men with normal glucose tolerance (NGT, solid squares and dotted line) and impaired glucose tolerance (IGT) before (open circles) and after weight loss (solid circles). Postprandial changes are defined are incremental postprandial AUC. A. Respiratory quotient in NGT and IGT men (postprandial change in $R Q, p=0.03)$. B. Carbohydrate oxidation ( $\mathrm{nmol}^{*} 100 \mathrm{ml}$ tissue $^{-1 *} \mathrm{~min}^{-1}$ ) in NGT and IGT men (postprandial change, $p=0.03$ ). C Fat oxidation ( $\mathrm{nmol}^{*} 100 \mathrm{ml}$ tissue ${ }^{-{ }^{*}} \mathrm{~min}^{-1}$ ) in NGT and IGT men. D Respiratory quotient in IGT men before and after weight loss (fasting, $p=$ 0.03; postprandial change, $p=0.03$ ). E. Carbohydrate oxidation in IGT men before and after weight loss (fasting, $p=0.07$; postprandial increment, $p=0.06$ ). F. Fat oxidation in IGT men before and after weight loss (fasting, $p=0.02$; postprandial increment, $p=0.08$ ). 
per se. In vivo, other factors may determine the final FFA uptake into skeletal muscle, like the FFA concentration gradient over the cell membrane, in its turn determined by the plasma FFA concentration and the rate of cellular metabolism (intracellular FFA concentration). The present study shows no differences in plasma-derived FFA uptake in forearm muscle between NGT and IGT men, neither before and after weight loss. We conclude that fatty acid uptake cannot explain the differences in substrate oxidation that were found between NGT and IGT men, nor the improvements after weight loss in metabolic flexibility of substrate oxidation, muscle fat storage and insulin resistance in IGT men.

The balance between fatty acid uptake and oxidation will eventually determine the accumulation of IMTG, which in turn may have an effect on insulin resistance (1-3). In this perspective, we examined IMTG content before and after weight loss and found that energy restriction reduced the amount of IMTG in 6 out of 7 subjects. This is in line with most other energy restriction studies $(33,34)$, although the decrease in IMTG (-35\%) found by Malenfant and coworkers was not significant (35). The present findings support the view that an improved regulation of postprandial substrate oxidation may have improved the fine tuning between fatty acid uptake and oxidation, thereby reducing IMTG content and reducing the amount of lipid intermediates with the potential to induce insulin resistance, such as long chain acyl-CoA, diacylglycerol and ceramide (10-12), although this needs confirmation by further investigation.

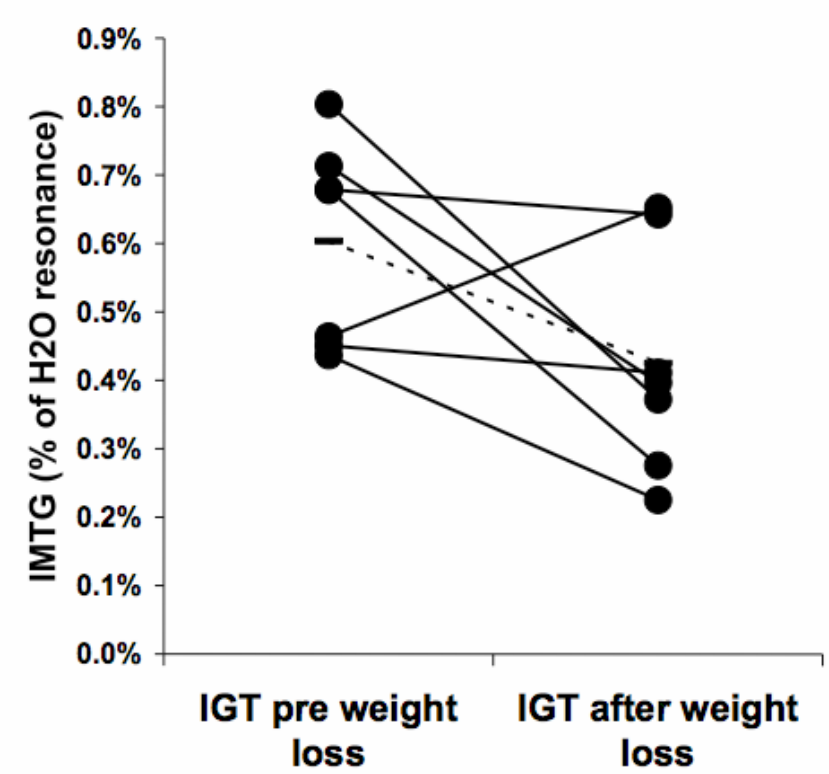

Figure 3.3. Intramyocellular triglycerides before and after weight loss in men with impaired glucose tolerance. Individual changes in IMTG, $p=0.08$. The dotted line indicates mean IMTG.
It is difficult to indicate which mechanisms underlie an impaired regulation of fat oxidation. In our study, the activity of HAD in skeletal muscle did not change after weight loss, whereas the activity of citrate synthase increased, supporting the idea that improvements in mitochondrial oxidative capacity may have played a role in the improvement of substrate oxidation. It has been suggested that an impaired fat oxidation could be the result of a reduced mitochondrial 
number and/or function (36-38). It was also found in obese DM2 subjects that the mitochondrial electron transport capacity was reduced, especially in the subsarcolemmal pool (39). These mitochondria play an important role in the bioenergetic support of signal transduction, fat oxidation and substrate transport $(39,40)$.

In summary, this study has shown for the first time that in prediabetic men, the postprandial switch from fat oxidation to carbohydrate oxidation was impaired relative to obese controls. This provides strong evidence that the impaired ability to regulate muscle fat oxidation may be an early and intrinsic factor in the development towards diabetes mellitus type 2. Furthermore, weight loss was able to improve the ability of skeletal muscle to stimulate fat oxidation during fasting and to improve the postprandial switch from fat oxidation to carbohydrate oxidation, which shows that in the prediabetic state, the impaired 'metabolic flexibility' of substrate oxidation in skeletal muscle is also (partly) dependent on obesity and/or insulin resistance.

\section{ACKNOWLEDGEMENTS}

In the first place we want to thank the volunteers for their time and effort to make these studies possible. We thank Jos Stegen, Annemie Gijsen and Joan Senden for their excellent analytical support, the dieticians Tanja Hermans-Limpens and Marja Ockeloen - van der Hulst for their support and dietary advice, Eveline Peeters-Tielen for assistance with the MRS scanning and Judith Huskens and Dorien Mintjes for their practical support. Supported by grants from the Dutch Diabetes Research Foundation (DFN 98.901 and DFN 2000.00.020).

\section{REFERENCES}

1 Krssak M, Falk Petersen K, Dresner A, et al. Intramyocellular lipid concentrations are correlated with insulin sensitivity in humans: a 1H NMR spectroscopy study. Diabetologia. 1999;42:113-6.

2 Levin K, Daa Schroeder H, Alford FP and Beck-Nielsen H. Morphometric documentation of abnormal intramyocellular fat storage and reduced glycogen in obese patients with Type II diabetes. Diabetologia. 2001;44:824-33.

3 Ravussin E and Smith SR. Increased fat intake, impaired fat oxidation, and failure of fat cell proliferation result in ectopic fat storage, insulin resistance, and type 2 diabetes mellitus. Ann N Y Acad Sci. 2002;967:363-78. 
Kriketos AD, Furler SM, Gan SK, Poynten AM, Chisholm DJ and Campbell LV. Multiple indexes of lipid availability are independently related to whole body insulin action in healthy humans. J Clin Endocrinol Metab. 2003;88:793-8.

Blaak EE. Basic disturbances in skeletal muscle fatty acid metabolism in obesity and type 2 diabetes mellitus. Proc Nutr Soc. 2004;63:323-30.

Blaak EE, van Aggel-Leijssen DP, Wagenmakers AJ, Saris WH and van Baak MA. Impaired oxidation of plasma-derived fatty acids in type 2 diabetic subjects during moderate-intensity exercise. Diabetes. 2000;49:2102-7.

7 Blaak EE, Wagenmakers AJ, Glatz JF, et al. Plasma FFA utilization and fatty acid-binding protein content are diminished in type 2 diabetic muscle. Am J Physiol Endocrinol Metab. 2000;279:E146-54.

Kelley DE and Simoneau JA. Impaired free fatty acid utilization by skeletal muscle in non-insulin-dependent diabetes mellitus. J Clin Invest. 1994;94:2349-56.

9 Kelley DE, Goodpaster B, Wing RR and Simoneau JA. Skeletal muscle fatty acid metabolism in association with insulin resistance, obesity, and weight loss. Am J Physiol. 1999;277:E1130-41.

Schmitz-Peiffer C. Signalling aspects of insulin resistance in skeletal muscle: mechanisms induced by lipid oversupply. Cell Signal. 2000;12:583-94.

11 Itani SI, Ruderman NB, Schmieder F and Boden G. Lipid-induced insulin resistance in human muscle is associated with changes in diacylglycerol, protein kinase $C$, and IkappaB-alpha. Diabetes. 2002;51:2005-11.

12 Boden G and Laakso M. Lipids and glucose in type 2 diabetes: what is the cause and effect? Diabetes Care. 2004;27:2253-9.

13 Zurlo F, Lillioja S, Esposito-Del Puente A, et al. Low ratio of fat to carbohydrate oxidation as predictor of weight gain: study of 24-h RQ. Am J Physiol. 1990;259:E650-7.

14 Seidell JC, Muller DC, Sorkin JD and Andres R. Fasting respiratory exchange ratio and resting metabolic rate as predictors of weight gain: the Baltimore Longitudinal Study on Aging. Int J Obes Relat Metab Disord. 1992;16:667-74.

15 Turpeinen AK, Takala TO, Nuutila $\mathrm{P}$, et al. Impaired free fatty acid uptake in skeletal muscle but not in myocardium in patients with impaired glucose tolerance: studies with PET and 14(R,S)-[18F]fluoro-6-thia-heptadecanoic acid. Diabetes. 1999;48:1245-50.

16 World Health Organization. Definition, diagnosis and classification of diabetes mellitus and its complications. Report of a WHO consultation part 1: diagnosis and classification of diabetes mellitus. WHO technical report series. 1999:1-59.

17 Siri W. The gross composition of the body. Adv Bio Med Physiol. 1956;4:239-80.

18 Mensink M, Corpeleijn E, Feskens EJ, et al. Study on lifestyle-intervention and impaired glucose tolerance Maastricht (SLIM): design and screening results. Diabetes Res Clin Pract. 2003;61:49-58.

19 Bergstrom J, Hermansen L, Hultman E and Saltin B. Diet, muscle glycogen and physical performance. Acta Physiol Scand. 1967;71:140-50. 
Schrauwen-Hinderling VB, van Loon LJ, Koopman R, Nicolay K, Saris WH and Kooi ME. Intramyocellular lipid content is increased after exercise in nonexercising human skeletal muscle. J Appl Physiol. 2003;95:2328-32.

21 Frayn $\mathrm{KN}$, Lund $\mathrm{P}$ and Walker M. Interpretation of oxygen and carbon dioxide exchange across tissue beds in vivo. Clin Sci (Colch). 1993;85:373-84.

22 Steele R. Influences of glucose loading and of injected insulin on hepatic glucose output. Ann N Y Acad Sci. 1959;82:420-30.

23 Mensink M, Blaak EE, van Baak MA, Wagenmakers AJ and Saris WH. Plasma free Fatty Acid uptake and oxidation are already diminished in subjects at high risk for developing type 2 diabetes. Diabetes. 2001;50:2548-54.

24 Shepherd D and Garland PB. Methods Enzymology. 1969;13:11-16.

25 Bergmeyer HU. Methods of Enzymatic Analysis;1:474.

26 Kelley DE. Skeletal muscle fat oxidation: timing and flexibility are everything. J Clin Invest. 2005;115:1699-702.

27 Goodpaster BH, Katsiaras A and Kelley DE. Enhanced fat oxidation through physical activity is associated with improvements in insulin sensitivity in obesity. Diabetes. 2003;52:2191-7.

28 Gaster M, Rustan AC, Aas V and Beck-Nielsen H. Reduced lipid oxidation in skeletal muscle from type 2 diabetic subjects may be of genetic origin: evidence from cultured myotubes. Diabetes. 2004;53:542-8.

29 Ukropcova B, McNeil M, Sereda O, et al. Dynamic changes in fat oxidation in human primary myocytes mirror metabolic characteristics of the donor. J Clin Invest. 2005;115:1934-41.

30 Blaak EE, Wolffenbuttel BH, Saris WH, Pelsers MM and Wagenmakers AJ. Weight reduction and the impaired plasma-derived free fatty acid oxidation in type 2 diabetic subjects. J Clin Endocrinol Metab. 2001;86:1638-44.

31 Luiken JJ, Arumugam Y, Dyck DJ, et al. Increased rates of fatty acid uptake and plasmalemmal fatty acid transporters in obese Zucker rats. J Biol Chem. 2001;276:40567-73.

32 Bonen A, Parolin ML, Steinberg GR, et al. Triacylglycerol accumulation in human obesity and type 2 diabetes is associated with increased rates of skeletal muscle fatty acid transport and increased sarcolemmal FAT/CD36. Faseb J. 2004;18:1144-6.

33 Goodpaster BH, Theriault R, Watkins SC and Kelley DE. Intramuscular lipid content is increased in obesity and decreased by weight loss. Metabolism. 2000;49:467-72.

34 Gray RE, Tanner CJ, Pories WJ, MacDonald KG and Houmard JA. Effect of weight loss on muscle lipid content in morbidly obese subjects. Am J Physiol Endocrinol Metab. 2003;284:E726-32.

35 Malenfant P, Tremblay A, Doucet E, Imbeault P, Simoneau JA and Joanisse DR. Elevated intramyocellular lipid concentration in obese subjects is not reduced after diet and exercise training. Am J Physiol Endocrinol Metab. 2001;280:E632-9.

36 Lowell BB and Shulman GI. Mitochondrial dysfunction and type 2 diabetes. Science. 2005;307:384-7. 
37 Mootha VK, Lindgren CM, Eriksson KF, et al. PGC-1alpha-responsive genes involved in oxidative phosphorylation are coordinately downregulated in human diabetes. Nat Genet. 2003;34:267-73.

38 Patti ME, Butte AJ, Crunkhorn S, et al. Coordinated reduction of genes of oxidative metabolism in humans with insulin resistance and diabetes: Potential role of PGC1 and NRF1. Proc Natl Acad Sci U S A. 2003;100:8466-71.

39 Ritov VB, Menshikova EV, He J, Ferrell RE, Goodpaster BH and Kelley DE. Deficiency of subsarcolemmal mitochondria in obesity and type 2 diabetes. Diabetes. 2005;54:8-14.

40 Hood DA. Invited Review: contractile activity-induced mitochondrial biogenesis in skeletal muscle. J Appl Physiol. 2001;90:1137-57. 


\title{
CHAPTER 4
}

\section{Insulin acutely upregulates protein expression of the fatty acid transporter CD36 in human skeletal muscle in vivo}

\author{
Disturbed regulation in insulin resistance
}

Eva Corpeleijn (1), Maurice M.A.L. Pelsers (2), Stijn Soenen (1), Marco Mensink (1), Freek G. Bouwman (1), Marianne E. Kooi (3), Wim H.M. Saris (1), Jan F.C. Glatz (3), Ellen E. Blaak (1)

From the (1) Department of Human Biology, the Nutrition and Toxicology Research Institute (NUTRIM), Maastricht University, Maastricht, The Netherlands; (2) Department of movement sciences, the Nutrition and Toxicology Research Institute NUTRIM, Maastricht University, Maastricht, The Netherlands; (3) the Department of Radiology, University Hospital Maastricht, Maastricht, The Netherlands; and the (4) Department of Molecular Genetics, Cardiovascular Research Institute Maastricht (CARIM), Maastricht University, Maastricht, The Netherlands. 


\begin{abstract}
Context: Insulin resistance and diabetes mellitus type 2 are related to impairments in fatty acid uptake in skeletal muscle.

Objective and design: We investigated the regulation of the fatty acid transporter CD36 (FAT) and the cytosolic fatty acid binding protein FABPc in skeletal muscle during fasting and after insulin stimulation in obese men with impaired glucose tolerance (IGT), a prediabetic state, and obese men with normal glucose tolerance (NGT). During a hyperinsulinemic euglycemic clamp, insulin sensitivity was determined and biopsies ( $\mathrm{m}$. vastus lateralis) were taken before and after clamp. Protein expression was analyzed with ELISA and intramyocellular triglycerides with ${ }^{1} \mathrm{H}$-magnetic resonance spectroscopy and Oil Red O staining.

Results: No differences in CD36 and FABPc expression were found between IGT and NGT. Muscle protein expression of CD36, but not of FABPc, was 1.5-fold increased $(\mathrm{p}<0.05)$ after $3-\mathrm{hrs}$ of insulin stimulation. The increase in CD36 protein was positively related to insulin resistance $(r=0.56, p<0.05)$ and to an increase in intramyocellular triglycerides after the clamp (Pearson $\mathrm{r}=0.89, \mathrm{p}<0.05)$.

Conclusions: We conclude that the CD36 protein expression in human skeletal muscle is acutely upregulated by insulin in vivo. Furthermore, the degree of upregulation is dependent on the degree of insulin resistance, which supports the hypothesis that the regulation of fatty acid uptake is disturbed in insulin resistant subjects.
\end{abstract}




\section{INTRODUCTION}

Conditions characterized by insulin resistance are accompanied by disturbances in fatty acid metabolism, e.g. an increased level of circulating free fatty acids and a reduced fatty acid utilization in skeletal muscle. The uptake of plasma free fatty acids (FFA) was found to be reduced in skeletal muscle of diabetic patients in the postabsorptive state $(1,2)$ as well as during exercise (2). Interestingly, these findings were extended to subjects with the pre-diabetic condition of impaired glucose tolerance (IGT), suggesting that an impaired FFA utilization may be an important etiological factor in the development of diabetes mellitus type $2(3,4)$.

It is important to realize that the majority of the people in Western countries are in the fed state most of the day. Therefore, it is very relevant to consider the regulation of fatty acid uptake into skeletal muscle in insulinstimulated conditions. In healthy subjects, both the fatty acid uptake and fatty acid oxidation are suppressed after a meal. In diabetic patients, fatty acid uptake is reduced in the fasting state relative to healthy lean subjects, whilst in the postprandial phase, the fatty acid uptake is not adequately suppressed (1). A high fatty acid uptake relative to oxidation in the postprandial state may enhance the storage of triglycerides in skeletal muscle, which is strongly associated with insulin resistance (5-7).

New insights have shown that trans-membrane fatty acid uptake is not just a passive process, but that it is regulated by specific transport proteins (8). Alterations in gene and protein expression of fatty acid transporters have been associated with a disturbed uptake of FFAs $(9,10)$ and insulin resistance (11-14). Two important fatty acid transporters in skeletal muscle are the membrane-bound fatty acid translocase (CD36 or FAT) (15) and cytosolic fatty acid binding protein (FABPc)(16). Evidence is accumulating that alterations in CD36 are related to insulin resistance and/or diabetes $(13,17,18)$. In diabetic subjects, the FABPc protein content in skeletal muscle was lower than in lean controls (19). This reduced FABPc content was found in parallel with a reduced fatty acid uptake in the postabsorptive state, despite high circulating FFA concentrations, suggesting that a reduced amount of fatty acid transporters may be involved in a reduced skeletal muscle FFA uptake.

Little is known about the regulation of fatty acid transporters by insulin in human skeletal muscle. Previously, it was found that insulin stimulated the translocation of CD36 from an intracellular compartment to the membrane in rat cardiac and skeletal muscle (20). Recently, it was demonstrated in rat cardiomyocytes that insulin not only induced the translocation of CD36, but also very rapidly upregulated both the mRNA and protein expression of CD36 (21). This supports the hypothesis that fatty acid transporters and fatty acid uptake are 
part of a carefully regulated system. In humans, an increased amount of CD36 protein was located at the plasma membrane of abdominal muscle strips obtained from insulin resistant subjects during fasting (22), suggesting disturbances in CD36 translocation and/or internalization. Up till now, the effect of in vivo insulin stimulation on CD36 protein expression in skeletal muscle of humans has never been addressed before.

The purpose of the present study was to investigate whether CD36 protein expression was increased after $3 \mathrm{hrs}$ of insulin stimulation in human skeletal muscle in vivo. Furthermore, we investigated in obese men with impaired glucose tolerance, a prediabetic state, and obese controls whether the baseline and insulinmediated protein expression of these fatty acid transporters in skeletal muscle were different, and how this was related to the intramyocellular triglyceride content.

\section{SUBJECTS AND METHODS}

\section{Subjects}

Nine obese men with impaired glucose tolerance (IGT) and eight obese men with normal glucose tolerance (NGT), matched for age and BMI, participated in the study. The NGT men had no family history of diabetes. Glucose tolerance was determined with a standard oral glucose tolerance test according to the WHO guidelines (23). Additional inclusion criteria were obesity (BMI $>30 \mathrm{~kg} / \mathrm{m}^{2}$ ), diastolic blood pressure $<100 \mathrm{~mm} \mathrm{Hg}$, no major organ dysfunction, and no use of medication that could interfere with the results. Subjects were not involved in any regular physical activity for more than 3 hours a week. The experimental protocol was approved by the local Medical Ethical Committee of the Maastricht University. All subjects gave written informed consent.

\section{Experimental design}

The NGT and IGT men underwent measurements for body composition, aerobic capacity and insulin sensitivity. Muscle biopsies were taken before and after insulin-stimulation to analyze fatty acid transporters and lipid content using Oil Red O staining. Intramyocellular lipid content was additionally measured, on a separate day, in the fasting state with the ${ }^{1} \mathrm{H}$-Magnetic Resonance Spectroscopy technique. 


\section{Body composition and aerobic capacity}

Body weight was determined on an electronic scale. Body composition (fat mass and fat free mass) was determined by hydrostatic weighing with simultaneous correction for lung volume according to Siri (24). Maximal aerobic power (Wmax) and peak oxygen uptake ( $\mathrm{VO}_{2}$ peak) were determined during an incremental exhaustive bicycle test as described before (25). Waist and hip circumference were measured to the nearest $1 \mathrm{~cm}$.

\section{Insulin sensitivity and muscle biopsies}

Insulin sensitivity was determined by a hyperinsulinemic euglycemic clamp. Subjects arrived at the laboratory by car or public transport after an overnight fast (10-12 hrs). Insulin was infused at a constant rate $\left(1 \mathrm{mU}^{*} \mathrm{~kg} \mathrm{BW}-{ }^{-1 *} \mathrm{~min}^{-1}\right)$ with glucose clamped at $4.5 \pm 0.9 \mathrm{mmol} / \mathrm{l}$ with an intravenous infusion of $20 \% \mathrm{w} / \mathrm{v}$ glucose solution. The insulin concentration during the steady state was $109 \pm 5$ $\mathrm{mU} / \mathrm{L}$. Insulin sensitivity (M-value) was calculated as the glucose infusion rate per $\mathrm{kg}$ fat free mass $\left(\mathrm{mmol}^{*} \mathrm{kgFFM}^{-1 *} \mathrm{~min}^{-1}\right)$ during a steady state of 30 minutes after at least 120 minutes of insulin infusion. Before the clamp and at the end of the steady state, a percutaneous needle biopsy was taken from the $\mathrm{m}$. vastus lateralis under local anesthesia of the skin using the Bergström method with suction (26). Biopsies were freed from any visible fat and blood and immediately frozen in liquid nitrogen. Biopsies for immunofluorescence were first frozen in isopentane at its melting point and embedded in Tissue-Tek (Sakura Europe, Zoeterwoude, The Netherlands). All biopsies were stored at $-80{ }^{\circ} \mathrm{C}$ until analysis.

\section{Intramyocellular triglycerides}

Postabsorptive intramyocellular triglyceride content (IMTG) was quantified in the $\mathrm{m}$. vastus lateralis with magnetic resonance spectroscopy ( $\left.{ }^{1} \mathrm{H}-\mathrm{MRS}\right)$. Measurements with ${ }^{1} \mathrm{H}-\mathrm{MRS}$ were performed on a $1.5 \mathrm{~T}$ whole body scanner (Intera, Philips Medical Systems, Best, The Netherlands) using the average of at least two voxels $(12 \times 11 \times 18 \mathrm{~mm})$ as described before (27). IMTG content is expressed as \% of the area of the $\mathrm{CH}_{2}$ resonance of IMTG compared to the area of water resonance, corrected for T1 and T2 relaxation. Complete data sets of 8 NGT and 8 IGT men were obtained.

In addition, IMTG was quantified in biopsies from the $\mathrm{m}$. vastus lateralis before and at the end of the clamp, using Oil red O staining in combination with immufluorescence and computerized quantification of lipid droplets as described before (28). In short, serial cross sections $(4 \mu \mathrm{m})$ of frozen muscle were thaw 
mounted on uncoated precleaned glass slides and air dried for 15 minutes. Slices were fixated by a $3.7 \%$ formaldehyde solution for 1 hour, rinsed, and treated with $0.5 \%$ Triton X-100 in PBS for 5 minutes. Slides were incubated with a primary antibody against adult human slow myosin heavy chain (A4.951, Developmental Studies Hybridoma Bank, Iowa City, USA), to determine fibre type, and a rabbit polyclonal antiserum against human laminine ( $\mathrm{pLam}$, Sigma), to visualize myocyte membranes, for 45 minutes at room temperature. The slides were rinsed and incubated with the appropriate secondary fluorescin antibodies (GAM-IgG1 Alexa Fluor 488 and GAR-IgG alexa Fluor 350 respectively, Molecular Probes) for 45 minutes and washed. Thereafter, slides were immersed in an Oil red O solution (Fluka Chemie, Buchs, Switzerland) for 30 minutes and washed. Stained sections were embedded in $10 \%$ glycerol in $10 \mathrm{mM}$ TRIS- $\mathrm{HCl}, \mathrm{pH} 8.5$, and covered with Mowiol and a coverslip. Images were captured using a Nikon E800 fluorescence microscope (Uvikon, Bunnik, The Netherlands) and a colour CCD camera (Basler A101 C) with 240 times magnification. Per biopsy, at least 50 different cells were analyzed using Lucia 5.49 software as described before (28). Fibre type area 1 was calculated as the measured fibre type 1 area divided by total measured area.

\section{Biochemical analysis}

Plasma FFA and glucose were analyzed in EDTA plasma using standard enzymatic techniques automated on the COBAS Fara centrifugal analyzer at 550 nm (for FFA: FFA-C test kit, Wako chemicals, Neuss, Germany; for glucose: Roche Unikit III, Hoffman-la-Roche, Basel, Switzerland). Insulin was analyzed using a fluoroimmunometric assay (autoDELFIA Insulin, PerkinElmer, Turku, Finland) with no cross-reactivity with pro-insulin or split forms of proinsulin. For the determination of protein content of fatty acid transporters, muscle biopsies were homogenized in ice-cold tris-EDTA buffer at $\mathrm{Ph}$ 7.4. Homogenates were subsequently sonicated for 15 seconds, 4 times. CD36 was measured by a sandwich-type ELISA with mAb 131.4 as the capture antibody (29). In four subjects, the increase in CD36 content was additionally confirmed by Western blot analysis. This was done to exclude the possibility that the findings with the ELISA method were due to methodological aspects, e.g. the antibody that was used. The Western blot analysis was performed according to Keizer et al. with minor modifications (30). The membrane was blocked in 5\% BSA in Tris buffered saline containing $0.1 \%$ Tween-20. The dilution of the primary antibody (MO25) against CD36 was 1:100.000 and the secondary horseradish peroxidase-conjugated rabbit anti-mouse Ig (DAKO, Glostrup, Denmark) antibody dilution was 1:20.000. For the determination of cytosolic fatty acid binding protein (FABPc), the homogenates were centrifuged at $10000 \mathrm{~g}$ for $2 \mathrm{~min}$ to remove cell debris 
(membranes). Muscle type FABPc was measured by means of ELISA (Hycult Biotechnology, Uden, TheNetherlands), using recombinant human FABPc as standard (31).

\section{Statistical analysis}

Results are given as mean \pm sem. A two-tailed Student's t-test for independent samples was used to compare groups. Correlations were tested using Pearson's correlation coefficient $(r)$. Since correlations between the changes in protein content and insulin resistance, as shown in Figure 2B, may also be dependent on the baseline values of the protein content, we divided the changes in CD36 protein by their initial values and related these to insulin resistance as well (Figure 2C). A p-value $<0.05$ was considered statistically significant. Statistical analysis was performed using SPSS 10.0 for Macintosh.

\section{RESULTS}

\section{Subject characteristics}

The IGT and NGT men were well matched for age and body composition (Table 4.1.). Also maximal aerobic capacity was comparable between groups. Insulin sensitivity tended to be lower in IGT compared to NGT ( $p=0.08$, Table 4.2.). Fasting glucose, insulin and FFA were not significantly different between IGT and NGT (Table 4.2.).

Table 4.1. General and metabolic characteristics

\begin{tabular}{|c|c|c|}
\hline & NGT & IGT \\
\hline & $\mathrm{n}=9$ & $\mathrm{n}=8$ \\
\hline Age (yrs) & $57.1 \pm 2.6$ & $58.1 \pm 2.7$ \\
\hline Body mass index $\left(\mathrm{kg} / \mathrm{m}^{2}\right)$ & $34.2 \pm 1.5$ & $32.6 \pm 0.6$ \\
\hline Body fat $(\%)$ & $34.7 \pm 1.5$ & $32.7 \pm 1.1$ \\
\hline Fat free mass $(\mathrm{kg})$ & $69.5 \pm 10.8$ & $62.7 \pm 3.8$ \\
\hline Waist-hip ratio & $1.02 \pm 0.02$ & $1.03 \pm 0.01$ \\
\hline $\mathrm{VO}_{2} \max \left(\mathrm{ml} \mathrm{O}_{2} * \mathrm{~kg} \mathrm{FFM}^{-1} * \min ^{-1}\right)$ & $40.5 \pm 2.0$ & $38.9 \pm 1.8$ \\
\hline Triglycerides $(\mathrm{mmol} / \mathrm{l})$ & $1.73 \pm 0.29$ & $1.54 \pm 0.27$ \\
\hline
\end{tabular}


Table 4.2. M-value and plasma metabolites during fasting and during the steady state of the hyperinsulinemic euglycemic clamp

\begin{tabular}{lcccc}
\hline & \multicolumn{2}{c}{ NGT } & \multicolumn{2}{c}{ IGT } \\
& Fasting & $\mathrm{SS}$ & fasting & $\mathrm{SS}$ \\
\hline Glucose $(\mathrm{mmol} / \mathrm{l})$ & $5.7 \pm 0.1$ & $4.5 \pm 0.1$ & $6.2 \pm 0.2 *$ & $4.4 \pm 0.1$ \\
Insulin $(\mathrm{mU} / \mathrm{l})$ & $16.8 \pm 4.1$ & $111 \pm 6$ & $14.1 \pm 1.8$ & $108 \pm 9$ \\
Free fatty acids $(\mu \mathrm{mol} / \mathrm{l})$ & $539 \pm 54$ & $140 \pm 19$ & $696 \pm 81$ & $167 \pm 13$ \\
Insulin sensitivity & n.a. & $32.2 \pm 4.5$ & n.a. & $21.2 \pm 3.7^{*}$ \\
$\left(\mathrm{M}-\mathrm{value}, \mu \mathrm{mol}^{*} \mathrm{~kg} \mathrm{FFM}\right.$ & & & &
\end{tabular}

Mean \pm sem. Student's t-test for unpaired samples, two-tailed; * $\mathrm{p}<0.10 ; \mathrm{FFM}=$ fat free mass; IGT $=$ impaired glucose tolerance; n.a. = not applicable; NGT = normal glucose tolerance; $\mathrm{SS}=$ steady state at the end of the clamp procedure.

\section{Skeletal muscle protein content}

No significant differences were found in the FABPc protein or CD36 protein content in vastus lateralis muscle between IGT and NGT during fasting (Table 4.3.). A 3-hr insulin stimulation had no effect on FABPc content but significantly increased CD36 protein content $\sim 1.5$-fold in skeletal muscle (Figure 1A and 1B) with no differences between NGT and IGT men. This increase in CD36, as measured with ELISA, was confirmed with Western blot analysis in four subjects (before clamp $=0.106 \pm 0.043 \mathrm{AU}$; during clamp $=0.181 \pm 0.035 \mathrm{AU}$ ).

Insulin sensitivity (M-value) was positively related to CD36 protein content during fasting (Figure 2A). Furthermore, the insulin-mediated increase in CD36 protein was negatively related to insulin sensitivity (the M-value, Figure 2B). To exclude that the correlation was due to differences in baseline values, we related insulin sensitivity to the change in CD36 protein content divided by their initial CD36 value. This correlation was significant as well (Figure 2C, Pearson $r=$ -0.64, $\mathrm{p}=0.02$ ). No associations were found between CD36 protein content at baseline and fasting FFA concentration, fasting glucose concentration, the percentage of muscle type 1 fiber area or body fat percentage. The suppression of plasma FFA during clamp and the increase in CD36 protein content were not related either.

Table 4.3. CD36 protein, FABPc protein, IMTG content and fibre type in $\mathbf{m}$. vastus lateralis of obese men with normal glucose tolerance (NGT) and impaired glucose tolerance (IGT).

\begin{tabular}{lcc}
\hline & NGT & IGT \\
\hline CD36 (ng/g wet weight) & $20.0 \pm 4.1(\mathrm{n}=9)$ & $16.5 \pm 4.3(\mathrm{n}=8)$ \\
FABPc $(\mu \mathrm{g} / \mathrm{g}$ wet weight) & $93.6 \pm 13.6(\mathrm{n}=9)$ & $83.5 \pm 13.8(\mathrm{n}=8)$ \\
IMTG $\left({ }^{1} \mathrm{H}-\mathrm{MRS}, \%\right.$ of $\mathrm{H}_{2} \mathrm{O}$ resonance) & $0.842 \pm 0.124(\mathrm{n}=8)$ & $0.716 \pm 0.083(\mathrm{n}=8)$ \\
IMTG (Oil Red O, lipid stained area fraction) & $0.058 \pm 0.034(\mathrm{n}=5)$ & $0.068 \pm 0.041(\mathrm{n}=4)$ \\
Fibre type area (\% type 1 fibre) & $46.5 \pm 8.7(\mathrm{n}=5)$ & $51.3 \pm 11.6(\mathrm{n}=4)$ \\
\hline Mean \pm sem; IMTG $=$ intramyocellular triglycerides. & &
\end{tabular}


A

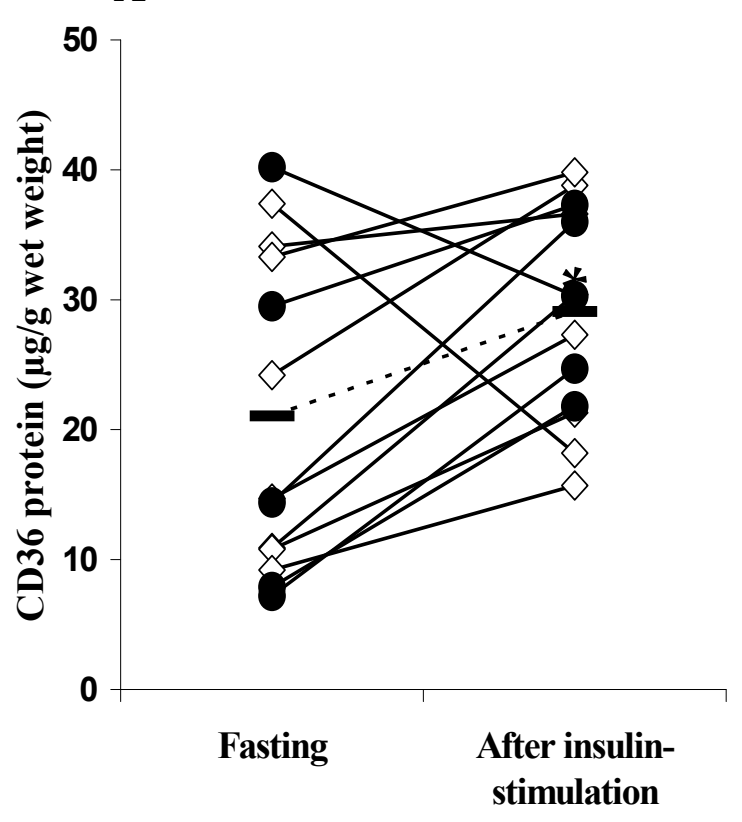

B

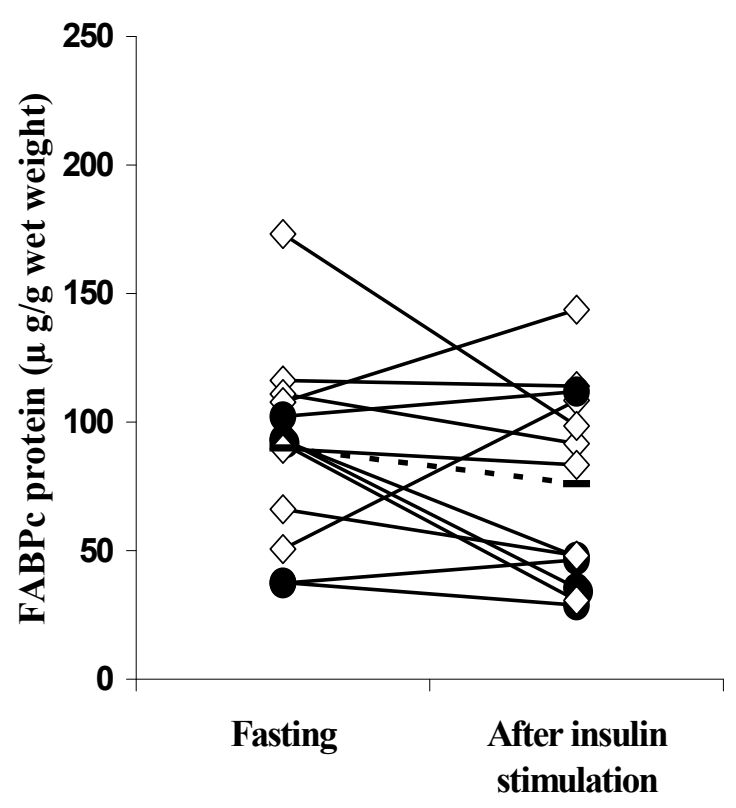

Figure 1. Skeletal muscle protein content $(\mu g / g$ wet weight) of $C D 36(1 A)$ and $F A B P c(1 B)$ during fasting and after insulin stimulation in obese men. Open diamonds are NGT subjects; filled circles are IGT subjects; flat object with dotted line is the mean.

${ }^{*} p<0.05$, paired Student's $t$-test, two-tailed.

\section{Skeletal muscle lipid content}

At baseline, no differences in IMTG content were seen between IGT and NGT men as measured with ${ }^{1} \mathrm{H}-\mathrm{MRS}$ or Oil Red O staining (Table 4.3). The purpose of the Oil Red O method was to measure lipid content in skeletal muscle before and after clamp. Due to methodological problems we were able to analyze 9 biopsies before clamp and 6 biopsies after clamp, which resulted in five pairs of biopsies (3 NGT and 2 IGT) before and after clamp, which could be compared to changes in CD36 protein content. The lipid content in skeletal muscle (expressed as the lipid fraction of total stained area) before clamp was $0.085 \pm 0.054$ for NGT and $0.086 \pm$ 0.083 for IGT. After clamp it was $0.030 \pm 0.028$ for NGT and $0.112 \pm 0.111$ for IGT. The insulin-induced change in lipid content of skeletal muscle determined by ORO staining was positively related to the increase in CD36 protein during clamp (Figure 3). 

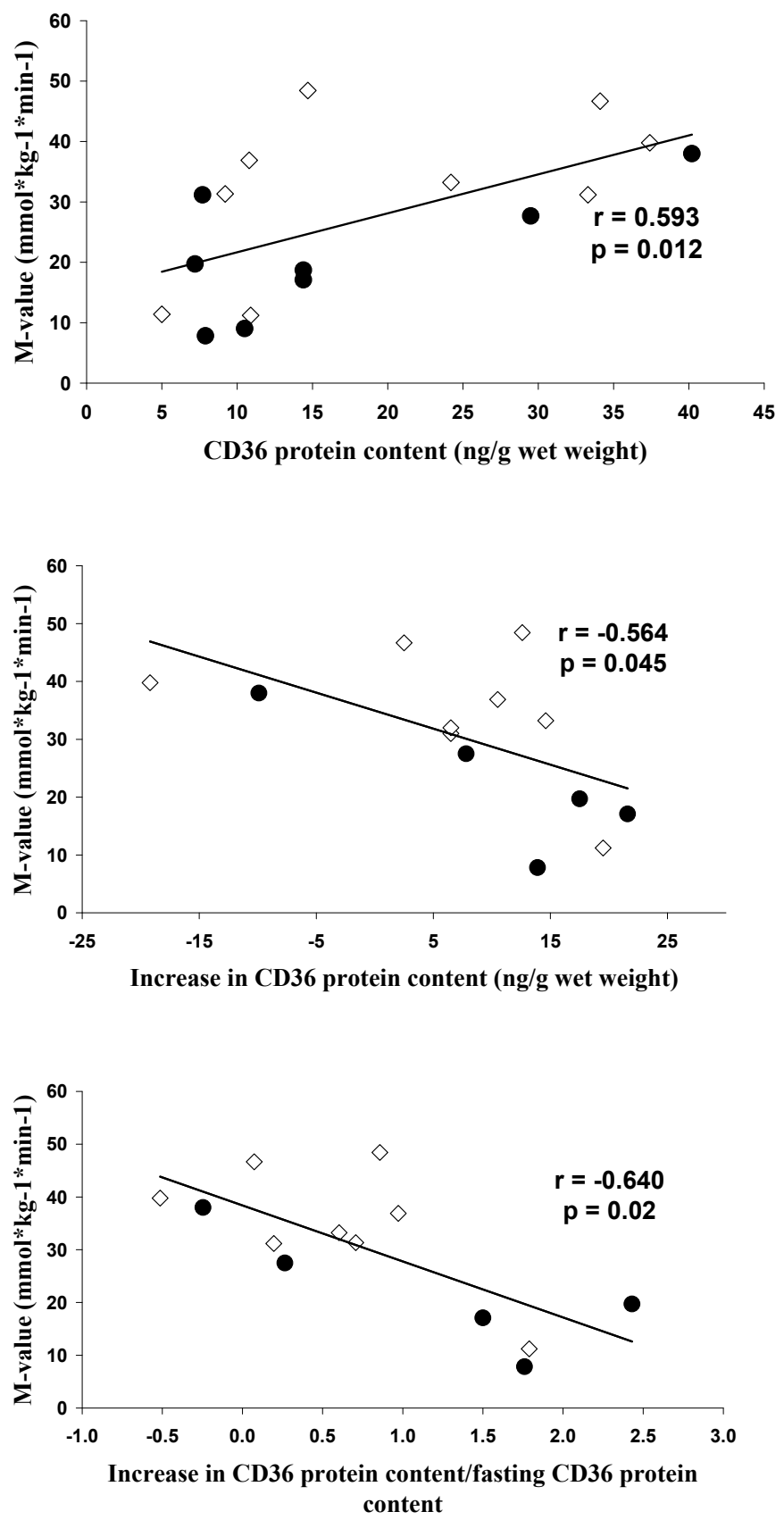

Figure 2A. Relationship between fasting CD36 protein content and insulin sensitivity ( $M-$ value) in obese control men (open diamonds, $n=9$ ) and obese IGT men (filled circles, $n=8$ ).

Figure 2B. Relationship between the increase in CD36 protein content after insulin stimulation and insulin sensitivity (Mvalue) in obese control men (open diamonds, $n=8$ ) and obese IGT men (filled circles, $n=5$ )

Figure 2C. Relationship between the increase in CD36 protein content after insulin stimulation corrected for fasting CD36 protein levels and insulin sensitivity (M-value) in obese control men (open diamonds, $n=$ 8) and obese IGT men (filled circles, $n=5$ )

\section{DISCUSSION}

The major finding of the present study is that insulin very rapidly upregulates the protein expression of CD36 in human skeletal muscle, but did not alter FABPc protein content. To our knowledge, this is the first study to report on CD36 protein content in human skeletal muscle of insulin resistant subjects after in vivo stimulation with insulin. Furthermore, the increase in CD36 protein content was most pronounced in the most insulin resistant subjects. This supports the 
hypothesis that the uptake of plasma FFA into skeletal muscle is not only regulated by insulin at the level of lipolysis in adipose tissue but is actively regulated at the level of skeletal muscle itself and that this regulation may be disturbed in skeletal muscle of insulin resistant subjects.

The changes in CD36 protein content in human skeletal muscle after insulin-stimulation in vivo are supported by rodent studies. In rat cardiomyocytes, insulin mediated an increase in CD36 protein expression, which was preceded by an increase in mRNA expression (21). A large part of the newly synthesized CD36 protein was translocated to the plasma membrane, suggesting that the newly synthesized CD36 may directly contribute to the fatty acid uptake capacity of the muscle cell.

The CD36 protein expression in the postabsorptive state was inversely related to insulin resistance, in other words CD36 protein was reduced in more insulin resistant subjects. This is in accordance with studies that found a reduced fatty acid uptake in fasting human skeletal muscle as measured in vivo with the use of stable isotope techniques $(1,3,18,19,32)$. Interestingly, whereas we found that in the more insulin resistant subjects fasting CD36 protein content was reduced, the insulin-mediated change in CD36 protein content was increased with insulin resistance. This fits well with the findings of Kelley and coworkers who reported that in diabetic patients relative to healthy lean controls, the fasting fatty acid uptake into skeletal muscle was reduced, whereas the insulin-stimulated suppression of fatty acid uptake in the postprandial phase was impaired (1). In addition, the regulation of fat oxidation was found to be impaired in insulin resistant subjects as well $(33,34)$. This led to the hypothesis of 'metabolic flexibility', stating that a mal-adaptation to a new situation, e.g. during insulin stimulation after a meal, could dysregulate the balance between fatty acid uptake and fatty acid oxidation, eventually enhancing the accumulation of IMTG and intermediates of intracellular lipid metabolism (35), which may in turn deteriorate skeletal muscle insulin resistance (5-7). This concept is supported by our own findings that the insulin-stimulated increase in CD36 protein expression was positively related to the change in skeletal muscle lipid content after clamp. Previous studies have shown that in diabetic patients the postprandial suppression of FFA uptake in skeletal muscle was blunted, as mentioned before (1), and the postprandial incorporation of FFA into IMTG was increased (36). Taken together, it is tempting to speculate that in insulin resistant subjects, a large increase in CD36 protein may contribute to this blunted suppression of fatty acid uptake (i.e. the relatively high fatty acid uptake) in the insulin-stimulated condition, enhancing triglyceride storage and further deteriorating insulin resistance in skeletal muscle. However, these findings are still primary and require further confirmation. 


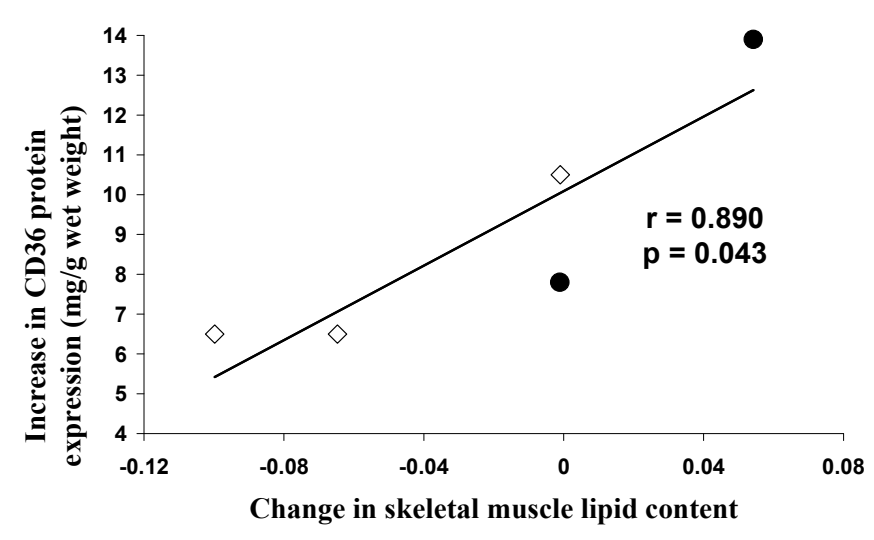

Figure 3. Relationship between the increase in CD36 protein content after insulin stimulation and the change in intramyocellular lipids (lipid stained area fraction) in obese control men (open diamonds, $n=3$ ) and obese IGT men (filled circles, $n=$ 2)

A previous study in which it was suggested that CD36 could be involved in the accumulation of intramyocellular triglycerides was performed by Bonen and coworkers. They investigated the expression of CD36 protein in an ex vivo model using abdominal muscle strips of lean, overweight, obese and overweight diabetic subjects (22). They showed that obesity and diabetes were associated with an increased amount of CD36 protein at the cellular membrane of abdominal muscle biopsies. Fatty acid transport measured with the giant vesicle model showed an approximately 4 -fold increase in fatty acid uptake in the diabetic patients. They reported no differences in total CD36 protein content among lean, overweight, obese and diabetic patients, which is in contrast with the findings in the fasting condition of the present study. The reason for this discrepancy with the literature is not entirely clear, but may be due to differences between the study of Bonen et al. and the present study in type of muscle (abdominal vs vastus lateralis), in characterization of the subjects (lean/obese/diabetic vs insulin resistance with clamp) or conditions at the moment of biopsy sampling, such as the duration of fasting (16-18 hrs vs 10-12 hrs) and being under general anaesthesia or resting in consciousness, respectively. Obviously, further research is required to elucidate the regulation of both protein content and the translocation of CD36 in skeletal muscle in vivo in healthy subjects and DM2.

Differences in CD36 protein content could be related to differences in muscle fibre type or numbers of capillaries in skeletal muscle, since it is known that CD36 is very abundant in capillaries and more abundant in type 1 muscle fibres than in type 2 fibres $(30,37)$. The fibre type composition may in turn be affected by training status. In the present study, the relation between CD36 and insulin resistance could not be explained by differences in fibre type or aerobic capacity $\left(\mathrm{VO}_{2} \mathrm{max}\right)$, since they were both unrelated to $\mathrm{CD} 36$ protein content or insulin sensitivity.

The changes in IMTG and muscle CD36 protein that we observed occur in a relatively short period of time. This makes sense since substrate metabolism in 
skeletal muscle is subject to very rapid changes in energy demand and substrate supply. Rapid reductions in IMTG (up to $-50 \%$ ) have been found after exercise (38), whereas a 6-hr insulin-stimulation combined with high plasma FFA availability resulted in a large change in IMTG, significantly from two hours on, in the soleus muscle $(+20 \%)$ and the tibialis anterior muscle (+64\%) (39). Chabowski and colleagues reported a rapid increase in CD36 protein within 1 hour of insulin stimulation in rat cardiomyocytes (21).

The role of the fatty acid transporter CD36 for net fatty acid uptake into skeletal muscle is not entirely clear yet. As has been known for many years, the insulin-medated suppression of plasma FFA concentrations is an important factor in the regulation of fatty acid uptake. In addition to previous data, the present study supports the idea that fatty acid uptake is also regulated at the level of skeletal muscle itself. Mice that lack CD36 show impairments in fatty acid uptake in particular when the FFA:BSA (bovine serum albumin) ratios are low (11), suggesting that CD36 may be especially important for fatty acid uptake when the FFA concentration is low, as is the case in the postprandial phase. Moreover, the prediabetic state is characterized by impairments in the postprandial phase, thus increasing the relevance of postprandial impairments in the regulation of CD36 for the progression towards DM2.

In summary, insulin rapidly upregulates the protein expression of CD36 in human skeletal muscle. This study confirms that also in humans in vivo, the uptake of plasma FFA into skeletal muscle is actively regulated at the level of skeletal muscle itself. No differences in CD36 protein expression were found between obese prediabetic men and obese control men, although the protein expression of CD36 in the postabsorptive state was reduced in the more insulin resistant subjects. Interestingly, the insulin-induced increase in CD36 protein was increased with insulin resistance, which may enhance the dysbalance between fatty acid uptake and oxidation. This disturbed balance may lead to the storage of triglycerides in skeletal muscle in the postprandial phase, which is associated with insulin resistance. We conclude that the CD36 protein expression in human skeletal muscle in vivo is disturbed in subjects with insulin resistance. 


\section{ACKNOWLEDGEMENTS}

Antibody MO25 was kindly provided by Dr. N. N. Tandon, Otsuka America Pharmaceutical, Inc., Rockville, MD, USA. We would like to thank the volunteers without whom this study would not have been possible. We thank Jos Stegen, Gert Schaart and Joan Senden for their excellent analytical support, Eveline Peeters-Tielen for assistance with the MRS scanning and Judith Huskens and Dorien Mintjes for their practical support. Supported by grants from the Dutch Diabetes Research Foundation (DFN 98.901 and DFN 2000.00.020). JFCG is Netherlands Heart Foundation Professor of Cardiac Metabolism.

\section{REFERENCES}

1 Kelley DE, Simoneau JA 1994 Impaired free fatty acid utilization by skeletal muscle in non-insulin-dependent diabetes mellitus. J Clin Invest 94:2349-2356

2 Blaak EE, van Aggel-Leijssen DP, Wagenmakers AJ, Saris WH, van Baak MA 2000 Impaired oxidation of plasma-derived fatty acids in type 2 diabetic subjects during moderate-intensity exercise. Diabetes 49:2102-2107

3 Turpeinen AK, Takala TO, Nuutila P, Axelin T, Luotolahti M, Haaparanta M, Bergman J, Hamalainen H, Iida H, Maki M, Uusitupa MI, Knuuti J 1999 Impaired free fatty acid uptake in skeletal muscle but not in myocardium in patients with impaired glucose tolerance: studies with PET and 14(R,S)-[18F]fluoro-6-thia-heptadecanoic acid. Diabetes 48:1245-1250

4 Mensink M, Blaak EE, van Baak MA, Wagenmakers AJ, Saris WH 2001 Plasma free Fatty Acid uptake and oxidation are already diminished in subjects at high risk for developing type 2 diabetes. Diabetes 50:2548-2554

5 Pan DA, Lillioja S, Kriketos AD, Milner MR, Baur LA, Bogardus C, Jenkins AB, Storlien LH 1997 Skeletal muscle triglyceride levels are inversely related to insulin action. Diabetes 46:983-988

6 Krssak M, Falk Petersen K, Dresner A, DiPietro L, Vogel SM, Rothman DL, Roden M, Shulman GI 1999 Intramyocellular lipid concentrations are correlated with insulin sensitivity in humans: a 1H NMR spectroscopy study. Diabetologia 42:113-116

7 Schmitz-Peiffer C 2000 Signalling aspects of insulin resistance in skeletal muscle: mechanisms induced by lipid oversupply. Cell Signal 12:583-594

8 Luiken JJ, Schaap FG, van Nieuwenhoven FA, van der Vusse GJ, Bonen A, Glatz JF 1999 Cellular fatty acid transport in heart and skeletal muscle as facilitated by proteins. Lipids 34 Suppl:S169-175 
9 Nozaki S, Tanaka T, Yamashita S, Sohmiya K, Yoshizumi T, Okamoto F, Kitaura Y, Kotake C, Nishida H, Nakata A, Nakagawa T, Matsumoto K, Kameda-Takemura K, Tadokoro S, Kurata Y, Tomiyama Y, Kawamura K, Matsuzawa Y 1999 CD36 mediates long-chain fatty acid transport in human myocardium: complete myocardial accumulation defect of radiolabeled long-chain fatty acid analog in subjects with CD36 deficiency. Mol Cell Biochem 192:129-135

10 Tanaka T, Nakata T, Oka T, Ogawa T, Okamoto F, Kusaka Y, Sohmiya K, Shimamoto K, Itakura K 2001 Defect in human myocardial long-chain fatty acid uptake is caused by FAT/CD36 mutations. J Lipid Res 42:751-759

11 Febbraio M, Abumrad NA, Hajjar DP, Sharma K, Cheng W, Pearce SF, Silverstein RL 1999 A null mutation in murine CD36 reveals an important role in fatty acid and lipoprotein metabolism. J Biol Chem 274:19055-19062

12 Aitman TJ, Glazier AM, Wallace CA, Cooper LD, Norsworthy PJ, Wahid FN, AlMajali KM, Trembling PM, Mann CJ, Shoulders CC, Graf D, St Lezin E, Kurtz TW, Kren V, Pravenec M, Ibrahimi A, Abumrad NA, Stanton LW, Scott J 1999 Identification of CD36 (Fat) as an insulin-resistance gene causing defective fatty acid and glucose metabolism in hypertensive rats. Nat Genet 21:76-83

13 Pravenec M, Landa V, Zidek V, Musilova A, Kren V, Kazdova L, Aitman TJ, Glazier AM, Ibrahimi A, Abumrad NA, Qi N, Wang JM, St Lezin EM, Kurtz TW 2001 Transgenic rescue of defective $\mathrm{Cd} 36$ ameliorates insulin resistance in spontaneously hypertensive rats. Nat Genet 27:156-158

14 Coort SL, Hasselbaink DM, Koonen DP, Willems J, Coumans WA, Chabowski A, van der Vusse GJ, Bonen A, Glatz JF, Luiken JJ 2004 Enhanced sarcolemmal FAT/CD36 content and triacylglycerol storage in cardiac myocytes from obese zucker rats. Diabetes 53:1655-1663

15 Abumrad N, Harmon C, Ibrahimi A 1998 Membrane transport of long-chain fatty acids: evidence for a facilitated process. J Lipid Res 39:2309-2318

16 Glatz JF, Bonen A, Luiken JJ 2002 Exercise and insulin increase muscle fatty acid uptake by recruiting putative fatty acid transporters to the sarcolemma. Curr Opin Clin Nutr Metab Care 5:365-370

17 Pravenec M, Landa V, Zidek V, Musilova A, Kazdova L, Qi N, Wang J, St Lezin E, Kurtz TW 2003 Transgenic expression of CD36 in the spontaneously hypertensive rat is associated with amelioration of metabolic disturbances but has no effect on hypertension. Physiol Res 52:681-688

18 Wilmsen HM, Ciaraldi TP, Carter L, Reehman N, Mudaliar SR, Henry RR 2003 Thiazolidinediones upregulate impaired fatty acid uptake in skeletal muscle of type 2 diabetic subjects. Am J Physiol Endocrinol Metab 285:E354-362 
19 Blaak EE, Wagenmakers AJ, Glatz JF, Wolffenbuttel BH, Kemerink GJ, Langenberg CJ, Heidendal GA, Saris WH 2000 Plasma FFA utilization and fatty acid-binding protein content are diminished in type 2 diabetic muscle. Am J Physiol Endocrinol Metab 279:E146-154

20 Luiken JJ, Koonen DP, Willems J, Zorzano A, Becker C, Fischer Y, Tandon NN, Van Der Vusse GJ, Bonen A, Glatz JF 2002 Insulin stimulates long-chain fatty acid utilization by rat cardiac myocytes through cellular redistribution of FAT/CD36. Diabetes 51:3113-3119

21 Chabowski A, Coort SL, Calles-Escandon J, Tandon NN, Glatz JF, Luiken JJ, Bonen A 2004 Insulin stimulates fatty acid transport by regulating expression of FAT/CD36 but not FABPpm. Am J Physiol Endocrinol Metab 287:E781-789

22 Bonen A, Parolin ML, Steinberg GR, Calles-Escandon J, Tandon NN, Glatz JF, Luiken JJ, Heigenhauser GJ, Dyck DJ 2004 Triacylglycerol accumulation in human obesity and type 2 diabetes is associated with increased rates of skeletal muscle fatty acid transport and increased sarcolemmal FAT/CD36. Faseb J 18:1144-1146

23 World Health Organization 1999 Definition, diagnosis and classification of diabetes mellitus and its complications. Report of a WHO consultation part 1: diagnosis and classification of diabetes mellitus. WHO technical report series:1-59

24 Siri W 1956 The gross composition of the body. Adv Bio Med Physiol 4:239-80

25 Mensink M, Corpeleijn E, Feskens EJ, Kruijshoop M, Saris WH, de Bruin TW, Blaak EE 2003 Study on lifestyle-intervention and impaired glucose tolerance Maastricht (SLIM): design and screening results. Diabetes Res Clin Pract 61:49-58

26 Bergstrom J, Hermansen L, Hultman E, Saltin B 1967 Diet, muscle glycogen and physical performance. Acta Physiol Scand 71:140-150

27 Schrauwen-Hinderling VB, van Loon LJ, Koopman R, Nicolay K, Saris WH and Kooi ME 2003 Intramyocellular lipid content is increased after exercise in nonexercising human skeletal muscle. J Appl Physiol. 95:2328-32

28 Koopman R, Schaart G, Hesselink MK 2001 Optimisation of oil red O staining permits combination with immunofluorescence and automated quantification of lipids. Histochem Cell Biol 116:63-68

29 Pelsers MM, Lutgerink JT, Nieuwenhoven FA, Tandon NN, van der Vusse GJ, Arends JW, Hoogenboom HR, Glatz JF 1999 A sensitive immunoassay for rat fatty acid translocase (CD36) using phage antibodies selected on cell transfectants: abundant presence of fatty acid translocase/CD36 in cardiac and red skeletal muscle and upregulation in diabetes. Biochem J 337 (Pt 3):407-414

30 Keizer HA, Schaart G, Tandon NN, Glatz JF, Luiken JJ 2004 Subcellular immunolocalisation of fatty acid translocase (FAT)/CD36 in human type-1 and type-2 skeletal muscle fibres. Histochem Cell Biol 121:101-107 
31 Wodzig KW, Pelsers MM, van der Vusse GJ, Roos W, Glatz JF 1997 One-step enzymelinked immunosorbent assay (ELISA) for plasma fatty acid-binding protein. Ann Clin Biochem 34 (Pt 3):263-268

32 Blaak EE 2004 Basic disturbances in skeletal muscle fatty acid metabolism in obesity and type 2 diabetes mellitus. Proc Nutr Soc 63:323-330

33 Kelley DE, Goodpaster B, Wing RR, Simoneau JA 1999 Skeletal muscle fatty acid metabolism in association with insulin resistance, obesity, and weight loss. Am J Physiol 277:E1130-1141

34 Blaak EE, Wagenmakers AJ 2002 The fate of [U-(13)C]palmitate extracted by skeletal muscle in subjects with type 2 diabetes and control subjects. Diabetes 51:784-789

35 Kelley DE 2005 Skeletal muscle fat oxidation: timing and flexibility are everything. J Clin Invest 115:1699-1702

36 Ravikumar B, Carey PE, Snaar JE, Deelchand DK, Cook DB, Neely RD, English PT, Firbank MJ, Morris PG, Taylor R 2005 Real-time assessment of postprandial fat storage in liver and skeletal muscle in health and type 2 diabetes. Am J Physiol Endocrinol Metab 288:E789-797

37 Vistisen B, Roepstorff K, Roepstorff C, Bonen A, van Deurs B, Kiens B 2004 Sarcolemmal FAT/CD36 in human skeletal muscle colocalizes with caveolin-3 and is more abundant in type 1 than in type 2 fibers. J Lipid Res 45:603-609

38 Watt MJ, Heigenhauser GJ, Spriet LL 2002 Intramuscular triacylglycerol utilization in human skeletal muscle during exercise: is there a controversy? J Appl Physiol 93:11851195

39 Bachmann OP, Dahl DB, Brechtel K, Machann J, Haap M, Maier T, Loviscach M, Stumvoll M, Claussen CD, Schick F, Haring HU, Jacob S 2001 Effects of intravenous and dietary lipid challenge on intramyocellular lipid content and the relation with insulin sensitivity in humans. Diabetes 50:2579-2584 



\section{CHAPTER 5}

\section{Direct association of a promoter polymorphism in the CD36/FAT fatty acid transporter gene with diabetes mellitus type 2 and insulin resistance}

E. Corpeleijn (1), C.J.H. van der Kallen (2), M. Kruijshoop (2), M.G.P. Magagnin (1), T.W.A. de Bruin (2), E.J.M. Feskens (3), W.H.M. Saris (1), E.E. Blaak (1)

(1) Department of Human Biology, the Nutrition and Toxicology Research Institute NUTRIM, Maastricht University, Maastricht, The Netherlands

(2) Department of Medicine and Endocrinology, Cardiovascular Research Institute CARIM, University Hospital Maastricht, Maastricht, The Netherlands

(3) Department of Health and Nutrition, National Institute for Public Health and the Environment, Bilthoven, The Netherlands 


\begin{abstract}
Aims: The membrane-bound fatty acid transporter CD36/FAT may play a role in disturbed fatty acid handling as observed in the metabolic syndrome and diabetes mellitus type 2 (DM2). Genetic variation in the CD36 gene may contribute to the aetiology of diabetes.

Methods: A population based cohort in the Netherlands (age $>40$ years and body mass index $(\mathrm{BMI})>25 \mathrm{~kg} / \mathrm{m}^{2}$ ) of 675 subjects was phenotyped with respect to glucose metabolism with an oral glucose tolerance test and was genotyped for a known $478 \mathrm{C} \rightarrow \mathrm{T}$ substitution and a $\mathrm{C} / \mathrm{T}$ snp in the upstream promoter region (rs1527479) in the CD36 gene.

Results: DM2 was more prevalent in the TT genotype than in the CC genotype. This was most pronounced in women and in the subjects with a high BMI (BMI > $27 \mathrm{~kg} / \mathrm{m}^{2}$ ). In addition, within the group of diabetic patients, the TT genotype was commoner in subjects with increased homeostasis model assesment (HOMA) index for insulin resistance. The $478 \mathrm{C} \rightarrow \mathrm{T}$ substitution, previously found in the Japanese population, was not found in our caucasian population.

Conclusions: This is the first study to show a direct association of a CD36 snp with DM2. Moreover, within the diabetic subjects, this CD36 snp was associated with insulin resistance (HOMA index).
\end{abstract}




\section{INTRODUCTION}

Conditions characterized by insulin resistance are accompanied by disturbances in fatty acid metabolism, e.g. a reduced capacity to take up and oxidize fatty acids in skeletal muscle during postabsorptive conditions, during $\beta$-adrenergic stimulation [1] and exercise [2]. In particular modifications in expression and protein level of CD36/fatty acid transporter have been associated with disturbed uptake of free fatty acids [3, 4] and insulin resistance [5-8]. It has been suggested that disturbances in cellular fatty acid transport could contribute to storage of intramyocellular triacylglycerol in skeletal muscle, enhancing insulin resistance and type 2 diabetes mellitus (DM2) [9]. Interestingly, the positive effect of thiazolidinediones on insulin sensitivity and DM2 may be mediated in part by increased CD36 mRNA and protein expression in skeletal muscle cells [10].

Information on the genetic variability in the CD36/FAT gene in DM2 is still sparse. So far, one study has shown a rare non-sense mutation in the CD36 gene in a French family with autosomal dominant diabetes [11]. Another study has found three mutations in the CD36 gene that were associated with low adiponectin concentrations, which may reflect an positive association with insulin resistance [12]. However, untill now no direct association of a CD36 polymorphism with diabetes was found in the general population. Here, we report the result of an investigation of two polymorphisms in the CD36 gene that have not been related to impaired glucose tolerance (IGT) and/or insulin resistance previously.

\section{METHODS}

\section{Study subjects}

All participants were selected from a large population-based cohort, monitored for health and disease by the National Institute for Public Health and the Environment [13]. The subjects participated in random screening for disturbances in glucose tolerance as previously described [14, 15]. Inclusion criteria were age $>40$ years for all subjects and, in addition, at least one of the following criteria: BMI $>25 \mathrm{~kg} / \mathrm{m}^{2}$; a positive family history of diabetes; a history of gestational diabetes and/or glucosuria; and known DM2. Exclusion criteria were non-caucasian ethnicity, the use of insulin therapy and the use of thyroid hormones. Subsequently, subjects participated in the Study on Lifestyleintervention and Impaired glucose tolerance Maastricht (SLIM) or in the Cohort study of Diabetes and Atherosclerosis Maastricht (CoDAM) [14, 15]. The study 
was approved by the local Medical Ethical Committee of the Maastricht University. All subjects gave written informed consent.

\section{Phenotypic characterization}

After an overnight fast, subjects underwent a standard 75-g oral glucose tolerance test (OGTT) with venous blood sampling and were characterized for glucose tolerance according to the World Health Organization criteria of 1999 [16]. After the OGTT, body weight $(\mathrm{kg})$ and height $(\mathrm{m})$ were measured to calculate BMI. Waist and hip circumference were measured to calculate waist-hip ratio (WHR). Blood pressure was measured twice with a standard sphygmomanometer after 15 minutes of rest in supine position. Family history of diabetes was assessed with a questionnaire. All plasma glucose concentrations were measured with the hexokinase glucose-6-phosphate dehydrogenase method (HK-G6PD method, ABX Diagnostics Glucose HK 125, Montpellier, France). In the SLIM-study, plasma insulin concentration was measured with an ELISA assay (Mercodia, Uppsala, Sweden), which shows no cross-reactivity with pro-insulin. In the CODAM-study, plasma insulin concentration was measured with a two-sided immunoradiometric test, using paired monoclonal antibodies (Medgenix Diagnostics, Fleurus, Belgium). Insulin sensitivity (HOMA-IR) and $\beta$-cell function (HOMA- $\beta$ cell) were estimated with HOMA indices [17].

\section{CD36 polymorphisms}

Two CD36 single nucleotide polymorphisms (snp), which had not yet been associated with DM2, were selected. DNA was isolated from buffy coats with a QIAamp DNA Blood Mini Kit (Qiagen, Hilden, Germany). Genotypes of the C/T single nucleotide polymorphism rs1527479 in the upstream promoter region (VEGA gene ID OTTHUMG00000023490, intron 1B, -3489 bp relative to the translation start site) of the CD36 gene were identified from AlwNI digested fragments of polymerase chain reaction (PCR)-amplified products with the forward primer 5'-TAGAGAGGGAGCCATTGGAG-3' and reverse primer 5'TTTGCAACTCTGACAAATGTGAT-3'. Genotypes of the $478 \mathrm{C} \rightarrow \mathrm{T}$ substitution [18] were identified from ECO01091 digested fragments of PCR-amplified products with the forward primer 5'-CTGACTCAAGGCTGCAAACA-3' and reverse primer 5'-TTAGGATTCTATACAGACAGGAAAA-3'. Of each genotype, PCR products of randomly chosen samples were verified by direct sequencing with a 310 Genetic Analyzer (ABI Prism, Applied Biosystems, Nieuwekerk a/d IJssel, The Netherlands). 
Table 5.1. Characteristics of subjects with normal glucose tolerance (NGT), impaired glucose tolerance (IGT) or type 2 diabetes mellitus (DM2).

\begin{tabular}{lccc}
\hline & $\begin{array}{c}\text { NGT } \\
(\mathrm{n}=308)\end{array}$ & $\begin{array}{c}\text { IGT } \\
(\mathrm{n}=216)\end{array}$ & $\begin{array}{c}\text { DM2 } \\
(\mathrm{n}=151)\end{array}$ \\
\hline Age $(\mathrm{yrs})$ & $58.1 \pm 7.4$ & $57.9 \pm 7.2$ & $60.3 \pm 6.2^{*} \dagger$ \\
Men $(\%)$ & $61 \%$ & $52 \%^{*}+$ & $66 \%$ \\
BMI $\left(\mathrm{kg} / \mathrm{m}^{2}\right)$ & $27.8 \pm 4.0$ & $29.3 \pm 3.8^{*}$ & $30.4 \pm 4.6^{*} \dagger$ \\
Fasting glucose $(\mathrm{mmol} / \mathrm{l})$ & $5.3 \pm 0.4$ & $5.8 \pm 0.5^{*}$ & $8.0 \pm 1.8^{*} \dagger$ \\
2-hr glucose $(\mathrm{mmol} / \mathrm{l})$ & $5.6 \pm 1.2$ & $8.9 \pm 1.6^{*}$ & $13.0 \pm 3.4 * \dagger$ \\
Body fat $(\%)$ & $31.2 \pm 7.1$ & $36.9 \pm 6.8^{*}$ & $36.0 \pm 6.3 * \dagger$ \\
Waist-hip ratio & $0.94 \pm 0.08$ & $0.97 \pm 0.08^{*}$ & $0.99 \pm 0.07 * \dagger$ \\
\hline
\end{tabular}

Mean \pm SD. * $\mathrm{p}<0.05$ for the comparison with NGT subjects; $\uparrow \mathrm{p}<0.05$ for the comparison with IGT subjects; $\ddagger$ $\mathrm{p}<0.05$ for the comparison with DM2 subjects; one-way ANOVA.

\section{Statistical methods}

Differences in genotype frequencies were tested with a $\chi 2$ test, using the normal glucose-tolerant subjects as the reference group. Insulin and indices of insulin secretion and sensitivity calculated from the insulin concentration were lntransformed to obtain normal distributions. The differences in parameters between the genotype groups (TT vs CT vs CC) were tested using multivariate analysis of variance with adjustment for age, gender and BMI. The data are presented as mean \pm SD. A value of $p<0.05$ was considered to be statistically significant. Hardy-Weinberg equilibrium was tested in the overall group. SPSS version 10.0 for Macintosh was used (SPSS Inc., Chicago, IL, USA).

\section{RESULTS}

Of the included subjects $(n=675), 308$ were normal glucose tolerant (NGT), 216 had IGT and 151 had DM2, of whom 61 were newly diagnosed, 11 were recently diagnosed ( $<1$ year), 34 had had diabetes for 1-4 years and 45 had had diabetes for $>4$ years. Subject characteristics are give in Table 5.1. For the C/T promoter polymorphism (rs1527479), the allele frequencies in the overall group were 0.464 and 0.536 for the $\mathrm{T}$ and $\mathrm{C}$ alleles, respectively. The alleles were in Hardy-Weinberg equilibrium. The frequency of the TT genotype was higher in the DM2 $(26.5 \%, \mathrm{p}=$ $0.035)$ and in the IGT subjects $(24.1 \%, \mathrm{p}=0.020)$ than in the NGT subjects $(19.5 \%)$ (Table 5.2.). No differences were found in age, gender or BMI between the different genotypes (table 5.3.). Notably, the TT genotype subjects had significantly higher fasting glucose concentrations and HOMA-IR than the CT and CC genotype 
Table 5.2. Distribution of genotype frequencies of the $\mathrm{CD36} \mathrm{C} / \mathrm{T}$ promoter polymorphism (rs1527479) in the different categories of glucose tolerance (WHO 1999).

\begin{tabular}{lccc}
\hline & NGT & IGT & DM2 \\
$(\mathrm{n}=308)$ & $(\mathrm{n}=216)$ & $(\mathrm{n}=151)$ \\
\hline CC genotype & $26.6 \%$ & $31.5 \%$ & $29.1 \%$ \\
CT genotype & $53.9 \%$ & $44.4 \%$ & $44.4 \%$ \\
TT genotype & $19.5 \%$ & $24.1 \% *$ & $26.5 \% \dagger$ \\
\hline
\end{tabular}

Data are given as percentages within the glucose tolerance groups. The frequency distributions were compared with a multiple Chi-square test. $* p=0.020$ for the comparison with NGT subjects; $\uparrow \mathrm{p}=0.035$ for the comparison with NGT subjects.

subjects, which persisted after adjustment for age, gender and BMI (Table 5.3.). In addition, we found that within the group of DM2 patients, those with the TT genotype had a significantly higher HOMA index for insulin resistance (TT $=4.55$ $\pm 1.88(\mathrm{n}=40), \mathrm{CT}=4.56 \pm 1.94(\mathrm{n}=66)$ and $\mathrm{CC}=4.02 \pm 1.98(\mathrm{n}=44), \mathrm{p}=0.02)$. Fasting glucose concentrations were not significantly different. No association was found between genotype and family history of DM2, blood pressure, WHR, fasting plasma free fatty acids, triglycerides, total cholesterol, low-density lipoprotein (LDL)-cholesterol or high-density lipoprotein (HDL)-cholesterol (data not presented).

Additional interactions were assessed for BMI and gender with genotype. In subjects with a $\mathrm{BMI}>27 \mathrm{~kg} / \mathrm{m}^{2}\left(\mathrm{BMI}=30.9 \pm 3.6 \mathrm{~kg} / \mathrm{m}^{2}, \mathrm{n}=444\right)$, the TT genotype was more frequent in DM2 patients $(27.0 \%, \mathrm{p}=0.005)$ and in IGT $(22.7 \%$, $\mathrm{p}=0.008)$ than in NGT $(16.5 \%)$. This was reflected in the TT genotype subjects by a higher fasting blood glucose concentration and a higher HOMA-IR than in the CT and CC subjects (fasting glucose $6.6 \pm 1.7,6.2 \pm 1.5$ and $6.2 \pm 1.3 \mathrm{mmol} / \mathrm{l}$, respectively, $p<0.05$; HOMA.IR $3.33 \pm 1.90,2.89 \pm 1.87$ and $3.04 \pm 1.84$, respectively, $\mathrm{p}<0.05)$. No differences were found in subjects with a $\mathrm{BMI} \leq 27$ $\mathrm{kg} / \mathrm{m}^{2}\left(\mathrm{BMI}=24.8 \pm 1.8 \mathrm{~kg} / \mathrm{m}^{2}, \mathrm{n}=230\right)$. The relation between the CD36 polymorphism and diabetes depended not only on BMI, but also on gender. In women $(n=276)$, the TT genotype was more frequent in DM2 patients $(30.8 \%, p=$ $0.005)$ and in IGT $(25.2 \%, \mathrm{p}=0.004)$ than in NGT $(14.9 \%)$, whilst in men $(\mathrm{n}=399)$ no significant differences were seen. The TT genotype, compared with the CC genotype, was related to a higher fasting glucose concentration in both women $(6.2 \pm 1.6$ vs $5.7 \pm 0.9 \mathrm{mmol} / \mathrm{l}, \mathrm{p}<0.05)$ and men $(6.3 \pm 1.5$ vs $6.2 \pm 1.3 \mathrm{mmol} / \mathrm{l}, \mathrm{p}<$ $0.05)$, but to an increased postload blood glucose concentration only in women $(9.1$ \pm 3.9 vs $7.7 \pm 2.6 \mathrm{mmol} / \mathrm{l}, \mathrm{p}<0.05)$. The CT genotype showed an intermediate phenotype. For gender, no associations were found between genotype and WHR, or fasting concentrations of free fatty acids, triglycerides, total cholesterol, HDL cholesterol or LDL cholesterol (data not presented). A random selection of 199 
Table 5.3. Characteristics of the TT, CT and CC genotypes of the C/T promoter polymorphism (rs1527479) in the CD36 gene.

\begin{tabular}{lccc}
\hline & TT & CT & CC \\
& $(\mathrm{n}=152 ; 22.5 \%)$ & $(\mathrm{n}=329 ; 48.7 \%)$ & $(\mathrm{n}=194,28.7 \%)$ \\
\hline DM2(\%) & 26.3 & 20.4 & 22.7 \\
Men (\%) & 61 & 57 & 62 \\
Age (years) & $57.8 \pm 7.6$ & $58.7 \pm 7.2$ & $58.9 \pm 6.5$ \\
BMI (kg/m $\left.{ }^{2}\right)$ & $28.7 \pm 4.3$ & $28.8 \pm 4.2$ & $29.0 \pm 4.2$ \\
Waist-to-hip ratio & $0.96 \pm 0.07$ & $0.96 \pm 0.07$ & $0.96 \pm 0.07$ \\
Fasting glucose (mmol/l) & $6.3 \pm 1.5^{*}$ & $6.0 \pm 1.4$ & $6.0 \pm 1.2$ \\
2-hr glucose (mmol/l) & $8.4 \pm 3.6$ & $7.8 \pm 3.3$ & $8.0 \pm 3.1$ \\
Fasting insulin (mU/l) & $9.9 \pm 1.7$ & $9.3 \pm 1.7$ & $9.6 \pm 1.7$ \\
HOMA-IR & $2.62 \pm 1.90^{*}$ & $2.41 \pm 1.91$ & $2.52 \pm 1.85$ \\
HOMA- $\beta$ cell & $77.8 \pm 1.7$ & $84.3 \pm 1.7$ & $84.9 \pm 1.7$ \\
\hline
\end{tabular}

Mean \pm SD. All parameters except for age, $\%$ men and BMI are corrected for age, gender and BMI in the Multivariate Analysis of Variance. ${ }^{*} \mathrm{p}<0.05$ for the comparison with the other two genotypes.

subjects from the database was screened for the $478 \mathrm{C} \rightarrow \mathrm{T}$ substitution. All subjects proved to be homozygote wildtypes (CC), showing that the $\mathrm{T}$ allele was not prevalent or very rare in this caucasian population ( $\mathrm{T}$ allele frequency $<0.005$ ).

\section{DISCUSSION}

In the present study, we have demonstrated for the first time that the TT genotype of a promoter polymorphism in the CD36 gene was related to higher fasting glucose concentrations, insulin resistance and DM2. Interestingly, the relation between the promoter polymorphism in the CD36 gene and diabetes was most pronounced in the more overweight subjects (BMI $>27 \mathrm{~kg} / \mathrm{m}^{2}$ ) and in women. This suggests an unfavourable interaction of the $\mathrm{T}$ allele of the CD36 polymorphism rs1527479 with gender and BMI, factors known to modify the risk of DM2. We suggest that the CD36 gene is a modifier gene in the polygenic aetiology of DM2 and regard the TT genotype as disadvantageous.

Evidence from literature clearly shows that modifications in the CD36 gene expression or protein content are related to insulin resistance, probably through its contribution to a disturbed fatty acid metabolism. For example, at least two strains of the spontaneous hypertensive rat (SHR-TG10 and SHR-TG19), a model for the metabolic syndrome, have a spontaneous deletion in CD36. Transgenic rescue of the CD36 gene in the rat genome specifically restored insulin sensitivity $[7,19]$. Wilmsen and coworkers [10] showed that ex vivo treatment of human skeletal muscle fibres of DM2 patients with thiazolidinediones, which are insulin-sensitising drugs, restored protein-mediated palmitate uptake. This was 
strongly associated with upregulation of CD36 expression [10], suggesting that CD36 may mediate part of the insulin-sensitising effects of thiazolidinediones. The exact functionality of the $\mathrm{C} / \mathrm{T}$ polymorphism in our study is not yet known. Since the studied C/T polymorphism is a polymorphism in the upstream promoter region of CD36, it suggests that either transcription or alternative splicing may be involved, altering the amount or function of the CD36 protein. Alternatively, this polymorphism may be in linkage disequilibrium with a coding polymorphism located elsewhere in the CD36 gene or in another gene located nearby the CD36 gene on chromosome 7q11.2.

Studies on the relation between CD36 gene polymorphisms and insulin resistance in humans are still sparse. A recent French study revealed a rare nonsense mutation in the CD36 gene in a French family with a strong history of DM2 [11], indicating that mutations in CD36 gene per se may play a role in the aetiology of DM2. A very recent study in Italian men has shown that a haplotype of five CD36 polymorphisms was associated with increased plasma free fatty acids, but not with glucose metabolism [20]. However, all subjects with glucose $\geq$ $7.0 \mathrm{mmol} / 1$ were excluded, possibly masking an association of variation in the CD36 gene with diabetes. Recently, Lepretre and coworkers showed that three mutations in the CD36 gene were associated with adiponectin concentrations, which may reflect an association with insulin resistance [12]. So far, no common snp has been associated directly to diabetes. In our study, we find that subjects with the TT genotype have a higher prevalence of diabetes, a finding which was significant and very consistent in the overall group as well as in the subgroups. In addition, within the group of diabetic patients, the TT genotype was also associated with higher insulin resistance, even with a relatively low number of subjects. Our study is the first to show a direct association of a common CD36 polymorphism with diabetes in the general population and within the diabetic population with insulin resistance.

The $478 \mathrm{C} \rightarrow \mathrm{T}$ substitution in the CD36 gene is the most common polymorphism associated with CD36 deficiency in Japanese patients with heart disease [4, 18]. It has been suggested that CD36 deficiency is related to insulin resistance in the Japanese population [21]. However, in our study none of the randomly selected caucasian subjects carried this $478 \mathrm{C} \rightarrow \mathrm{T}$ substitution.

According to the hypothesis of the thrifty genotype, the expressed phenotype of a certain genotype may be dependent of the environment [22]. Our results show that the TT genotype of the CD36 promoter polymorphism has a stronger association with diabetes in obese subjects. An increased BMI in general is associated with increased insulin resistance and increased plasma concentrations of free fatty acids and triglycerides [23]. It is possible that an alteration in the CD36 protein structure or amount contributes more to disturbances in fat and glucose 
metabolism when the body is physiologically burdened, i.e. in the more obese person. Another modifier was gender. It remains difficult to explain why the results were more pronounced in women. Gale has suggested that women have a genetically determined 'female insulin advantage', defined as a comparable insulin sensitivity with higher adipose tissue mass, partly protecting women from metabolic disadvantages caused by obesity [24]. An unfavourable genetic background may reduce this 'female insulin advantage' and make women of the CD36 TT genotype relatively more vulnerable for the development of insulin resistance. There are also indications that the basal fat oxidation is lower in females than in males [25]. This may make women more prone to the storage of triglycerides in non-adipose tissue when the balance between fatty acid oxidation and fatty acid uptake is disturbed. However, this needs confirmation by future studies.

In conclusion, we show a direct association of the TT genotype of the CD36 promoter snp rs1527479 with the presence of DM2 in subjects from a caucasian population at risk for the metabolic syndrome. This is most evident in women and in obese subjects. These data suggest that genetic variability in the fatty acid transporter CD36 can play a role in the aetiology of DM2 by modifying the susceptibility to DM2.

\section{ACKNOWLEDGEMENTS}

Supported by grants from the Dutch Diabetes Research Foundation (DFN 98.901 and DFN 2000.00.020) and from the Netherlands Organization for Scientific Research (ZonMW 940-35-034). We thank Jos Stegen, Tanja Hermans-Limpens, Ilse Nijs, Ellen H. Lambrichs, Vicky Vermeulen and Margee Robertus-Theunissen for their excellent analytical and practical support.

\section{REFERENCES}

1 Blaak EE, Wagenmakers AJ, Glatz JF, Wolffenbuttel BH, Kemerink GJ, Langenberg CJ, Heidendal GA, Saris WH. Plasma FFA utilization and fatty acid-binding protein content are diminished in type 2 diabetic muscle. Am J Physiol Endocrinol Metab 2000; 279: E146-54.

2 Mensink M, Blaak EE, van Baak MA, Wagenmakers AJ, Saris WH. Plasma free Fatty Acid uptake and oxidation are already diminished in subjects at high risk for developing type 2 diabetes. Diabetes 2001; 50: 2548-54. 
Nozaki S, Tanaka T, Yamashita S, Sohmiya K, Yoshizumi T, Okamoto F, Kitaura Y, Kotake C, Nishida H, Nakata A, Nakagawa T, Matsumoto K, Kameda-Takemura K, Tadokoro S, Kurata Y, Tomiyama Y, Kawamura K, Matsuzawa Y. CD36 mediates long-chain fatty acid transport in human myocardium: complete myocardial accumulation defect of radiolabeled long-chain fatty acid analog in subjects with CD36 deficiency. Mol Cell Biochem 1999; 192: 129-35.

Tanaka T, Nakata T, Oka T, Ogawa T, Okamoto F, Kusaka Y, Sohmiya K, Shimamoto K, Itakura K. Defect in human myocardial long-chain fatty acid uptake is caused by FAT/CD36 mutations. J Lipid Res 2001; 42: 751-9.

Febbraio M, Abumrad NA, Hajjar DP, Sharma K, Cheng W, Pearce SF, Silverstein RL. A null mutation in murine CD36 reveals an important role in fatty acid and lipoprotein metabolism. J Biol Chem 1999; 274: 19055-62.

Aitman TJ, Glazier AM, Wallace CA, Cooper LD, Norsworthy PJ, Wahid FN, Al-Majali KM, Trembling PM, Mann CJ, Shoulders CC, Graf D, St Lezin E, Kurtz TW, Kren V, Pravenec M, Ibrahimi A, Abumrad NA, Stanton LW, Scott J. Identification of Cd36 (Fat) as an insulinresistance gene causing defective fatty acid and glucose metabolism in hypertensive rats. Nat Genet 1999; 21: 76-83.

7 Pravenec M, Landa V, Zidek V, Musilova A, Kren V, Kazdova L, Aitman TJ, Glazier AM, Ibrahimi A, Abumrad NA, Qi N, Wang JM, St Lezin EM, Kurtz TW. Transgenic rescue of defective $\mathrm{Cd} 36$ ameliorates insulin resistance in spontaneously hypertensive rats. Nat Genet 2001; 27: 156-8.

Coort SL, Hasselbaink DM, Koonen DP, Willems J, Coumans WA, Chabowski A, van der Vusse GJ, Bonen A, Glatz JF, Luiken JJ. Enhanced sarcolemmal FAT/CD36 content and triacylglycerol storage in cardiac myocytes from obese zucker rats. Diabetes 2004; 53: 1655-63.

Schmitz-Peiffer C. Signalling aspects of insulin resistance in skeletal muscle: mechanisms induced by lipid oversupply. Cell Signal 2000; 12: 583-594.

10 Wilmsen HM, Ciaraldi TP, Carter L, Reehman N, Mudaliar SR, Henry RR. Thiazolidinediones upregulate impaired fatty acid uptake in skeletal muscle of type 2 diabetic subjects. Am J Physiol Endocrinol Metab 2003; 285: E354-62.

Lepretre F, Vasseur F, Vaxillaire M, Scherer PE, Ali S, Linton K, Aitman T, Froguel P. A CD36 nonsense mutation associated with insulin resistance and familial type 2 diabetes. Hum Mutat 2004; $24: 104$.

Lepretre F, Linton KJ, Lacquemant C, Vatin V, Samson C, Dina C, Chikri M, Ali S, Scherer P, Seron K, Vasseur F, Aitman T, Froguel P. Genetic study of the CD36 gene in a French diabetic population. Diabetes Metab 2004; 30: 459-63.

13 van Dam RM, Boer JM, Feskens EJ, Seidell JC. Parental history of diabetes modifies the association between abdominal adiposity and hyperglycemia. Diabetes Care 2001; 24: 1454-9.

14 Mensink M, Corpeleijn E, Feskens EJ, Kruijshoop M, Saris WH, de Bruin TW, Blaak EE. Study on lifestyle-intervention and impaired glucose tolerance Maastricht (SLIM): design and screening results. Diabetes Res Clin Pract 2003; 61: 49-58.

Kruijshoop M, Feskens EJ, Blaak EE, de Bruin TW. Validation of capillary glucose measurements to detect glucose intolerance or type 2 diabetes mellitus in the general population. Clin Chim Acta 2004; 341: 33-40. 
World Health Organization. Definition, diagnosis and classification of diabetes mellitus and its complications. Report of a WHO consultation part 1: diagnosis and classification of diabetes mellitus. WHO technical report series 1999, 1-59.

17 Matthews DR, Hosker JP, Rudenski AS, Naylor BA, Treacher DF, Turner RC. Homeostasis model assessment: insulin resistance and beta-cell function from fasting plasma glucose and insulin concentrations in man. Diabetologia 1985; 28: 412-9.

18 Kashiwagi H, Tomiyama Y, Nozaki S, Kiyoi T, Tadokoro S, Matsumoto K, Honda S, Kosugi S, Kurata Y, Matsuzawa Y. Analyses of genetic abnormalities in type I CD36 deficiency in Japan: identification and cell biological characterization of two novel mutations that cause CD36 deficiency in man. Hum Genet 2001; 108: 459-66.

19 Pravenec M, Landa V, Zidek V, Musilova A, Kazdova L, Qi N, Wang J, St Lezin E, Kurtz TW. Transgenic expression of CD36 in the spontaneously hypertensive rat is associated with amelioration of metabolic disturbances but has no effect on hypertension. Physiol Res 2003; 52: 681-8.

20 Ma X, Bacci S, Mlynarski W, Gottardo L, Soccio T, Menzaghi C, Iori E, Lager RA, Shroff AR, Gervino EV, Nesto RW, Johnstone MT, Abumrad NA, Avogaro A, Trischitta V, Doria A. A common haplotype at the CD36 locus is associated with high free fatty acid levels and increased cardiovascular risk in Caucasians. Hum Mol Genet 2004; 13: 2197-205.

21 Furuhashi M, Ura N, Nakata T, Shimamoto K. Insulin sensitivity and lipid metabolism in human CD36 deficiency. Diabetes Care 2003; 26: 471-4.

22 Stannard SR, Johnson NA. Insulin resistance and elevated triglyceride in muscle: more important for survival than "thrifty" genes? J Physiol. 2004; 554: 595-607.

23 Arner P. Insulin resistance in type 2 diabetes: role of fatty acids. Diabetes Metab Res Rev 2002; 18 Suppl 2: S5-9.

24 Gale EA, Gillespie KM. Diabetes and gender. Diabetologia 2001; 44: 3-15.

25 Blaak EE. Gender differences in fat metabolism. Curr Opin Clin Nutr Metab Care 2001; 4: 499502.

Picture: Design by Leendert Jan Vis @ gebruikt met toestemming van Paperclip International @

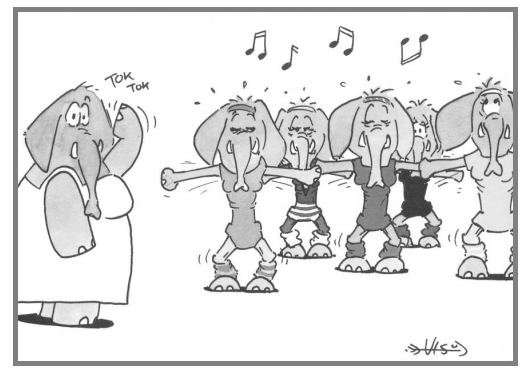





\section{CHAPTER 6}

\section{Postprandial Interleukin-6 Release from Skeletal Muscle in Men with Impaired Glucose Tolerance can be Reduced by Weight Loss}

Eva Corpeleijn (1), Wim H. M. Saris (1), Eugène H.J.M. Jansen (2), Paul M.H.J. Roekaerts (3), Edith J. M. Feskens (4), Ellen E. Blaak (1)

From the (1) Department of Human Biology, the Nutrition and Toxicology Research Institute NUTRIM, Maastricht University, Maastricht, The Netherlands (2) the Laboratory for Toxicology, Pathology and Genetics, National Institute for Public Health and the Environment, Bilthoven, The Netherlands

(3) the Department of Anesthesiology, University Hospital Maastricht, Maastricht, The Netherlands

(4) the Centre for Nutrition and Health, National Institute for Public Health and the Environment, Bilthoven, The Netherlands 


\begin{abstract}
Context: Obesity and type 2 diabetes mellitus are associated with increased levels of interleukin-6 (IL-6), a marker of inflammation.

Objective: This study addressed the question of whether IL-6 was released from skeletal muscle after a high fat meal in men with impaired glucose tolerance (IGT), a prediabetic state, and whether IL-6 release could be reduced by weight loss.

Design: Skeletal muscle metabolism was studied in men with IGT $(\mathrm{n}=11)$ and compared to men with normal glucose tolerance (NGT, $n=9$ ), matched for BMI and age. IL-6 flux over skeletal muscle was measured with the forearm model. Eight IGT men were willing to participate in a 12-week weight loss program and were tested again.

Results: IL-6, but not C-reactive protein, tumor necrosis factor-alfa receptor 1 and 2 , was released by skeletal muscle. Muscle IL-6 release was higher in IGT than in NGT, during fasting (IGT $=2.26 \pm 1.89$ vs NGT $=0.87 \pm 0.48 \mathrm{fmol}^{*} 100 \mathrm{ml}$ tissue${ }^{1 *} \mathrm{~min}^{-1}, \mathrm{p}=0.04$ ) and after a meal (mean area under the curve/minute: IGT $=3.48 \pm$ 2.63 vs NGT $=1.37 \pm 0.75 \mathrm{fmol}^{*} 100 \mathrm{ml}$ tissue ${ }^{-1 *} \mathrm{~min}^{-1}, \mathrm{p}=0.03$ ). In the IGT men, body weight loss resulted in a decrease of postprandial IL-6 release from skeletal muscle $(-52 \%, p=0.04)$, reaching levels of the obese, NGT controls.

Conclusion: The present data suggest that a high fat meal can evoke IL-6 release from muscle and that the IL- 6 release is a consequence rather than a cause of the obese, insulin resistant and/or impaired glucose tolerant state.
\end{abstract}




\section{INTRODUCTION}

Obesity and type 2 diabetes mellitus (DM2) have been associated with sub-clinical inflammation. Markers of inflammation, like the cytokine interleukin-6 (IL-6) and the acute-phase protein C-Reactive Protein (CRP) are elevated in obese, insulin resistant subjects $(1,2,3)$. Also TNF- $\alpha$ receptors, as markers for TNF- $\alpha$ action (4), and to a lesser extent TNF- $\alpha$ itself, have been found to be elevated in patients with DM2 (3) and in some studies also in subjects with impaired glucose tolerance (IGT), a prediabetic state (5). IL-6 is a cytokine that is produced by many cell types and is increased in cancer cachexia (6), after endotoxin stimulation (7) and after vaccination (8). IL-6 is also increased in obesity, insulin resistance and DM2, and plasma IL-6 has been shown to be predictive of the development of DM2 in several prospective studies $(9,10)$. So, besides its role in inflammation, IL-6 may also affect insulin sensitivity or glucose metabolism.

It was suggested that IL-6 may cause insulin resistance in organs like liver and skeletal muscle. In human HepG2 cells and primary mouse hepatocytes, IL-6 has been shown to impair insulin signaling by reducing the tyrosine phosphorylation of insulin receptor substrate (IRS)-1 and reducing the association of the p85 subunit of phosphatidylinositol 3 (PI3)-kinase with IRS-1 (11). Insulin receptor autophosphorylation and IRS-1 tyrosine phosphorylation were also reduced in vivo in the livers of mice after chronic infusion with IL-6 (12). On the other hand, in the same study, no effect was found on skeletal muscle. In addition, IL-6 administration to myocytes in culture had no effect on insulin action (13) and a short-term infusion of IL-6 in rats did not affect insulin sensitivity or whole-body glucose uptake (14). A study with healthy young men showed that the infusion of high amounts of recombinant human IL-6 did not alter glucose uptake or oxidation. This shows that acute high concentrations of IL-6 might not disturb insulin sensitivity or glucose disposal in skeletal muscle in healthy subjects (15).

The observation that increased IL- 6 concentrations are associated with DM2 leads to the suggestion that the systemic production of IL-6 is increased in the insulin resistant state. It is known that adiposity plays a role in sub-clinical inflammation, as adipose tissue produces inflammation markers like IL-6 (16). Recently however, the skeletal muscle has become an interesting organ in the production of IL-6 as well, as it released IL-6 during and after exercise $(17,18)$. So far, few studies addressed the role of muscle IL- 6 production in man in the development of insulin resistance in conditions like impaired glucose tolerance and DM2. During exercise, no significant differences were found in muscle IL-6 production in skeletal muscle between controls and DM2 patients (19). However, an important stressor next to exercise is the intake of a high fat meal. In particular in DM2, the impaired handling of substrates in the postprandial phase may be of 
importance in the development or deterioration of insulin resistance and hyperglycemia. It has been found before that venous IL- 6 concentrations increased after a high fat meal in obese men (20). Additionally, it has been shown that after a high fat meal, the venous IL-6 concentrations slightly increased in healthy overweight subjects, and increased even more in newly diagnosed diabetic subjects (21).

The aim of this study was to examine 1) whether skeletal muscle produces IL-6 during fasting or in the postprandial phase; 2) whether the production of IL-6 by skeletal muscle is increased in obese men with impaired glucose tolerance compared to obese men with normal glucose tolerance and if so, 3) whether the production of IL-6 in skeletal muscle changes after weight loss in IGT men. In parallel with IL-6, other inflammatory markers like CRP and TNF- $\alpha$ receptors were monitored.

\section{SUBJECTS AND METHODS}

\section{Subjects}

Eleven obese men with impaired glucose tolerance (IGT) and nine obese men with normal glucose tolerance (NGT) matched for age and BMI participated in the study. Inclusion criteria were obesity $\left(B M I>30 \mathrm{~kg} / \mathrm{m}^{2}\right)$, diastolic blood pressure $<100 \mathrm{mmHg}$, no major health problems, and no use of medication that could influence the measurements. The NGT men had no family history of diabetes. Subjects were not involved in any regular physical activity for more than 3 hours a week. The participants were asked not to change their physical activity and smoking habits during the study. One IGT person smoked. The experimental protocol was approved by the local Medical Ethical Committee of the Maastricht University. All subjects gave written informed consent.

\section{Glucose tolerance, body composition, aerobic capacity and insulin sensitivity}

Subjects were screened for glucose metabolism with a standard oral glucose tolerance test (75 g glucose) with capillary blood sampling at baseline and after 2 hrs. Subjects were included according to the WHO criteria of 1999 for capillary plasma (IGT: fasting $<7.0 \mathrm{mmol} / \mathrm{l}, 2 \mathrm{hr}$ postload $>8.9$ and $<12.2 \mathrm{mmol} / \mathrm{l}$ ). Two subjects with glucose values (fasting $<8.0 \mathrm{mmol} / \mathrm{l}$ and $2 \mathrm{hr}$ postload $<14.8$ $\mathrm{mmol} / \mathrm{l}$ ) above the cutoff points were included as well. After inclusion, fat mass (FM) and fat free mass (FFM) were determined by underwater weighing with correction for residual lung volume (Volugraph 2000, Mijnhardt, Bunnik, The 
Netherlands) and calculated according to Siri (22). Extracellular water was estimated using bio-impedance (Hydra, Xitron Utilities, San Diego, USA). Maximal aerobic power (Wmax) and peak oxygen uptake $\left(\mathrm{VO}_{2} \max \right)$ were determined during an incremental exhaustive exercise test on an electronically braked bicycle ergometer (Lode, Groningen, The Netherlands). Insulin sensitivity was measured with a hyperinsulinemic euglycemic clamp (23). Insulin $\left(1 \mathrm{mU}^{*} \mathrm{~kg}\right.$ $\mathrm{BW}^{-1 *} \mathrm{~min}^{-1}$ ) was infused at a constant rate with glucose clamped at $4.6 \mathrm{mmol} / \mathrm{l}$ with an intravenous infusion of $20 \% \mathrm{w} / \mathrm{v}$ glucose infusion. M-value was calculated as the glucose infusion rate ( $\mathrm{mmol}$ glucose/min) per $\mathrm{kg}$ fat free mass (FFM) during a steady state of 30 minutes after at least $120 \mathrm{~min}$ of insulin infusion.

\section{High fat meal test}

Subjects were informed to refrain from heavy exercise like organized sports activities or heavy physical work and to consume a carbohydrate-rich dinner like pasta the day before the test. Subjects came to the laboratory by car or public transport after an overnight fast (12-14 hrs) during which they were only allowed to drink water. Forearm skeletal muscle was studied with the forearm model by measuring arterio-venous concentration differences across the muscle in combination with forearm blood flow measurements (24). Two catheters were inserted, one in the arteria radialis and one in a retrograde direction into a deep forearm vein. The $\mathrm{O}_{2}$-saturation in the deep venous forearm samples was less than $60 \%$, implying that deep venous blood was drawn mainly from skeletal muscle. Blood sampling and blood flow measurements took place before and after a high fat meal. The meal provided 2.6 MJ, which consisted of 61 energy \% (E\%) from fat (of which $35.5 \mathrm{E} \%$ saturated, $18.8 \mathrm{E} \%$ mono-unsaturated, and $1.7 \mathrm{E} \%$ polyunsaturated fat), $33 \mathrm{E} \%$ carbohydrates and $6 \mathrm{E} \%$ protein. To exclude metabolism in the hand, the hand circulation on the side of the deep venous catheter was occluded ( $>200 \mathrm{~mm} \mathrm{Hg}$ ) at every measurement. Immediately after occlusion, blood flow was measured with venous occlusion plethysmography (EC5R plethysmograph, Hokanson, Bellevue, USA). One minute after occlusion, arterial and deep venous blood samples were simultaneously drawn in EDTA syringes $(1.5 \mathrm{mg}$ EDTA $/ \mathrm{ml}$ ) for plasma analyses before (at $-60,-30$ and 0 minutes) and 30, 60, 90, 120, 180, and 240 minutes after the test meal. Blood samples were immediately centrifuged and plasma was frozen in liquid nitrogen and stored for analysis at -80 degrees Celsius. Plasmaflow was calculated as bloodflow $(1-$ (hematocrit/100)). Metabolite fluxes were calculated as arterio-venous differences of metabolites multiplied by plasmaflow. A positive flux is uptake from plasma and a negative flux is release by muscle. 
Table 6.1. General and metabolic characteristics of the obese men

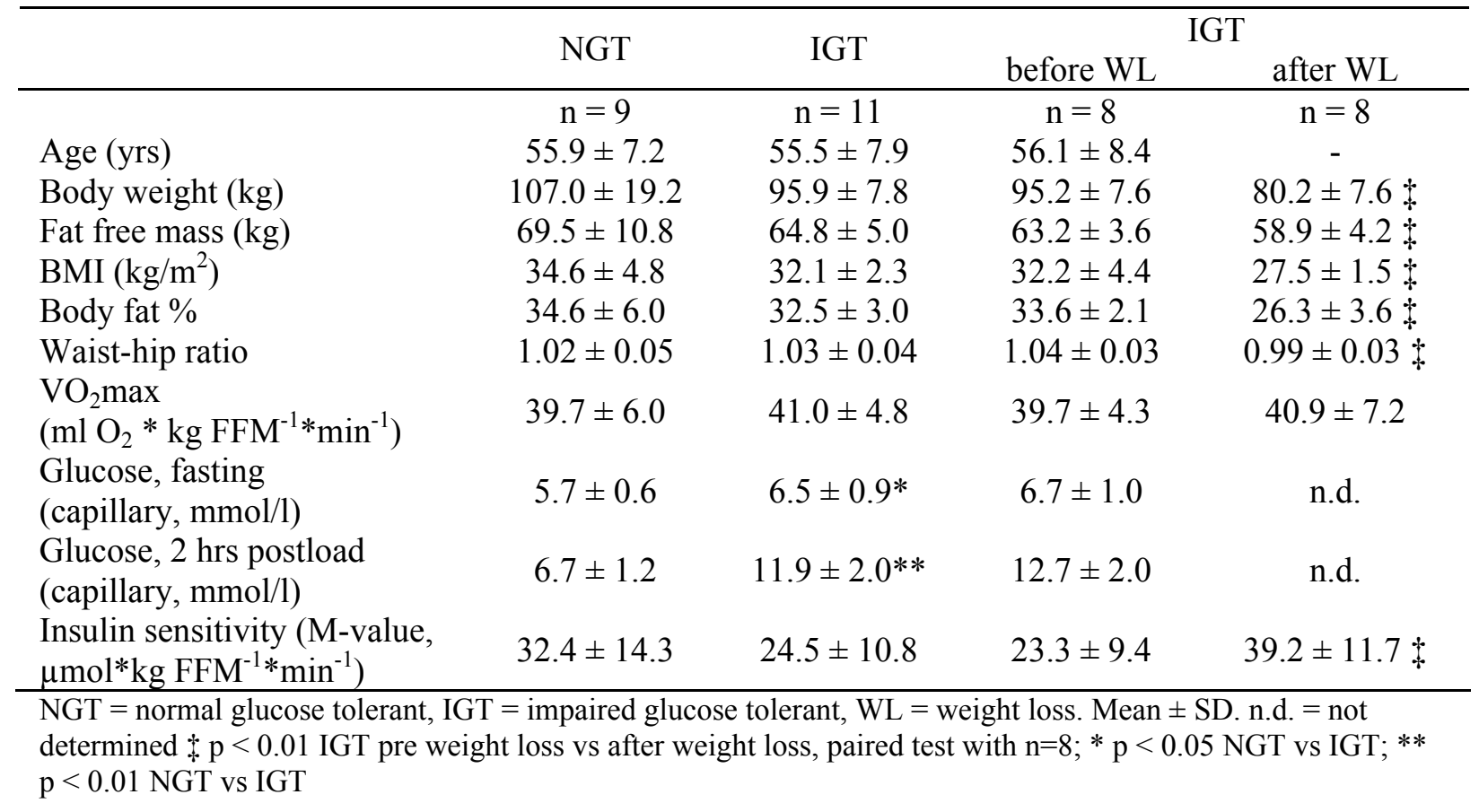

\section{Weight loss period}

After the measurements, eight men from the IGT group were willing to follow a 12-week weight loss program and visited a dietician every week. Every week, the subjects were weighed and capillary plasma glucose was checked. During the first four weeks the subjects were provided with a very low calorie diet (2 MJ/day) based on shakes (Modifast, Nutrition et Santé, Breda, the Netherlands) containing all the essential macro- and micronutrients. Beside the shakes, subjects were stimulated to eat at least $150 \mathrm{~g}$ of raw non-starchy vegetables each day. From week 5 to 8 , the shakes were gradually replaced by meals, increasing the energy content of the diet up to $4.2 \mathrm{MJ} /$ day. In week 8 to 12 , the subjects were kept in energy balance by prescribing detailed weekly menus. All measurements, i.e. clamp, forearm model, hydrostatic weighing and the exercise test, were repeated in week 11 and 12 .

\section{Biochemical analysis}

Plasma free fatty acids and glucose were analyzed using standard enzymatic techniques automated on the COBAS Fara centrifugal analyzer at 550 nm (for FFA: FFA-C test kit, Wako chemicals, Neuss, Germany; for glucose: Roche Unikit III, Hoffman-la-Roche, Basel, Switzerland). Insulin was analyzed using a fluoroimmunometric assay (autoDELFIA Insulin, PerkinElmer, Turku, Finland) with no cross-reactivity with proinsulin or split forms of proinsulin. IL-6 was 
analyzed with an ultra-sensitive ELISA kit (R\&D systems, Quantikine HS SixPak, Abingdon, UK, intraassay coefficient of variation (CV) of 3.8\%), CRP-s (soluble) was analysed on an autoanalyser Hitachi 912 (Roche, High Sensitive kit 11972855, Almere, The Netherlands, intra assay CV of 2.6\%). The TNF-receptors R1 and R2 (soluble) were analyzed with an ELISA kit from Biosource (TNF-R1/p55: KAC1762, intra assay CV of 7.9\%; TNF-R2/p75: KAC1772, Nivelles, Belgium, intra assay $\mathrm{CV}$ of $6.6 \%$ ). All metabolites were analyzed in duplo (duplo $\mathrm{CV}<10 \%$ ).

\section{Statistical analysis}

NGT and IGT men were compared with a two-tailed Student's t-test for independent samples. IGT men before and after weight loss were compared with a two-tailed Student's t-test for paired samples. For fasting values the average of time points $-60,-30$ and 0 was taken. For postprandial responses the total areas under the curve divided by time (AUC/min) were compared. Results in the tables and text are given in mean $\pm \mathrm{SD}$. Data in figures are given in mean \pm SEM. A pvalue $<0.05$ was considered as statistically significant. Statistical analysis was performed using SPSS 10.0 for Macintosh.

\section{RESULTS}

\section{General}

No differences were seen in age, BMI, body fat percentage and aerobic capacity between the IGT men and the NGT men. Insulin sensitivity was not significantly different (Table 6.1.).

\section{Fasting metabolites and postprandial response in forearm muscle}

Fasting concentrations of glucose, insulin and free fatty acids were not different between IGT and NGT men. Postprandially, arterial glucose tended to increase more $(p=0.10)$ in the IGT men, but the postprandial increase of arterial insulin and the postprandial decrease of arterial free fatty acid concentrations were not different between NGT and IGT (Table 6.2.) Arterial IL-6 concentrations were not different between groups in the fasting state, nor after the meal. Deep venous IL-6 concentrations, however, were higher in the IGT men during fasting $(\mathrm{IGT}=3.89 \pm 1.99 \mathrm{vs} \mathrm{NGT}=2.31 \pm 0.73 \mathrm{pg} / \mathrm{ml}, \mathrm{p}=0.03)$, and in the postprandial phase $(\mathrm{AUC} / \mathrm{min}$ : IGT $=5.06 \pm 3.18$ vs NGT $=2.86 \pm 0.77 \mathrm{pg} / \mathrm{ml}, \mathrm{p}=0.05$, Figure 6.1.). 
Table 6.2. Fasting and postprandial arterial concentrations of glucose, insulin and free fatty acids in men with normal glucose tolerance, impaired glucose tolerance, and impaired glucose tolerance after weight loss

\begin{tabular}{|c|c|c|c|c|}
\hline & \multirow{2}{*}{ NGT } & \multirow{2}{*}{ IGT } & \multicolumn{2}{|c|}{ IGT } \\
\hline & & & before WL & after WL \\
\hline & $\mathrm{n}=9$ & $\mathrm{n}=11$ & $\mathrm{n}=8$ & $\mathrm{n}=8$ \\
\hline Glucose, fasting (mmol/l) & $5.8 \pm 0.3$ & $6.0 \pm 0.5$ & $5.9 \pm 0.6$ & $5.3 \pm 0.5 \dagger$ \\
\hline Postprandial AUC & $6.57 \pm 0.47$ & $7.08 \pm 0.65 \#$ & $7.07 \pm 0.75$ & $6.47 \pm 0.33 \dagger$ \\
\hline Insulin, fasting (mU/L) & $18.0 \pm 12.7$ & $14.4 \pm 3.8$ & $14.3 \pm 4.5$ & $6.5 \pm 3.1 \ddagger$ \\
\hline Postprandial AUC & $31.5 \pm 13.7$ & $38.2 \pm 14.7$ & $34.5 \pm 11.5$ & $20.9 \pm 9.0 \dagger$ \\
\hline FFA, fasting $(\mu \mathrm{mol} / \mathrm{l})$ & $555 \pm 166$ & $675 \pm 184$ & $697 \pm 201$ & $556 \pm 102 \dagger$ \\
\hline Postprandial AUC & $359 \pm 70$ & $440 \pm 148$ & $473 \pm 163$ & $360 \pm 92 \dagger$ \\
\hline
\end{tabular}

Similar differences were found for IL-6 flux, as blood flow was not different between groups during fasting (NGT $=1.51 \pm 0.47$; IGT $=1.78 \pm 0.60 \mathrm{ml}^{*} 100 \mathrm{ml}$ tissue $\left.^{-1 *} \mathrm{~min}^{-1}\right)$ or after a meal $(\mathrm{AUC} / \mathrm{min}, \mathrm{NGT}=1.82 \pm 0.62$; IGT $=1.97 \pm 0.85$ $\mathrm{ml}^{*} 100 \mathrm{ml}$ tissue $\left.\mathrm{e}^{-1 *} \mathrm{~min}^{-1}\right)$. It was found that the IL-6 release from muscle was higher in the IGT group than in the NGT group, both in the fasting state (IGT = $2.26 \pm 1.89$ vs NGT $=0.87 \pm 0.48 \mathrm{fmol}^{*} 100 \mathrm{ml}$ tissue $\left.{ }^{-1 *} \mathrm{~min}^{-1}, \mathrm{p}=0.04\right)$ and in the postprandial phase (AUC/min: IGT $=3.48 \pm 2.63$ vs NGT $=1.37 \pm 0.75 \mathrm{fmol}^{*} 100 \mathrm{ml}$ tissue $^{-1 *} \min ^{-1}, \mathrm{p}=0.03$, Figure 6.2.). The postprandial IL-6 release (AUC/min) was higher than the fasting IL-6 release $(\mathrm{p}<0.05)$ in the group as a whole. Arterial CRP, TNF-R1 and TNF-R2 concentrations were not different between groups (Table 6.3.). CRP, TNF-R1 and TNF-R2 arterio-venous differences were all less than $1 \%$ of arterial concentrations. Subsequently all fluxes were around zero, showing that CRP, TNF-R1 and TNF-R2 were not released from muscle, neither in the fasting, nor in the postprandial phase.

\section{Extrapolated estimated muscle IL-6 production}

It can be calculated to what extent the release of IL-6 from muscle can contribute to systemic IL-6 levels. It has to be taken into account that these are calculated estimates, partly based on assumptions. We assumed that muscle mass, estimated as $\sim 55 \%$ (25) of fat free mass, released IL-6 at the same rate as the forearm muscle studied here, and used an estimated half-life of $3 \mathrm{~min}$ (26). We estimated the IL-6 production rate of total muscle mass during fasting (mеanтотAL GROUP $=0.58 \mathrm{ng} / \mathrm{min}$, range $0.12-2.11 \mathrm{ng} / \mathrm{min}$ ) and postprandially (meanTOTAL GROUP $=$ 
Table 6.3. Fasting arterial concentrations of IL-6, CRP and TNF- $\alpha$ receptors in men with normal glucose tolerance, impaired glucose tolerance, and impaired glucose tolerance after weight loss.

\begin{tabular}{lcccccc}
\hline & NGT & IGT & p-value & IGT before WL & IGT after WL & p-value \\
& $\mathrm{n}=9$ & $\mathrm{n}=11$ & & $\mathrm{n}=8$ & \\
\hline IL-6 & $1.33 \pm 0.57$ & $1.47 \pm 0.42$ & 0.57 & $1.58 \pm 0.40$ & $1.41 \pm 0.41$ & 0.23 \\
CRP-s & $2.21 \pm 1.71$ & $3.46 \pm 1.90$ & 0.15 & $4.21 \pm 1.75$ & $2.09 \pm 1.15$ & 0.004 \\
TNF-R1 & $1.52 \pm 0.22$ & $1.45 \pm 0.23$ & 0.55 & $1.45 \pm 0.27$ & $1.35 \pm 0.28$ & 0.06 \\
TNF-R2 & $3.27 \pm 0.89$ & $3.65 \pm 0.87$ & 0.42 & $3.59 \pm 0.67$ & $3.65 \pm 2.01$ & 0.79 \\
\hline
\end{tabular}

NGT $=$ normal glucose tolerant. IGT $=$ Impaired glucose tolerant, $\mathrm{WL}=$ weight loss. Mean \pm sd. IL-6 is given in $\mathrm{pg} / \mathrm{ml}$, CRP-S in $\mathrm{mg} / \mathrm{l}$, and TNF-R1 and TNF-R2 are given in $\mathrm{ng} / \mathrm{ml}$.

$0.90 \mathrm{ng} / \mathrm{min}$, range $0.06-2.61 \mathrm{ng} / \mathrm{min})$. The estimated contribution of IL-6 release from skeletal muscle to systemic IL-6, using whole body extracellular fluid estimated from bio-impedance (Hydra, Xitron Utilities, San Diego, USA), was 12\% (range $2 \%-42 \%$ ) for the whole group in the fasting state. In the postprandial phase it was $11 \%$ (range $2 \%-21 \%$ ) in NGT men and highest in IGT men $(25 \%$, range $2 \%-66 \%)$.

\section{Effect of weight loss}

Eight IGT men were willing to participate in the weight loss program. They lost on average $15.0 \pm 3.4 \mathrm{~kg}$ of body weight (Table 6.1.). Approximately $72 \%$ of this weight loss was owing to a reduced fat mass and $28 \%$ to a reduction in fat free mass. Body weight was $82.4 \pm 8.3 \mathrm{~kg}$ in week 8 , at the end of the weight loss period, and $82.5 \pm 9.4 \mathrm{~kg}$ in week 10 , just before repeating the measurements, indicating that subjects were in energy balance during the measurement period. Weight loss improved insulin sensitivity (Table 6.1.), reduced fasting arterial glucose, insulin and free fatty acid concentrations and reduced postprandial hyperglycemia (-8\%) and hyperinsulinemia (-41\%) (Table 6.2.). No change was seen in aerobic capacity (Table 6.1.).

After weight loss (WL), no significant change was observed in fasting arterial IL-6 concentrations (Table 6.3.) or fasting IL-6 release from muscle (IGTPRE wL: $2.22 \pm 1.86$ vs IGT AFTER WL: $1.40 \pm 1.32 \mathrm{fmol}^{*} 100 \mathrm{ml} \mathrm{tissue}^{-1 *} \mathrm{~min}^{-1}$, Figure 6.1. $\mathrm{p}=$ 0.24 ), but postprandial IL-6 release had decreased (IGTPRE WL : $2.99 \pm 2.58$ vs IGT AFTER WL: $1.45 \pm 1.33 \mathrm{fmol}^{*} 100 \mathrm{ml}$ tissue ${ }^{-1 *} \mathrm{~min}^{-1}, \mathrm{p}=0.04$ ) after weight loss ( Figure 6.2.). Weight loss also decreased the arterial CRP level $(-45 \%, p=0.004$, Table 6.3.) whereas the TNF-R1 receptor showed a trend for a lower concentration $(-7 \%, p=0.06$, Table 6.3.). No correlations between M-value, body weight loss and IL-6 release were found. 


\section{DISCUSSION}

A major finding of the present study is that the cytokine IL-6 was released from skeletal muscle of obese IGT and obese NGT men during fasting and after a high fat meal. Interestingly, the IL-6 release from forearm muscle was higher in obese men with impaired glucose tolerance compared to obese men with normal glucose tolerance. Furthermore, in IGT men, the IL-6 release from muscle after a high fat meal was reduced after weight loss, in concert with improvements in insulin sensitivity and glucose tolerance.

It has been reported before that the venous IL- 6 concentration increases after a meal, especially after a high fat meal $(20,21)$. This is the first report describing IL-6 release in the postprandial phase by skeletal muscle. In the present study, it can be calculated that the estimated total muscle mass would produce 7

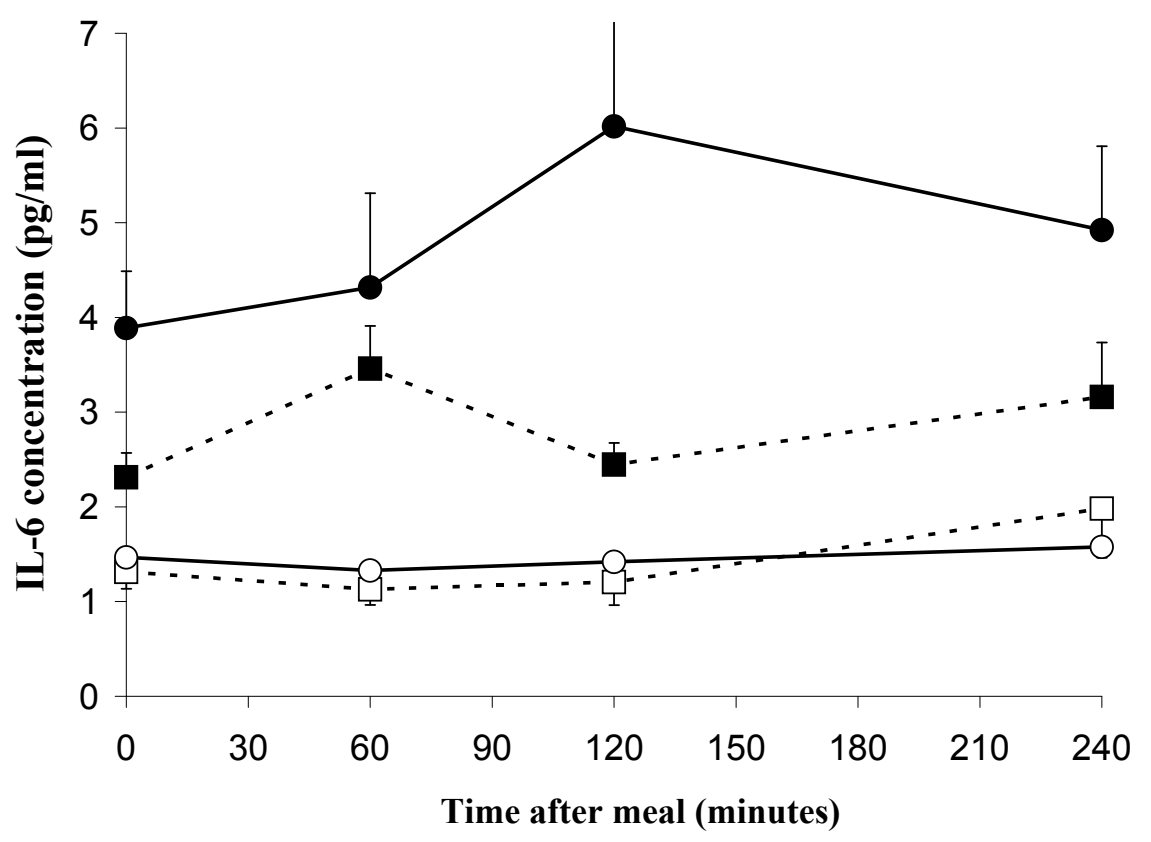

- IGT, deep venous

O IGT, arterial

NGT, deep venous

$\square$ NGT, arterial

Figure 1. Arterial and deep venous concentrations of IL-6 across forearm muscle during fasting and after a meal: compare normal glucose tolerant (NGT) and impaired glucose tolerant (IGT) men. Arterial IGT (open circles); deep venous IGT (closed circles); arterial NGT (open squares); deep venous NGT (closed squares). Means \pm sem.

Groups were compared with an unpaired Student's t-test: arterial IL-6 concentration during fasting, $p=0.492$; deep venous IL-6 concentration, $p=0.031$; postprandial AUC for arterial IL-6 concentration, $p=0.698$; postprandial AUC for deep venous IL-6 concentration, $p=0.049$. Arterial vs venous concentrations, paired Student's t-test: all differences $p<0.01$. 


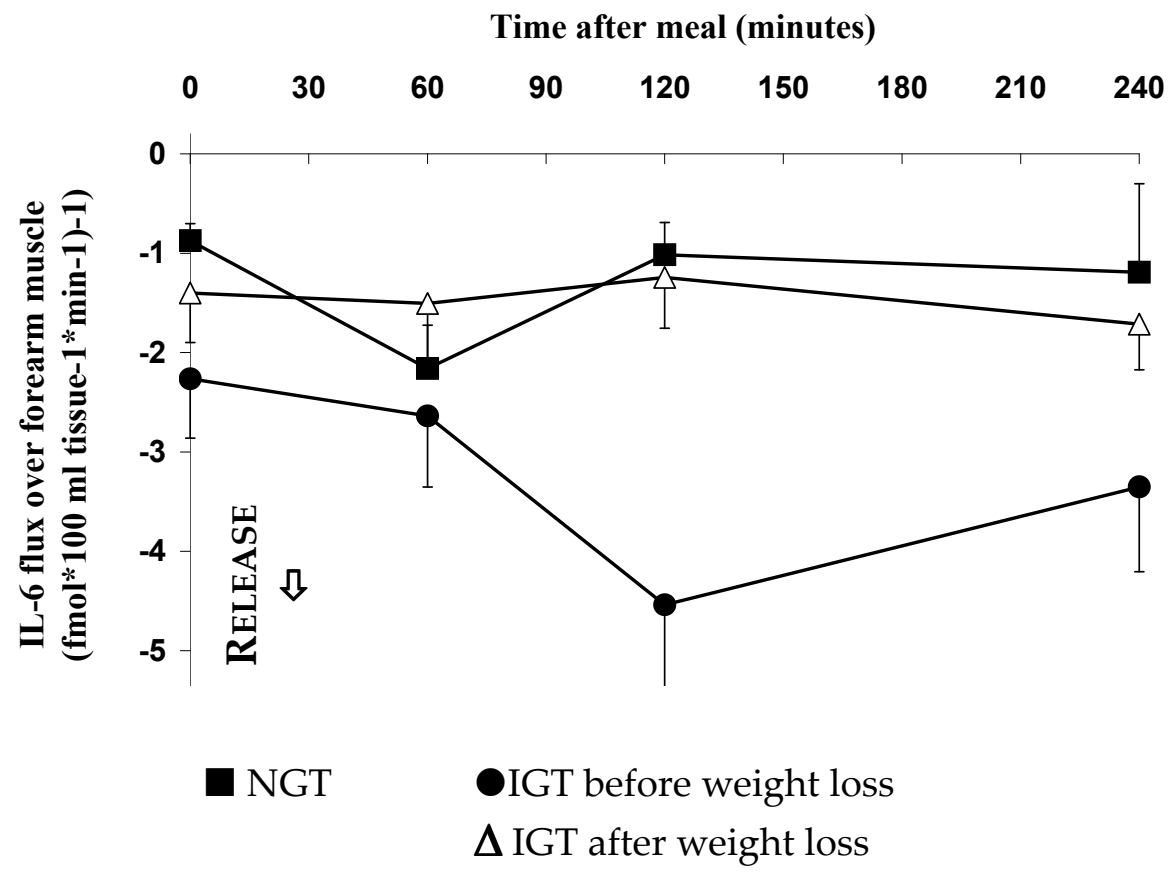

Figure 2. IL-6 flux over skeletal muscle during fasting and after a meal: compare obese normal glucose tolerant men (obese NGT, $n=9$ ) with obese men with impaired glucose tolerance before (obese IGT, $n=11$ ) and after weight loss (IGT after weight loss, $n=8$ ). NGT men (closed squares); IGT men before weight loss (closed circles); IGT men after weight loss (open triangle). Means \pm sem.

NGT men and IGT men before weight loss were compared with a Student's $t$-test for independent samples: IL-6 flux during fasting, $p=0.038$; postprandial AUC for IL-6 flux, $p=0.026$. IGT men $(n=8)$ before and after weight loss were compared with a Student's t-test for paired samples: IL-6 flux during fasting, $p=0.301$; postprandial AUC for IL-6 flux, $p=0.042$.

vs $16 \%$ of the systemic IL- 6 during fasting and 11 vs $25 \%$ in the postprandial phase for NGT and IGT subjects, respectively. Mohamed-Ali (27) previously reported that the estimated production rate of whole body adipose tissue was 1.41 $\mathrm{ng} / \mathrm{min}$ (range $0.22-2.67 \mathrm{ng} / \mathrm{min}$ ), which was in the same range as the values we found for muscle in the postprandial phase in IGT men before weight loss (1.17 $\mathrm{ng} / \mathrm{min}$, range $0.15-2.61 \mathrm{ng} / \mathrm{min}$ ). Thus, both adipose tissue and skeletal muscle contribute to circulating IL- 6 concentrations. The question remains whether the IL6 is produced by myocytes or by other cell types present in muscle, as it has recently been found that the IL- 6 release from adipose tissue derives for $90 \%$ from non-adipocytes (28). Although it is known that IL-6 can be released by muscle fibers itself $(13,29)$, the contribution of other cell types such as monocytes/ macrophages, endothelial cells, fibroblasts and smooth muscle cells cannot be excluded. The contribution of other tissues in the forearm, like adipose tissue, cannot be entirely excluded either, although the deep venous plasma was mainly drawn from muscle, as confirmed by an $\mathrm{O}_{2}$-saturation $<60 \%$. 
It is still unclear what may trigger IL-6 release from muscle. We cannot even exclude that the experimental conditions per se may have had an effect on IL-6 release from muscle, as we did not include a control group for the meal-effect. Nevertheless, it is likely that the meal per se evoked an effect on IL-6 release, as the postprandial IL-6 release (AUC/min) was higher than the fasting IL-6 release $(\mathrm{p}<0.05)$ in the group as a whole. Several factors may provoke IL-6 release from muscle. In the first place, the production of cytokines in skeletal muscle, like IL-6, may be stimulated by oxidative stress (30). One of the factors that may cause oxidative stress in the postprandial period is impaired substrate handling (31), as described in impaired glucose tolerance and type 2 diabetes mellitus $(24,32)$. Impairments in lipid (33) and glucose (34) handling may both lead to oxidative stress. In the second place, impairments in lipid metabolism, like a reduced oxidation of plasma derived fatty acids $(24,32)$ in DM2 subjects may lead to the accumulation of interstitial or cytosolic free fatty acids. Especially saturated fatty acids like palmitate can directly stimulate the production of IL-6 in myocytes from DM2 patients (13) when present in abundance. So, impairments in substrate handling, as found in IGT and DM2, may lead to the production of oxidative stress and/or to an increment of local concentrations of saturated free fatty acids. Each of these may stimulate the production of IL-6 in the postprandial phase. The physiological significance of IL-6 release from muscle is still unclear. Pedersen (35) suggested that IL-6 may be an inter-organ signaling molecule during exercise, reporting a signal from skeletal muscle to the liver to indicate the use of glycogen. However, this is not likely to be the case after meal intake.

What may be the effect of the cytokines that are produced on skeletal muscle metabolism? It has been shown that systemic IL-6 infusion, resulting in high arterial IL-6 concentrations ( $150 \mathrm{pg} / \mathrm{ml})$, stimulates lipolysis and fatty acid oxidation in humans in rest (36), although it is not known whether similar effects will be found in the physiological range. However, in adipose tissue it has been shown that interstitial IL-6 concentrations may be up to 100 times as high as plasma values (37). Likewise, high interstitial amounts of IL-6 may affect fatty acid metabolism in an auto- or paracrine manner. On the other hand, it has been reported that IL-6 infusion did not affect glucose uptake or oxidation, and in vitro and in vivo studies show no effect of IL-6 on insulin action in skeletal muscle (12, $13,14)$. However, IL-6 may induce tissue insulin resistance in other organs, e.g. in liver $(11,12)$, thus contributing to the further progression of impaired glucose tolerance to type 2 diabetes mellitus.

After weight loss, arterial IL-6 concentrations had not changed, but the postprandial release of IL-6 from muscle was decreased $(-52 \%, p=0.04)$. This improvement in IL-6 release after weight loss may have been a consequence of the reduction in body weight, the improvement of glucose tolerance and/or the 
increase in insulin sensitivity. This supports the concept that the postprandial increase in IL-6 production may have been triggered by disturbances in glucose and/or fat metabolism found in obese IGT men.

The lack of differences between NGT and IGT subjects in arterial concentrations of IL-6, CRP, TNF-R1 and TNF-R2 is in accordance with some (5, 38), but not all studies (3) and may be explained by the fact that the observed groups are equally obese and only slightly different in insulin resistance.

In conclusion, we observed IL- 6 release from forearm muscle in obese NGT and obese IGT subjects, both during fasting and after a meal. IL-6 release was significantly higher in IGT men during the postprandial phase when compared to obese NGT men. In these IGT men, the postprandial IL-6 release decreased after body weight loss, reaching levels that were found in the obese, normal glucose tolerant controls. We suggest that the high fat meal may be an important metabolic stressor, evoking IL-6 release from skeletal muscle, due to the impairment in substrate handling in IGT men and that the IL-6 production may rather be a consequence than a cause of the obese, insulin resistant and/or impaired glucose tolerant state. Further studies have to provide more information on the mechanisms that are responsible for the increased IL- 6 production by muscle, and whether the production of IL-6 in muscle may lead to a further increase in insulin resistance, contributing to the progression of impaired glucose tolerance to type 2 diabetes mellitus.

\section{ACKNOWLEDGEMENTS}

Supported by grants from the Dutch Diabetes Research Foundation (DFN 98.901 and DFN 2000.00.020). We thank Jos Stegen, Hans Cremers, and Rya van Loenen for their excellent analytical support, the dieticians Tanja Hermans-Limpens and Marja Ockeloen - van der Hulst for their support and dietary advice, and Judith Huskens and Dorien Mintjes for their practical support.

\section{REFERENCES}

1. Hanley AJ, Festa A, D'Agostino RB, Jr., Wagenknecht LE, Savage PJ, Tracy RP, Saad MF, Haffner SM 2004 Metabolic and inflammation variable clusters and prediction of type 2 diabetes: factor analysis using directly measured insulin sensitivity. Diabetes 53:1773-81

2. Laaksonen DE, Niskanen L, Nyyssonen K, Punnonen K, Tuomaine n TP, Valkonen VP, Salonen $\mathrm{R}$, Salonen JT 2004 C-reactive protein and the development of the metabolic syndrome and diabetes in middle-aged men. Diabetologia 47:1403-10 
3. Muller S, Martin S, Koenig W, Hanifi-Moghaddam P, Rathmann W, Haastert B, Giani G, Illig T, Thorand B, Kolb H 2002 Impaired glucose tolerance is associated with increased serum concentrations of interleukin 6 and co-regulated acute-phase proteins but not TNF-alpha or its receptors. Diabetologia 45:805-12

4. Fernandez-Real JM, Broch M, Ricart W, Casamitjana R, Gutierrez C, Vendrell J, Richart C 1998 Plasma levels of the soluble fraction of tumor necrosis factor receptor 2 and insulin resistance. Diabetes 47:1757-62

5. Dzienis-Straczkowska S, Straczkowski M, Szelachowska M, Stepien A, Kowalska I, Kinalska I 2003 Soluble tumor necrosis factor-alpha receptors in young obese subjects with normal and impaired glucose tolerance. Diabetes Care 26:875-80

6. Trikha M, Corringham R, Klein B, Rossi JF 2003 Targeted anti-interleukin-6 monoclonal antibody therapy for cancer: a review of the rationale and clinical evidence. Clin Cancer Res 9:4653-65

7. Krogh-Madsen R, Moller K, Dela F, Kronborg G, Jauffred S, Pedersen BK 2004 Effect of hyperglycemia and hyperinsulinemia on the response of IL-6, TNF-alpha, and FFAs to low-dose endotoxemia in humans. Am J Physiol Endocrinol Metab 286:E766-72

8. Bennermo M, Held C, Stemme S, Ericsson CG, Silveira A, Green F, Tornvall P 2004 Genetic predisposition of the interleukin-6 response to inflammation: implications for a variety of major diseases? Clin Chem 50:2136-40

9. Pradhan AD, Manson JE, Rifai N, Buring JE, Ridker PM 2001 C-reactive protein, interleukin 6, and risk of developing type 2 diabetes mellitus. Jama 286:327-34

10. Spranger J, Kroke A, Mohlig M, Hoffmann K, Bergmann MM, Ristow M, Boeing H, Pfeiffer AF 2003 Inflammatory cytokines and the risk to develop type 2 diabetes: results of the prospective population-based European Prospective Investigation into Cancer and Nutrition (EPIC)-Potsdam Study. Diabetes 52:812-7

11. Senn JJ, Klover PJ, Nowak IA, Mooney RA 2002 Interleukin-6 induces cellular insulin resistance in hepatocytes. Diabetes 51:3391-9

12. Klover PJ, Zimmers TA, Koniaris LG, Mooney RA 2003 Chronic exposure to interleukin-6 causes hepatic insulin resistance in mice. Diabetes 52:2784-9

13. Weigert C, Brodbeck K, Staiger H, Kausch C, Machicao F, Haring HU, Schleicher ED 2004 Palmitate, but not unsaturated fatty acids, induces the expression of interleukin-6 in human myotubes through proteasome-dependent activation of nuclear factor-kappaB. J Biol Chem 279:23942-52

14. Rotter Sopasakis V, Larsson BM, Johansson A, Holmang A, Smith U 2004 Short-term infusion of interleukin-6 does not induce insulin resistance in vivo or impair insulin signalling in rats. Diabetologia 47:1879-87

15. Steensberg A, Fischer CP, Sacchetti M, Keller C, Osada T, Schjerling P, van Hall G, Febbraio MA, Pedersen BK 2003 Acute interleukin-6 administration does not impair muscle glucose uptake or whole-body glucose disposal in healthy humans. J Physiol 548:631-8

16. Orban Z, Remaley AT, Sampson M, Trajanoski Z, Chrousos GP 1999 The differential effect of food intake and beta-adrenergic stimulation on adipose-derived hormones and cytokines in man. J Clin Endocrinol Metab 84:2126-33

17. Keller P, Keller C, Carey AL, Jauffred S, Fischer CP, Steensberg A, Pedersen BK 2003 Interleukin6 production by contracting human skeletal muscle: autocrine regulation by IL-6. Biochem Biophys Res Commun 310:550-4 
18. Fischer CP, Hiscock NJ, Penkowa M, Basu S, Vessby B, Kallner A, Sjoberg LB, Pedersen BK 2004 Supplementation with vitamins $C$ and $E$ inhibits the release of interleukin- 6 from contracting human skeletal muscle. J Physiol 558:633-45

19. Febbraio MA, Steensberg A, Starkie RL, McConell GK, Kingwell BA 2003 Skeletal muscle interleukin-6 and tumor necrosis factor-alpha release in healthy subjects and patients with type 2 diabetes at rest and during exercise. Metabolism 52:939-44

20. Jellema A, Plat J, Mensink RP 2004 Weight reduction, but not a moderate intake of fish oil, lowers concentrations of inflammatory markers and PAI-1 antigen in obese men during the fasting and postprandial state. Eur J Clin Invest 34:766-73

21. Nappo F, Esposito K, Cioffi M, Giugliano G, Molinari AM, Paolisso G, Marfella R, Giugliano D 2002 Postprandial endothelial activation in healthy subjects and in type 2 diabetic patients: role of fat and carbohydrate meals. J Am Coll Cardiol 39:1145-50.

22. Siri W 1956 The gross composition of the body. Adv Bio Med Physiol 4:239-280

23. Wallace TM, Matthews DR 2002 The assessment of insulin resistance in man. Diabet Med 19: 527 -534 .

24. Blaak EE, Wagenmakers AJ, Glatz JF, Wolffenbuttel BH, Kemerink GJ, Langenberg CJ, Heidendal GA, Saris WH 2000 Plasma FFA utilization and fatty acid-binding protein content are diminished in type 2 diabetic muscle. Am J Physiol Endocrinol Metab 279:E146-54.

25. Elia M, Folmer P, Schlatmann A, Goren A, Austin S 1988 Carbohydrate, fat, and protein metabolism in muscle and in the whole body after mixed meal ingestion. Metabolism 37:542-51

26. Castell JV, Geiger T, Gross V, Andus T, Walter E, Hirano T, Kishimoto T, Heinrich PC 1988 Plasma clearance, organ distribution and target cells of interleukin-6/hepatocyte-stimulating factor in the rat. Eur J Biochem 177:357-61

27. Mohamed-Ali V, Goodrick S, Rawesh A, Katz DR, Miles JM, Yudkin JS, Klein S, Coppack SW 1997 Subcutaneous adipose tissue releases interleukin-6, but not tumor necrosis factor-alpha, in vivo. J Clin Endocrinol Metab 82:4196-200

28. Fain JN, Madan AK, Hiler ML, Cheema P, Bahouth SW 2004 Comparison of the release of adipokines by adipose tissue, adipose tissue matrix, and adipocytes from visceral and subcutaneous abdominal adipose tissues of obese humans. Endocrinology 145:2273-82

29. Penkowa M, Keller C, Keller P, Jauffred S, Pedersen BK 2003 Immunohistochemical detection of interleukin-6 in human skeletal muscle fibers following exercise. Faseb J 17:2166-8

30. Kosmidou I, Vassilakopoulos T, Xagorari A, Zakynthinos S, Papapetropoulos A, Roussos C 2002 Production of interleukin- 6 by skeletal myotubes: role of reactive oxygen species. Am J Respir Cell Mol Biol 26:587-93

31. Ceriello A, Taboga C, Tonutti L, Quagliaro L, Piconi L, Bais B, Da Ros R, Motz E 2002 Evidence for an independent and cumulative effect of postprandial hypertriglyceridemia and hyperglycemia on endothelial dysfunction and oxidative stress generation: effects of short- and long-term simvastatin treatment. Circulation 106:1211-8

32. Mensink M, Blaak EE, van Baak MA, Wagenmakers AJ, Saris WH 2001 Plasma free Fatty Acid uptake and oxidation are already diminished in subjects at high risk for developing type 2 diabetes. Diabetes 50:2548-54

33. Tsai WC, Li YH, Lin CC, Chao TH, Chen JH 2004 Effects of oxidative stress on endothelial function after a high-fat meal. Clin Sci (Lond) 106:315-9

34. Ceriello A, Bortolotti N, Motz E, Crescentini A, Lizzio S, Russo A, Tonutti L, Taboga C 1998 Meal-generated oxidative stress in type 2 diabetic patients. Diabetes Care 21:1529-33 
35. Pedersen BK, Steensberg A, Keller P, Keller C, Fischer C, Hiscock N, van Hall G, Plomgaard P, Febbraio MA 2003 Muscle-derived interleukin-6: lipolytic, anti-inflammatory and immune regulatory effects. Pflugers Arch 446:9-16

36. van Hall G, Steensberg A, Sacchetti M, Fischer C, Keller C, Schjerling P, Hiscock N, Moller K, Saltin B, Febbraio MA, Pedersen BK 2003 Interleukin-6 stimulates lipolysis and fat oxidation in humans. J Clin Endocrinol Metab 88:3005-10

37. Sopasakis VR, Sandqvist M, Gustafson B, Hammarstedt A, Schmelz M, Yang X, Jansson PA, Smith U 2004 High local concentrations and effects on differentiation implicate interleukin-6 as a paracrine regulator. Obes Res 12:454-60

38. Bastard JP, Jardel C, Bruckert E, Blondy P, Capeau J, Laville M, Vidal H, Hainque B 2000 Elevated levels of interleukin 6 are reduced in serum and subcutaneous adipose tissue of obese women after weight loss. J Clin Endocrinol Metab 85:3338-42 


\section{CHAPTER 7}

\section{Improvements in glucose tolerance and insulin sensitivity after lifestyle intervention are related to changes in serum fatty acid profile and desaturase activities - the SLIM study}

E. Corpeleijn (1), E.J.M. Feskens (2, 3), E.H.J.M. Jansen (4), M. Mensink (1), W. H. M. Saris (1), T. W. A. de Bruin (5), E. E. Blaak (1)

From the (1) Department of Human Biology, the Nutrition and Toxicology Research Institute NUTRIM, Maastricht University, Maastricht, The Netherlands; (2) the Centre for Nutrition and Health, National Institute for Public Health and the Environment, Bilthoven, The Netherlands; (3) the Division of Human Nutrition, Wageningen University and Research Center, Wageningen, The Netherlands; (4) the Laboratory for Toxicology, Pathology and Genetics, National Institute for Public Health and the Environment, Bilthoven, The Netherlands; and (5)Department of Medicine and Endocrinology, Cardiovascular Research Institute CARIM, University Hospital Maastricht, Maastricht, The Netherlands.

Diabetologia, 03 August 2006. DOI: 10.1007/s00125-006-0383-4 


\begin{abstract}
Aims/hypothesis: We investigated whether lifestyle-intervention induced changes in serum fatty acid profile of cholesteryl esters and estimated desaturase activities were related to improvements in insulin sensitivity in subjects at risk for type 2 diabetes.

Methods: In the SLIM study, 97 men and women with impaired glucose tolerance were randomised to a combined diet-and-exercise program (47 intervention) or to a control group (50 control subjects). At baseline and after one year, an oral glucose tolerance test, an exercise test to determine maximal aerobic capacity, anthropometry and analysis of fatty acid profile in serum cholesteryl esters were performed.

Results: The lifestyle program was effective to reduce the intake of total and saturated fat, to increase physical activity, to reduce obesity and to improve insulin sensitivity and glucose tolerance. Regression analysis on the total population showed that an increase in C20:4 n-6/ C20:3 n-6 ratio (estimated $\Delta 5$ desaturase activity) and a reduction in C18:3 n-6/C18:2 n-6 ratio (estimated $\Delta 6$ desaturase activity) and C16:1 n-7/ C16:0 ratio (estimated $\Delta 9$-desaturase activity or stearoyl-CoA desaturase-1) in the total group were significantly associated with a decrease in HOMA index for insulin resistance. After adjustment for lifestyle changes (change in body fat percentage, aerobic capacity and saturated fat intake) these associations were partly reduced, but remained statistically significant. Conclusions/interpretation: Lifestyle-induced changes in fatty acid profile of cholesteryl esters and desaturase activities were independently related to changes in insulin sensitivity in subjects at risk for type 2 diabetes.
\end{abstract}




\section{INTRODUCTION}

In the past, the interest in the fat quality of the Western diet was raised by crosssectional epidemiological studies. These showed that the consumption of saturated fat was inversely related to insulin sensitivity and glucose tolerance, whereas a positive association was found for unsaturated fat [1-3]. Similar results were found for fatty acid composition in serum [4,5]. In addition, prospective studies in healthy subjects have shown that a serum fatty acid profile of high saturated fatty acids or low unsaturated fatty acids can predict the development of type 2 diabetes [1, 6, 7]. Recently, two well-controlled human studies demonstrated that replacing saturated fatty acids (SFA) in the diet either by monounsaturated fat (MUFA) [8] or poly-unsaturated fat (PUFA) [9] resulted in changes in serum fatty acid profile and an improved insulin sensitivity. This improvement in insulin sensitivity was found in particular in subjects with a relatively low total fat intake (below median 37 energy \%) [8].

The plasma fatty acid profile reflects not only dietary fat intake, but is also influenced by endogenous fatty acid metabolism, e.g. by desaturase enzymes. An important role for the desaturase enzymes is to regulate the degree of unsaturation of lipids throughout the body. This is important for the fluidity of cell membranes, affecting cell permeability and signalling, including insulin signalling [10]. The $\Delta 9$-desaturase catalyzes the conversion of palmitic and stearic acid into palmitoleic acid and oleic acid, respectively. These mono-unsaturated fatty acids are required for the fatty acid composition of membrane phospholipids and the synthesis of adipose tissue triglycerides and cholesteryl esters [10, 11]. The $\Delta 5$ - and $\Delta 6$-desaturases catalyze the synthesis of n- 6 and n-3 poly-unsaturated fatty acids [10], of which arachidonic acid (C20:4 n-6) is an eicosanoid precursor, and docosahexaenoic acid (C22:6 n-3) plays a role in the function of the retina and central nervous system. Some specific highly unsaturated fatty acids are regulators of the expression of genes involved in lipogenesis and lipid oxidation [12]. The activity of desaturase enzymes has been associated with insulin resistance [13-15]. Animal studies have shown that mice lacking stearoyl-CoA desaturase-1 (SCD-1), a mouse isoform of $\Delta 9$-desaturase, are more insulin sensitive than their wildtype littermates [13]. In human studies, an increased $\Delta 6$ desaturase activity and a decreased $\Delta 5$-desaturase activity have been associated with insulin resistance and type 2 diabetes [14, 16, 17]. Recently, a 20-yr prospective study in healthy Swedish men showed that high estimated $\Delta 9$ - and $\Delta 6$-desaturase activities and low $\Delta 5$-desaturase activities predicted the development of the metabolic syndrome [18]. These studies suggest that desaturase enzymes may be directly or indirectly involved in the development of insulin resistance. 
There is increasing evidence that serum fatty acid profiles and fatty acid desaturase activities may be influenced by lifestyle factors, such as diet $[3,16]$ and exercise $[19,20]$. Previously, we have shown that a combined lifestyle intervention program was effective to improve glucose tolerance and insulin sensitivity in prediabetic subjects, thereby reducing the risk for diabetes [21]. Therefore, we investigated whether changes in fatty acid profile of serum cholesteryl esters and estimated fatty acid desaturase activities were related to lifestyle-intervention induced changes in glucose tolerance and insulin sensitivity.

\section{METHODS}

\section{Subjects}

Subjects were recruited from a large existing cohort of the general population [22] and through advertisements in the local newspaper. Subjects were screened for impaired glucose tolerance with a standard oral glucose tolerance test (OGTT) with capillary sampling according to the World Health Organization guidelines [23]. Subjects with impaired glucose tolerance were invited to undergo a second OGTT and were included when the mean 2-hour glucose concentration was between 7.8 and $12.5 \mathrm{mmol} / \mathrm{l}$. Exclusion criteria were previously diagnosed diabetes other than gestational diabetes, medication use known to interfere with glucose metabolism, participation in vigorous exercise or an intensive weight loss program during the last year before participation, and any (chronic) disease that makes participation in a lifestyle program impossible, or has an improbable 5-year survival. The study protocol was approved by the local Medical Ethical Committee of the Maastricht University. All subjects gave written informed consent.

Subjects were randomized to the intervention group or the control group with stratification for gender and 2-hr glucose value. Of the 147 subjects, 131 completed the one-year intervention period. We obtained complete datasets of general and metabolic characteristics and serum fatty acid profile in cholesteryl esters of 97 subjects for regression analysis. Incomplete datasets were mainly due to missing values for dietary intake and aerobic capacity ( $\left.\mathrm{VO}_{2} \mathrm{max}\right)$. The number of women was higher in the group of excluded subjects (+29\%), but no differences in age, BMI, 2-hr glucose values or HOMA index for insulin resistance were found between excluded and included subjects. Also the number of excluded subjects in the intervention $(n=27)$ and control group $(n=23)$ was comparable. The results of this lifestyle-intervention have been published previously [21]. 
Table 7.1. Subject characteristics at baseline and after one year of lifestyle intervention

\begin{tabular}{|c|c|c|c|c|c|c|c|}
\hline & \multicolumn{2}{|c|}{ Intervention } & \multicolumn{2}{|c|}{ Control } & \multicolumn{3}{|c|}{ p-value } \\
\hline & baseline & $\begin{array}{c}\text { after } \\
\text { one year }\end{array}$ & baseline & $\begin{array}{c}\text { after } \\
\text { one year }\end{array}$ & group & time & $\begin{array}{c}\text { group } \\
x \\
\text { time }\end{array}$ \\
\hline $\mathrm{n}(\mathrm{m} / \mathrm{f})$ & $47(29 / 18)$ & $47(29 / 18)$ & $50(30 / 20)$ & $50(30 / 20)$ & & & \\
\hline Age $(y r)$ & $56.0 \pm 0.9$ & - & $58.5 \pm 1.0$ & - & 0.07 & - & - \\
\hline Body weight (kg) & $88.2 \pm 1.9$ & $85.4 \pm 1.8$ & $84.5 \pm 1.9$ & $83.8 \pm 1.8$ & 0.31 & $<0.01$ & $<0.01$ \\
\hline BMI $\left(\mathrm{kg} / \mathrm{m}^{2}\right)$ & $29.7 \pm 0.5$ & $28.8 \pm 0.5$ & $29.6 \pm 0.5$ & $29.4 \pm 0.5$ & 0.71 & $<0.01$ & 0.01 \\
\hline Body fat (\%) & $37.4 \pm 0.9$ & $35.8 \pm 0.9$ & $37.5 \pm 0.9$ & $36.8 \pm 0.9$ & 0.67 & $<0.01$ & 0.08 \\
\hline Waist $(\mathrm{cm})$ & $104 \pm 1$ & $100 \pm 2$ & $104 \pm 1$ & $102 \pm 1$ & 0.66 & $<0.1$ & 0.06 \\
\hline Fasting glucose & $6.1 \pm 0.1$ & $6.0 \pm 0.1$ & $5.8 \pm 0.1$ & $5.9 \pm 0.1$ & 0.17 & 0.70 & 0.05 \\
\hline 2-hr glucose & $9.0 \pm 0.3$ & $8.1 \pm 0.3$ & $8.5 \pm 0.3$ & $8.7 \pm 0.3$ & 0.91 & 0.10 & $<0.01$ \\
\hline $\mathrm{HbA1c}(\%)$ & $6.0 \pm 0.1$ & $5.8 \pm 0.1$ & $5.9 \pm 0.1$ & $5.7 \pm 0.1$ & 0.26 & $<0.01$ & 0.12 \\
\hline Fasting insulin & $17.9 \pm 1.2$ & $15.5 \pm 1.1$ & $17.3 \pm 1.2$ & $17.4 \pm 1.1$ & 0.70 & 0.06 & 0.04 \\
\hline 2-hr insulin & $93 \pm 12$ & $78 \pm 9$ & $103 \pm 11$ & $107 \pm 9$ & 0.16 & 0.31 & 0.06 \\
\hline HOMA-IR & $5.00 \pm 0.40$ & $4.22 \pm 0.35$ & $4.58 \pm 0.39$ & $4.67 \pm 0.34$ & 0.98 & 0.08 & 0.03 \\
\hline $\mathrm{VO}_{2} \max$ & $40.9 \pm 1.0$ & $43.3 \pm 1.1$ & $39.8 \pm 1.0$ & $39.9 \pm 1.0$ & 0.11 & $<0.01$ & 0.01 \\
\hline
\end{tabular}

Mean \pm sem. Glucose is given in $\mathrm{mmol} / \mathrm{l}$, insulin in $\mathrm{mU} / 1, \mathrm{VO}_{2} \mathrm{max}$ in $\mathrm{ml} \mathrm{O}_{2}{ }^{*} \mathrm{kgFFM}^{-1} * \mathrm{~min}^{-1}$.

\section{Lifestyle intervention program}

The lifestyle intervention program consisted of a dietary and physical activity part. Dietary recommendations were based on the Dutch guidelines for a healthy diet [24] and consisted of: carbohydrate intake of at least 55 energy\% (E\%); total fat intake below 30-35 E\% combined with a saturated fat intake below $10 \mathrm{E} \%$; cholesterol intake < $33 \mathrm{mg} / \mathrm{MJ}$. No (very) low calorie diets were used. Dietary advice was given by a skilled dietician on an individual basis, after consideration of an individual 3-day weighed food record. The first visit took place 4-6 weeks after randomization. Thereafter, every three months a visit was scheduled. Subjects were stimulated to increase their physical activity to at least 30 minutes of moderate physical activity a day for at least 5 days a week [25]. At the start of the study individual advice was given how to increase daily physical activity (walking, cycling, swimming), and well-defined goals were set. Furthermore, subjects were encouraged to participate in an exercise program, especially designed for this study, with components of both aerobic exercise training and resistance training. Exercise sessions were supervised by trainers. Subjects had free access to these training sessions and were stimulated to participate at least one hour a week. Subjects in the control group received oral and written information about the beneficial effects of a healthy diet, weight loss and increased physical activity once a year, whereas no individual advice or programs were provided. 
Table 7.2. Dietary intake of macronutrients for the intervention and control group at baseline and after 1 year of a combined diet-exercise lifestyle intervention.

\begin{tabular}{|c|c|c|c|c|c|c|c|}
\hline & \multicolumn{2}{|c|}{ Intervention } & \multicolumn{2}{|c|}{ Control } & \multicolumn{3}{|c|}{ p-value } \\
\hline & baseline & one year & baseline & one year & group & time & $\begin{array}{c}\text { group } \\
x \\
\text { time }\end{array}$ \\
\hline $\begin{array}{l}n \\
(\mathrm{~m} / \mathrm{f})\end{array}$ & $\begin{array}{c}47 \\
(29 / 18)\end{array}$ & $\begin{array}{c}47 \\
(29 / 18)\end{array}$ & $\begin{array}{c}50 \\
(30 / 20)\end{array}$ & $\begin{array}{c}50 \\
(30 / 20)\end{array}$ & & & \\
\hline Enery intake (MJ/day) & $9.2 \pm 0.4$ & $8.2 \pm 0.3$ & $8.6 \pm 0.4$ & $8.4 \pm 0.3$ & 0.63 & $<0.01$ & 0.07 \\
\hline Carbohydrates (E\%) & $42 \pm 1$ & $47 \pm 1$ & $43 \pm 1$ & $44 \pm 1$ & 0.61 & $<0.01$ & $<0.01$ \\
\hline Fat $(\mathrm{E} \%)$ & $35.9 \pm 0.9$ & $30.7 \pm 0.9$ & $35.3 \pm 0.9$ & $34.0 \pm 0.9$ & 0.21 & $<0.01$ & $<0.01$ \\
\hline SFA (E\%) & $13.6 \pm 0.4$ & $11.3 \pm 0.5$ & $13.7 \pm 0.4$ & $13.0 \pm 0.4$ & 0.08 & $<0.01$ & 0.01 \\
\hline MUFA (E\%) & $13.0 \pm 0.4$ & $10.9 \pm 0.4$ & $12.7 \pm 0.4$ & $12.0 \pm 0.4$ & 0.36 & $<0.01$ & 0.02 \\
\hline PUFA (E\%) & $6.8 \pm 0.3$ & $6.3 \pm 0.3$ & $6.5 \pm 0.3$ & $6.5 \pm 0.3$ & 0.82 & 0.30 & 0.28 \\
\hline Cholesterol (mg/MJ) & $27 \pm 1$ & $22 \pm 2$ & $26 \pm 1$ & $25 \pm 1$ & 0.56 & $<0.01$ & 0.04 \\
\hline Protein $(\mathrm{E} \%)$ & $16.5 \pm 0.5$ & $17.5 \pm 0.5$ & $16.0 \pm 0.5$ & $16.0 \pm 0.5$ & 0.07 & 0.15 & 0.21 \\
\hline Fibre (g/MJ) & $2.7 \pm 0.1$ & $3.3 \pm 0.1$ & $2.7 \pm 0.1$ & $2.8 \pm 0.1$ & 0.09 & $<0.01$ & $<0.01$ \\
\hline Alcohol (E\%) & $5.5 \pm 0.9$ & $4.7 \pm 0.9$ & $5.4 \pm 0.9$ & $5.4 \pm 0.9$ & 0.75 & 0.48 & 0.51 \\
\hline
\end{tabular}

Means \pm sem.

\section{Measurements}

Glucose tolerance was monitored with a standard glucose tolerance test with venous blood sampling at baseline and after 2 hours [22]. During the same visit, body weight was measured to the nearest $0.1 \mathrm{~kg}$ on an electronical scale, with the subject wearing only light clothing. Height was measured to the nearest $0.5 \mathrm{~cm}$ without shoes. Skinfold thickness was measured twice using a skinfold caliper at the triceps, biceps, subscapular and suprailiacal region. The sum of skinfolds was used to calculate body fat percentage [26]. Waist circumference (waist) was measured with the subject in standing position at the level midway between the lowest rib and iliacal crest to the nearest $0.5 \mathrm{~cm}$. A 3-day weighed food record (two weekdays and one weekend day) was kept in the two weeks just before the visit. Food records were checked by a dietician and the intake of nutrients was calculated with a validated computer program using the Dutch food table (NEVO). An incremental exhaustive exercise test was performed on an electronically braked bicycle ergometer to determine the maximal power output (Watt) and maximal oxygen consumption ( $\left.\mathrm{VO}_{2} \mathrm{max}\right)$.

\section{Biochemical analysis and calculations}

Plasma glucose was measured with a standard enzymatic technique automated on the Cobas Fara centrifugal analyzer (Glucose HK 125, ABX Diagnostics, Montpellier, France). Plasma insulin was measured with an ELISA assay (Mercodia, Uppsala, Sweden) with no cross-reactivity with pro-insulin. The 
HOMA index for insulin resistance (HOMA-IR) was calculated as described by Matthews et al. [27]. The HOMA index is the outcome of a mathematical model based on dose-response curves for glucose uptake and insulin production in a fasting, steady-state condition. Although it is not suitable for use at the individual level, as is the hyperinsulinemic euglycemic clamp, it is a fairly good marker for insulin resistance in larger groups $(\mathrm{n}>30)$ and is a better marker for insulin resistance than fasting insulin, in particular in obese and/or IGT subjects [28]. Glycated hemoblobin $(\mathrm{HbA} 1 \mathrm{c})$ was determined in fasting serum with HPLC (reference values for our laboratory $4.4-6.2 \%$ ).

The fatty acid profile of serum cholesteryl esters was determined by GCFID after solid phase extraction adapted from Agren and coworkers [29]. Shortly after deproteination and chloroform extraction the lipid extract was applied onto an aminopropyl solid-phase column (Bond-Elut NH2 $200 \mathrm{mg}$, Varian Ass, Middelburg, The Netherlands) and the cholesteryl-bound fatty acids were eluted with hexane. After hydrolysis and methylation, the fatty acid methyl esters (FAME) were separated on a $100 \times 0.25 \mathrm{~mm}$ ID WCOT fused silica capillary column using a GC-3900 gas chromatograph (Varian Ass.). Galaxie software (Varian Ass.) was used for quantification and identification of peaks. The relative amount of each fatty acid (\% of total fatty acids) was quantified by integrating the area under the peak and dividing the result by the total area of all fatty acids. The activity of $\Delta 5$-desaturase activity was estimated as the product-to-precursor ratio of the proportion of arachidonic acid (C20:4 n-6) to dihomo-gamma-linolenic acid (C20:3 n-6), the $\Delta 6$-desaturase activity was estimated as the proportion of gammalinolenic acid (C18:3 n-6) to linoleic acid (C18:2 n-6) and the $\Delta 9$-desaturase activity was estimated as the proportion palmitoleic acid (C16:1 n-7) to palmitic acid (C16:0).

\section{Statistical analysis}

Correlations were tested using Pearson's correlation coefficient (r), twotailed. Analysis of Variance (ANOVA) for repeated measures was used to test differences between groups and changes over time. Regression analysis was performed to identify the contribution of changes in lifestyle and fatty acid profile to changes in insulin resistance (HOMA-IR). When testing a one-year change as the dependent variable, the mean of the dependent variable ((year $0+$ year 1$) / 2$ ) was included in the model to correct for regression to the mean. Regression analysis was also performed with adjustment for the means of all variables, but this did not add to the explained variance of the model and did not change the outcomes, so only the mean of the dependent variable was included. All one-year changes were calculated as year 1 - year 0 . To investigate whether the relation 
between changes in desaturase activity and changes in insulin resistance was dependent on changes in lifestyle, we tested the contribution of desaturase activity alone (model 1), adjusted for the mean of the dependent variable. Then we added the intake of SFA as a reflection in changes in the diet (model 2), $\mathrm{VO}_{2}$ max as a reflection of changes in physical activity (model 3) and body fat percentage (model 4). None of these regression parameters showed intercorrelations larger than 0.6. HOMA index was ln-transformed to obtain a normal distribution. For regression analysis the beta coefficients and their $95 \%$ confidence intervals are presented. Other data are expressed as mean \pm sem. A p-value $<0.05$ was considered as statistically significant. Statistical analysis was performed using SPSS 10.0 for Macintosh.

\section{RESULTS}

\section{General lifestyle effects}

After one year of lifestyle intervention, body weight and BMI were reduced and $\mathrm{VO}_{2}$ max had increased, together with improvements in $2 \mathrm{hr}$ glucose values, fasting insulin and HOMA index for insulin resistance (Table 7.1.). The lifestyle intervention was effective to increase the intake of carbohydrates and fibre and to reduce the intake of total fat, saturated fat and concomitantly reduced mono-unsaturated fat intake (Table 7.2.), as previously reported in a smaller group in the same intervention study [22]. The reported intake of polyunsaturated fatty acids (PUFA) correlated well with poly-unsaturated fatty acids in serum, both at baseline $(\mathrm{r}=0.44, \mathrm{p}<0.05)$ and after one year $(\mathrm{r}=0.42, \mathrm{p}<0.001)$. This indicates that the reported intakes of fatty acids were well recorded and estimated.

\section{Serum fatty acid profile, glucose tolerance and insulin sensitivity}

After one year of lifestyle intervention, no direct changes were observed in individual fatty acids fractions. However, changes in several specific fatty acid fractions of the cholesteryl esters were related to changes in insulin resistance after 1 year (Table 7.3.). One-year changes in serum fractions of myristic (C14:0), palmitoleic acid (C16:1 n-7), $\gamma$-linolenic acid (C18:3 n-6) and dihomo- $\gamma$-linolenic acid (c20:3 n-6) correlated positively with changes in HOMA-IR, whereas this relation was inverse for oleic acid (C18:1 n-9) and arachidonic acid (C20:4 n-6). One-year decreases in estimated $\Delta 9$ - and $\Delta 6$-desaturase activities and an increase 
Table 7.3. Fatty acid fractions of serum cholesteryl esters at baseline, one-year changes in fatty acid fractions and the relation between changes in fatty acid fractions and lifestyle-induced changes in HOMA index for insulin resistance.

\begin{tabular}{|c|c|c|c|}
\hline & $\begin{array}{c}\text { baseline value } \\
\text { Mean } \pm \text { sem }\end{array}$ & $\begin{array}{c}\text { one-year change } \\
\text { Mean (range) }\end{array}$ & $\begin{array}{c}\Delta \text { homa-ir (ln) } \\
\mathrm{r}\end{array}$ \\
\hline $14: 0$ & $0.84 \pm 0.02$ & $-0.013(-0.49 ; 0.55)$ & $0.28 * *$ \\
\hline $16: 0$ & $11.7 \pm 0.1$ & $-0.005(-1.76 ; 1.60)$ & -0.13 \\
\hline $16: 1 \mathrm{n}-7$ & $3.4 \pm 0.1$ & $-0.06(-2.44 ; 2.46)$ & $0.22 *$ \\
\hline $18: 0$ & $0.95 \pm 0.02$ & $0.01(-0.45 ; 0.26)$ & -0.14 \\
\hline $18: 1 \mathrm{n}-9$ & $16.9 \pm 0.2$ & $0.51(-3.84 ; 5.82)$ & $-0.28 * *$ \\
\hline $18: 2 n-6$ & $52.7 \pm 0.5$ & $-0.49(-9.06 ; 5.46)$ & +0.19 \\
\hline $18: 3 n-3$ & $0.61 \pm 0.01$ & $0.04(-0.28 ; 0.60)$ & +0.13 \\
\hline $18: 3 n-6$ & $1.06 \pm 0.04$ & $0.04(-1.13 ; 1.59)$ & $+0.32 * *$ \\
\hline $20: 3 n-6$ & $0.87 \pm 0.02$ & $-0.001(-0.57 ; 0.32)$ & $+0.20^{*}$ \\
\hline $20: 4 n-6$ & $7.3 \pm 0.2$ & $-0.08(-3.22 ; 3.14)$ & $-0.29 * *$ \\
\hline $20: 5 n-3$ & $1.11 \pm 0.06$ & $0.02(-2.98 ; 1.14)$ & +0.14 \\
\hline $22: 6 n-3$ & $0.63 \pm 0.02$ & $0.00(-0.52 ; 0.36)$ & -0.13 \\
\hline$C 20: 4 n-6 / C 20: 3 n-6$ & $8.69 \pm 2.59$ & $-0.14(-8.92 ; 9.14)$ & $-0.31 * *$ \\
\hline C18:3 n-6/C18:2 n-6 & $0.021 \pm 0.008$ & $0.001(-0.022 ; 0.032)$ & $+0.28 * *$ \\
\hline C16:0/C16:1 n-7 & $0.286 \pm 0.109$ & $-0.005(-0.19 ; 0.25)$ & $+0.24 *$ \\
\hline
\end{tabular}

Fatty acid fractions of serum cholesteryl esters are expressed as $\%$ of total. $n=97 .{ }^{*} p<0.05 ;{ }^{* *} p<0.01$.

in estimated $\Delta 5$-desaturase were related to a reduction in HOMA index for insulin resistance (Table 7.3.).

To investigate whether the relation between desaturase activity and insulin resistance was dependent on changes in lifestyle, we performed regression analysis and presented the standardized beta coefficients of the estimated desaturase activities after the addition of changes in SFA intake, $\mathrm{VO}_{2}$ max and body fat percentage (Table 7.4.). The results show that the changes in $\Delta 9$-and $\Delta 6$ desaturase were positively related and changes in $\Delta 5$-desaturase were inversely related to changes in HOMA-IR. These relations remained statistically significant after adjustment for changes in lifestyle factors and body fat percentage for $\Delta 9$ and $\Delta 6$-desaturase and for $\Delta 5$-desaturase. The beta-coefficients of $\Delta 9$ - and $\Delta 6-$ desaturase were reduced after the addition of $\mathrm{VO}_{2} \max (-13 \%$ and $-14 \%$ respectively, model 3 ) and body fat percentage $(-24 \%$ and $-4 \%$ respectively, model 4 ) to the model, whereas the beta-coefficient of $\Delta 5$-desaturase only changed after correction for body fat percentage (-16\%, model 4$)$.

Since sometimes the correlation of a parameter with HOMA-IR can be fully explained by one component of the HOMA-index, we explored the associations of fasting glucose and fasting insulin with different fatty acid variables as well. We found that analysis of changes in fasting glucose or insulin as the dependent variable revealed significant correlations to changes in $\Delta 9-, \Delta 6$, and $\Delta 5$-desaturase indices as well. For the change in fasting insulin and changes in 
Table 7.4. Regression model for changes after 1 year: relationships between changes in HOMA-IR (In) and changes in estimated desaturase activity.

\begin{tabular}{|c|c|c|c|c|c|c|c|}
\hline & & $\begin{array}{l}\text { Std Beta }(95 \% \mathrm{CI}) \text { of } \Delta 9- \\
\text { desaturase activity }\end{array}$ & $\mathrm{aR}^{2}$ & $\begin{array}{l}\text { Std Beta }(95 \% \mathrm{CI}) \text { of } \Delta 6- \\
\text { desaturase activity }\end{array}$ & $\mathrm{aR}^{2}$ & $\begin{array}{l}\text { Std Beta }(95 \% \mathrm{CI}) \text { of } \Delta 5- \\
\text { desaturase activity }\end{array}$ & $\mathrm{aR}^{2}$ \\
\hline 1 & Desaturase & $0.234 *(0.032 ; 0.438)$ & 0.04 & $0.278 * *(0.077 ; 0.479)$ & 0.06 & $-0.307 * *(-0.501 ;-0.108)$ & 0.08 \\
\hline \multirow[t]{2}{*}{2} & Desaturase & $0.251 *(0.055 ; 0.448)$ & 0.10 & $0.274 * *(0.079 ; 0.479)$ & 0.11 & $-0.296 * *(-0.484 ;-0.102)$ & 0.13 \\
\hline & SFA_intake & $0.271 * *(0.076 ; 0.466)$ & & $0.252 *(0.059 ; 0.437)$ & & $0.242 *(0.050 ; 0.426)$ & \\
\hline \multirow[t]{3}{*}{3} & Desaturase & $0.218 *(0.028 ; 0.406)$ & 0.18 & $0.237 *(0.050 ; 0.426)$ & 0.19 & $-0.301 * *(-0.478 ;-0.118)$ & 0.23 \\
\hline & SFA intake & $0.281 * *(0.094 ; 0.468)$ & & $0.264 * *(0.085 ; 0.451)$ & & $0.255^{* *}(0.077 ; 0.434)$ & \\
\hline & $\mathrm{VO}_{2} \max$ & $-0.295 * *(-0.492 ;-0.111)$ & & $-0.289 * *(-0.470 ;-0.108)$ & & $-0.324 * *(-0.504 ;-0.144)$ & \\
\hline \multirow[t]{4}{*}{4} & Desaturase & $0.167 *(0.005 ; 0.331)$ & 0.40 & $0.226^{* *}(0.068 ; 0.386)$ & 0.43 & $-0.254 * *(-0.405 ;-0.097)$ & 0.44 \\
\hline & SFA intake & $0.194 *(0.034 ; 0.354)$ & & $0.178 *(0.025 ; 0.331)$ & & $0.175 *(0.017 ; 0.325)$ & \\
\hline & $\mathrm{VO}_{2} \max$ & $-0.310 * *(-0.465 ;-0.155)$ & & $-0.301 * *(-0.458 ;-0.144)$ & & $-0.332 * *(-0.474 ;-0.178)$ & \\
\hline & $\mathrm{BF} \%$ & $0.478^{* *}(0.315 ; 0.635)$ & & $0.491 * *(0.333 ; 0.649)$ & & $0.470 * *(0.317 ; 0.629)$ & \\
\hline & $\begin{array}{l}=97 .{ }^{*} \mathrm{p}<0.0 \\
\text { lare; Desatur } \\
\text { percentage. } \\
\text { del 1: chang } \\
\text { del 2: + cha } \\
\text { del 3: + cha }\end{array}$ & $\begin{array}{l}* * \mathrm{p}<0.01 \text {. Std Beta, stan } \\
\mathrm{e}, \text { desaturase activity mer } \\
\text { in desaturase activity, adj } \\
\mathrm{e} \text { in SFA intake ( } \mathrm{en} \%) \\
\mathrm{e} \text { in } \mathrm{VO}_{2} \mathrm{max}\left(\mathrm{ml} \mathrm{O}_{2} / \mathrm{kg} \mathrm{f}\right.\end{array}$ & dardize & $\begin{array}{l}\text { d Beta-coefficient; CI, co } \\
\text { above the column; SFA } \\
\text { or mean HOMA-IR. }\end{array}$ & $\begin{array}{l}\text { nfider } \\
\text { ntake }\end{array}$ & $\begin{array}{l}\text { ce interval; aR2adjusted } \mathrm{F} \\
\text { saturated fat intake; } \mathrm{BF} \%\end{array}$ & body \\
\hline
\end{tabular}

$\Delta 9-, \Delta 6-$, and $\Delta 5$-desaturase this was: $\mathrm{r}=0.151(\mathrm{p}=0.067), \mathrm{r}=0.196(\mathrm{p}=0.016)$ and $\mathrm{r}$ $=-0.243(\mathrm{p}=0.002)$, respectively. For the change in fasting glucose and changes in $\Delta 9-, \Delta 6-$, and $\Delta 5$-desaturase this was: $r=0.199(p=0.045), r=0.287(p=0.003)$ and $r$ $=-0.210(p=0.033)$, respectively. These data reveal that we cannot appoint one specific component of the HOMA-IR index (glucose or insulin) that could explain the correlations with HOMA-IR. It appears that both impaired glucose as well as impaired insulin concentrations are relevant, indicating impairments in the regulation of glucose metabolism. Since insulin resistance is most likely to be central to these impairments, we chose to present the data on HOMA-IR.

Interestingly, the relationships between changes in the estimated desaturase enzyme activities and changes in HOMA-IR were modified by total fat intake. Regression analysis revealed that changes in $\Delta 9$ - and $\Delta 6$-desaturase contributed significantly to the HOMA-IR model in subjects with a total fat intake $<35.5 \mathrm{E} \%$ (Figures 7.1A and 7.1C), which followed a similar pattern as was observed in the group as a whole, whereas in subjects with a fat intake above 35.5 $\mathrm{E} \%$, no significant association was found (Figures 7.1B and 7.1D). Also in regression analysis of the total group, a relevant interaction between fat intake (below or above $35.5 \mathrm{E} \%$ ) and change in $\Delta 9$-desaturase activity was found ( $\mathrm{p}=$ $0.13)$. The correlation between the change in $\Delta 5$-desaturase and insulin resistance was not affected by total fat intake (Figures 7.1E and 7.1F). 


\section{DISCUSSION}

A strong relation between the lifestyle-induced changes in insulin resistance and the changes in cholesteryl ester fatty acid profile were found after one year. An improvement in insulin resistance was typically associated with a reduction in myristic acid (C14:0), palmitoleic acid (C16:1 n-7), $\gamma$-linolenic acid (C18:3 n-6) and dihomo- $\gamma$-linolenic acid (c20:3 n-6) fractions, an increase in oleic acid (C18:1 n-9) and arachidonic acid (C20:4 n-6)fractions; and was further characterized by a decrease in estimated $\Delta 9$-desaturase (SCD-1) and $\Delta 6$-desaturase activities and an increase in $\Delta 5$-desaturase activity.

This specific pattern of individual fatty acids (high myristic, palmitoleic, $\gamma$-linolenic and dihomo- $\gamma$-linolenic acid fractions and a low arachidonic acid fraction) is typical for insulin resistance and is very consistent with previous reports $[5,9,18,30]$. Furthermore, we found a positive relation between one-year changes in oleic acid fractions and changes in insulin sensitivity, which is in line with most, but not all previous studies. On the one hand, dietary studies have found that insulin sensitivity is inversely associated with oleic acid fractions [18, 30]. On the other hand, exercise, assumed to be related to insulin sensitivity, is positively associated with high oleic acid fractions [19]. In addition, the replacement of dietary SFA by MUFA, (predominantly oleic acid) improved insulin sensitivity [8], which supports the positive relation between changes in serum oleic acid and insulin sensitivity in the present study.

The relation between insulin sensitivity and n-3 poly-unsaturated fatty acids is less clear. The present study shows no correlation between EPA (C20:5 n3) or DHA (C22:6 n-3) and insulin resistance (Table 7.3.). This is in accordance with other studies using other measures of insulin resistance, such as the euglycemic hyperinsulinemic clamp or an intravenous glucose tolerance test $[8$, $31,32,33]$.

The present study shows that also changes in insulin resistance were inversely related to the changes in $\Delta 5$-desaturase activity and positively to changes in $\Delta 6$ desaturase and $\Delta 9$-desaturase activities. Desaturase enzymes may be important in the development of insulin resistance, since mice with a $\Delta 9$-desaturase deficiency are very insulin sensitive [13], and a the $\Delta 9$-desaturase mRNA level in human skeletal muscle was positively related to the amount of triglyceride accumulation [15]. This accumulation of triglycerides in skeletal muscle is strongly associated with insulin resistance in sedentary subjects [34-36].

The associations between changes in $\Delta 9-, \Delta 6$ - and $\Delta 5$-desaturase activities and changes in insulin resistance in the present study were influenced by changes in saturated fat intake, $\mathrm{VO}_{2}$ max and/or body fat percentage, which suggests that desaturase activities are affected by lifestyle. The finding that lifestyle affects fatty 
acid profile is supported by both rodent and human studies. In mice, it was shown that a high fat diet increased the $\Delta 9$-desaturase activity in the liver [37, 38]. Dietary intervention studies in humans have shown that replacing saturated dietary fat by unsaturated dietary fat reduced the estimated $\Delta 6$-desaturase and $\Delta 9$-desaturase activities, and increased the estimated $\Delta 5$-desaturase activity [16]. Also an increased physical activity correlated with an increased estimated $\Delta 5$-desaturase activity in skeletal muscle phospholipids [20].

Part of the relation between changes in insulin resistance and the changes in $\Delta 6$-desaturase and $\Delta 9$-desaturase activity may be a direct consequence of changes in lifestyle. The finding that these associations nevertheless remained present after adjustment for lifestyle factors (saturated fat intake, $\mathrm{VO}_{2} \mathrm{max}$ and body fat percentage) indicates that changes in desaturase activities are also affected by endogenous factors. Many dietary, hormonal and environmental factors are involved in the regulation of $\Delta 9$-desaturase and most likely also of $\Delta 6$ and $\Delta 5$-desaturase $[10,39]$. Therefore, we cannot exclude that insulin resistance as such may have had an effect on desaturase activities. Other factors that may be involved are changes in insulin [40] or glucose itself, changes in leptin concentration [41] or changes in fatty acid handling with different preferences for saturated or unsaturated fatty acids in lipolytic and oxidative processes [42, 43]. For the future it remains a challenge to elucidate whether and how lifestyle factors can modify desaturase enzyme activities with consequences for the insulin resistant state, and on the other hand whether and how changes in metabolic profile, e.g. insulin resistance, may in its turn affect desaturase enzyme activity.

A general hypothesis on the molecular background of the relation between desaturase enzymes and insulin resistance is that desaturase enzymes can change the fatty acid composition of cell membranes, which influence membrane fluidity. This may result in changes in insulin receptor binding or affinity, membrane ion permeability and cell signalling [3]. Furthermore, $\Delta 9$ desaturase may produce precursors for compounds that have been associated with insulin resistance, like ceramide [13]. The $\Delta 6$ and $\Delta 5$-desaturases are involved in the synthesis of highly unsaturated fatty acids. These highly unsaturated fatty acids can be ligands for transcription factors like PPARs, HNF4, NFкB, and SREBP, which interact with genes that are involved in lipogenesis and fatty acid oxidation [12].

In the present study, the relations between changes in fatty acid profile and changes in insulin resistance were modified by total fat intake (Figure 7.1). The association of changes in estimated $\Delta 9$ - and $\Delta 6$-desaturase activity with changes in insulin sensitivity were more pronounced in subjects with a lower total fat intake (<35.5 E\%). This has been reported previously in the KANWU study, a large diet-controlled study [8]. In that study, the impact of fatty acid profile, 


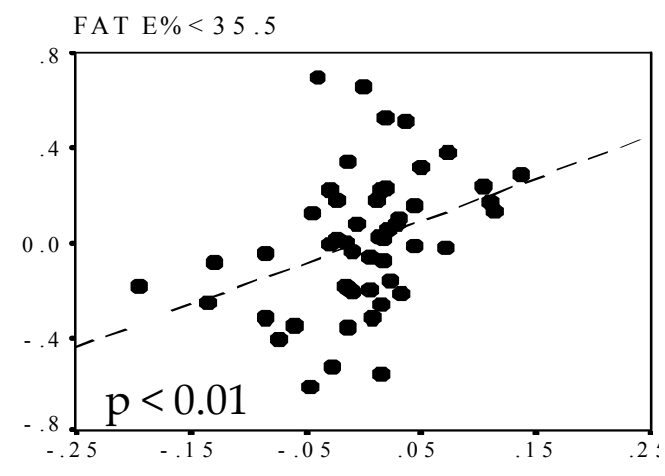

change in d $9-$ desaturase

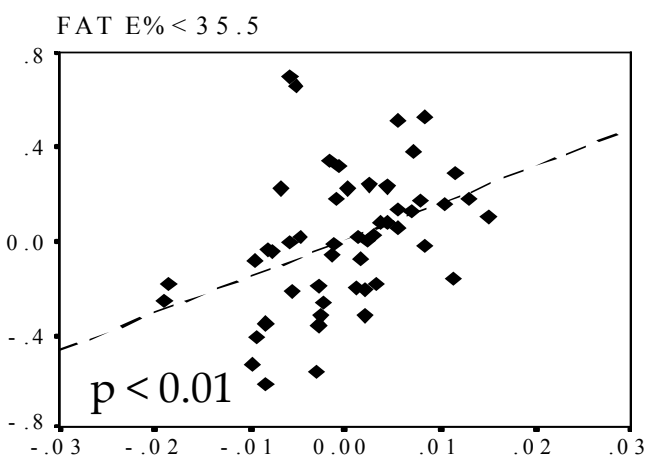

change in d 6 -desaturase

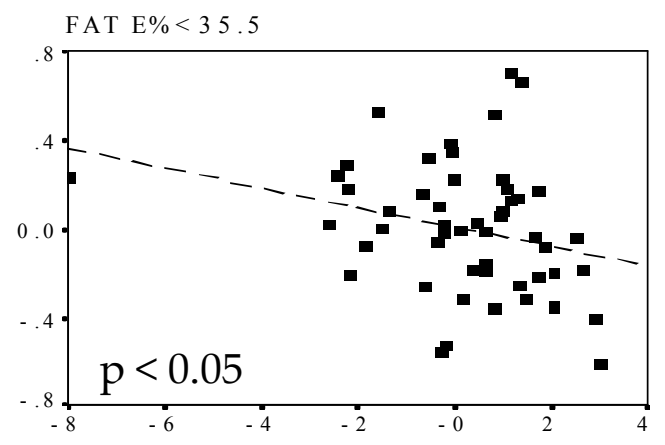

change in d $5-$ desaturase

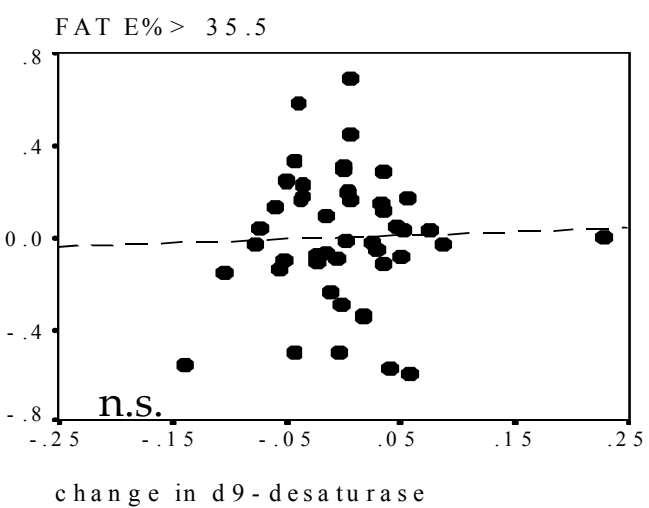

FAT E\% $>35.5$

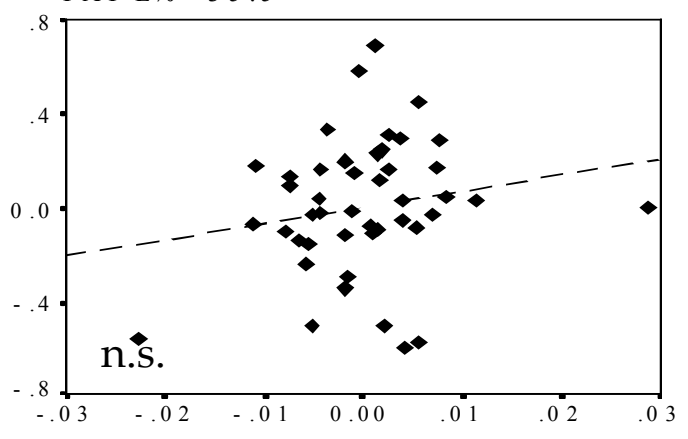

change in d $6-$ desaturase

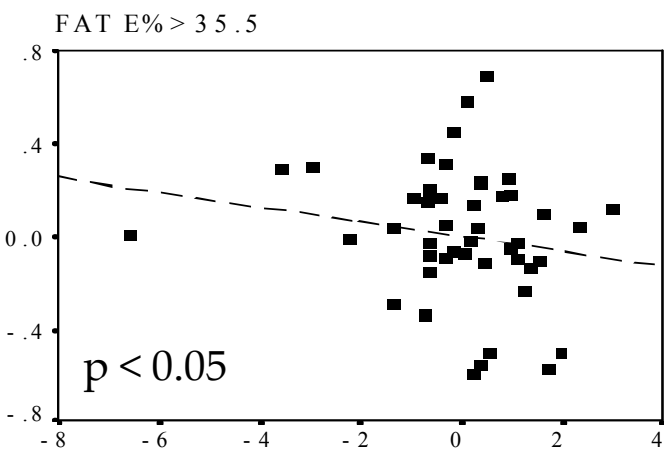

change in d $5-$ desaturase

Figure 7.1. Regression model for changes after 1 year: changes in HOMA-IR (ln) related to changes in estimated $\Delta 9$-desaturase activity $(a, b), \Delta 6$-desaturase activity $(c, d)$ and $\Delta 5$-desaturase activity $(e$, $f)$ in subjects with a total dietary fat intake below $(a, c, e)$ or above median $(35.5 E \%)(b, d, f)$. Partial correlations adjusted for mean HOMA-IR, change in SFA intake, change in VOzmax and change in body fat percentage (model 4). n.s. = not significant

reflecting dietary fat quality, on insulin sensitivity was mainly observed in subjects with a total fat intake below median $(<37 \mathrm{E} \%)$. This emphasises that both the quality and quantity of dietary fat intake are relevant in relation to insulin resistance. It also shows that a high fat intake may mask the potential relationship between fat quality and insulin resistance. The correlation between the change in 
$\Delta 5$-desaturase and insulin resistance was not affected by total fat intake (Figure 7.1 and Table 7.4.) nor by physical activity (Table 7.4.), which suggests that $\Delta 5$ desaturase activity may be less influenced by environmental factors than $\Delta 9$ - and $\Delta 6$-desaturase activity. A previous study examined the predictive effect of desaturase indices on the development of the metabolic syndrome, and found that the relation between $\Delta 9$ - and $\Delta 6$-desaturase and the development of the metabolic syndrome diminished after adjustment for BMI + smoking habit + physical activity, whereas the predictive value of $\Delta 5$-desaturase on the development of the metabolic syndrome was not affected after adjustment for BMI or physical activity [18].

In the present study, both insulin sensitivity and desaturase activity were measured with indirect measures. Nevertheless, the present data should be considered as a clear indication for the relationship between insulin resistance and fatty acid profile, including the activity of desaturase enzymes, which deserves further investigation. Mechanistic studies using more direct measures such as the hyperinsulinemic euglycemic clamp and analysis of desaturase activity and mRNA expression in a variety of tissues will be the next step to elucidate the relation between desaturase enzymes and lifestyle-induced changes in insulin sensitivity.

In summary, lifestyle-induced improvements in insulin sensitivity are independently explained by specific changes in fatty acid profile of serum cholesteryl esters. Moreover, an increase in insulin sensitivity is associated with an increase in estimated $\Delta 5$-desaturase activity and a decrease in estimated $\Delta 6$ - and $\Delta 9$-desaturase activities. The associations between changes in $\Delta 9-, \Delta 6-$ and $\Delta 5$ desaturase activities and changes in insulin resistance remained significant after adjustment for changes in diet, $\mathrm{VO}_{2} \mathrm{max}$ and/or body fat percentage. We conclude that lifestyle-induced changes in insulin sensitivity are partly related to changes in fatty acid profile, in particular to changes in desaturase activities. The association between insulin resistance and desaturase activities is depending on lifestyle, but also on changes in other, more endogenous factors that remain to be identified in the future.

\section{ACKNOWLEDGEMENTS}

We want to thank Jos Stegen and Hans Cremers for their excellent support for the analytical measurements. Furthermore we want to thank Tanja HermansLimpens, Ilse Nijs and Marja Ockeloen - van der Hulst for running the dietary intervention. This work was supported by grants from the Dutch Diabetes Research Foundation (DFN 98.901 and DFN 2000.00.020) and the Netherlands Organization for Scientific Research (ZonMW 940-35-034 and 2200.0139). 


\section{REFERENCES}

1 Feskens EJ and van Dam RM (1999) Dietary fat and the etiology of type 2 diabetes: an epidemiological perspective. Nutr Metab Cardiovasc Dis 9:87-95

2 Hu FB, van Dam RM and Liu S (2001) Diet and risk of Type II diabetes: the role of types of fat and carbohydrate. Diabetologia 44:805-817

3 Riccardi G, Giacco R and Rivellese AA (2004) Dietary fat, insulin sensitivity and the metabolic syndrome. Clin Nutr 23:447-456

4 Pelikanova T, Kohout M, Valek J, Base J and Kazdova L (1989) Insulin secretion and insulin action related to the serum phospholipid fatty acid pattern in healthy men. Metabolism 38:188-192

5 Vessby B, Tengblad S and Lithell H (1994) Insulin sensitivity is related to the fatty acid composition of serum lipids and skeletal muscle phospholipids in 70-year-old men. Diabetologia 37:1044-1050

6 Vessby B, Aro A, Skarfors E, Berglund L, Salminen I and Lithell H (1994) The risk to develop NIDDM is related to the fatty acid composition of the serum cholesterol esters. Diabetes 43:1353-1357

7 Wang L, Folsom AR, Zheng ZJ, Pankow JS and Eckfeldt JH (2003) Plasma fatty acid composition and incidence of diabetes in middle-aged adults: the Atherosclerosis Risk in Communities (ARIC) Study. Am J Clin Nutr 78:91-98

8 Vessby B, Unsitupa M, Hermansen K, et al. (2001) Substituting dietary saturated for monounsaturated fat impairs insulin sensitivity in healthy men and women: The KANWU Study. Diabetologia 44:312-319

9 Summers LK, Fielding BA, Bradshaw HA, et al. (2002) Substituting dietary saturated fat with polyunsaturated fat changes abdominal fat distribution and improves insulin sensitivity. Diabetologia 45:369-377

10 Nakamura MT and Nara TY (2004) Structure, function, and dietary regulation of delta6, delta5, and delta9 desaturases. Annu Rev Nutr 24:345-376

11 Dobrzyn A and Ntambi JM (2004) The role of stearoyl-CoA desaturase in body weight regulation. Trends Cardiovasc Med 14:77-81

12 Jump DB and Clarke SD (1999) Regulation of gene expression by dietary fat. Annu Rev Nutr 19:63-90

13 Dobrzyn A, Dobrzyn P, Lee SH, et al. (2005) Stearoyl-CoA desaturase-1 deficiency reduces ceramide synthesis by downregulating serine palmitoyltransferase and increasing beta-oxidation in skeletal muscle. Am J Physiol Endocrinol Metab 288:E599-607

14 Borkman M, Storlien LH, Pan DA, Jenkins AB, Chisholm DJ and Campbell LV (1993) The relation between insulin sensitivity and the fatty-acid composition of skeletalmuscle phospholipids. N Engl J Med 328:238-244 
15 Hulver MW, Berggren JR, Carper MJ, et al. (2005) Elevated stearoyl-CoA desaturase-1 expression in skeletal muscle contributes to abnormal fatty acid partitioning in obese humans. Cell Metab 2:251-261

16 Vessby B, Gustafsson IB, Tengblad S, Boberg M and Andersson A (2002) Desaturation and elongation of Fatty acids and insulin action. Ann N Y Acad Sci 967:183-195

17 Kelley DE, Goodpaster BH and Storlien L (2002) Muscle triglyceride and insulin resistance. Annu Rev Nutr 22:325-346

18 Warensjo E, Riserus U and Vessby B (2005) Fatty acid composition of serum lipids predicts the development of the metabolic syndrome in men. Diabetologia 48:19992005

19 Andersson A, Sjodin A, Olsson R and Vessby B (1998) Effects of physical exercise on phospholipid fatty acid composition in skeletal muscle. Am J Physiol 274:E432-438

20 Andersson A, Sjodin A, Hedman A, Olsson R and Vessby B (2000) Fatty acid profile of skeletal muscle phospholipids in trained and untrained young men. Am J Physiol Endocrinol Metab 279:E744-751

21 Mensink M, Blaak EE, Corpeleijn E, Saris WH, de Bruin TW and Feskens EJ (2003) Lifestyle intervention according to general recommendations improves glucose tolerance. Obes Res 11:1588-1596

22 Mensink M, Corpeleijn E, Feskens EJ, et al. (2003) Study on lifestyle-intervention and impaired glucose tolerance Maastricht (SLIM): design and screening results. Diabetes Res Clin Pract 61:49-58

23 World Health Organization (1999) Definition, diagnosis and classification of diabetes mellitus and its complications. Report of a WHO consultation part 1: diagnosis and classification of diabetes mellitus. WHO technical report series 1-59

24 Commissie Voedingsnormen en Voedingsraad (1992) Nederlandse voedingsnormen 1989. Den Haag: voorlichtingsbureau voor de voeding.

25 American College of Sports Medicine Position Stand (1998) The recommended quantity and quality of exercise for developing and maintaining cardiorespiratory and muscular fitness, and flexibility in healthy adults. Med Sci Sports Exerc 30:975991

26 Durnin JV and Womersley J (1974) Body fat assessed from total body density and its estimation from skinfold thickness: measurements on 481 men and women aged from 16 to 72 years. Br J Nutr 32:77-97

27 Matthews DR, Hosker JP, Rudenski AS, Naylor BA, Treacher DF and Turner RC (1985) Homeostasis model assessment: insulin resistance and beta-cell function from fasting plasma glucose and insulin concentrations in man. Diabetologia 28:412-419

28 Wallace TM, Levy JC and Matthews DR (2004) Use and abuse of HOMA modeling. Diabetes Care 27:1487-1495

29 Agren JJ, Julkunen A and Penttila I (1992) Rapid separation of serum lipids for fatty acid analysis by a single aminopropyl column. J Lipid Res 33:1871-1876 
30 Vessby B (2000) Dietary fat and insulin action in humans. Br J Nutr 83 Suppl 1:S91-96

31 Borkman M, Chisholm DJ, Furler SM, et al. (1989) Effects of fish oil supplementation on glucose and lipid metabolism in NIDDM. Diabetes 38:1314-1319

32 McManus RM, Jumpson J, Finegood DT, Clandinin MT and Ryan EA (1996) A comparison of the effects of n-3 fatty acids from linseed oil and fish oil in wellcontrolled type II diabetes. Diabetes Care 19:463-467

33 Rivellese AA, Maffettone A, Iovine C, et al. (1996) Long-term effects of fish oil on insulin resistance and plasma lipoproteins in NIDDM patients with hypertriglyceridemia. Diabetes Care 19:1207-1213

34 Pan DA, Lillioja S, Kriketos AD, et al. (1997) Skeletal muscle triglyceride levels are inversely related to insulin action. Diabetes 46:983-988

35 Krssak M, Falk Petersen K, Dresner A, et al. (1999) Intramyocellular lipid concentrations are correlated with insulin sensitivity in humans: a $1 \mathrm{H}$ NMR spectroscopy study. Diabetologia 42:113-116.

36 Schmitz-Peiffer C (2000) Signalling aspects of insulin resistance in skeletal muscle: mechanisms induced by lipid oversupply. Cell Signal 12:583-594

37 Hu CC, Qing K and Chen Y (2004) Diet-induced changes in stearoyl-CoA desaturase 1 expression in obesity-prone and -resistant mice. Obes Res 12:1264-1270

38 Biddinger SB, Almind K, Miyazaki M, Kokkotou E, Ntambi JM and Kahn CR (2005) Effects of diet and genetic background on sterol regulatory element-binding protein1c, stearoyl-CoA desaturase 1, and the development of the metabolic syndrome. Diabetes 54:1314-1323

39 Ntambi JM and Miyazaki M (2004) Regulation of stearoyl-CoA desaturases and role in metabolism. Prog Lipid Res 43:91-104

40 Brenner RR (2003) Hormonal modulation of delta6 and delta5 desaturases: case of diabetes. Prostaglandins Leukot Essent Fatty Acids 68:151-162

41 Cohen P and Friedman JM (2004) Leptin and the control of metabolism: role for stearoyl-CoA desaturase-1 (SCD-1). J Nutr 134:2455S-2463S

42 Blaak EE (2004) Basic disturbances in skeletal muscle fatty acid metabolism in obesity and type 2 diabetes mellitus. Proc Nutr Soc 63:323-330

43 Raclot T and Oudart H (1999) Selectivity of fatty acids on lipid metabolism and gene expression. Proc Nutr Soc 58:633-646 



\section{CHAPTER 8}

\section{GENERAL DISCUSSION}




\section{CONTENTS}

$\begin{array}{lr}\text { Introduction } & 149\end{array}$

$\begin{array}{ll}\text { Prevalence of impaired glucose metabolism } & 149\end{array}$

Lifestyle-intervention to prevent diabetes mellitus type $2 \quad 149$

Impairments in fatty acid handling $\quad \mathbf{1 5 0}$

Fatty acid uptake $\quad 150$

Fatty acid oxidation $\quad 154$

$\begin{array}{ll}\text { In summary } & 155\end{array}$

Effects of lifestyle on insulin resistance and fatty acid handling $\quad 155$

A diet-and-exercise lifestyle intervention program 155

Body weight loss $\quad 156$

Dietary fat quality and serum fatty acid profile $\quad 157$

In summary $\quad 159$

Impaired metabolic flexibility and inflammation $\quad 159$

$\begin{array}{ll}\text { Concluding remarks } & 160\end{array}$

$\begin{array}{ll}\text { Suggestion for future research } & 161\end{array}$ 


\section{Introduction}

\section{Prevalence of impaired glucose metabolism}

The prevalence of diabetes is increasing rapidly. Awareness of the diabetes problem is also rising. The justification for this concern is shown by the results in chapter 2. A single oral glucose tolerance test in 2715 subjects from a population at risk revealed that every three out of ten people with an increased risk for glucose intolerance, i.e. those of age $>40$ years and/or a family history of diabetes and/or a BMI $>25 \mathrm{~kg} / \mathrm{m}^{2}$, had an impaired glucose metabolism, and one out of twelve had diabetes. Although part of the increased prevalence in diabetes is due to demographic ageing and an improved alertness for diagnosis, lifestyle factors such as obesity, dietary habits and physical activity play a important role in the increased prevalence of diabetes worldwide.

\section{Lifestyle-intervention to prevent diabetes mellitus type 2}

Lifestyle intervention programs have shown that improvements in lifestyle habits can reduce the progression of IGT to diabetes with about $58 \%$ over three years $(1,2)$. These lifestyle intervention programs included dietary advice, an increase in physical activity and weight loss. In the SLIM study (Study on Lifestyle intervention in Impaired glucose tolerance Maastricht) subjects with impaired glucose tolerance participated in a combined diet and exercise intervention program which was effective to reduce body weight, to reduce the intake of saturated fat and to increase physical activity. After 2 years of intervention, the 2-hr postload glucose concentrations were $1.5 \mathrm{mmol} / \mathrm{l}$ lower than in the control group, which represents a substantial reduction in diabetes risk (3). Furthermore, it was found that after 3 years, the progression to DM2 was $18 \%$ in the lifestyle intervention group and $34 \%$ in the control group, showing that the order of magnitude of the lifestyle effect $(-53 \%$ risk) was comparable with previous studies (Cheryl Roumen, personal communication). This emphasises that a lifestyle intervention provides a very important means in the prevention of diabetes mellitus type 2 .

The effectiveness of different aspects of the lifestyle intervention may differ between subjects, depending in part on their metabolic state, their genetic background and the interaction of genes with lifestyle. It is important to elucidate the metabolic mechanisms that underlie the effects of lifestyle, since knowledge 
about these mechanisms not only contributes to a better understanding of the disease, it will also contribute to a more efficient and targeted intervention to prevent and/or treat diabetes in the future. Below, impairments in fatty acid handling which may be involved in the development of diabetes mellitus type 2 and which may be modified by lifestyle intervention will be discussed with a special focus on skeletal muscle metabolism.

\section{Impairments in fatty acid handling}

Insulin resistance in skeletal muscle is strongly associated to an accumulation of intramyocellular triglycerides (IMTG) (4-6). This accumulation of triglycerides is the result of an imbalance between fatty acid uptake and oxidation. Studies measuring in vivo substrate oxidation in skeletal muscle of obese, insulin resistant or diabetic subjects are sparse, but suggest that both fatty acid uptake as well as fatty acid oxidation can be impaired. Furthermore, it is still unclear whether the impairments in muscle fatty acid handling may be a primary factor in the development of diabetes mellitus type 2 or rather a consequence of the diabetic state. Therefore, we investigated skeletal muscle fatty acid uptake and oxidation in obese subjects with impaired glucose tolerance (IGT), a prediabetic state (chapter 3). To detect differences in forearm muscle metabolism that may be specific for the prediabetic state, we compared these subjects to normal glucose tolerant controls (NGT) with similar body fat percentage, age and fitness (maximal aerobic capacity). Since the majority of the people in Western countries are in the fed state most of the day, we studied fatty acid handling during fasting and after a mixed meal with high fat content.

\section{Fatty acid uptake}

Previously, it has been shown that whole body FFA disposal was reduced both during fasting and during moderate-intensity exercise in diabetic and IGT subjects compared to obese controls $(7,8)$. Also fatty acid uptake specifically into skeletal muscle was reduced in obese subjects (9), in IGT subjects (10) and in diabetic patients during fasting $(11,12)$ and in diabetic patients after betaadrenergic stimulation (12). An overview of human studies measuring fatty acid uptake in insulin resistant subjects is given in Table 8.1. Since very little is known about impairments in muscle metabolism after a meal and even less is known about these impairments in the prediabetic state, this was investigated in chapter 3. Surprisingly, we found that both in the fasting state as well as after the mixed meal with high fat content, no differences in fatty acid uptake were found between 
IGT and NGT men. This suggests that an impaired plasma free fatty acid uptake into skeletal muscle may not play a primary role in the progression of NGT to DM2, for which IGT is considered to be the necessary transitional state. On the other hand, from the literature we know that fatty acid uptake is reduced in the obese, insulin resistant state. Thus, an impaired fatty acid uptake may not be directly related to the development of DM2, but may be impaired due to the obese, insulin resistant state per se and thereby contribute secondarily to an impaired balance between fatty acid uptake and oxidation.

In addition to the uptake of free fatty acids from plasma, it is assumed that lipolysis of chylomicrons and VLDL-TG can contribute to the fatty acid uptake into muscle as well. In chapter 3, we measured the net flux of triglycerides over skeletal muscle during fasting and postprandial conditions, but found no differences between IGT and NGT men. Since it has been suggested that the fatty acids derived from triglycerides mix with plasma FFA to one pool (14), one may argue that impairments that are found in the uptake of plasma FFA may also apply for plasma TG-FA. We cannot exclude that more sophisticated methods to measure the uptake of fatty acids from chylomicrons and VLDL-TG could reveal impairments in IGT subjects.

Fatty acid uptake into muscle has also been studied in in vitro models, called giant vesicles. These vesicles are constructed from skeletal muscle biopsies and consist of plasma and cytosolic membranes, but lack intracellular metabolism. With this model, Bonen and coworkers have shown a 4-fold higher absolute FFA uptake in abdominal muscle from diabetic subjects relative to those from lean subjects. This was related to an increased amount of the fatty acid transporter CD36 located at the membrane (15). They suggested that the FFA uptake in insulin resistant conditions is increased and may thus result in IMTG accumulation. This may at first sight seem in contrast with the studies mentioned above, reporting a decreased fatty acid uptake in the insulin resistant condition (7-12). However, since these giant vesicles contain plasma and cytosolic membranes but lack intracellular metabolism, this model is likely to reflect the fatty acid transport capacity of the muscle in and of itself. Whether this relates to an increased fatty acid uptake into muscle in vivo will also be dependent on the concentration gradient over the muscle membrane, which is determined by the plasma FFA concentration and the intracellular FFA concentration (rate of cellular metabolism). This may explain the differences in fatty acid uptake that are found between in vivo and in vitro experiments.

Evidence from the past years has shown that fatty acid uptake in skeletal muscle is not just a passive diffusion process, but that it is facilitated by specific transport proteins (16). Fatty acid uptake is regulated by insulin at the level of lipolysis in adipose tissue, but the presence of fatty acid transporters in muscle 


\begin{tabular}{|c|c|c|c|c|}
\hline \multicolumn{5}{|l|}{ Range } \\
\hline Colberg $1995(9)$ & Lean to obese women & $\begin{array}{l}\text { A-V difference over leg; } \\
\text { stable isotopes }\end{array}$ & Fasting (overnight) & $\begin{array}{l}\text { FFA uptake inversely related to } \\
\text { visceral fat }(r=-0.60, p=-0.01)\end{array}$ \\
\hline \multicolumn{5}{|c|}{ DM2 compared to lean } \\
\hline Kelley $1994(11)$ & Obese DM2 vs lean & $\begin{array}{l}\text { A-V difference over leg; } \\
\text { stable isotopes }\end{array}$ & $\begin{array}{l}\text { Fasting (overnight) } \\
\text { Postprandial (mixe d meal) }\end{array}$ & $\begin{array}{l}\text { reduced d uring fasting; } \\
\text { blunted suppression postprandially }\end{array}$ \\
\hline Blaak 2000 (12) & Obese DM2 vs lean & $\begin{array}{l}\text { A-V difference over forearm; } \\
\text { stable isotop es }\end{array}$ & $\begin{array}{l}\text { Fasting (overnight); } \\
\S \text {-adrenergic stimulation }\end{array}$ & $\begin{array}{l}\text { Reduced during fasting; } \\
\text { Impaired increase }\end{array}$ \\
\hline Bonen 2004 (15) & $\begin{array}{l}\text { DM2, obese, overweight } \\
\text { and lean }\end{array}$ & $\begin{array}{l}\text { giant vesicles; } \\
\text { abdominal muscle }\end{array}$ & Fasting $(15-18 \mathrm{~h})$ & increased in DM2 and obese \\
\hline Turpeinen 1999 (10) & Obese IGT vs lean & $\begin{array}{l}\text { Positron Emission Tomography; } \\
\text { Femoral regions }\end{array}$ & Fasting (12-15 h) & reduced \\
\hline \multicolumn{5}{|c|}{ Obese compared to lean } \\
\hline Blaak 1994 (13) & Obese vs lean & A-V difference over forearm & $\S$-adrenergic stimulation & Impaired increase in FFA uptake \\
\hline Kelley 1999 (18) & Obese vs lean & $\begin{array}{l}\text { A-V difference over leg; } \\
\text { stable isotopes }\end{array}$ & $\begin{array}{l}\text { Fasting (overnight); } \\
\text { insulin stimulati on }\end{array}$ & comparable \\
\hline \multicolumn{5}{|c|}{ DM2/IGT compared to BMI-matched controls } \\
\hline Blaak $2000(7)$ & $\begin{array}{l}\text { Obese DM2 vs } \\
\text { obese control }\end{array}$ & $\begin{array}{l}\text { whole body; } \\
\text { stable isotopes }\end{array}$ & $\begin{array}{l}\text { Fasting (overnight); } \\
\text { exercise }\end{array}$ & $\begin{array}{l}\text { whole body FFA disposal reduced } \\
\text { in both conditions }\end{array}$ \\
\hline Mensink 2001 (8) & $\begin{array}{l}\text { Obese IGT vs } \\
\text { obese NGT }\end{array}$ & $\begin{array}{l}\text { whole body; } \\
\text { stable isotopes }\end{array}$ & $\begin{array}{l}\text { Fasting (overnight); } \\
\text { exercise }\end{array}$ & $\begin{array}{l}\text { whole body FFA disposal reduced } \\
\text { in both conditions }\end{array}$ \\
\hline Chapter 3 & $\begin{array}{l}\text { Obese IGT vs } \\
\text { obese NGT }\end{array}$ & $\begin{array}{l}\text { A-V difference over forearm; } \\
\text { stable isotopes }\end{array}$ & $\begin{array}{l}\text { Fasting (overnight); } \\
\text { Postprandial (mixe d meal) }\end{array}$ & comparable in both conditions \\
\hline
\end{tabular}

Table 8.1. Studies that have measured fatty acid uptake in insulin resistant subjects in vivo or directly in muscle obtained from insulin resistant subjects. 
suggests that fatty acid uptake may also be actively regulated at the level of skeletal muscle itself. It appears that the fatty acid transporter CD36 may play a critical role in this facilitated diffusion of fatty acids. Therefore, we studied CD36 protein content of skeletal muscle before and after insulin stimulation in relation to insulin resistance (chapter 4). We found no significant difference between the IGT and NGT men. However, we found that the baseline protein content of CD36 in skeletal muscle was negatively related to insulin resistance, which is in accordance with previous reports showing that fasting fatty acid uptake into skeletal muscle is reduced in the insulin resistant state $(11,12)$. Surprisingly, we also found that insulin can rapidly increase CD36 protein expression in skeletal muscle. Such a fast upregulation of CD36 protein by insulin was found before in rat cardiomyocytes (17). In these rat cardiomyocytes, a large part of the newly synthesized CD36 protein was translocated to the plasma membrane, suggesting that the newly synthesized CD36 may directly contribute to the fatty acid uptake capacity of the muscle cell. Interestingly, whereas we found that in more insulin resistant subjects fasting CD36 protein content was reduced, the insulin-mediated upregulation of CD36 protein expression was increased with insulin resistance. This is in line with the finding that in diabetic patients, relative to healthy lean controls, the fasting fatty acid uptake into skeletal muscle was reduced, whereas the insulin-stimulated suppression of fatty acid uptake in the postprandial phase was blunted (11). It is tempting to speculate that in the insulin-stimulated condition, an increased upregulation of the CD36 protein may contribute to the lack of suppression of postprandial fatty acid uptake as previously observed in diabetic subjects. This could then lead to an excess fatty acid uptake in the postprandial phase and a postprandial accumulation of IMTG. This concept is supported by the finding in chapter 4 that the insulin-stimulated increase in CD36 protein was positively related to the change in skeletal muscle lipid content. However, these findings are only based on associations and need further confirmation.

Genetic evidence that the fatty acid transporter CD36 indeed may play a role in the development of insulin resistance is presented in chapter 5 . We show that the TT genotype of a promoter polymorphism in the CD36 gene (rs1527479) is more common in diabetic subjects than in subjects with normal glucose tolerance. This TT genotype is related to a higher insulin resistance in general as well as within the group of diabetic patients. This supports the hypothesis that fatty acid uptake is differently regulated in the insulin resistant state, and that the fatty acid transporter CD36 may play a role in this. 


\section{Fatty acid oxidation}

Beside impairments in fatty acid uptake, impairments in fatty acid oxidation of skeletal muscle could also lead to the accumulation of triglycerides in skeletal muscle. The major finding in chapter 3 is that, in the postprandial phase, the switch from fat oxidation to carbohydrate oxidation was blunted in IGT relative to NGT. This inability to switch between fuels in the insulin stimulated condition may play a role in the development towards DM2, since IGT is considered to be the transitional state between normal glucose tolerance and diabetes mellitus type 2. These findings are in line with the concept of 'metabolic flexibility' as proposed by Kelley and coworkers. They observed that leg muscle fat oxidation was reduced in the fasting state and did not change in the postprandial phase in overweight, established diabetic subjects (11) as well as in (visceral) obese men when compared to lean controls (18). The concept of 'metabolic flexibility' of substrate oxidation states that in the insulin resistant condition, the ability to stimulate fat oxidation in the fasting state and to suppress fat oxidation after insulin stimulation is impaired.

The question whether the impairments in 'metabolic flexibility' are primary or rather a consequence of the obese, insulin resistant and/or diabetic state is difficult to answer. Interestingly, weight loss studies showed a lack of improvement in the impaired ability to increase fat oxidation during betaadrenergic stimulation in obese subjects (19) and in the ability to stimulate fat oxidation during exercise in diabetic patients (20). This reduced ability to stimulate fat oxidation during exercise was already present in IGT subjects (8). These studies suggest that the inability to regulate fat oxidation may be a primary factor of skeletal muscle in prediabetic or diabetic subjects. This is consistent with data from in vitro models with cultured myotubes derived from diabetic patients which show a lower baseline fat oxidation relative to cultured myotubes from BMI-matched controls (21). On the other hand, in chapter 3 we show a clear improvement in fasting fat oxidation and in the ability to suppress fat oxidation after a meal in skeletal muscle of IGT men, which will be discussed in more detail under the heading "body weight loss". Nevertheless, even in cultured myotubes from healthy young men, the ability to regulate fat oxidation in vitro was positively related to the 'metabolic flexibility' of muscle substrate oxidation of the donor, suggesting that the impaired ability to switch between fuels may be a primary characteristic of skeletal muscle (22). Studies with micro-array techniques show that a whole cluster of genes under the control of PGC-1alfa (PPARgamma coactivator-1), involved in fat oxidation and mitochondrial biogenesis, was coordinately downregulated in muscle biopsies from diabetic patients (23) as well 
as in healthy offspring of diabetic subjects (24). These studies support the evidence that at least part of the impaired fat oxidation may be of genetic origin.

\section{In summary}

The ability of forearm muscle to switch from fat oxidation to carbohydrate oxidation in the postprandial phase is impaired in IGT relative to NGT men. This difference in postprandial 'metabolic flexibility' of substrate oxidation could not be explained by differences in fatty acid uptake.

Furthermore we found that the protein content of the fatty acid transporter CD36 in skeletal muscle was negatively related to insulin resistance. Surprisingly, insulin rapidly increased the protein expression of the fatty acid transporter CD36 in skeletal muscle of both IGT and NGT men. The increase in CD36 protein was positively related to insulin resistance. This illustrates that fatty acid uptake is actively regulated in skeletal muscle itself, but that the regulation of the CD36 protein expression is disturbed in insulin resistance.

Although we did not find differences in fatty acid uptake and fatty acid transporters between IGT and NGT men, there may be slight disturbances related to insulin resistance per se. This way, an impaired fatty acid uptake could indirectly play a role in the aetiology of diabetes.

\section{Effects of lifestyle on insulin resistance and fatty acid handling}

\section{A diet-and-exercise lifestyle intervention program}

The DPP (Diabetes prevention Program) and the DPS (Diabetes Prevention Study) are lifestyle intervention studies which have shown that changes in diet, physical activity and adiposity can prevent or postpone the progression of IGT to diabetes mellitus type $2(1,2)$. The SLIM study (Study on Lifestyle intervention in Impaired glucose tolerance Maastricht) showed that lifestyle can significantly reduce the 2-hr glucose concentration after an oral glucose tolerance test, thus reducing diabetes risk (3). Each of these lifestyle aspects may have specific effects on metabolism. It is important to elucidate the metabolic mechanisms that underlie the effects of lifestyle, since knowledge about these mechanisms may contribute to a more efficient and targeted intervention to prevent and/or treat DM2 in the future. 


\section{Body weight loss}

As described previously, the insulin resistant state is characterized by an impaired 'metabolic flexibility' of substrate oxidation. As insulin resistance and diabetes are strongly associated with obesity, it seems reasonable to suggest that weight loss would improve insulin sensitivity and reduce concomitant impairments in metabolism.

We studied the effect of weight loss on muscle fat oxidation in prediabetic subjects (chapter 3) and found that weight loss (-15 kg) in IGT men improved insulin sensitivity together with an improved stimulation of muscle fat oxidation in the fasting state as well as an improved switch from fat oxidation to carbohydrate oxidation after a meal, which indicates that the impairments in fat oxidation in skeletal muscle are still reversible in obese, IGT men. The findings from our study with regard to the postprandial phase are well in line with previous studies. These have shown an improvement in the insulin-mediated suppression of fat oxidation in obese subjects after weight loss induced by energy restriction $(-15 \mathrm{~kg})(18)$ and after weight loss induced by a combined energy restriction (- $7 \mathrm{~kg}$ body weight loss) and exercise (+ $20 \%$ increase in $\mathrm{VO}_{2}$ max) program (25). In additon, the findings in chapter 3 provide evidence that also fasting fat oxidation can be improved by weight reduction. However, previous studies report different findings on fasting fat oxidation. In the studies mentioned above, weight loss showed either an improvement (25) or no change (18) in fasting fat oxidation in skeletal muscle. Furthermore, weight loss in diabetic patients (-15 $\mathrm{kg}$ ) had no effect on plasma-derived fatty acid oxidation and whole body fat oxidation during fasting or during exercise (20). Altogether, there are clear indications that weight loss is able to reverse impairments in metabolic flexibility of substrate oxidation, although with respect to fasting fat oxidation, this could not be confirmed in all studies.

To our knowledge, the study in chapter 3 is the first to report on in vivo skeletal muscle fatty acid uptake before and after weight loss in men with impaired glucose tolerance. No differences were found in fatty acid uptake before versus after weight loss. This suggests that in skeletal muscle, differences in fatty acid uptake cannot explain the improvements in the regulation of fasting and postprandial fat oxidation. One previous study examined skeletal muscle fatty acid uptake in obese, insulin resistant subjects before and after weight loss relative to lean subjects (18). Weight loss reduced fasting FFA uptake, but did not affect fasting fat oxidation. Furthermore, the obese were not different from lean with regard to muscle fatty acid uptake during fasting or insulin stimulation, whereas the oxidation of fatty acids in obese was lower during fasting and the suppression of fat oxidation after insulin stimulation was blunted. From our own results 
presented in chapter 3 and the literature reported above, we conclude that impairments in skeletal muscle fat oxidation in the IGT state cannot be directly explained by impairments in skeletal muscle fatty acid uptake.

In chapter 3, we show that weight loss reduced IMTG in 6 out of 7 subjects. This is consistent with most other studies $(26,27)$, although the decrease in IMTG (-35\%) found by Malenfant and coworkers was not significant (28). Recently, it was suggested that the intermediates of intramyocellular lipid metabolism, like fatty acyl-CoA, ceramides and diacylglycerol, rather than IMTG itself may induce insulin resistance (29-32). The capacity to mobilize and/or oxidize IMTG stores may be one of the main factors that modulates the association between IMTG storage and the development of skeletal muscle insulin resistance (33). In chapter 3, we show that an improved 'metabolic flexibility' of substrate oxidation after weight loss is accompanied by a reduction in IMTG and an improvement in insulin sensitivity. Although we cannot distinguish cause from consequence in that study, an improved metabolic flexibility of substrate oxidation could be accompanied with a higher efficiency and fine tuning of fatty acid uptake and oxidation. This could reduce the amount of lipid intermediates in the cytoplasm and thus reduce their effect on insulin signaling (29-32).

\section{Dietary fat quality and serum fatty acid profile}

Insulin resistance and diabetes mellitus type 2 are characterized by serum fatty acid profiles reflecting a high intake of saturated fat and a low intake of unsaturated fat (34-36). High saturated fat intake and high levels of saturated fatty acids in serum are risk factors for the progression of diabetes (34, 37-40). Serum fatty acid profiles are partly determined by desaturase enzymes (mainly present in the liver and adipose tissue), since these enzymes regulate the degree of unsaturation of lipids throughout the body. This is important for the fluidity of cell membranes, affecting cell permeability and signaling, including insulin cell signaling (41).

Since we know that the reduction of saturated fat intake is an important aspect of the lifestyle intervention, and that lifestyle intervention is effective to reduce diabetes risk, we investigated the effect of a diet-exercise lifestyle program on serum fatty acid profiles in relation to changes in insulin resistance (chapter 7). Desaturase activities were estimated by their product-to-precursor ratios in plasma cholesteryl esters, considered an estimate of desaturase activities in the liver. We found a strong relation between the lifestyle-induced changes in insulin resistance and the changes in serum fatty acid profile in cholesteryl esters after one year. An improvement in insulin resistance was typically associated with a reduction in myristic acid (C14:0), palmitoleic acid (C16:1 n-7), $\gamma$-linolenic acid 
(C18:3 n-6) and dihomo- $\gamma$-linolenic acid (c20:3 n-6) fractions, an increase in oleic acid (C18:1 n-9) and arachidonic acid (C20:4 n-6); and was further characterized by a decrease in estimated $\Delta 9$-desaturase (SCD-1) and $\Delta 6$-desaturase activities and an increase in $\Delta 5$-desaturase activity. The associations between changes in $\Delta 9-, \Delta 6$ and $\Delta 5$-desaturase activities and changes in insulin resistance were influenced by changes in aerobic capacity ( $\mathrm{VO}_{2} \mathrm{max}$ ) and/or body fat percentage, which supports the hypothesis that desaturase activities are affected by lifestyle. This evidence, that lifestyle affects fatty acid profile, is supported by two recent, well-controlled human studies. These demonstrate that replacing saturated fatty acids (SFA) in the diet either by mono-unsaturated fat (MUFA) (42) or poly-unsaturated fat (PUFA) (43) results in changes in serum fatty acid profile and improves insulin sensitivity. Also an increased physical activity was associated with an increased estimated $\Delta 5$ desaturase activity in skeletal muscle phospholipids $(44,45)$.

On the other hand it was shown in chapter 7 that the association between desaturase activities and insulin resistance was still significant after correction for lifestyle factors. This indicates that other factors, which were not accounted for in this study, may interfere with the relation between insulin resistance and endogenous fatty acid production, e.g. an impaired fatty acid handling (uptake, oxidation or storage) or hormones like insulin (46) or leptin (47). As illustrated in this thesis, insulin resistance is strongly related to impairments in skeletal muscle fatty acid handling. The question rises whether there are indications that lipid profiles or desaturase activities may play a role specifically in skeletal muscle fatty acid handling or in the development of insulin resistance.

There is a growing body of experimental evidence in rodents and humans that desaturase enzymes are related to insulin resistance. Mice lacking stearoylCoA desaturase-1 (SCD-1), a mouse isoform of $\Delta 9$-desaturase, are more insulin sensitive than their wildtype littermates (48). In humans, insulin resistance was associated with a fatty acid profile of muscle phospholipids characterized by a low fraction of unsaturated fatty acids and a low estimated $\Delta 5$-desaturase activity (49). Recently, it was found that the $\Delta 9$-desaturase mRNA expression in rectus abdominus muscle of obese subjects is increased (50). Cultured myocytes from these obese subjects revealed a reduced fat oxidation, an increased protein expression of $\Delta 9$-desaturase protein and increased fatty acid esterification. This $\Delta 9$-desaturase may enhance triglyceride storage by providing the preferential fatty acids for storage (C16:1 n-7 and C18:1 n-9) (51). Whether desaturase enzymes can play a primary role in the development of diabetes, and whether lifestyle (diet and exercise) can change desaturase activities in muscle of obese, insulin resistant or diabetic subjects needs further investigation. 


\section{In summary}

Energy restriction leading to body weight loss in obese men with impaired glucose tolerance improves insulin resistance and improves 'metabolic flexibility' of substrate oxidation, which is strongly related to a reduction in IMTG content. A combined diet- and exercise program improves insulin resistance and reduced postprandial hyperglycemia, thus reducing diabetes risk. The effect of changes in lifestyle (saturated fat intake, physical activity, body weight) on insulin resistance may be partly mediated by changes in fatty acid profile and estimated desaturase activities.

\section{Impaired metabolic flexibility and inflammation}

After the discovery that adipose tissue is a very active endocrine organ, secreting adipokines and cytokines like IL-6, it was hypothesized that sub-clinical inflammation could be involved in the development of obesity-induced insulin resistance (52-55). Indeed, sub-clinical inflammation is a risk factor for the progression of IGT to DM2 $(56,57)$, and also for cardiovascular disease $(58)$. A very interesting and new finding, reported in chapter 6 , is that not only adipose tissue but also skeletal muscle releases the cytokine IL-6 in considerable amounts, both in obese IGT and NGT men. This IL-6 release from skeletal muscle is increased after the ingestion of a meal with high fat content, in particular in the IGT men. Weight loss reduced this meal-induced response in muscle IL-6 release. This IL-6 release may have been provoked by oxidative stress induced by the high fat meal or by the abundant presence of saturated fatty acids such as palmitate in the cytoplasm. From previous studies it is known that a high fat meal can induce an increase in circulating IL-6 concentrations $(59,60)$. Furthermore, it is known that a meal, in particular a high fat meal, induces oxidative stress in diabetic patients $(61,62)$. In addition, specific fatty acids, such as palmitate, have been shown to induce IL-6 release from myocytes in vitro (63). Both oxidative stress as well as the accumulation of intracellular palmitate could be enhanced by an impaired fine tuning between fatty acid uptake and oxidation. Indeed, in our study described in chapter 6, the weight loss-induced reduction in postprandial IL-6 release after a meal was accompanied by an improvement in 'metabolic flexibility' of substrate oxidation. There are indications that IL-6 can interfere with muscle fatty acid handling in isolated rat soleus muscle (64) and C2C12 muscle cells (65), although it is not sure yet whether IL-6 may affect insulin resistance in human skeletal muscle $(63,66,67)$. Moreover, IL-6 may affect the function of other organs, since it is known that IL-6 can induce liver insulin resistance $(66,68)$. 


\section{Concluding remarks}

In this thesis it is shown that the ability of skeletal muscle to switch from fat oxidation to carbohydrate oxidation in the postprandial phase may play a role in the aetiology of diabetes mellitus type 2. Furthermore, the amount of fatty acid transporter CD36 is acutely upregulated by insulin, indicating that fatty acid uptake is actively regulated at the level of skeletal muscle itself. The insulininduced upregulation of CD36 protein is impaired with insulin resistance. This may contribute to an impaired balance between fatty acid uptake and oxidation in the insulin resistant skeletal muscle, which may in turn enhance in the accumulation of intramyocellular lipid intermediates and insulin resistance. In addition, the impairments in fat oxidation in the prediabetic state may be present in particular when the system is "stressed" to adapt to a new situation, e.g. after a meal. It is important to realize that these postprandial impairments in skeletal muscle can have a large impact on whole body metabolism, since muscle metabolism makes a large contribution to whole body metabolism and most of the people in Western countries are in the fed state most of the day.

Lifestyle changes can have a variety of effects on the metabolic state of an insulin resistant individual. In this thesis, we show that lifestyle changes impact on substrate oxidation, lipid storage, fatty acid transport and inflammation in skeletal muscle, serum fatty acid profile and in particular estimated desaturase activities, and indeed improves insulin sensitivity in subjects with impaired glucose tolerance, thereby reducing diabetes risk. In general, a large variety of changes in the metabolic state, induced by changes in lifestyle, touch upon muscle metabolism, although the link between desaturase activities and fatty acid handling in skeletal muscle needs further confirmation. Since skeletal muscle is an important contributor to whole body metabolism, this suggests that skeletal muscle plays a major role in mediating the beneficial effects of lifestyle.

A point that is sometimes made about lifestyle studies is that the effects on metabolism may appear to be rather small. The opposite is true. Lifestyle intervention studies in subjects at high risk for DM2, i.e. IGT, show that small changes in lifestyle based on general recommendations such as 30 minutes of physical activity per day and 3-4 $\mathrm{kg}$ of weight loss may reduce diabetes risk more than $50 \%$ over a period of 3 years. Just bear in mind that it may take many years to develop diabetes, and that: "Small deviations in metabolism over a large period of time will have a great impact on the development of diabetes". Turn this around, and find that according to the same principle: "Small improvements, induced by changes in lifestyle, will have a great impact on the prevention of diabetes." 


\section{Suggestions for future research}

Now that we have travelled between 'eat'iology and 'aet'iology, it appears that there is a lot that we do know, and even more that we don't know, and some of it is listed below.

- In this thesis we have shown that fatty acid uptake into skeletal muscle was not different between NGT and IGT nor in IGT before and after weight loss. Therefore, fatty acid uptake could not explain the impaired regulation of substrate oxidation in impaired glucose tolerance. Nevertheless, previous work shows that fatty acid uptake into muscle can certainly be impaired in obesity, thus impairments in fatty acid uptake may rather be related to insulin resistance than to impaired glucose tolerance per se. Further investigation on the regulation of the fatty acid transporter CD36 and on the contribution of TG-derived fatty acids to fatty acid uptake and oxidation in the (late) postprandial phase may provide more insight on the dynamics between fatty acid uptake, oxidation and the accumulation of IMTG in skeletal muscle. Studies with impaired glucose tolerant subjects or with myocytes in culture derived from diabetic patients may serve as models to elucidate whether the impairments may be primary to the development of DM2. This could contribute to clarifying the aetiology of insulin resistance and provide strategies for intervention.

- It is well known that diabetes is characterized by low-grade inflammation. However, it remains unclear whether inflammation is a cause or consequence of diabetes and whether it should be treated or not. Now that we know that not only adipose tissue but also muscle can release the cytokine IL-6, it will be a challenge to investigate the endocrine and auto- or paracrine effect of IL6 on muscle metabolism and to further define the relationship between insulin resistance, (impaired) muscle fat metabolism and inflammation. This will provide more insight on whether and how sub-clinical inflammation should be dealt with in order to reduce the development of insulin resistance and/or DM2, and the diabetes-associated risk for cardiovascular disease.

- Evidence is emerging that the impaired fat oxidative capacity of skeletal muscle may play a primary role in the aetiology of insulin resistance and diabetes mellitus type 2. In order to elucidate underlying molecular and genetic factors without losing contact with the 'real' in vivo situation in humans, we could com- 
combine the in vivo studies with experiments in myocyte cultures from these subjects to link the in vitro findings to the donor phenotype. In order to achieve this, it is suggested to apply and/or develop in vitro protocols for muscle cells that reflect different metabolic conditions.

- There is strong evidence that healthy changes in lifestyle can reduce or postpone the development of diabetes. It is likely that the effectiveness of changes in lifestyle will depend on many factors, such as socio-economic factors, psychological factors, physiological factors and genetic background. Further investigation on these determinants of lifestyle effect may provide knowledge for a more efficient and targeted intervention to prevent and treat diabetes. 


\section{REFERENCES}

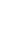

Tuomilehto J, Lindstrom J, Eriksson JG, et al. (2001) Prevention of type 2 diabetes mellitus by changes in lifestyle among subjects with impaired glucose tolerance. N Engl J Med 344:13431350.

Knowler WC, Barrett-Connor E, Fowler SE, et al. (2002) Reduction in the incidence of type 2 diabetes with lifestyle intervention or metformin. N Engl J Med 346:393-403

Mensink M, Blaak EE, Corpeleijn E, Saris WH, de Bruin TW and Feskens EJ (2003) Lifestyle intervention according to general recommendations improves glucose tolerance. Obes Res 11:1588-1596

Pan DA, Lillioja S, Kriketos AD, et al. (1997) Skeletal muscle triglyceride levels are inversely related to insulin action. Diabetes 46:983-988

Krssak M, Falk Petersen K, Dresner A, et al. (1999) Intramyocellular lipid concentrations are correlated with insulin sensitivity in humans: a 1H NMR spectroscopy study. Diabetologia 42:113-116.

Perseghin G, Scifo P, De Cobelli F, et al. (1999) Intramyocellular triglyceride content is a determinant of in vivo insulin resistance in humans: a $1 \mathrm{H}-13 \mathrm{C}$ nuclear magnetic resonance spectroscopy assessment in offspring of type 2 diabetic parents. Diabetes 48:1600-1606.

Blaak EE, van Aggel-Leijssen DP, Wagenmakers AJ, Saris WH and van Baak MA (2000) Impaired oxidation of plasma-derived fatty acids in type 2 diabetic subjects during moderateintensity exercise. Diabetes 49:2102-2107.

Mensink M, Blaak EE, van Baak MA, Wagenmakers AJ and Saris WH (2001) Plasma free Fatty Acid uptake and oxidation are already diminished in subjects at high risk for developing type 2 diabetes. Diabetes 50:2548-2554

Colberg SR, Simoneau JA, Thaete FL and Kelley DE (1995) Skeletal muscle utilization of free fatty acids in women with visceral obesity. J Clin Invest 95:1846-1853

Turpeinen AK, Takala TO, Nuutila P, et al. (1999) Impaired free fatty acid uptake in skeletal muscle but not in myocardium in patients with impaired glucose tolerance: studies with PET and 14(R,S)-[18F]fluoro-6-thia-heptadecanoic acid. Diabetes 48:1245-1250

Kelley DE and Simoneau JA (1994) Impaired free fatty acid utilization by skeletal muscle in non-insulin-dependent diabetes mellitus. J Clin Invest 94:2349-2356

Blaak EE, Wagenmakers AJ, Glatz JF, et al. (2000) Plasma FFA utilization and fatty acid-binding protein content are diminished in type 2 diabetic muscle. Am J Physiol Endocrinol Metab 279:E146-154.

3 Blaak EE, Van Baak MA, Kemerink GJ, Pakbiers MT, Heidendal GA and Saris WH (1994) Betaadrenergic stimulation of energy expenditure and forearm skeletal muscle metabolism in lean and obese men. Am J Physiol 267:E306-315

4 Teusink B, Voshol PJ, Dahlmans VE, et al. (2003) Contribution of fatty acids released from lipolysis of plasma triglycerides to total plasma fatty acid flux and tissue-specific fatty acid uptake. Diabetes 52:614-620

5 Bonen A, Parolin ML, Steinberg GR, et al. (2004) Triacylglycerol accumulation in human obesity and type 2 diabetes is associated with increased rates of skeletal muscle fatty acid transport and increased sarcolemmal FAT/CD36. Faseb J 18:1144-1146 
Glatz JF, Bonen A and Luiken JJ (2002) Exercise and insulin increase muscle fatty acid uptake by recruiting putative fatty acid transporters to the sarcolemma. Curr Opin Clin Nutr Metab Care 5:365-370

Chabowski A, Coort SL, Calles-Escandon J, et al. (2004) Insulin stimulates fatty acid transport by regulating expression of FAT/CD36 but not FABPpm. Am J Physiol Endocrinol Metab 287:E781-789

Kelley DE, Goodpaster B, Wing RR and Simoneau JA (1999) Skeletal muscle fatty acid metabolism in association with insulin resistance, obesity, and weight loss. Am J Physiol 277:E1130-1141

Blaak EE, Van Baak MA, Kemerink GJ, Pakbiers MT, Heidendal GA and Saris WH (1994) betaAdrenergic stimulation of skeletal muscle metabolism in relation to weight reduction in obese men. Am J Physiol 267:E316-322

Blaak EE, Wolffenbuttel BH, Saris WH, Pelsers MM and Wagenmakers AJ (2001) Weight reduction and the impaired plasma-derived free fatty acid oxidation in type 2 diabetic subjects. J Clin Endocrinol Metab 86:1638-1644

Gaster M, Rustan AC, Aas V and Beck-Nielsen H (2004) Reduced lipid oxidation in skeletal muscle from type 2 diabetic subjects may be of genetic origin: evidence from cultured myotubes. Diabetes 53:542-548

Ukropcova B, McNeil M, Sereda O, et al. (2005) Dynamic changes in fat oxidation in human primary myocytes mirror metabolic characteristics of the donor. J Clin Invest 115:1934-1941

Mootha VK, Lindgren CM, Eriksson KF, et al. (2003) PGC-1alpha-responsive genes involved in oxidative phosphorylation are coordinately downregulated in human diabetes. Nat Genet 34:267-273

Patti ME, Butte AJ, Crunkhorn S, et al. (2003) Coordinated reduction of genes of oxidative metabolism in humans with insulin resistance and diabetes: Potential role of PGC1 and NRF1. Proc Natl Acad Sci U S A 100:8466-8471

Goodpaster BH, Katsiaras A and Kelley DE (2003) Enhanced fat oxidation through physical activity is associated with improvements in insulin sensitivity in obesity. Diabetes 52:2191-2197

Goodpaster BH, Theriault R, Watkins SC and Kelley DE (2000) Intramuscular lipid content is increased in obesity and decreased by weight loss. Metabolism 49:467-472

Gray RE, Tanner CJ, Pories WJ, MacDonald KG and Houmard JA (2003) Effect of weight loss on muscle lipid content in morbidly obese subjects. Am J Physiol Endocrinol Metab 284:E726732

Malenfant P, Tremblay A, Doucet E, Imbeault P, Simoneau JA and Joanisse DR (2001) Elevated intramyocellular lipid concentration in obese subjects is not reduced after diet and exercise training. Am J Physiol Endocrinol Metab 280:E632-639.

Adams JM, 2nd, Pratipanawatr T, Berria R, et al. (2004) Ceramide content is increased in skeletal muscle from obese insulin-resistant humans. Diabetes 53:25-31

Ellis BA, Poynten A, Lowy AJ, et al. (2000) Long-chain acyl-CoA esters as indicators of lipid metabolism and insulin sensitivity in rat and human muscle. Am J Physiol Endocrinol Metab 279:E554-560

31 Itani SI, Ruderman NB, Schmieder F and Boden G (2002) Lipid-induced insulin resistance in human muscle is associated with changes in diacylglycerol, protein kinase $C$, and IkappaBalpha. Diabetes 51:2005-2011 
Schmitz-Peiffer C (2000) Signalling aspects of insulin resistance in skeletal muscle: mechanisms induced by lipid oversupply. Cell Signal 12:583-594

van Loon LJ (2004) Use of intramuscular triacylglycerol as a substrate source during exercise in humans. J Appl Physiol 97:1170-1187

Feskens EJ and van Dam RM (1999) Dietary fat and the etiology of type 2 diabetes: an epidemiological perspective. Nutr Metab Cardiovasc Dis 9:87-95

Hu FB, van Dam RM and Liu S (2001) Diet and risk of Type II diabetes: the role of types of fat and carbohydrate. Diabetologia 44:805-817

Riccardi G, Giacco R and Rivellese AA (2004) Dietary fat, insulin sensitivity and the metabolic syndrome. Clin Nutr 23:447-456

Vessby B, Aro A, Skarfors E, Berglund L, Salminen I and Lithell H (1994) The risk to develop NIDDM is related to the fatty acid composition of the serum cholesterol esters. Diabetes 43:1353-1357

Salmeron J, Hu FB, Manson JE, et al. (2001) Dietary fat intake and risk of type 2 diabetes in women. Am J Clin Nutr 73:1019-1026

Marshall JA, Hoag S, Shetterly S and Hamman RF (1994) Dietary fat predicts conversion from impaired glucose tolerance to NIDDM. The San Luis Valley Diabetes Study. Diabetes Care $17: 50-56$

Wang L, Folsom AR, Zheng ZJ, Pankow JS and Eckfeldt JH (2003) Plasma fatty acid composition and incidence of diabetes in middle-aged adults: the Atherosclerosis Risk in Communities (ARIC) Study. Am J Clin Nutr 78:91-98

Nakamura MT and Nara TY (2004) Structure, function, and dietary regulation of delta6, delta5, and delta9 desaturases. Annu Rev Nutr 24:345-376

Vessby B, Unsitupa M, Hermansen K, et al. (2001) Substituting dietary saturated for monounsaturated fat impairs insulin sensitivity in healthy men and women: The KANWU Study. Diabetologia 44:312-319

Summers LK, Fielding BA, Bradshaw HA, et al. (2002) Substituting dietary saturated fat with polyunsaturated fat changes abdominal fat distribution and improves insulin sensitivity. Diabetologia 45:369-377

44 Andersson A, Sjodin A, Olsson R and Vessby B (1998) Effects of physical exercise on phospholipid fatty acid composition in skeletal muscle. Am J Physiol 274:E432-438

Andersson A, Sjodin A, Hedman A, Olsson R and Vessby B (2000) Fatty acid profile of skeletal muscle phospholipids in trained and untrained young men. Am J Physiol Endocrinol Metab 279:E744-751

Brenner RR (2003) Hormonal modulation of delta6 and delta5 desaturases: case of diabetes. Prostaglandins Leukot Essent Fatty Acids 68:151-162

Cohen P and Friedman JM (2004) Leptin and the control of metabolism: role for stearoyl-CoA desaturase-1 (SCD-1). J Nutr 134:2455S-2463S

Dobrzyn A, Dobrzyn P, Lee SH, et al. (2005) Stearoyl-CoA desaturase-1 deficiency reduces ceramide synthesis by downregulating serine palmitoyltransferase and increasing betaoxidation in skeletal muscle. Am J Physiol Endocrinol Metab 288:E599-607

Borkman M, Storlien LH, Pan DA, Jenkins AB, Chisholm DJ and Campbell LV (1993) The relation between insulin sensitivity and the fatty-acid composition of skeletal-muscle phospholipids. N Engl J Med 328:238-244 
Hulver MW, Berggren JR, Carper MJ, et al. (2005) Elevated stearoyl-CoA desaturase-1 expression in skeletal muscle contributes to abnormal fatty acid partitioning in obese humans. Cell Metab 2:251-261

Nakamura MT and Nara TY (2004) Structure, function, and dietary regulation of delta6, delta5, and delta9 desaturases. Annu Rev Nutr 24:345-376

Orban Z, Remaley AT, Sampson M, Trajanoski Z and Chrousos GP (1999) The differential effect of food intake and beta-adrenergic stimulation on adipose-derived hormones and cytokines in man. J Clin Endocrinol Metab 84:2126-2133

Hanley AJ, Festa A, D'Agostino RB, Jr., et al. (2004) Metabolic and inflammation variable clusters and prediction of type 2 diabetes: factor analysis using directly measured insulin sensitivity. Diabetes 53:1773-1781

Laaksonen DE, Niskanen L, Nyyssonen K, et al. (2004) C-reactive protein and the development of the metabolic syndrome and diabetes in middle-aged men. Diabetologia 47:1403-1410

Muller S, Martin S, Koenig W, et al. (2002) Impaired glucose tolerance is associated with increased serum concentrations of interleukin 6 and co-regulated acute-phase proteins but not TNF-alpha or its receptors. Diabetologia 45:805-812

Pradhan AD, Manson JE, Rifai N, Buring JE and Ridker PM (2001) C-reactive protein, interleukin 6, and risk of developing type 2 diabetes mellitus. Jama 286:327-334

Spranger J, Kroke A, Mohlig M, et al. (2003) Inflammatory cytokines and the risk to develop type 2 diabetes: results of the prospective population-based European Prospective Investigation into Cancer and Nutrition (EPIC)-Potsdam Study. Diabetes 52:812-817

Fernandez-Real JM and Ricart W (2003) Insulin resistance and chronic cardiovascular inflammatory syndrome. Endocr Rev 24:278-301

Nappo F, Esposito K, Cioffi M, et al. (2002) Postprandial endothelial activation in healthy subjects and in type 2 diabetic patients: role of fat and carbohydrate meals. J Am Coll Cardiol 39:1145-1150

Jellema A, Plat J and Mensink RP (2004) Weight reduction, but not a moderate intake of fish oil, lowers concentrations of inflammatory markers and PAI-1 antigen in obese men during the fasting and postprandial state. Eur J Clin Invest 34:766-773

Ceriello A, Taboga C, Tonutti L, et al. (2002) Evidence for an independent and cumulative effect of postprandial hypertriglyceridemia and hyperglycemia on endothelial dysfunction and oxidative stress generation: effects of short- and long-term simvastatin treatment. Circulation 106:1211-1218

Kosmidou I, Vassilakopoulos T, Xagorari A, Zakynthinos S, Papapetropoulos A and Roussos C (2002) Production of interleukin-6 by skeletal myotubes: role of reactive oxygen species. Am J Respir Cell Mol Biol 26:587-593

Weigert C, Brodbeck K, Staiger H, et al. (2004) Palmitate, but not unsaturated fatty acids, induces the expression of interleukin-6 in human myotubes through proteasome-dependent activation of nuclear factor-kappaB. J Biol Chem 279:23942-23952

Bruce CR and Dyck DJ (2004) Cytokine regulation of skeletal muscle fatty acid metabolism: effect of interleukin-6 and tumor necrosis factor-alpha. Am J Physiol Endocrinol Metab 287:E616-621

Jove M, Planavila A, Laguna JC and Vazquez-Carrera M (2005) Palmitate-induced interleukin 6 production is mediated by protein kinase $\mathrm{C}$ and nuclear-factor kappaB activation and leads to glucose transporter 4 down-regulation in skeletal muscle cells. Endocrinology 146:3087-3095 
66 Klover PJ, Zimmers TA, Koniaris LG and Mooney RA (2003) Chronic exposure to interleukin-6 causes hepatic insulin resistance in mice. Diabetes 52:2784-2789

67 Rotter Sopasakis V, Larsson BM, Johansson A, Holmang A and Smith U (2004) Short-term infusion of interleukin-6 does not induce insulin resistance in vivo or impair insulin signalling in rats. Diabetologia 47:1879-1887

68 Senn JJ, Klover PJ, Nowak IA and Mooney RA (2002) Interleukin-6 induces cellular insulin resistance in hepatocytes. Diabetes 51:3391-3399 

SAMENVATTING / SUMMARY 


\section{SAMENVATTING}

van het proefschrift getiteld 'Fatty acid metabolism, impaired glucose tolerance and the effects of lifestyle' oftewel 'Vetzuurmetabolisme, een gestoorde glucose tolerantie en de effecten van leefwijze'.

Diabetes mellitus type 2 (DM2), ook wel ouderdomssuikerziekte genoemd, komt steeds meer voor. Gelukkig neemt de aandacht voor het probleem 'diabetes' ook toe. Dat dit terecht is, is te lezen in hoofdstuk 2. Er is een orale glucose tolerantie test uitgevoerd bij 2715 mensen met een verhoogd risico op een gestoord glucose metabolisme, d.w.z. leeftijd > 40 jaar en/of een familiegeschiedenis van diabetes en/of een BMI $>25 \mathrm{~kg} / \mathrm{m}^{2}$. De resultaten laten zien dat drie op de tien mensen met een verhoogd risico een gestoord glucose metabolisme heeft (gestoorde gevaste glucose, gestoorde glucose tolerantie of DM2) en dat één op de twaalf diabetes heeft.

Eerder werd aangetoond dat een leefstijl interventie de insuline gevoeligheid en de glucose tolerantie verbeterde en het risico op DM2 verminderde in mensen met een gestoorde glucose tolerantie. Een gestoorde glucose tolerantie wordt gezien als een voorstadium van diabetes. De leefstijl interventies waren gericht op het verbeteren van het voedingspatroon (minder totaal en verzadigd vet en meer vezel inname) en het verhogen van de lichamelijke activiteit. Ook de resultaten van de SLIM studie (Study on Lifestyle intervention and Impaired glucose tolerance Maastricht) laten zien dat verbeteringen in het patroon van vetinname, lichamelijke activiteit en een matige afname van lichaamsgewicht in belangrijke mate konden bijdragen aan het verlagen van het risico op diabetes mellitus type 2 bij mensen met een gestoorde glucose tolerantie.

Verstoringen die aanwezig zijn in het voorstadium van diabetes vertegenwoordigen factoren die oorzakelijk zijn of in ieder geval een grote rol spelen bij het ontstaan van diabetes mellitus type 2 . De effecten van leefwijze op het risico op diabetes en de mechanismen waardoor dit bewerkstelligd wordt zijn daarom goed te bestuderen in deze groep mensen. Verbeteringen in het vetzuurmetabolisme van de skeletspier worden verondersteld een belangrijke fysiologische rol te spelen in de gunstige effecten van veranderingen in leefwijze. De belangstelling voor de rol van het vetzuurmetabolisme in de skeletspier (opname, verbranding en opslag van vetten) is ontstaan door de bevinding dat insuline resistentie en diabetes mellitus type 2 worden gekenmerkt door een verhoogde opslag van triglyceriden (vetten) in de spier. Met name een verstoorde regulering van het vetzuurmetabolisme in de spier zou kunnen leiden tot een dysbalans tussen opname en verbranding en zo tot een opéénhoping van vetten en intermediairen van het vetzuurmetabolisme in de spier. Met name van deze 
intermediairen wordt verondersteld dat ze de insuline resistentie en daarmee het risico op diabetes verhogen.

In dit proefschrift is gekeken naar de metabole verstoringen die aanwezig zijn in het voorstadium van diabetes, en naar de effecten van leefwijze op deze metabole verstoringen. Omdat de meeste mensen in de Westerse gemeenschap overdag doorgaans in de gevoede toestand zijn, is er extra aandacht besteed aan verstoringen in de regulering van het vetzuurmetabolisme in de skeletspier na het eten.

In hoofdstuk 3 laten we zien dat de capaciteit van de skeletspier om om te schakelen van vetverbranding tijdens het vasten naar voornamelijk koolhydraatverbranding na het eten, is verminderd bij mensen in de prediabete fase (impaired glucose tolerance, IGT), zelfs als ze vergeleken worden met mensen van gelijk lichaamsvetpercentage en lichamelijke fitheid zonder gestoord glucose metabolisme (normal glucose tolerance, NGT). De verschillen in vetverbranding konden niet verklaard worden door verschillen in opname van vetten of suikers in de skeletspier. Deze bevindingen geven een sterke aanwijzing dat een verminderde capaciteit om de vetverbranding te reguleren (een verminderde 'metabole flexibiliteit' van de vetverbranding) een vroege en mogelijk oorzakelijke verstoring is in het ontstaan van diabetes mellitus type 2. Gewichtsverlies verbeterde niet alleen het vermogen van de skeletspier om om te schakelen van vetverbranding naar koolhydraatverbranding maar ook om de vetverbranding tijdens het vasten te doen toenemen. Deze veranderingen gingen gepaard met een verbeterde insuline gevoeligheid. Daarnaast was de ophoping van vetten in de spier afgenomen in 6 van de 7 proefpersonen. Hoewel we in deze studie oorzaak en gevolg niet kunnen onderscheiden, past dit wel in de gedachte dat een verbeterde 'metabole flexibiliteit' zorgt voor een verbeterde efficiëntie en afstemming tussen vetzuuropname en -verbranding, wat vervolgens zorgt voor een vermindering in de hoeveelheid triglyceriden in de spier.

Hoewel in hoofdstuk 3 geen verschillen werden gevonden in de vetzuuropname door de spier tussen obese mannen met IGT en obese mannen met NGT, is in het verleden wel aangetoond dat de vetzuuropname in de spier van mensen met insuline resistentie en diabetes verlaagd is t.o.v. mensen met een gezond gewicht. Deze verlaagde vetzuuropname in de spier zou deels verklaard kunnen worden door verstoringen in functie en hoeveelheid van vetzuurtransporters in de skeletspier. De rol van de vetzuurtransporter CD36 m.b.t. insuline resistentie en een gestoorde glucose tolerantie is onderzocht in hoofdstuk 4 en 5. Inderdaad was een verlaagde hoeveelheid CD36 tijdens het vasten gerelateerd aan insuline resistentie, maar niet verschillend tussen NGT en IGT. Een belangrijke observatie was de acute toename in CD36 eiwit in de skeletspier na insuline stimulering in vivo. Dit geeft aan dat vetzuuropname niet 
alleen indirect gereguleerd wordt door vetzuuraanvoer, maar ook direct en actief wordt gereguleerd op het niveau van de spier zelf. Ook vonden we dat de insuline-geïnduceerde toename van CD36 eiwit positief gerelateerd was aan insuline resistentie, wat wijst op een verstoorde regulering van de vetzuuropname capaciteit in de insuline resistente conditie. Deze verhoogde toename van CD36 eiwit met toenemende insuline resistentie zou kunnen bijdragen aan de dysbalans tussen vetzuuropname en -verbranding in insuline-gestimuleerde omstandigheden, met als gevolg een verhoogde hoeveelheid van triglyceriden en intermediairen van vetmetabolisme in de spier. De bevinding dat diabetes mellitus type 2 meer voorkomt bij mensen van het TT genotype van een genvariatie in de promoter van CD36 (hoofdstuk 5), draagt bij aan het concept dat de vetzuurtransporter CD36 betrokken zou kunnen zijn bij het ontstaan of de verergering van insuline resistentie en diabetes mellitus type 2 .

Overgewicht en insuline resistentie zijn ook geassocieerd met een verhoogde afgifte van ontstekingsmarkers door het vetweefsel. Hoewel reeds bekend was dat vetweefsel ontstekingsmarkers kan afgeven, is nu ook aangetoond dat spierweefsel ontstekingsmarkers zoals interleukine-6 (IL-6) kan afgeven, met name tijdens extreme inspanning. Een belangrijke bevinding in hoofdstuk 6 is dat wij nu aantonen dat IL-6 ook wordt afgegeven door de skeletspier van insuline resistente mensen, d.w.z. in obese mannen met IGT als met NGT, en zowel tijdens vasten als na het eten. Buitengewoon interessant was de bevinding dat deze IL-6 afgifte toenam na eten van een hoog-vet maaltijd, en dat dit met name toenam bij de mannen met een gestoorde glucose tolerantie. Gewichtsverlies verminderde deze maaltijd-geïnduceerde IL-6 afgifte, tezamen met een verbeterde insuline gevoeligheid en een verbeterde 'metabole flexibiliteit' van de vetverbranding. Dit geeft aan dat een hoog-vet maaltijd een metabole stressor is, met name in de prediabete fase. Een mogelijk verklaring is dat de verminderde capaciteit om de vetverbranding te reguleren zorgt voor een opeenhoping van intermediairen die kunnen leiden tot oxidatieve stress. Zowel oxidatieve stress als vrije vetzuren zoals palmitaat zelf kunnen in de skeletspier de afgifte van IL-6 provoceren.

Een ander mechanisme waardoor leefstijl een gunstig effect zou kunnen hebben op insuline resistentie en het risico op diabetes, is het effect van het soort vetzuur op het metabolisme. Aangezien een vermindering in de verzadigd vet consumptie een belangrijk aspect is van een gezonde leefwijze, en aangezien leefstijl adviezen het risico op diabetes kunnen verminderen, hebben we in hoofdstuk 7 gekeken naar de effecten van een leefstijl interventie programma op de serum vetzuurprofielen en het verband met insuline resistentie. Een vermindering in insuline resistentie werd gekenmerkt door een vermindering in de fractie van myristinezuur (C14:0), palmitoleïnezuur (C16:1 n-7), $\gamma$-linoleenzuur (C18:3 n-6) en dihomo- $\gamma$-linoleenzuur (c20:3 n-6), en een toename in oliezuur 
(C18:1 n-9) en arachidonzuur (C20:4 n-6). Een verminderde insuline resistentie werd verder gekenmerkt door een afname in geschatte $\Delta 9$-desaturase (StearylCoA Desaturase-1) en $\Delta 6$-desaturase activiteit en een toename in geschatte $\Delta 5$ desaturase activiteit. De associaties tussen veranderingen in $\Delta 9-, \Delta 6-$ en $\Delta 5$ desaturase activiteit en insuline resistentie verminderden wel na correctie voor leefstijl parameters zoals voeding, lichamelijke activiteit en lichaamsvetpercentage, maar bleven significant. Dit houdt in dat andere factoren, waarvoor niet gecorrigeerd is in deze studie, effect kunnen hebben op de relatie tussen het serum vetzuurprofiel en insuline resistentie. Factoren die hiervoor in aanmerking komen zijn veranderingen in hormonen en gen-omgevingsinteracties. Met name de $\Delta 9$-desaturase activiteit zou interessant kunnen zijn m.b.t. een verstoord vetmetabolisme en insuline resistentie in de skeletspier. Onlangs is gesuggereerd dat een verhoogde $\Delta 9$-desaturase activiteit de opslag van triglyceriden in de skeletspier zou kunnen bevorderen door te zorgen voor de omzetting van palmitaat tot palmitoleïnezuur en stearaat tot oliezuur, wat betere substraten zijn voor opslag dan de hier genoemde verzadigde vetzuren. Daarnaast zouden desaturase enzymen de vloeibaarheid van de celmembraan kunnen beïnvloeden en zo indirect een effect kunnen hebben op membraangebonden processen zoals insuline signalering en substraat opname.

\section{In het kort toont het onderzoek in dit proefschrift aan dat:}

- het vermogen om de vetverbranding te reguleren, hier metabole flexibiliteit genoemd, is verminderd in de skeletspier van mannen in de prediabete fase, wat erop duidt dat dit een rol kan spelen in het ontstaan van diabetes mellitus type 2 . Gewichtsverlies kan dit vermogen om de vetverbranding te reguleren verbeteren. Dit ging samen met een afname van triglyceriden in de spier en een verbetering in insuline gevoeligheid.

- de hoeveelheid van de vetzuurtransporter CD36 in de skeletspier acuut toeneemt na insuline stimulering in vivo, en dat deze insuline-gemedieerde opregulatie van het CD36 eiwit meer verstoord is met een toegenomen insuline resistentie. Dit geeft aan dat CD36 mogelijk betrokken is bij een verstoorde balans tussen vetzuuropname en -verbranding in de insuline resistente spier.

- IL-6, een pro-inflammatoir cytokine, wordt afgegeven door de skeletspier van insuline resistente mannen. Deze afgifte neemt toe na het eten, met name in de prediabete mannen. Gewichtsverlies reduceert deze maaltijd-geïnduceerde IL-6 afgifte, tezamen met een verbeterde 'metabole flexibiliteit' van de vetverbranding en een verbetering in insuline gevoeligheid.

- een vermindering in insuline resistentie werd gekarakteriseerd door veranderingen in het serum vetzuurprofiel en enzymen die de verzadiging van de 
vetzuren reguleren (zoals een afname in geschatte $\Delta 9$ - en $\Delta 6$-desaturase activiteit en een toename in geschatte $\Delta 5$-desaturase activiteit). Deze associaties verminderden wel na correctie voor leefstijl factoren (voeding, lichamelijke activiteit, lichaamsvetpercentage), maar bleven significant.

De resultaten en conclusies van dit proefschrift dragen bij aan de kennis over het ontstaan van insuline resistentie en diabetes mellitus type 2, alswel aan de kennis over de fysiologische mechanismen die verantwoordelijk zijn voor het effect van leefwijze op insuline resistentie en het diabetes risico.

\section{Verklarende woordenlijst}

$\Delta 9$-, $\Delta 6$-, en $\Delta 5$ - desaturase

eiwitten (enzymen) die de vetzuurketens meer onverzadigd maken door op specifieke plaatsen in de vetzuurketen een dubbele binding aan de te brengen

insuline resistentie

$I G T$ verminderde gevoeligheid voor de werking van het hormoon insuline. Insuline stimuleert o.a. de weefsels (met name de skeletspier) om glucose uit het bloed op te nemen.

afkorting voor 'gestoorde glucose tolerantie', het lichaam heeft moeite de suiker te verwerken maar er is nog geen sprake van diabetes

'metabole flexibiliteit'van de vet- en koolhydraatverbranding

$N G T$

ontstekingsmarker

orale glucose tolerantie test

skeletspier

triglyceriden

vetzuur metabolisme

vetzuurtransporters

vrije vetzuren de capaciteit van de cellen en/of weefsels om zich adequaat aan te passen aan veranderingen in het interne milieu, bv door om te schakelen van vetverbranding naar koolhydraatverbranding na de maaltijd of om terug om de schakelen naar vetverbranding tijdens vasten

afkorting voor 'normale glucose tolerantie', het lichaam kan de suiker goed verwerken

stoffen die in geval van een ontsteking in het bloed worden aangetroffen en die vaak een rol spelen in het ontstekingsproces

Een test met een suikerdrank (gestandaardiseerde hoeveelheid) om te kijken of er verstoringen zijn in het glucose (suiker) metabolisme

de spieren die gebruikt worden voor beweging en waar je bewuste controle over uit kunt voeren

vetten die bestaan uit drie vetzuurketens die verbonden zijn met elkaar door een glycerol molecuul ('normaal'vet)

de opname, opslag en verbranding van vetten in het lichaam

eiwitten in de wand (membraan) van een cel die ervoor zorgen dat vetten door deze wand kunnen worden opgenomen of die vetzuren binnen in de cel binden en transporteren

losse vetzuurketens (wel grotendeels gedragen door bloedeiwitten of andere bindingseiwitten) 


\section{SUMMARY}

The prevalence of diabetes is increasing rapidly. Fortunately, the awareness of diabetes as a problem of major concern is also rising. The justification for this concern is shown by the results in chapter 2 . A single oral glucose tolerance test was performed in 2715 subjects at high risk for glucose intolerance, i.e. those of age $>40$ years and/or a family history of diabetes and/or a BMI $>25 \mathrm{~kg} / \mathrm{m}^{2}$. This revealed that every three out of ten people at risk had an impairment in glucose metabolism (impaired fasting glucose, impaired glucose tolerance or diabetes mellitus type 2), and one out of twelve had diabetes mellitus type 2.

Previously it was shown that a lifestyle intervention program aimed at diet (reducing total and saturated fat intake and increasing fibre intake) and increasing physical activity in subjects with impaired glucose tolerance, a prediabetic state, could improve insulin sensitivity, reduce postprandial glucose concentrations and reduce the incidence of DM2. Results from the SLIM study (Study on Lifestyle intervention and Impaired glucose tolerance Maastricht) show that improvements in dietary fat quality, physical activity pattern and body weight contribute to a reduction in diabetes risk.

Disturbances that are found in IGT subjects, a prediabetic state, may represent primary or early factors in the development towards DM2 rather than metabolic adaptations due to the diabetic state. This makes IGT subjects a very suitable population to investigate the effects of different lifestyle aspects on diabetes risk and the mechanisms by which this is mediated. An important physiological mechanism that may mediate these beneficial effects of lifestyle may be related to improvements in fatty acid handling by skeletal muscle. The interest in the role of fatty acid handling in skeletal muscle (uptake, oxidation and storage of fatty acids) was raised by the finding that in insulin resistance and DM2, the accumulation of triacylglycerol in muscle was high and showed a strong positive association to insulin resistance. Dysregulation of fatty acid handling may lead to a dysbalance between uptake and use (oxidation) of fatty acids, thereby enhancing the accumulation of lipids and intermediates of lipid metabolism in skeletal muscle. In particular these intermediates of lipid metabolism are thought to interfere with insulin signalling, thereby enhancing insulin resistance and thus diabetes risk.

This thesis is focussed on metabolic impairments that are related to the development of diabetes mellitus type 2, which is investigated in subjects with impaired glucose tolerance, and evaluates the effects of different lifestyle aspects on these metabolic impairments. Since the majority of people in Western societies 
is in the postprandial state most of the day, we have paid special attention to the handling of fatty acids by skeletal muscle after a meal.

We found that the ability of skeletal muscle to switch from fat oxidation to carbohydrate oxidation after a meal was reduced in IGT subjects relative to NGT subjects that were well matched for body fat mass and physical activity (chapter 3). This provides strong evidence that this reduced postprandial 'metabolic flexibility' of substrate oxidation is an early and intrinsic characteristic of skeletal muscle involved in the development of DM2. Weight loss was able to reverse the impaired capacity of forearm muscle to switch from fat to carbohydrate oxidation after the meal, and improved fasting fat oxidation as well, in parallel with an improved insulin sensitivity. This suggests that the degree of impairment is partly dependent on obesity and/or insulin resistance. In this study, no differences were found in skeletal muscle fatty acid uptake between IGT or NGT, or before and after weight loss. Thus, the findings on substrate oxidation could not be explained by differences in fatty acid uptake. The improved metabolic flexibility of substrate oxidation after weight loss is accompanied by a reduction in intramyocellular triacylglycerol in 6 out of 7 subjects.

Although we found no differences in skeletal muscle fatty acid uptake between men with impaired glucose tolerance and BMI-matched normal glucose tolerant men, previous studies have shown that free fatty acid uptake into skeletal muscle is reduced in the insulin resistant and/or diabetic state when compared to overweight or lean controls. This may be the result of impairments in fatty acid transport. The role of the fatty acid transporter CD36 in insulin resistance and impaired glucose tolerance was investigated in chapters 4 and 5 . No differences were observed between IGT and NGT. We found that the amount of fatty acid transporter CD36 is acutely upregulated by insulin, indicating that fatty acid uptake is actively regulated at the level of skeletal muscle itself. Furthermore, insulin resistance was associated with a reduced CD36 protein in skeletal muscle during fasting, but with an increased upregulation of CD36 protein expression during insulin stimulation. This altered regulation of CD36 protein content may contribute to an impaired balance between fatty acid uptake and oxidation in the insulin resistant skeletal muscle, which may in turn enhance in the accumulation of intramyocellular lipid intermediates. In addition, we showed that DM2 was more prevalent among subjects with the TT genotype of a promoter polymorphism in the CD36 gene (chapter 5) and that TT homozygotes were more insulin resistant, even within the group of diabetes patients.

Obesity and insulin resistance have also been associated with increased release of pro-inflammatory markers from adipose tissue, with a potential effect on insulin resistance. Recently, it was shown that in addition to adipose tissue, skeletal muscle could also release the pro-inflammatory cytokine interleukin-6, 
during exercise. A major finding presented in chapter 6 is that the cytokine IL-6 was released from skeletal muscle of obese IGT and obese NGT men during fasting and even more after a mixed meal with high fat content, in particular in the IGT subjects. The IL-6 release from muscle induced by a high fat meal was reduced after weight loss in IGT men, in parallel with improvements in insulin sensitivity and metabolic flexibility of substrate metabolism. We suggest that a mixed meal with high fat content may be an important metabolic stressor, evoking IL-6 release from skeletal muscle, in particular in insulin resistant men in the prediabetic state. A possible explanation for this may be found in the impairments in skeletal muscle substrate oxidation in IGT men.

Another mechanism by which lifestyle may have a positive effect on insulin resistance and diabetes risk is by the effect of different kinds of fatty acids on metabolism. Since the reduction of saturated fat intake is an important aspect of the lifestyle intervention, and since lifestyle intervention is effective to reduce diabetes risk, we investigated the effect of a diet-exercise lifestyle program on serum fatty acid profiles in relation to changes in insulin resistance (chapter 7). An improvement in insulin resistance was typically associated with a reduction in myristic acid (C14:0), palmitoleic acid (C16:1 n-7), $\gamma$-linolenic acid (C18:3 n-6) and dihomo- $\gamma$-linolenic acid (c20:3 n-6) fractions, an increase in oleic acid (C18:1 n-9) and arachidonic acid (C20:4 n-6). Reduced insulin resistance was further characterized by a decrease in estimated $\Delta 9$-desaturase (SCD-1) and $\Delta 6$-desaturase activities and an increase in estimated $\Delta 5$-desaturase activity. The associations between changes in $\Delta 9-, \Delta 6$ - and $\Delta 5$-desaturase activities and changes in insulin resistance were influenced by changes in aerobic capacity ( $\mathrm{VO}_{2} \mathrm{max}$ ) and/or body fat percentage, supporting the hypothesis that desaturase activities are affected by lifestyle. Furthermore, the finding that the association between desaturase activities and insulin resistance was still significant after correction for lifestyle factors (diet, physical activity, body fat percentage) indicates that other factors, which were not accounted for in this study, may interfere with the relation between insulin resistance and endogenous fatty acid production, e.g. an impaired fatty acid handling (uptake, oxidation or storage) or hormones like insulin or leptin. In particular the $\Delta 9$-desaturase activity may be of interest for fatty acid handling in skeletal muscle. Recently it was suggested that an increased $\Delta 9$ desaturase activity may enhance the storage of triacylglycerol in skeletal muscle by providing the preferential substrates for storage (palmitoleic and oleic acid). Furthermore, desaturase enzymes can influence membrane fluidity, affecting membrane-associated processes such as hormone signaling and transport, including insulin signaling, and glucose and FFA transport. 
In conclusion, this thesis shows that:

- the ability to regulate fat oxidation in skeletal muscle, indicated here as 'metabolic flexibility' of substrate oxidation, is specifically impaired in prediabetic subjects and may be an early factor in the development towards diabetes mellitus type 2. Weight loss improves metabolic flexibility in parallel with an improvement in insulin sensitivity and a decrease in IMTG.

- the protein content of the fatty acid transporter CD36 in skeletal muscle is acutely upregulated by insulin and its regulation is disturbed with insulin resistance. Thus, CD36 may be involved in the impaired handling of fatty acids by skeletal muscle in the insulin resistant condition.

- IL-6, a pro-inflammatory cytokine, is released by skeletal muscle of insulin resistant subjects. This release is increased after a mixed meal with high fat content, in particular in prediabetic subjects. Weight loss reduces this postprandial IL-6 response of skeletal muscle, in parallel with an improved insulin sensitivity and an improved metabolic flexibility of substrate oxidation in skeletal muscle.

- an improvement in insulin resistance was typically associated with a decrease in estimated $\Delta 9$-desaturase (Stearyl CoA Desaturase-1) and $\Delta 6$-desaturase activities and an increase in estimated $\Delta 5$-desaturase activity, and that these associations are partly modified by diet, physical activity and body fat percentage but remain significant after adjustment for these lifestyle factors.

The results and conclusions of this thesis contribute to the understanding of the development of insulin resistance and diabetes mellitus type 2, as well as to the knowledge about physiological mechanisms that are responsible for the effect of lifestyle on diabetes risk. 
Explanatory list

$\Delta$ 9-, $\Delta 6$-, en $\Delta 5$ - desaturase

insulin resistence

$I G T$

'metabolic flexibility' of fatand carbohydrate oxidation

$N G T$

inflammatory markers

oral glucose tolerance test

skeletal muscle

triglycerides

fatty acid metabolism

fatty acid transporters

free fatty acids proteins (enzymes) that increase the degree of unsaturation of fatty acid chains

decreased sensitivity to the action of the hormoen insulin. Insulin stimulates tissues (predominantly skeletal muscle) to clear glucose from the blood

abbreviation for 'impaired glucose tolerance', the body has difficulty in processing the glucose, but diabetes has not developed (yet)

the capacity of cells and/or tissues to be able to switch between fuels for oxidation, e.g. from fat to carbohydrate oxidation after a meal and back to fat oxidation during fasting

abbreviation for 'normal glucose tolerance', the body has no problem in processing glucose

chemical compounds that can be found in the blood during inflammation and that usually play a role in inflammatory processes

a 'sugerdrink' test with a standardized amount of glucose to diagnose impairments in glucose metabolism

muscles that are used to facilitate movement and generally contract voluntarily

fats made up of three fatty acid chains bound together by glycerol ('normal' fat)

the uptake, storage and oxidation of fatty acids in the body proteins in the cell walls (membranes) that allow fats to be taken up through this wall or that bind and transport fatty acids within the cell

single fatty acids chains (mostly carried by plasma protein or other binding proteins) 



\section{DANKWOORD}




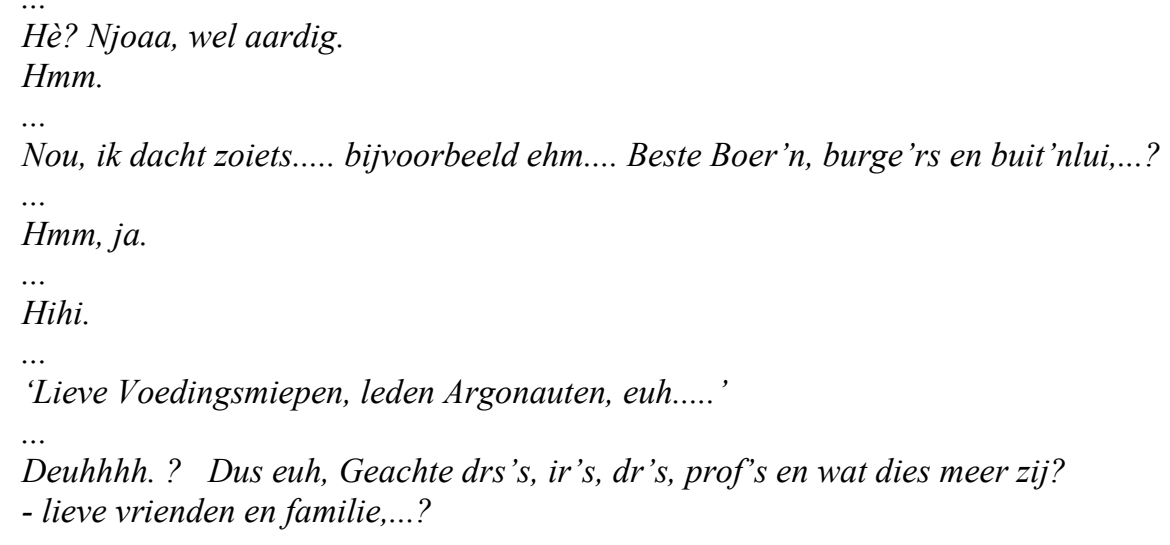

Geachte Lezer,

hier voor $\mathrm{u}$ ligt mijn proefschrift. Niemand hoeft meer bang te zijn voor een moeilijke blik bij de vraag hoe het er mee staat. Ik kan nu volmondig en blij zeggen "Goed!". Het is af. Het einde van een lange reis, of misschien wel het begin.

Voor mij was het een reis langs allerlei onderzoeksgebieden, van de genetische epidemiologie langs de interventie-studies naar de humaan-fysiologische experimenten en daar dan weer wat dieper de cel in. Het was een spannende reis en ik heb veel gezien en geleerd. Ik heb er erg van genoten en soms ook ontberingen geleden, zoals dat gaat op lange reizen. Maar achteraf onthoud je toch de goede dingen, heb je wat mooie kroegverhalen en laat je trots al je artikelen zien. Deze reis heb ik beslist niet alleen gemaakt, en daarom wil ik een heleboel mensen bedanken die ik op mijn weg ben tegengekomen.

Allereerst de proefpersonen. Zij hebben enorm veel tijd, moeite en geduld geïnvesteerd in deze onderzoeken, en moeten zich soms als de galeislaven van ons schip hebben gevoeld (vooral tijdens de maximaaltesten op de fiets ;-), maar hebben een wezenlijke bijdrage kunnen leveren aan het onderzoek om m.b.v. veranderingen in leefwijze de opmars van diabetes te kunnen stuiten. Mijn dank daarvoor is groot.

Zeer geachte Dr. Ir. Ellen Blaak, beste Ellen, ik kan met recht zeggen dat ik blij ben dat ik jou als begeleider heb getroffen, je hebt me veel geleerd, en op de goede 
momenten moed ingepraat (bijvoorbeeld als ons boomerang-artikel weer eens terugkwam). In het laatste jaar was je ook een goede sparring-partner, wat me erg heeft uitgedaagd om een goede discussie neer te zetten. Ik hoop dat ik in mijn wetenschappelijke carriëre nog vaak met je van gedachten mag wisselen over de 'metabole flexibiliteit' in de spier en al die andere aspecten van het metabolisme die óók zo interessant zijn in relatie tot diabetes.

Uiteraard bedank ik mijn promotoren, Wim Saris en Tjerk de Bruin, die mij met goede vragen en tips zowel inhoudelijk als met betrekking tot de toekomst tot steun zijn geweest.

Carla van der Kallen, je hebt me enorm geholpen met het CD36-snp artikel, en zonder jouw expertise en onze creatieve gesprekken had het nu misschien nog op mijn bureau gelegen! Heel erg bedankt dat je altijd tijd wilde maken hiervoor. Ook belangrijk voor mij: dr. Edith Feskens. Hoewel ik tijdens mijn studie in Wageningen eigenlijk geen voorkeur had voor de epidemiologie, heb ik me toch nog behoorlijk wat bezig gehouden met modellen in SPSS en heb je me geholpen op koers te blijven in een zee van analyses. En daarnaast was het gewoon altijd heel gezellig.

Ook wil ik de beoordelingscommissie, bestaande uit prof. Ronald Mensink, prof. Coen Stehouwer, dr. Hans Keizer, prof. Keith Frayn en prof. Jaap Seidell, bedanken voor het lezen en beoordelen van het manuscript. To prof. Keith Frayn, from the start of my PhD work I've really been an admirer of your research and techniques, and I am very grateful that you have found the time to read the manuscript and be present at the defense.

Lieve Margriet (K.), vriendin, kroeg- en sportmaatje, je ging mij als het ware voor in het onderzoek en promoveren, en het was goed om al eens in de aula gestaan te hebben. En natuurlijk bedankt voor de vele kopjes thee en de goede gesprekken van vrouwen onder mekaar die 30 zijn (geworden).... Ik hoop met jou nog ver in de tijd te kunnen reizen.

Lieve Cheryl, ik ben blij met jou als opvolgster en collega! Ondanks dat je al maanden gewapend met een fotocamera rondloopt om slechte momenten vast te leggen (alles wat je doet kan en zal tegen je worden gebruikt) vind ik je een supermeid en ben je volgens mij ook nog een supervrouw en -moeder, en ik ben blij dat ik voorlopig onze hardloopuurtjes nog niet hoef te missen! En op reis zijn we natuurlijk 'very irresistable' ;-).

Tanja en Marja, bedankt voor jullie betrouwbare hulp met de SLIM en de substudies, jullie hebben me geholpen om door een paar zware stormen te komen. 
Daarnaast was en is het supergezellig en is het eigenlijk maar goed dat jullie er meestal niet tegelijk zijn!

Aan het begin van mijn reis heb ik volop de gelegenheid gehad om mij moed in te drinken in John Mullins samen met Jos, Luc, Joost, Margriet, Michiel, Freddy, Gabby, Petra, Guy en vele anderen. Eenmaal goed op weg is dat wat minder geworden maar gelukkig heeft Jos de vrijdagmiddagborrel ingevoerd en dat het ver weg zou zijn kan voor niemand meer een excuus wezen!

En wat kwam ik zoal tegen op mijn reis?

Het begon met de SLIM, en ik dank Marco Mensink voor de uitleg en later voor de praktische hulp bij deze studie zowel als bij de substudie. Voor de SLIM ook heel belangrijk: het professionele bewegingsprogramma dat verzorgd werd door Birgitte Hendrikx en de sportdocenten, waaronder Ruud, Loek, Beate, Wendy, Chantal en Esther, wiens enthousiasme heeft zonder meer bijgedragen aan het succes van het bewegingsprogramma, en ik ben blij dat het nog een staartje krijgt! Verder is er vooral bij de substudie heel wat 'spierwerk' verzet, in samenwerking met Eline Kooi van Radiologie, Hans Keizer van Bewegingswetenschappen, Paul Roekaerts van Anesthesiologie, Eugene Jansen van het RIVM en Jan Glatz (we zijn nog lang niet uitgediscussieerd, wat mij betreft :-) van Moleculaire Genetica. Wat betreft het werk aan de CD36-vetzuurtransporter dank ik ook voor de medewerking van Gert Schaart, Michaël Magagnin en Maurice Pelsers en ik dank Annemie, Freek, Wendy en Joan voor hópen analyses, die essentieel waren voor mijn onderzoek. Ook de stagiairen Judith, Dorien en Stijn verdienen lof voor het proefpersonen bellen, vele cupjes schrijven, testen draaien en coupes snijden, plakken, kleuren en tellen. Laat ik ook vooral de mensen niet vergeten die op cruciale momenten tijd hadden om te helpen met het zetten van infusen, naast Marco, Joan (dank voor je geduld toen ik het moest leren) en Gabby natuurlijk ook Gerrit, succes verzekerd!

En natuurlijk Jos, Jos, Jos, en Jos, van wie je altijd op aan kon/kunt voor hulp ("wille we nie kunne we nie doen we nie. Wat moet je?") en die op deze reis wel veel meer OGTT's op zich af heeft zien komen dan hem lief was. Ook dank daarvoor.

Rian, ik ben op jouw kamertje met mijn AIO-schap begonnen en heb het er ook weer beëindigd. Het is een rustig kamertje, en ik was blij met de gezellige gesprekken en je tips over de specifieke vrije vetzuren.

Loek en Paul: jullie waren de redders in nood van oxycons, plethysmografen en computers! 
En was je hoofd dan even de weg kwijt, dan was het fijn om even aanspraak te hebben bij Berber, Myriam, Wendy, Ping, Ralph (from the White House), Gijs, Antoine, Anneke, Hanneke, Sjonnie Sjocken (als je een snoepje komt -euh- halen), Edwin en Herman.

Een verassing op het einde van mijn reis was de kennismaking met een hele bijzondere groep andere 'AIO's-in-de-laatste-fase', en ik hoop nog vaak met jullie (Bianca, Babette, Magda, Danitsja, Judith, Daniel) te gaan picknicken om jullie verhalen te horen.

Arlien, je bent en blijft gewoon familie! Blijf vooral cocktails feestjes houden ;-) Marco Mout, je hebt me laten ontdekken dat creativiteit inderdaad in ieder mens schuilt. Fotocursusgenoten: het was gezellig in het donker. Daarnaast was het gezelling even bij te kunnen komen in 'Holland' met Martine, Janneke, Annemiek, Monique, Irene, Annelies, Diane (we komen langs!), Menno en Mascha en al onze Paasvrienden, de Chaootjes, Joop, Paul en Patricia.

En natuurlijk de echte familie, die misschien nog niet zo vaak naar Maastricht is gekomen maar nu van harte welkom is in de B\&B Berkeleijn te Bunde: Matthijs natuurlijk, ik hoop ook eens met Ali, en Wil \& Willy, Guus + kids, Jean \& Nel, en de 'nichtjes' met gezin.

Mam, ik mocht doen wat ik het liefste deed, en je hebt me daarin altijd gestimuleerd. Ook al beginnen we allebei op een heel andere manier aan een reis, je hebt me nooit tegengehouden. Ik wil je bedanken omdat je zo verstandig bent, en zo geduldig, en voor alles wat je me geleerd hebt over de mensen en het leven.

Michaël, jij bent voor mij heel bijzonder, en je vele sportieve en creatieve momenten waaronder de uitvinding van het "Mheuuh"-moment zijn mij enorm tot steun geweest.

Op weg naar de toekomst! 



\section{CURRICULUM VITAE}

Eva Corpeleijn was born on April the 6th 1976 in Groenlo, The Netherlands. She completed secondary school at the Rooms-Katholieke Scholengemeenschap 'Marianum' in Groenlo in 1994. After a one-year stay in Paris, France, she started her study Nutrition \& Health with specialization in Human and Animal Physiology at the Wageningen University in 1995. In 1998 she started her first MSc-project at the Laboratory for Animal Physiology at the Rijksuniversiteit Groningen which involved the interaction of hunger- and satiety-pathways in the brain with stress-signalling pathways. In 1999 she performed a second MScproject at the Department of Human and Animal Physiology at the Wageningen University. After her intership at the Department of Human Nutrition, Otago University, New Zealand, she graduated in 2000.

In 2001 she started her $\mathrm{PhD}$ at the Department of Human Biology (NUTRIM), Maastricht University, under supervision of Dr. Ellen Blaak, Prof. Wim H.M. Saris and Prof. Tjerk W.A. de Bruin and with funding from the Dutch Diabetes Research Foundation. Currently she is working as a postdoctoral fellow at the Department of Human Biology, Maastricht University on the project 'Long term effects of changes in lifestyle on glucose tolerance and adherence to the intervention program in subjects with impaired glucose tolerance' funded by the Netherlands Organisation for Scientific Research (NWO).

In December 2005 she was granted an International Travel Grant by the Dutch Diabetes Foundation to work in the lab of Prof. Arild Rustan at the School of Pharmacy, University of Oslo, Norway.

In May 2006 she was granted a 'Talent for the Future' scholarship of the faculty of Health Sciences of Maastricht University to continue her work on muscle physiology and the development of diabetes mellitus type 2, with a special focus on the molecular aspects of impairments in substrate metabolism and inflammation. 


\section{LIST OF PUBLICATIONS}

Corpeleijn E, Feskens E, Jansen E, Mensink M, Saris W, de Bruin T, Blaak E. Improvements in glucose tolerance and insulin sensitivity after lifestyle intervention are related to changes in serum fatty acid profile and desaturase activities. Diabetologia, August 2006. DOI: 10.1007/s00125-006-0383-4

E. Corpeleijn, C.J.H. van der Kallen, M. Kruijshoop, M.G.P. Magagnin, T.W.A. de Bruin, E.J.M. Feskens, W.H.M. Saris, E.E. Blaak. Direct association of a promoter polymorphism in the CD36/FAT fatty acid transporter gene with diabetes mellitus type 2 and insulin resistance. Diab Med 23(8): 907-911, 2006

Eva Corpeleijn, Marco Mensink, Marianne E. Kooi, Paul MHJ Roekaerts, Wim HM Saris, Ellen E Blaak. Weight loss improves metabolic flexibility of substrate oxidation in skeletal muscle of men with impaired glucose tolerance. Submitted

Eva Corpeleijn, Maurice M.A.L. Pelsers, Stijn Soenen, Marco Mensink, Freek G. Bouwman, Marianne E. Kooi, Wim H.M. Saris, Jan F.C. Glatz, Ellen E. Blaak Insulin acutely upregulates protein expression of the fatty acid transporter CD36 in human skeletal muscle in vivo - Disturbed regulation in insulin resistance. Submitted

E.Corpeleijn, E.J.M, Feskens, E.H.J.M. Jansen, M. Mensink, W. H. M. Saris, E. E. Blaak. Effect of lifestyle intervention on adipokines in subjects at high risk for diabetes mellitus type 2 - the SLIM study. Submitted

C. Roumen, E. Corpeleijn, E.J.M. Feskens, M. Mensink, W.H.M. Sairs, E.E. Blaak. Impact of a 3-year lifestyle interventionon postprandial glucose metabolism: the SLIM study. Submitted

E. Corpeleijn, W.H.M. Saris, E. E. Blaak. The concept of metabolic flexibility in obesity and type 2 diabetes mellitus. In preparation for International Journal of Obesity

Corpeleijn E, Saris WH, Jansen EH, Roekaerts PM, Feskens EJ, Blaak EE. Postprandial Interleukin-6 Release from Skeletal Muscle in Men with Impaired Glucose Tolerance can be Reduced by Weight Loss. J Clin Endocrinol Metab. 90(10): 5819-5824, 2005

Mensink M, Corpeleijn E, Feskens EJ, Kruijshoop M, Saris WH, de Bruin TW, Blaak EE: Study on lifestyle-intervention and impaired glucose tolerance Maastricht (SLIM): design and screening results. Diabetes Research of Clinical Practice 61:49-58, 2003

Mensink M, Blaak EE, Corpeleijn E, Saris WH, de Bruin TW, Feskens EJ: Lifestyle intervention according to general recommendations improves glucose tolerance. Obesity Research 11:1588-1596, 2003 


\section{ABSTRACTS}

E. Corpeleijn, E.J.M. Feskens, E.H.J.M. Jansen, M. Mensink, W.H.M. Saris, T.W.A. de Bruin, E. E. Blaak. Improvements in Glucose Tolerance and Insulin Sensitivity after Lifestyle Intervention Are Related to Changes in Serum Fatty Acid Desaturase Activities. Diabetes abstract volume, 66th ADA, 2515-PO, 2006

E. Corpeleijn, M.M.A.L. Pelsers, S. Soenen, M. Mensink, F. G. Bouwman, W.H.M. Saris, J.F.C. Glatz, E.E. Blaak. Acute Insulin-Mediated Increase in the Skeletal Muscle Fatty Acid Transporter CD36/FAT Is Impaired in Insulin Resistant Conditions. Diabetes abstract volume, 66th ADA, 1426-P, 2006

E Corpeleijn, M Mensink, WHM Saris, ME Kooi, PMHJ Roekaerts, EE Blaak. The impaired capacity to switch between fat and glucose oxidation in skeletal muscle of impaired glucose tolerant men during fasting and after a meal improves after weight loss. Diabetologia abstract volume, 41st EASD, OS5, nr. 91, p A10, 2005

Corpeleijn E, Saris WH, Jansen EH, Roekaerts PM, Feskens EJ, Blaak EE. Increased postprandial Interleukin-6 Release from Skeletal Muscle in Men with Impaired Glucose Tolerance can be Reduced by Weight Loss. Diabetologia abstract volume, 41st EASD, PS100, nr. 1064, p A384, 2005

Impaired glucose tolerance (IGT): skeletal muscle fatty acid handling after a mixed meal before and after weight loss. Corpeleijn E, Mensink M, Saris W, Blaak E. IJO 28 (suppl.1) 13th ECO, S105, T3:P3-004, 2004.

Association of a polymorphism in the fatty acid transporter cd36 with the prevalence of type 2 diabetes mellitus. Corpeleijn E, van der Kallen C, Magagnin M, Kruijshoop M, de Bruin T, Blaak E. IJO 28 (suppl.1) 13th ECO, S179, T2:P2a-016, 2004.

Impaired glucose tolerance (IGT): does skeletal muscle fatty acid handling after a high fat meal improve after weight loss in IGT men? Corpeleijn E, Mensink M, Saris WHM, Blaak EE. Will be presented at the EASD 2004, München, Germany

Impaired glucose tolerance (IGT): skeletal muscle fatty acid handling after a high fat meal before and after weight loss. Corpeleijn E, Mensink M, Saris WHM, Blaak EE. EJCI 34 (suppl. 1), 38th ESCI, p.27, nr. 97, 2004.

Impaired glucose tolerance (IGT): skeletal muscle fatty acid handling after a high fat meal. Corpeleijn E, Mensink M, Saris WHM, Blaak EE. IJO 27(suppl.1) 12th ECO, S46, T1:P1-014, 2003.

Prevalence of glucose intolerance in a dutch risk population: impact of sex, age, and body mass index. E Corpeleijn, M Mensink, EJM Feskens, TWA de Bruin, WHM Saris en EE Blaak. Diabetologia abstract volume, 38th EASD, PS5, nr. 287, p.A96, 2002. 


\section{ABBREVIATIONS}

('H)-MRS

ACBP

ACC

ACE-inhibitors

ADP

AMP

AMPK

ARBs

ATGL

ATP

BMI

BSA

BW

CI

$\mathrm{CHO}$

$\mathrm{CO}_{2}$

$\mathrm{CoA}$

CODAM

CPT-1

CRP

CS

DAG

DM2

DPP

DPS

$\mathrm{E} \%$

ECG

EDTA

ELISA

FABPc

FABPm

FAD

FAT/CD36

FATP

FBG

FFA (NEFA)

FFM

FM

GC

Glut4

HAD

$\mathrm{HbA1c}$

HDL

HK

HNF4

HOMA- $\beta$ cell

HOMA-IR

HPLC (proton) Magnetic Resonance Spectroscopy

Acetyl-CoA Binding Protein

Acetyl-CoA Carboxylase

Angiotensin Converting Enzyme - inhibitors

Adenosine Di-Phosphate

Adenosine Mono-Phosphate

AMP-activated protein kinase

Angiotensin II Receptor Blockers

Adipose Triglyceride Lipase

Adenosine Tri-Phosphate

Body Mass Index

Bovine Serum Albumin

Wody Weight

Confidence Interval

Carbohydrate

Carbon dioxide

Co-enzyme A

Cohort study of Diabetes and Atherosclerosis Maastricht

Carnitine Palmitoyl Transferase-1

C-Reactive Protein

Citrate Synthase

Diacylglyerol

Diabetes Mellitus type 2

Diabetes Prevention Program (USA)

Diabetes Prevention Study (Finland)

Energy \%

Electrocardiogram

Ethyleen-Diamine-Tetra-Acetate

Enzyme-Linked Immuno-Sorbent Assay

Cytosolic Fatty Acid Binding Protein

Membrane-bound Fatty Acid Binding Protein

Flavin Adenine Dinucleotide

Fatty Acid Transporter/CD36

Fatty Acid Transport Protein

Fasting Blood Glucose

(plasma) Free Fatty Acid (non-esterified fatty acid)

Fat Free Mass

Fat Mass

Gas Chromatography

Glucose Transporter 4

Hydroxyacyl-CoA Dehydrogenase

Glycated hemoglobin

High Density Lipoprotein

Hexokinase

Hepatocyte nuclear factor 4

HOMA index for $\beta$-cell function determined by the Homeostasis Model

Assesment method

HOMA index for insulin resistance determined by HOMA

High Pressure Liquid Chromatogaphy 


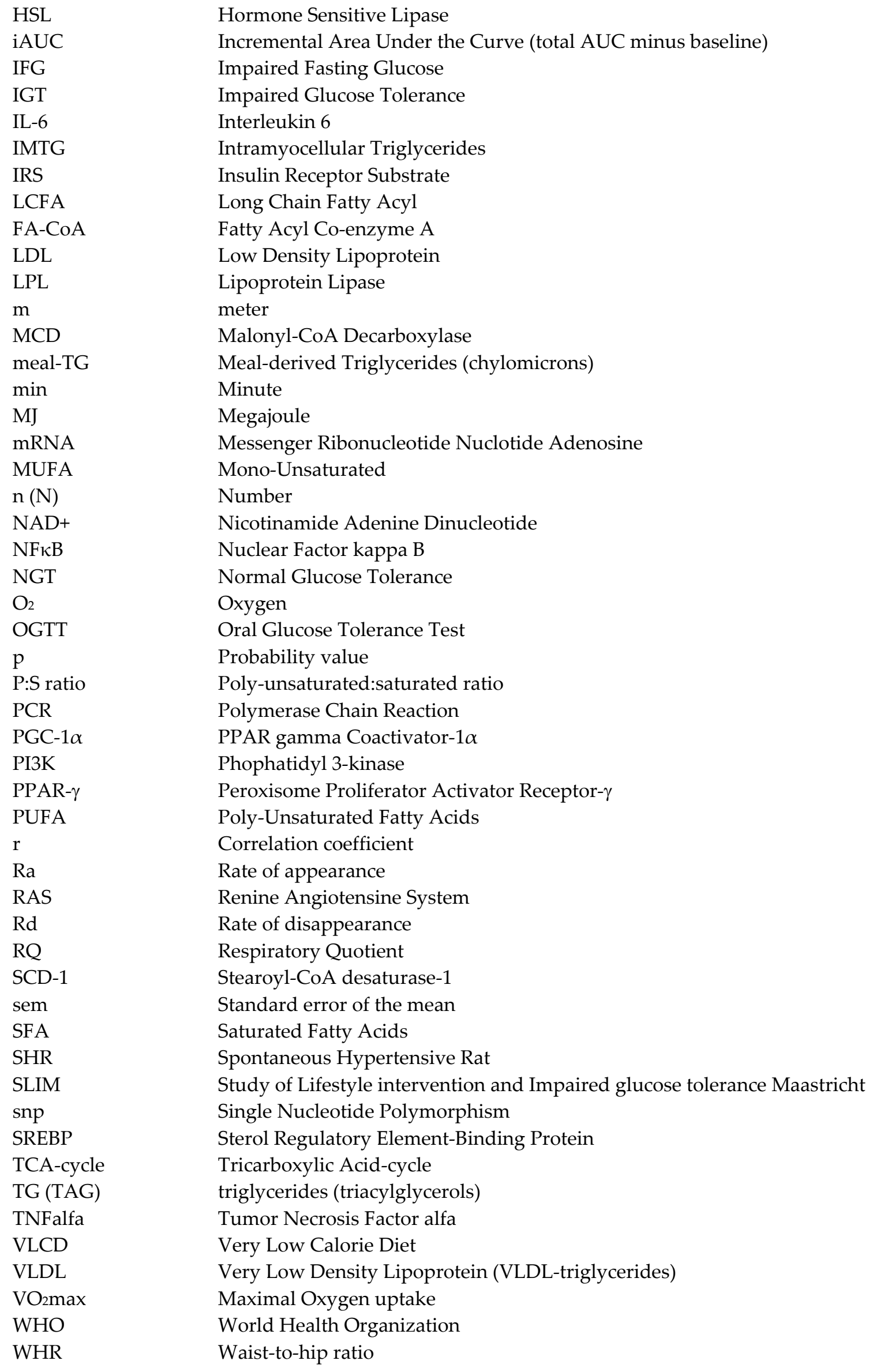


?

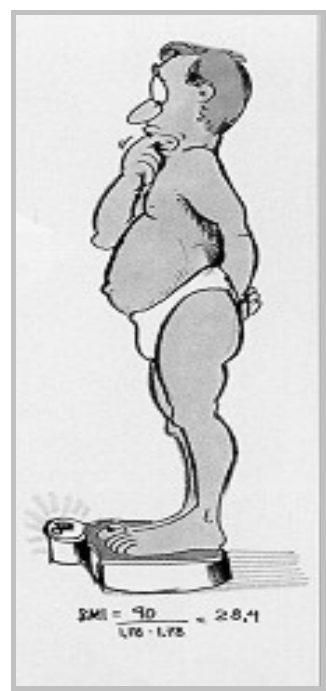

